\title{
Tropical deforestation monitoring using Landsat time series and breakpoint detection
}




\section{Thesis committee}

\section{Promotor}

Prof. Dr M. Herold

Professor of Geo-information Science and Remote Sensing

Wageningen University \& Research

\section{Co-promotors}

Dr J.G.P.W. Clevers

Associate professor, Laboratory of Geo-information Science and Remote Sensing Wageningen University \& Research

Dr J. Verbesselt

Associate professor, Laboratory of Geo-information Science and Remote Sensing Wageningen University \& Research

\section{Other members}

Prof. Dr G.J. Nabuurs, Wageningen University \& Research

Dr R. de Jong, University of Zürich, Switzerland

Dr H. Lee, Karlsruhe Institute of Technology, Germany

Dr T.A. Groen, University of Twente, Enschede, The Netherlands

This research was conducted under the auspices of the C.T. de Wit Graduate School of Production Ecology \& Resource Conservation (PE\&RC) 


\section{Tropical deforestation monitoring using Landsat time series and breakpoint detection}

Michael Schultz

Thesis

submitted in fulfilment of the requirements for the degree of doctor

at Wageningen University

by the authority of the Rector Magnificus,

Prof. Dr A.P.J. Mol,

in the presence of the

Thesis Committee appointed by the Academic Board

to be defended in public

on Monday 15 October 2018

at 1.30 p.m. in the Aula. 
Michael Schultz

Tropical deforestation monitoring using Landsat time series and breakpoint detection, 132 pages.

PhD thesis, Wageningen University, Wageningen, the Netherlands (2018)

With references, with summary in English

ISBN: 978-94-6343-466-9

DOI: https://doi.org/10.18174/454885 


\section{Table of Contents}

$\begin{array}{lll}\text { Chapter } 1 & \text { Introduction } & 1\end{array}$

$\begin{array}{lll}\text { Chapter } 2 & \text { Carbon emissions from land cover change in central Vietnam } & 15\end{array}$

$\begin{array}{lll}\text { Chapter } 3 & \text { Error sources in deforestation detection using BFAST } & 35\end{array}$

Monitor on Landsat time series across three tropical sites

$\begin{array}{lll}\text { Chapter } 4 & \text { Performance of vegetation indices from } & 57\end{array}$

Landsat time series in deforestation monitoring

Chapter $5 \quad$ Forest cover and vegetation degradation detection in the 75

Kavango Zambezi Transfrontier Conservation Area using BFAST Monitor

Chapter $6 \quad$ Synthesis

95

$\begin{array}{ll}\text { References } & 110\end{array}$

$\begin{array}{ll}\text { Summary } & 124\end{array}$

$\begin{array}{ll}\text { Acknowledgements } & 126\end{array}$

$\begin{array}{ll}\text { List of Publications } & 128\end{array}$

$\begin{array}{ll}\text { Short Biography } & 129\end{array}$

$\begin{array}{ll}\text { PE\&RC Training and Education Statement } & 130\end{array}$ 

Chapter 1

Chapter 1

Introduction 


\subsection{Background}

Human population growth and economic development currently occurs at the costs of biodiversity, often resulting in species extinction (McKinney and Lockwood, 1999). Human induced land cover change is a major cause of species loss (Gillespie et al., 2008). The majority of the terrestrial surface of the planet was transformed by human activity during recent centuries (Hooke et al., 2012; Waters et al., 2016). Understanding the spatial extent and the dynamics of human land transformation is key to addressing important issues such as biodiversity loss or climate change (Klein Goldewijk et al., 2011). Knowledge of land cover dynamics is essential for a permanent human existence on Earth (Wulder and Franklin, 2012).

During this century, forest loss accelerated by approximately two thousand $\mathrm{km}^{2}$ (the size of Monaco) annually (Hansen et al., 2013). Because forest biomass consists for a large part of carbon, deforestation and forest degradation have been the second largest contributor to human-induced carbon emissions to the atmosphere, accounting for one fifth of global $\mathrm{CO}_{2}$ emissions (Alley et al., 2007; van der Werf et al., 2009). $\mathrm{CO}_{2}$ is an important greenhouse gas (GHG), and increasing concentrations of such gases in the atmosphere incurs rapid global warming (Gullison et al., 2007), which in return negatively affects the global climate system (Alley et al., 2007). Deforestation is defined as a "direct human-induced conversion of forested land to non-forested" of any conterminous forest patch larger than 0.5 ha where trees are capable of reaching a height of at least 2 - 5 meters with a canopy cover of at least $10-30 \%$ (UNFCCC, 2002). Forest degradation is defined less distinctive (FAO, 2011). When referring to emission reductions, forest degradation is commonly defined as any human action that causes a loss of a forest carbon stock but does not directly result in deforestation (Olander et al., 2008).

Tropical forests are especially under pressure when economies prioritize economic gains over nature conservation (Ghazoul and Sheil, 2010). Commercial logging (Ghazoul and Sheil, 2010), mining, agriculture and infrastructure development (Hosonuma et al., 2012) are the most important drivers of tropical deforestation. Deforestation is often preceded by degradation, which is driven by fuelwood collection, selective logging and animal grazing (Vargas et al., 2013). Forest degradation attracts unplanned deforestation by locals (Pedroni, 2012), which then serves as a catalyst for deforestation (Griscom et al., 2009) by extended logging activities (Pratihast et al., 2014). Additionally the absence of forest management or law enforcement and continued unlawful use of forest resources creates economic losses through illegally created timber products that depress regional and global timber prices (Nellemann, 2012). As a result, tropical forests have been transformed by degradation and deforestation activities at large scales in the past four decades (Achard et al., 2014).

Policy systems such as Reducing Emissions from Deforestation and forest Degradation (REDD+) try to encourage nations to slow forest decline and conserve or increase carbon sink capacities of forests (Scholz and Schmidt, 2008). Progress and feasibility of REDD+ implementation is quantified using Monitoring, Reporting and Verification (MRV) as a bookkeeping device for forest status and changes. The heart of a REDD+ MRV system is therefore the measurement of the so-called activity data (Herold and Skutsch, 2011). Activity data are defined as the human actions that result in GHG emissions or removals for a specific place within a given period of time (Houghton et al., 1997). According to the prior definitions of deforestation and forest degradation, consistent and long term medium resolution (10 $60 \mathrm{~m}$ ) monitoring capacities are required for accurate quantification. Remote sensing devices provide such abilities across large regions at lower costs when compared to approaches using only data collected 
on the ground (Arino et al., 2012; Herold et al., 2011). Typically, field data pertaining to land cover and specific carbon emission factors are collected and combined with areal estimates from remote sensing data (Arino et al., 2012). From the available remote sensing missions, the Landsat legacy mission is particularly suitable to serve long-term needs described here. It provides the longest continuous global record of the surface of the Earth with a progressive no-cost data access policy, a potential continuity of half a century and ambitious efforts for future missions (Hansen and Loveland, 2012; Loveland and Dwyer, 2012; Wulder et al., 2012; Zhu, 2017). Data captured by Landsat satellites can be considered as a standard bookkeeping device for REDD+ MRV (Arino et al., 2012).

\subsection{Tropical forest change detection using Landsat}

Landsat was identified to suit deforestation detection in accordance with REDD+ (Arino et al., 2012) as it is recognized for its consistent, global extent and ability to assess both anthropogenic and natural changes of ecosystems (Townshend and Justice, 1988). The Landsat mission is the only spatially, spectrally and temporally consistent device enabling us to observe the past four decades of Earth's surface evolution. The successful application of Landsat for tropical forest change mapping was broadly recognized by the end of the 20th century and current technologies enable scientists to tap into its full potential (Hansen et al., 2013; Skole and Tucker, 1993). Three key pillars supported this development: massive processing capabilities (Hansen et al., 2013), consistent and predictable processing characteristics (Markham and Helder, 2012), and a data policy encouraging utilization (Woodcock et al., 2008; Wulder et al., 2012). An abundance of review articles exists where Landsat-based tropical forest change mapping is discussed (Coppin and Bauer, 1996; Hansen and Loveland, 2012; Singh, 1989; Zhu, 2017).

Image comparison and time series analysis are used to measure changes in Earth's ecosystems. Image comparison or bi-temporal change detection uses an image pair acquired at different moments in time. This technology is commonly used with Landsat today (Hansen and Loveland, 2012; Thonfeld et al., 2010) and deforestation can be reliably detected (Arino et al., 2012). Pairs of images can also be compared among multiple time steps, usually temporally adjacent observations are assessed and combined during post-processing. An abundance of methods exists (Thonfeld et al., 2010). The importance of bi-temporal remote sensing applications is well demonstrated by the Instituto Nacional de Pesquisas Espaciais (INPE) Projeto de Estimativa do Desflorestamento da Amazônia (PRODES) product, a wall to wall forest change mapping effort for entire Brazil updated every year. Annual composites are created making use of images acquired throughout the year. Spectral mixture analysis, user driven unsupervised clustering and spatial segmentation are the methods performed. An image interpreter visually inspects the information layers and determines forest change areas (Shimabukuro et al., 1998).

Compared to bi-temporal approaches, time series analysis-based methods yield the advantage of tapping into multiple time steps often ranging across a decade or more and take advantage of existing automatized pre-processing schemes (Masek et al., 2012), which allow rapid and large scale deployment of data for analysis (Hansen et al., 2013). A time series is a set of measurements for a spatial entity (typically a pixel) organized by acquisition date. Small time series can consist of two measurements captured at two different moments in time (bi-temporal), while longer time series can consist of hundreds of measurements each captured at different moments in time. Analysis of a time series is the systematic exploration of measured signal intensity patterns along a time axis. For Landsat, there 
currently is an increasing shift from bi-temporal approaches towards time series analysis (Hansen and Loveland, 2012; Zhu, 2017). Some approaches aim to create temporal equidistant, often annual composites to enable time series analysis (Cohen et al., 2010; Griffiths et al., 2014; Huang et al., 2010), while others provide complex solutions particularly when observation frequency varies (Broich et al., 2011). Among the abundance of methods, the Breaks For Additive Season and Trend (BFAST) type time series analysis technique was developed and designed for generic application and thus promising for a variety of remote sensing applications including deforestation detection (Verbesselt et al., 2010).

\subsection{Application of BFAST type models}

BFAST is a harmonic analysis model for detection of structural changes in image time series by fitting trigonometric terms to image-derived indices using least-squares methods (Verbesselt et al., 2010a). Since its introduction it was used across the globe for a variety of applications. We identified and reviewed 34 studies which appeared in recognized international remote sensing journals from January 2010 to March 2018 that made use of BFAST type models, excluding those studies presented in this thesis as they will be presented in substantial detail. BFAST was first applied to detect forest change within temperate mixed needle leaf forests in southern Australia (Verbesselt et al., 2010b) and almost in parallel on measuring vegetation cover decline in a Savanna landscape in Madagascar (Jacquin et al., 2010). Both studies made use of the Normalized Difference Vegetation Index (NDVI) (Tucker, 1979) derived over 16-days measurement cycles of Moderate Resolution Imaging Spectroradiometer (MODIS) data, which were also the most frequently used data for all other studies using BFAST (Table 1.1 and Figure 1.1). BFAST works by decomposing times series in trend, harmonic components and the remainder (error term) aimed at detecting the moment and location of structural changes within time series. While the two previously mentioned studies targeted the detection of rather abrupt events, the potential of BFAST to detect more subtly phenological changes and long term trends was demonstrated in a different study (Verbesselt et al., 2010b). The first and so far only global BFAST application was aimed at detecting greening and browning trends using very long-time series (de Jong et al., 2012). Another large scale application of BFAST is aimed at building understanding for phenological trends across Australia (De Keersmaecker et al., 2017). Both studies have been the only ones facilitating the use of Advanced Very High-Resolution Radiometer (AVHRR) Global Inventory for Mapping and Modeling Studies (GIMMS) data in conjunction with BFAST. Another long term study used a combination of AVHRR and MODIS data to determine phenological changes for mixed and deciduous forest across the eastern United States (Liu et al., 2017). In another series of publications BFAST and MODIS $250 \mathrm{~m}$ NDVI data were applied across the globe on a variety of forest change detection applications, such as deforestation detection in boreal forests (Hüttich et al., 2014), clear cut mapping in temperate forest (Lambert et al., 2015), mixed forest change detection in Australia on hyper-temporal data (Schmidt et al., 2015) and deforestation detection in various different dry tropical forest types using the Normalized Difference Moisture Index (NDMI) (Grogan et al., 2016). BFAST was also found to be a robust change detection device capable of isolating changes from temporally and spatially autocorrelated Enhanced Vegetation Index 2 (EVI2) time series within moist tropical forests (Lu et al., 2016).

The most common use of MODIS and BFAST has been vegetation dynamics analysis, for instance aimed at detecting drivers of vegetation change in Canada (Fang et al., 2018) or to describe the impact of climate on vegetation phases in the Murray Darling Basin of Australia (Wen and Saintilan, 2015). Remarkably, BFAST has also been applied for inundation measurement of the Yangtze river (Cai et al., 
2016) and fluctuation of lake size in Tibet (Che et al., 2017). BFAST MODIS NDVI has also been innovatively applied to urban expansion monitoring of Ulaanbaatar (Tsutsumida et al., 2013).

Sensor wise, Radio Detection And Ranging (RADAR) backscatter data in conjunction with BFAST were first used to measure forest water stress and related changes within the amazon rain forest (Saatchi et al., 2013). BFAST was also applied in conjunction with Synthetic Aperture Radar (SAR) and Landsat data to estimate Above Ground Biomass (AGB) for dry and moist tropical forests in central America (Urbazaev et al., 2016), and another application used land surface temperature (LST) data as temporal trajectories for the time series analysis to detect vegetation fire and vegetation recovery (Hulley et al., 2014). Multiple optical sensors with different spatial resolutions $(0.25-1 \mathrm{~km})$ have been used to map vegetation dynamics across distinctively different types of land cover around Mount Kilimanjaro (Detsch et al., 2016).

An entirely new realm of near real time BFAST applications has opened up with the introduction of BFAST Monitor (Verbesselt et al., 2012). This method is more flexible regarding observation reoccurrence patterns allowing more robust estimation of deforestation timing and intensity when data are scarce or irregularly available (Reiche et al., 2015). However, BFAST Monitor was designed to analyze time series tails for changes, not entire time series as BFAST does. BFAST Monitor works by creating a model based on historic observations and forecasts this into a monitoring period, where observations are compared against this model. The most extreme deviations of observed and modelled values within the monitoring period are provided as change magnitude values and if deviation is significant at a specific moment in time, this timing is provided. BFAST Monitor is almost exclusively applied to Landsat or similar data, characterized by irregular observation cycles and about $30 \mathrm{~m}$ spatial resolution. Following the combination of SAR and optical time series (Reiche et al., 2015) for analysis with BFAST Monitor, the next application was the detection of forest degradation within a tropical moist forest in southern Ethiopia. Here, BFAST Monitor was applied in a sequential way, where each year of the monitoring period ranging from 2006 - 2009 was analyzed individually alongside incrementing the historic period (DeVries et al., 2015b). The capacity of BFAST Monitor to accommodate seasonal patterns, while still providing sensitivity to forest cover loss, was tested in a study site in Bolivia. Two additional regressor variables were used to provide an additional stream of information to clearly distinguish anthropogenic caused changes from reoccurring seasonal changes (Dutrieux et al., 2015). In another study site in south America BFAST Monitor provided estimations of forest disturbance, which were used to track potential regrowth (DeVries et al., 2015a). An adaptation of BFAST was used for reconstructing land use history using long Landsat time series (Dutrieux et al., 2016). A combination of community based monitoring (CBM) and BFAST Monitor within an integrated forest monitoring system was a significant step combining ground truth based measurements and the BFAST Monitor time series device (Pratihast et al., 2016). In a connected study at the same site CBM data was used to calibrate BFAST Monitor time series of various spectral bands to improve forest degradation detection performance (DeVries et al., 2016). Suppression of noise and normalization of seasonality to improve timing accuracy using spatial contextual information was another crucial research item achieved by the same research group (Hamunyela et al., 2016). Exploration of the full spectral potential offered by Landsat data, Normalized Burned Index (NBI), NDVI, NDMI, Tasseled Cap measures and Principle Component Analysis (PCA) time series were explored for suitability of deforestation detection (Lu et al., 2017). The study also featured a new Saturation Reduced Index (SRI), which aimed at reducing seasonal effects to create a stronger background against the detection of potential changes. Although BFAST and 
BFAST Monitor were most extensively applied for deforestation and forest degradation application, the methods have also been applied to other studies, for example a BFAST Monitor framework to detect burned areas in a savannah landscape (Liu et al., 2018), for the estimation of forest canopy change (Romero-Sanchez and Ponce-Hernandez, 2017) and as a BFAST Standardized PrecipitationEvapotranspiration Index (SPEI) to substantiate climate phase influence on the vegetation health of forest across southern Australia (Wen and Saintilan, 2015).

Figure 1.1 provides an overview of the referred studies and shows that the method and its variations have been applied across different ecosystems, on every continent but Antarctica. We have identified six application domains, notably biomass change, fire detection, deforestation and/or degradation detection, urban expansion detection, changes in water extent and vegetation trends. Variations of BFAST include BFAST Monitor, sequential BFAST Monitor and other adaptions. Some studies combine BFAST and BFAST Monitor and their adaption hence creating complex interlinked BFAST systems. Figure 1.1 also shows that the largest fraction of BFAST applications has been implemented in southern America and globally within tropical environments, thus emphasizing that preferred BFAST application is on tropical forest landscapes, followed by applications within temperate forest and then arid environments.

Table 1.1 Current BFAST and BFAST Monitor applications in literature

\begin{tabular}{|c|c|c|c|c|c|c|c|}
\hline & Application & $\begin{array}{l}\text { BFAST } \\
\text { type }\end{array}$ & $\begin{array}{l}\text { Time } \\
\text { series } \\
\text { resolution }\end{array}$ & $\begin{array}{l}\text { Time series } \\
\text { range }\end{array}$ & Target & Study area & Reference \\
\hline 1 & $\begin{array}{l}\text { Forest } \\
\text { change } \\
\text { detection }\end{array}$ & BFAST & $\begin{array}{l}250 \mathrm{~m} \\
\text { NDVI, } \\
\text { regular }\end{array}$ & $2000-09$ & $\begin{array}{l}\text { Temperate } \\
\text { Forest } \\
\text { (mixed, } \\
\text { needle } \\
\text { leafed) }\end{array}$ & $\begin{array}{l}\text { South east } \\
\text { Australia }\end{array}$ & $\begin{array}{l}\text { (Verbesselt } \\
\text { et al., 2010a) }\end{array}$ \\
\hline 2 & $\begin{array}{l}\text { Vegetation } \\
\text { cover } \\
\text { degradation }\end{array}$ & BFAST & $\begin{array}{l}250 \mathrm{~m} \\
\text { NDVI, } \\
\text { regular }\end{array}$ & $2000-2007$ & Savanna & $\begin{array}{l}\text { Marovoay } \\
\text { watershed } \\
\text { Madagascar }\end{array}$ & $\begin{array}{l}\text { (Jacquin et } \\
\text { al., 2010) }\end{array}$ \\
\hline 3 & $\begin{array}{l}\text { Phenologica } \\
\text { I change } \\
\text { detection }\end{array}$ & BFAST & $\begin{array}{l}250 m \\
\text { NDVI, } \\
\text { regular }\end{array}$ & $2000-09$ & $\begin{array}{l}\text { Temperate } \\
\text { Forest } \\
\text { (mixed, } \\
\text { needle } \\
\text { leafed) }\end{array}$ & $\begin{array}{l}\text { South east } \\
\text { Australia }\end{array}$ & $\begin{array}{l}\text { (Verbesselt } \\
\text { et al., } \\
2010 \mathrm{~b} \text { ) }\end{array}$ \\
\hline 4 & $\begin{array}{l}\text { Global } \\
\text { greening } \\
\text { and } \\
\text { browning } \\
\text { trends }\end{array}$ & BFAST & $\begin{array}{l}8 \mathrm{~km} \text { NDVI, } \\
\text { regular }\end{array}$ & $\begin{array}{l}1982- \\
2008\end{array}$ & $\begin{array}{l}\text { forest, } \\
\text { shrubland } \\
\text { grassland, } \\
\text { savannahs, } \\
\text { cropland }\end{array}$ & Global & $\begin{array}{l}\text { (de Jong et } \\
\text { al., 2012) }\end{array}$ \\
\hline 5 & $\begin{array}{l}\text { drought- } \\
\text { related } \\
\text { vegetation } \\
\text { disturbance } \\
\text { s detection }\end{array}$ & $\begin{array}{l}\text { BFAST } \\
\text { Monitor }\end{array}$ & $\begin{array}{l}250 \mathrm{~m} \\
\text { NDVI, } \\
\text { regular }\end{array}$ & $\begin{array}{l}2000-09 \\
\text { (history), } 10 \\
-11 \\
\text { (monitor) }\end{array}$ & $\begin{array}{l}\text { Arid- semi } \\
\text { arid } \\
\text { vegetated } \\
\text { areas, } \\
\text { savannahs } \\
\text { and }\end{array}$ & Somalia & $\begin{array}{l}\text { (Verbesselt } \\
\text { et al., 2012) }\end{array}$ \\
\hline
\end{tabular}




\begin{tabular}{|c|c|c|c|c|c|c|c|}
\hline & & & & & $\begin{array}{l}\text { tropical } \\
\text { forest }\end{array}$ & & \\
\hline 6 & $\begin{array}{l}\text { Urban } \\
\text { expansion } \\
\text { monitoring }\end{array}$ & BFAST & $\begin{array}{l}250 m \\
\text { NDVI }\end{array}$ & $2000-10$ & $\begin{array}{l}\text { Various } \\
\text { land cover }\end{array}$ & $\begin{array}{l}\text { Ulaanbataar, } \\
\text { Mongolia }\end{array}$ & $\begin{array}{l}\text { (Tsutsumida } \\
\text { et al., 2013) }\end{array}$ \\
\hline 7 & $\begin{array}{l}\text { Forest } \\
\text { decline }\end{array}$ & BFAST & $\begin{array}{l}250 \mathrm{~m} \\
\mathrm{NDVI}\end{array}$ & $2000-11$ & Forest & Europe & $\begin{array}{l}\text { (Lambert et } \\
\text { al., 2013) }\end{array}$ \\
\hline 8 & $\begin{array}{l}\text { Forest } \\
\text { water stress }\end{array}$ & BFAST & $\begin{array}{l}0.25 \text { degre } \\
e, H \\
\text { backscatte } \\
r\end{array}$ & $2000-10$ & $\begin{array}{l}\text { Tropical } \\
\text { rainforest } \\
\text { Forest }\end{array}$ & $\begin{array}{l}\text { Amazon rain } \\
\text { forest }\end{array}$ & $\begin{array}{l}\text { (Saatchi et } \\
\text { al., 2013) }\end{array}$ \\
\hline 9 & $\begin{array}{l}\text { Deforestati } \\
\text { on }\end{array}$ & BFAST & $250 \mathrm{~m} \mathrm{EVI}$ & $2000-14$ & $\begin{array}{l}\text { Boreal } \\
\text { forest }\end{array}$ & $\begin{array}{l}\text { Central } \\
\text { Siberia }\end{array}$ & $\begin{array}{l}\text { (Hüttich et } \\
\text { al., 2014) }\end{array}$ \\
\hline 10 & $\begin{array}{l}\text { Vegetation } \\
\text { fire and } \\
\text { recovery } \\
\text { detection }\end{array}$ & BFAST & $1 \mathrm{~km}, \mathrm{LST}$ & $2001-06$ & $\begin{array}{l}\text { Various } \\
\text { land cover } \\
\text { (soil cover } \\
\text { with } \\
\text { vegetation } \\
\text { and } \\
\text { forests) }\end{array}$ & $\begin{array}{l}\text { Jornada } \\
\text { Experimental } \\
\text { range, New } \\
\text { Mexico }\end{array}$ & $\begin{array}{l}\text { (Hulley et } \\
\text { al., 2014) }\end{array}$ \\
\hline 11 & $\begin{array}{l}\text { Deforestati } \\
\text { on } \\
\text { detection }\end{array}$ & $\begin{array}{l}\text { BFAST } \\
\text { Monitor }\end{array}$ & $\begin{array}{l}30 \mathrm{~m} \mathrm{NDVI} \\
\text { and 30m } \\
\text { L-band } \\
\text { HVHH, } \\
\text { irregular }\end{array}$ & $\begin{array}{l}2000-07 \\
\text { (history), } 08 \\
-10 \\
\text { (monitor) }\end{array}$ & $\begin{array}{l}\text { Plantation } \\
\text { forest }\end{array}$ & $\begin{array}{l}\text { North West } \\
\text { of Viti Levu } \\
\text { Fidji (Lat. } \\
17,32^{\circ} \mathrm{S}, \\
\text { Lon. } 177.37^{\circ} \\
\text { E) }\end{array}$ & $\begin{array}{l}\text { (Reiche et } \\
\text { al., 2015) }\end{array}$ \\
\hline 12 & $\begin{array}{l}\text { Forest } \\
\text { degradation } \\
\text { detection }\end{array}$ & $\begin{array}{l}\text { Sequential } \\
\text { BFAST } \\
\text { Monitor }\end{array}$ & $\begin{array}{l}\text { 30m NDVI, } \\
\text { irregular }\end{array}$ & $\begin{array}{l}1999- \\
2005 \\
\text { (history), } 06 \\
-09 \\
\text { (monitor) }\end{array}$ & $\begin{array}{l}\text { moist } \\
\text { broadleaf } \\
\text { evergreen } \\
\text { forests }\end{array}$ & $\begin{array}{l}\text { UNESCO } \\
\text { Kafa } \\
\text { Biosphere } \\
\text { Reserve } \\
\text { southwest } \\
\text { Ethiopia } \\
\end{array}$ & $\begin{array}{l}\text { (DeVries et } \\
\text { al., 2015b) }\end{array}$ \\
\hline 13 & $\begin{array}{l}\text { Forest cover } \\
\text { loss } \\
\text { monitoring }\end{array}$ & $\begin{array}{l}\text { BFAST } \\
\text { Monitor }\end{array}$ & $\begin{array}{l}30 \mathrm{~m} \mathrm{NDVI}, \\
\text { irregular } \\
\text { and } \\
\text { external } \\
\text { regressors }\end{array}$ & $\begin{array}{l}2000-07 \\
\text { (history), } 08 \\
-14 \\
\text { (monitor) }\end{array}$ & $\begin{array}{l}\text { Tropical } \\
\text { dry forest }\end{array}$ & $\begin{array}{l}\text { Eastern } \\
\text { Bolivia }\end{array}$ & $\begin{array}{l}\text { (Dutrieux et } \\
\text { al., 2015) }\end{array}$ \\
\hline 14 & $\begin{array}{l}\text { Forest } \\
\text { disturbance } \\
\text { detection } \\
\text { followed by } \\
\text { regrowth } \\
\text { mapping }\end{array}$ & $\begin{array}{l}\text { Sequential } \\
\text { BFAST } \\
\text { Monitor }\end{array}$ & $\begin{array}{l}\text { 30m NDVI, } \\
\text { irregular }\end{array}$ & $\begin{array}{l}1990-99 \\
\text { (history) } \\
2000-14 \\
\text { (monitor) }\end{array}$ & $\begin{array}{l}\text { Moist } \\
\text { tropical } \\
\text { forest }\end{array}$ & Peru & $\begin{array}{l}\text { (DeVries et } \\
\text { al., 2015a) }\end{array}$ \\
\hline 15 & $\begin{array}{l}\text { Forest } \\
\text { clearing }\end{array}$ & BFAST & $30 \mathrm{~m} \mathrm{NDVI}$ & $2000-12$ & $\begin{array}{l}\text { Mixed } \\
\text { forest }\end{array}$ & $\begin{array}{l}\text { Injune, } \\
\text { Queensland }\end{array}$ & $\begin{array}{l}\text { (Schmidt et } \\
\text { al., 2015) }\end{array}$ \\
\hline
\end{tabular}




\begin{tabular}{|c|c|c|c|c|c|c|c|}
\hline 16 & $\begin{array}{l}\text { Impact of } \\
\text { climate } \\
\text { phase on } \\
\text { vegetation }\end{array}$ & BFAST & $\begin{array}{l}250 m \\
N D V I\end{array}$ & $2000-13$ & $\begin{array}{l}\text { semi-arid } \\
\text { floodplain } \\
\text { forests }\end{array}$ & $\begin{array}{l}\text { Murray } \\
\text { Darling Basin } \\
\text { of Australia }\end{array}$ & $\begin{array}{l}\text { (Wen and } \\
\text { Saintilan, } \\
\text { 2015) }\end{array}$ \\
\hline 17 & $\begin{array}{l}\text { Forest clear } \\
\text { cut } \\
\text { detection }\end{array}$ & BFAST & $\begin{array}{l}250 m \\
N D V I\end{array}$ & $2000-11$ & $\begin{array}{l}\text { Coniferous } \\
\text { forest }\end{array}$ & $\begin{array}{l}\text { south- } \\
\text { western } \\
\text { Massif } \\
\text { Central } \\
\text { Mountains in } \\
\text { France }\end{array}$ & $\begin{array}{l}\text { (Lambert et } \\
\text { al., 2015) }\end{array}$ \\
\hline 18 & $\begin{array}{l}\text { Land use } \\
\text { history } \\
\text { mapping }\end{array}$ & $\begin{array}{l}\text { BFAST } \\
\text { adaption }\end{array}$ & $\begin{array}{l}\text { 30m NDVI } \\
\text { irregular }\end{array}$ & $1984-2016$ & $\begin{array}{l}\text { Moist } \\
\text { tropical } \\
\text { forest, } \\
\text { agriculture }\end{array}$ & $\begin{array}{l}\text { Brazil, } \\
\text { central } \\
\text { Amazonas }\end{array}$ & $\begin{array}{l}\text { (Dutrieux et } \\
\text { al., 2016) }\end{array}$ \\
\hline 19 & $\begin{array}{l}\text { Forest } \\
\text { degradation } \\
\text { detection }\end{array}$ & $\begin{array}{l}\text { Sequential } \\
\text { BFAST } \\
\text { Monitor }\end{array}$ & $\begin{array}{l}\text { 30m NDVI, } \\
\text { irregular }\end{array}$ & $\begin{array}{l}1999- \\
2005 \\
\text { (history), } 06 \\
-09 \\
\text { (monitor) }\end{array}$ & $\begin{array}{l}\text { moist } \\
\text { broadleaf } \\
\text { evergreen } \\
\text { forests }\end{array}$ & $\begin{array}{l}\text { UNESCO } \\
\text { Kafa } \\
\text { Biosphere } \\
\text { Reserve } \\
\text { southwest } \\
\text { Ethiopia } \\
\end{array}$ & $\begin{array}{l}\text { (Pratihast et } \\
\text { al., 2016) }\end{array}$ \\
\hline 20 & $\begin{array}{l}\text { Deforestati } \\
\text { on and } \\
\text { forest } \\
\text { degradation }\end{array}$ & $\begin{array}{l}\text { BFAST } \\
\text { adaption }\end{array}$ & $250 \mathrm{~m}$ EVI2 & $2000-2012$ & $\begin{array}{l}\text { Moist } \\
\text { tropical } \\
\text { forest }\end{array}$ & $\begin{array}{l}\text { Brazil, Mato } \\
\text { Grosso }\end{array}$ & $\begin{array}{l}\text { (Lu et al., } \\
2016)\end{array}$ \\
\hline 21 & $\begin{array}{l}\text { Deforestati } \\
\text { on } \\
\text { detection }\end{array}$ & $\begin{array}{l}\text { BFAST } \\
\text { Monitor }\end{array}$ & $30 \mathrm{~m} \mathrm{NDVI}$ & $\begin{array}{l}1984- \\
2004 \\
\text { (history), } \\
2005 \text { - } \\
2015 \\
\text { (monitor) }\end{array}$ & $\begin{array}{l}\text { Moist and } \\
\text { dry } \\
\text { tropical } \\
\text { forest }\end{array}$ & $\begin{array}{l}\text { Rondonia, } \\
\text { Brazil and } \\
\text { Santa Cruz } \\
\text { de la Sierra, } \\
\text { Bolivia }\end{array}$ & $\begin{array}{l}\text { (Hamunyela } \\
\text { et al., 2016) }\end{array}$ \\
\hline 22 & $\begin{array}{l}\text { Vegetation } \\
\text { dynamics }\end{array}$ & BFAST & $\begin{array}{l}0.25-1 \mathrm{~km} \\
\mathrm{NDVI}\end{array}$ & $1982-2011$ & $\begin{array}{l}\text { Highly } \\
\text { diverse, } \\
\text { glaciers - } \\
\text { savanna }\end{array}$ & $\begin{array}{l}\text { Kilimanjaro } \\
\text { region }\end{array}$ & $\begin{array}{l}\text { (Detsch et } \\
\text { al., 2016) }\end{array}$ \\
\hline 23 & $\begin{array}{l}\text { AGB } \\
\text { biomass } \\
\text { estimation }\end{array}$ & BFAST & $\begin{array}{l}250 \mathrm{~m} \\
\mathrm{NDVI}\end{array}$ & $2005-11$ & $\begin{array}{l}\text { dry } \\
\text { deciduous } \\
\text { forests } \\
\text { and } \\
\text { tropical } \\
\text { rain forest }\end{array}$ & $\begin{array}{l}2 \text { sites in } \\
\text { southern } \\
\text { Mexico }\end{array}$ & $\begin{array}{l}\text { (Urbazaev et } \\
\text { al., 2016) }\end{array}$ \\
\hline 24 & $\begin{array}{l}\text { Inundation } \\
\text { measureme } \\
\text { nt }\end{array}$ & BFAST & $\begin{array}{l}250, \\
\text { NDMI, } \\
\text { Red, } \\
\text { Green, } \\
\text { Blue }\end{array}$ & $2000-14$ & $\begin{array}{l}\text { Vegetation } \\
\text {, land } \\
\text { cover on } \\
\text { riparian } \\
\text { area }\end{array}$ & $\begin{array}{l}\text { Yangtze } \\
\text { catchment }\end{array}$ & $\begin{array}{l}\text { (Cai et al., } \\
\text { 2016) }\end{array}$ \\
\hline
\end{tabular}




\begin{tabular}{|c|c|c|c|c|c|c|c|}
\hline 25 & $\begin{array}{l}\text { Deforestati } \\
\text { on } \\
\text { detection }\end{array}$ & BFAST & $\begin{array}{l}250 \mathrm{~m}, \\
\text { NDMI }\end{array}$ & $2000-13$ & $\begin{array}{l}\text { Tropical } \\
\text { dry forests }\end{array}$ & $\begin{array}{l}\text { South east } \\
\text { Asia }\end{array}$ & $\begin{array}{l}\text { (Grogan et } \\
\text { al., 2016) }\end{array}$ \\
\hline 26 & $\begin{array}{l}\text { Deforestati } \\
\text { on } \\
\text { detection }\end{array}$ & $\begin{array}{l}\text { BFAST } \\
\text { Monitor }\end{array}$ & $\begin{array}{l}30 \mathrm{~m}, \mathrm{NBI}, \\
\text { NDVI, } \\
\text { NDMI, TQ, } \\
\text { TG, TB, SRI } \\
\text { and PCA }\end{array}$ & $\begin{array}{l}1984- \\
2004 \\
\text { (history), } \\
2005 \text { - } \\
2015 \\
\text { (monitor) }\end{array}$ & $\begin{array}{l}\text { Moist and } \\
\text { dry } \\
\text { tropical } \\
\text { forest }\end{array}$ & $\begin{array}{l}\text { Rondonia, } \\
\text { Brazil and } \\
\text { Santa Cruz } \\
\text { de la Sierra, } \\
\text { Bolivia }\end{array}$ & $\begin{array}{l}\text { (Lu et al., } \\
2017 \text { ) }\end{array}$ \\
\hline 27 & \begin{tabular}{|l|} 
Forest \\
degradation
\end{tabular} & $\begin{array}{l}\text { BFAST } \\
\text { Monitor }\end{array}$ & $\begin{array}{l}30 \mathrm{~m} \\
\text { canopy } \\
\text { cover } \\
\text { estimates }\end{array}$ & $\begin{array}{l}1984- \\
2005 \\
\text { (history), } \\
2005 \text { - } \\
2014 \\
\text { (monitor) }\end{array}$ & $\begin{array}{l}\text { Semi } \\
\text { deciduous } \\
\text { tropical } \\
\text { forest }\end{array}$ & $\begin{array}{l}\text { South east } \\
\text { Mexico }\end{array}$ & $\begin{array}{l}\text { (Romero- } \\
\text { Sanchez and } \\
\text { Ponce- } \\
\text { Hernandez, } \\
\text { 2017) }\end{array}$ \\
\hline 28 & $\begin{array}{l}\text { Deforestati } \\
\text { on, } \\
\text { agriculture } \\
\text { cultivation } \\
\text { cycles }\end{array}$ & $\begin{array}{l}\text { Sequential } \\
\text { BFAST } \\
\text { Monitor }\end{array}$ & $30 \mathrm{~m} \mathrm{NDMI}$ & $\begin{array}{l}1984-86 \\
\text { (historic) } \\
1987- \\
2015 \\
\text { (monitoring } \\
\text { ) }\end{array}$ & $\begin{array}{l}\text { Tropical } \\
\text { rainforest }\end{array}$ & $\begin{array}{l}\text { Brazil, } \\
\text { central } \\
\text { Amazonas }\end{array}$ & $\begin{array}{l}\text { (Jakovac et } \\
\text { al., 2017) }\end{array}$ \\
\hline 29 & $\begin{array}{l}\text { Lake extent } \\
\text { changes }\end{array}$ & BFAST & $\begin{array}{l}250 m, \\
\text { NDMI }\end{array}$ & $2000-15$ & $\begin{array}{l}\text { Vegetation } \\
\text {, land } \\
\text { cover on } \\
\text { riparian } \\
\text { area }\end{array}$ & $\begin{array}{l}\text { Tibetan } \\
\text { plateu }\end{array}$ & $\begin{array}{l}\text { (Che et al., } \\
\text { 2017) }\end{array}$ \\
\hline 30 & \begin{tabular}{|l|} 
Tropical \\
forest \\
disturbance \\
s \\
\end{tabular} & $\begin{array}{l}\text { BFAST, } \\
\text { BFAST } \\
\text { Monitor }\end{array}$ & $\begin{array}{l}30-250 \mathrm{~m} \\
\mathrm{NDVI}\end{array}$ & $1980-2016$ & $\begin{array}{l}\text { Tropical } \\
\text { forest }\end{array}$ & $\begin{array}{l}\text { Columbian } \\
\text { Andes }\end{array}$ & $\begin{array}{l}\text { (Murillo- } \\
\text { Sandoval et } \\
\text { al., 2017) }\end{array}$ \\
\hline 31 & $\begin{array}{l}\text { Phenologica } \\
\text { I trends }\end{array}$ & BFAST & $5 \mathrm{~km}, \mathrm{EVI} 2$ & $1982-2014$ & $\begin{array}{l}\text { Deciduous } \\
\text { and mixed } \\
\text { forest }\end{array}$ & $\begin{array}{l}\text { Eastern } \\
\text { United } \\
\text { States }\end{array}$ & $\begin{array}{l}\text { (Liu et al., } \\
2017 \text { ) }\end{array}$ \\
\hline 32 & $\begin{array}{l}\text { Vegetation } \\
\text { response to } \\
\text { climate shift }\end{array}$ & BFAST & $8 \mathrm{~km}, \mathrm{NDVI}$ & $1982-2006$ & $\begin{array}{l}\text { All land } \\
\text { cover }\end{array}$ & Australia & $\begin{array}{l}\text { (De } \\
\text { Keersmaeck } \\
\text { er et al., } \\
\text { 2017) }\end{array}$ \\
\hline 33 & $\begin{array}{l}\text { Burned area } \\
\text { detection }\end{array}$ & $\begin{array}{l}\text { Sequential } \\
\text { BFAST } \\
\text { Monitor }\end{array}$ & $\begin{array}{l}30-500 m \\
N D V I\end{array}$ & $2000-2016$ & Savannah & $\begin{array}{l}\text { Southern } \\
\text { Burkina Faso }\end{array}$ & $\begin{array}{l}\text { (Liu et al., } \\
2018 \text { ) }\end{array}$ \\
\hline 34 & $\begin{array}{l}\text { Vegetation } \\
\text { dynamics } \\
\text { and change } \\
\text { drivers }\end{array}$ & BFAST & $\begin{array}{l}250 \mathrm{~m} \\
\mathrm{NDVI}\end{array}$ & $2000-2011$ & Vegetation & $\begin{array}{l}\text { Quebec, } \\
\text { Canada }\end{array}$ & $\begin{array}{l}\text { (Fang et al., } \\
2018 \text { ) }\end{array}$ \\
\hline
\end{tabular}




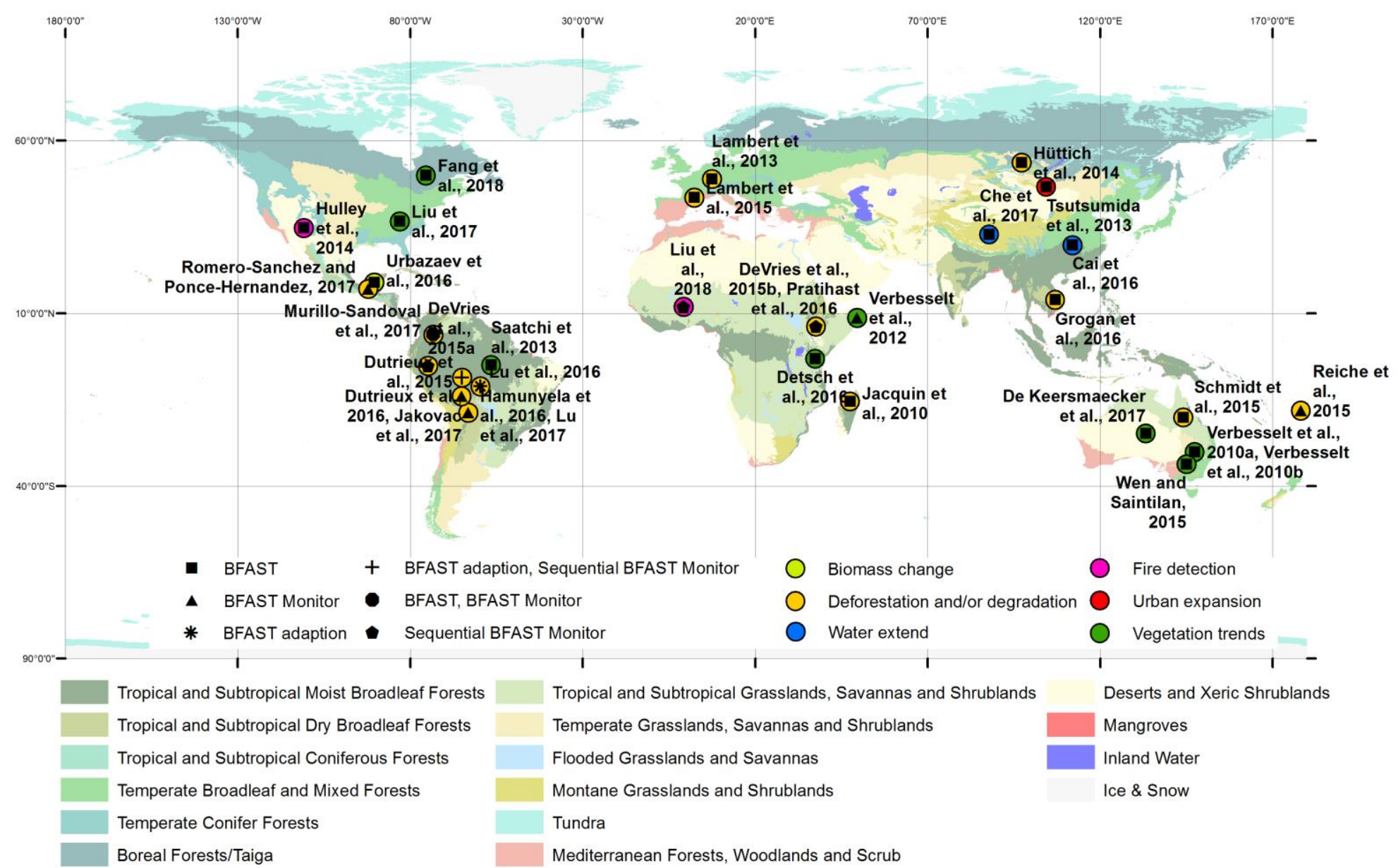

Figure 1.1 To date locations of scientific BFAST applications; symbols show BFAST type and colored circles show mapping application; (Sayre et al., 2014) provided background information of terrestrial ecosystems; not shown is a global analysis using BFAST for vegetation trend analysis by de Jong et al., (2012) 


\subsection{Research needs and questions}

REDD+ or similar approaches can only work if responsible bodies have the desire and capacity to apply them. Sophisticated remote sensing approaches can be unpractical for some tropical countries (Romijn et al., 2012). Successful REDD+ implementations meet country specific requirements and provide remote sensing solutions in accordance with their capacities and Verified Carbon Standard (VCS) criteria. VCS supplies clear recommendations for remote sensing based activity data reporting, suggesting that from the start of a REDD+ project, forest changes should be estimated within a historic baseline of 10 years or more and an ongoing annual reporting of deforestation for the entire project duration (Pedroni, 2012). BFAST type time series analysis for REDD+ project monitoring can be a successful and applicable method. BFAST Monitor time series analyses are comparatively intuitive concepts in contrast to 'conservative' change detection techniques. Consolidated change techniques such as principal component analysis (PCA) fail to depict a physical reasoning of change and require a strong mathematical understanding (Chuvieco, 2009). In contrast, a time series of a signal evolution can be interpreted intuitively. Time series analysis approaches are often open source and run on remote servers and therefore do not require expensive software licenses or the existence of local IT infrastructure. Even a country with low REDD+ MRV capacities has been able to successfully use and accommodate such innovative and intuitive solutions (TÜV SÜD, 2018). Prime research ambition in the current PhD study was the investigation of Landsat BFAST Monitor application as generic tool for tropical deforestation detection. For this application, in this thesis we assessed the Landsat BFAST Monitor limitations and possibilities for deforestation monitoring, or in other words activity data measurement. Available literature indicates the method is increasingly being used and applied for different use cases. However, existing literature provides little insight into the sensitivity of BFAST Monitor to specific error sources, hence we have focused on this gap to create a solid foundation of future BFAST Monitor applications. Different indices for forest and vegetation development have been used by others; however, none have been specifically assessed for their suitability for deforestation monitoring in conjunction with BFAST Monitor and Landsat. Also, while the method has been applied to various locations and forest types, until now no large scale long-time series analysis case study exists where a variety of biomes have been covered or the performance of activity data measurement across them was quantified. Landsat BFAST Monitor performance is often reported, but a systematic comparison of performance of different monitoring targets, especially in challenging environments is lacking. BFAST type research applications developed by Wageningen University are internationally recognized (Zhu, 2017). Within the vehicle of REDD+ and concerns about carbon emissions (Pelletier et al., 2011) we present the latest research on Landsat BFAST Monitor deforestation activity detection.

Carbon emissions are produced by various land cover change processes and there is growing evidence about the complexity of these events (Achard et al., 2014; Bongers et al., 2015; Don et al., 2011). To embed our research in REDD+ activities we first needed to disentangle deforestation-based carbon emissions from other land cover types, including emissions originating from natural sources below ground and soil. Among tropical countries, Vietnam is especially contributing to GHG emissions and targeted REDD+ efforts have been implemented (Hoa et al., 2014; Minang et al., 2014; Romijn et al., 2012). Hence, we choose to implement the first part of our research in a relevant site in Vietnam to support the REDD+ process. Our ambition was to separate and quantify emissions based on deforestation activities from other terrestrial sources to understand its relevance with respect to deforestation related emissions. Our first research question was: 
- What is the proportion of carbon emissions from deforestation in relation to other terrestrial carbon pools for a REDD+ relevant site in central Vietnam?

By drawing a clear picture of the different carbon sources for a relevant REDD+ site in central Vietnam, a clear perspective of activity data caused by deforestation was developed and the importance of accurate deforestation area estimation was highlighted. We then moved on to research the usage of BFAST Monitor for measurement of areas of activity data from deforestation within a subset of the previous site. BFAST Monitor deforestation detection performance is dependent on data pre-processing, and an investigation of error sources was setup to gain knowledge about BFAST Monitor best practices. To gain a more comprehensive understanding of error sources related to the site and observation frequency we included two sites in Ethiopia and Brazil, which were also characterized by increasing deforestation activities. Our second research question was:

- What is the performance of BFAST Monitor for deforestation detection and what are the major sources of error?

Relevant to the question above was our concern regarding the performance of different vegetation indices for deforestation monitoring among these same sites. Also, we aimed at understanding whether there were combinations of indices that were particularly suitable. Our third research question was:

- Which vegetation indices suit BFAST Monitor best for deforestation detection?

Finally, BFAST Monitor performance was researched when applied to varying degrees of forest degradation. Aim was the identification of target dependent performance differences when using a consistent BFAST Monitor setup across a large area. The Savannah landscape of the Kavango Zambezi region (KAZA) in southern Africa was chosen as it contains a complex and diverse landscape where very long-time series of Landsat data were available. Fourth research question was:

- To which extent is BFAST Monitor suited to detect degradation across large areas of forests, bushlands and grasslands?

\subsection{Thesis outline}

The core of this thesis consists of a series of four chapters where each addressed a research question. First, carbon emissions from tropical deforestation were estimated using remote sensing and ground truth data and, secondly, BFAST Monitor is explored as a tool for continuous monitoring of deforestation. Error sources, the influence of input variables, suitability of vegetation indices in varying forest and savannah landscapes and the magnitude output of BFAST Monitor. Refer to Figure 1.2 for an overview of the thesis outline.

In chapter 2, research question 1 is addressed by using local field data and bi-temporal remote sensing derived land cover change detection results to estimate carbon emissions from deforestation. During two field campaigns in 2011 and 2012 biomass data were captured and sites of recent tropical deforestation were inspected. It is demonstrated that activity data measured by remote sensing can support tropical carbon emission estimation. From the measured carbon pools present, deforestation was identified as a major emission source, confirming previous findings.

In chapter 3, research question 2 is addressed by developing a framework to estimate error sources in deforestation detection when using BFAST Monitor on Landsat time series. Time series pre-processing, 
time series properties and environmental properties are varied to investigate diverse types of time series. A set of descriptive variables is used to model error sources.

In chapter 4, we address research question 3 by testing the suitability of different vegetation indices for deforestation detection in the tropics. Time series of different vegetation indices are tested for their potential to accurately measure area change by deforestation. Spectral mixture analysis based Normalized Difference Fraction Index (NDFI) or fusions of VI magnitudes are studied.

In chapter 5 , we address research question 4 by testing to what extent BFAST Monitor is capable in detecting degradation within savannah landscapes: very sparsely vegetated forest, bushlands and grassland. Analysis of this chapter focuses on a large area and very long-time series in southern Africa and included a ground truth campaign across KAZA for method calibration.

Chapter 6 provides a synthesis of this work and summarizes the main findings of the thesis and provides an outlook for further research activities within this domain.

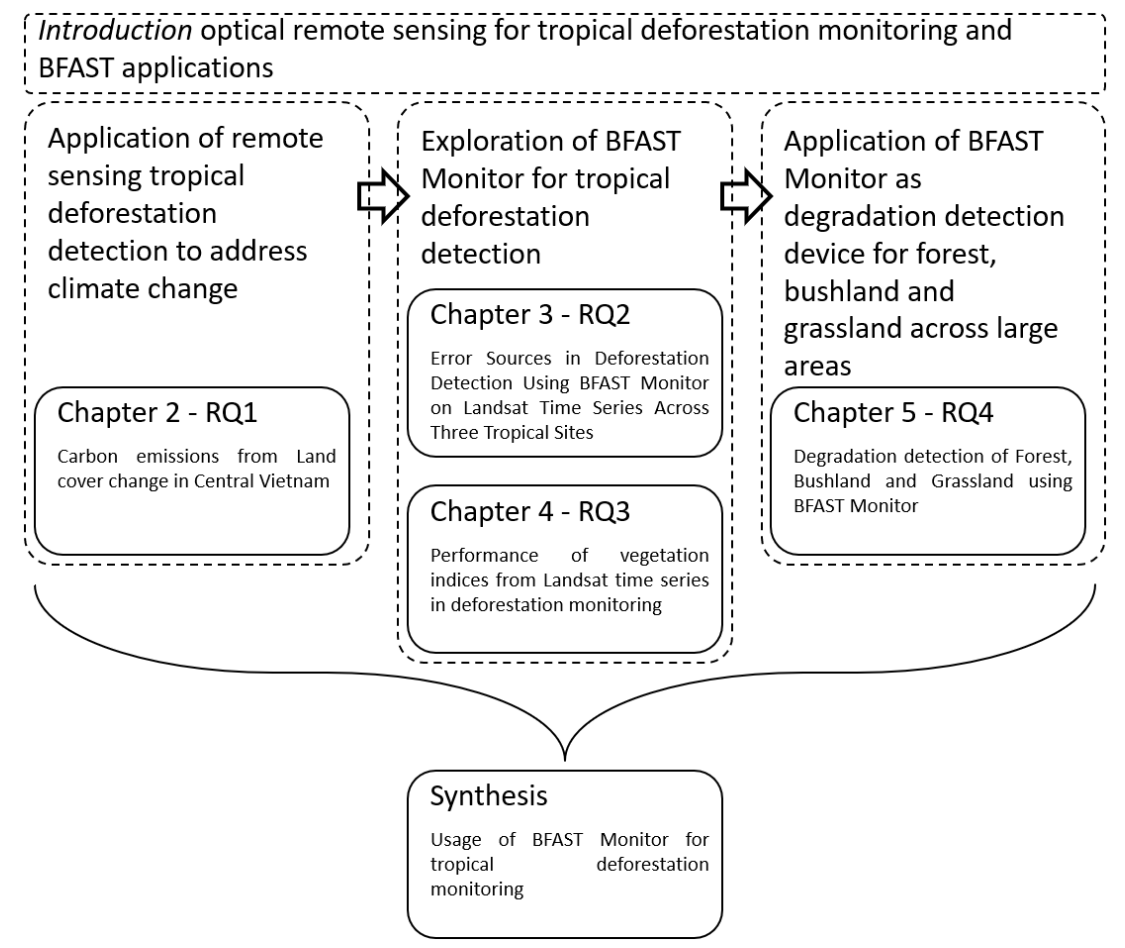

Figure 1.2 Overview of chapters and their related research questions 
Chapter 2

\section{Chapter 2}

\section{Carbon emissions from land cover change in central Vietnam}

Valerio Avitabile, Michael Schultz, Nadine Herold, Sytze de Bruin, Arun Kumar Pratihast, Cuong Pham Manh, Hien Vu Quang and Martin Herold

Published in Carbon Management, 7 (2016), 5-6, 333 - 346, DOI: 10.1080/17583004.2016.1254009 


\begin{abstract}
The carbon emissions and removals due to land cover changes between 2001 and 2010 in the Vu Gia Thu Bon River Basin, Central Vietnam, were estimated using Landsat satellite images and 3083 forest inventory plots. The net emissions from above- and belowground vegetation biomass were equal to 1.76 $\pm 0.12 \mathrm{Tg} \mathrm{CO}$, about $1.1 \%$ of the existing stocks. The vast majority of carbon emissions were due to forest loss, with the conversion of forest to cropland accounting for $67 \%$ of net emissions. Forest regrowth had a substantial impact on net carbon changes, removing $22 \%$ of emissions from deforestation. Most deforestation occurred in regrowth forest (60\%) and plantations (29\%), characterized by low carbon stock density. Thus identifying the type of forest where deforestation occurred and using local field data were critical with net emissions being 4 times larger when considering only one forest class with average carbon stock, and 5-7 times higher when using literature default values or global emission maps. Carbon emissions from soil (up to $30 \mathrm{~cm}$ ) were estimated for the main land change class. Due to the low emission factors from biomass, soils proved a key emission category, accounting for $30 \%$ of total land emissions that occurred during the monitoring period.
\end{abstract}




\subsection{Introduction}

Managing the carbon footprint of the land use sector is currently a key focus for climate change mitigation in developing countries (Canadell and Schulze, 2014; Metz et al., 2007; UNFCCC, 2008). In the terrestrial ecosystems, forests play a major role for the mitigation and adaptation to climate change via carbon storage, and furthermore by providing important ecosystem services such as water storage, soil fertility regulation and biodiversity preservation (Gullison et al., 2007; Houghton et al., 2015; van der Werf et al., 2009). In recent years the United Nations collaborative initiative on Reducing Emissions from Deforestation and forest Degradation (REDD+) program has gained increasing attention in the policy arena, presenting a valuable incentive for developing countries to reduce emissions from forest land and at the same time promoting sustainable forest management and improving local livelihoods (Goetz et al., 2015; UNFCCC, 2016).

Assessing the amounts of carbon stored in forest ecosystems and their changes is key for quantifying their climate change mitigation capability and to design and implement REDD+ activities. Such task can be accomplished by combining ground and remote sensing data at increasing levels of resolution and accuracy to move from estimates based on regional default values and global maps towards locallycalibrated, accurate and comprehensive carbon emission and removal estimates (Avitabile et al., 2016a; Ciais et al., 2014; Goetz et al., 2015; UNFCCC, 2016). Carbon changes due to deforestation in the 2000's have been estimated for the tropical regions (Achard et al., 2014; Baccini et al., 2012; Harris et al., 2012; Pan et al., 2011; Zarin et al., 2016) but most estimates consider only gross emissions from aboveground biomass, do not include forest regrowth processes and assume no biomass in the post-deforestation land uses. However, there is growing evidence that carbon removals due to forest regrowth play an important role in the carbon cycle at global and local scales (Bongers et al., 2015; Chazdon et al., 2016; Espírito-Santo et al., 2014; Poorter et al., 2016) and their impact has been included in a recent assessment of carbon changes in the tropics during the 1990-2010 period (Achard et al., 2014). Similarly, changes in soil organic carbon, even though they tend to occur at a slower pace than those in the biomass pool, have a significant impact on net emissions occurring in the tropics (Don et al., 2011; Grace et al., 2014). Moreover, in order to move towards a complete carbon accounting, the residual carbon stock in deforested lands should be accounted for (Morton, 2016) and the carbon dynamics from all land change processes should be considered (Ciais et al., 2014).

The land sector is one of the main emission sources in Vietnam, accounting for $53 \%$ of the total domestic greenhouse gases in 2000 (MONRE, 2010) Vietnam has been actively developing climate change mitigation and adaptation strategies during the last few years, and is currently in the process of identifying, planning and implementing land use practices that are sustainable, climate-smart and adapted to local needs (MONRE, 2010). Such strategies are driven by the imminent threat to be amongst the countries most severely affected by climate change impacts, with large areas at risk of increasing droughts and loss of agricultural crops (DANDIA, 2008; MONRE, 2009; UN, 2012).

Vietnam's forest coverage declined from $41 \%$ to $27 \%$ between 1943 and 1990, and during this period vast areas of primary forests were converted to secondary forests (FAO, 2010). Threatened by the negative consequences of forest resources depletion (World Bank, 2008), Vietnam has made considerable efforts to increase its forest cover during the last few decades, and expanded it to $39.7 \%$ of land area (13.5 million ha) in 2011 (MARD, 2012). However, both forest gain and forest loss processes were identified in Vietnam during the 1990 - 2010 period (Stibig et al., 2014). In particular, the increase 
of forest area was mainly due to new plantations ( 2.9 million ha) and the expansion of natural forests on grasslands and shrublands, while deforestation and extensive degradation still remained prevalent with the result that over two-thirds of Vietnam's natural forests are considered poor or regenerating (Meyfroidt and Lambin, 2008a, 2008b).

To counteract these processes, the Vietnam National Strategy on Climate Change (2011) and National Strategy on Green Growth (2012) identified the protection, sustainable use and expansion of existing forests as key national priorities. Vietnam has substantially improved its forest monitoring and forest inventory capacities between 2005 and 2015 (Romijn et al., 2015) and adopted a nation-wide and landscape-based approach for the REDD+ implementation. Among various strategies to mitigate the emissions from the land sector, forest protection has the highest carbon sequestration potential (Hoa et al., 2014) and is a key measure to obtain the objective of reducing $20 \%$ of emissions from the land sector in the period 2011-2020 (REDD Vietnam, 2012).

In order to support the implementation of the REDD+ program and other mitigation activities, it is necessary first to assess the carbon dynamics due to land cover change occurred during a historical reference period. According to the Intergovernmental Panel on Climate Change (IPCC) Guidelines (IPCC, 2006), greenhouse gas emissions and removals occurring on a certain piece of land can be calculated on the basis of two inputs: activity data and emission factors. Activity data consist on the areal extent of an activity that causes emissions or removals, usually referred to as area change data. Emission Factors consist of the amount of emissions or removals per unit area related to a certain activity, usually referred to as changes in stocks between two land cover types. Such dynamics may then be used to estimate the Reference Emission Levels against which the REDD+ emission reductions can be accounted for.

In this context, the present study quantified the carbon emissions and removals in vegetation biomass owing to land cover changes that occurred between 2001 and 2010 in the Vu Gia Thu Bon River Basin in Central Vietnam. The contribution of carbon emissions from soil was also estimated for the main change processes. Activity data were obtained by mapping land cover and land cover changes using satellite images, while emission factors were derived from forest inventory data. The objectives of this study were to assess the main change processes and carbon pools driving net carbon emissions from the land sector, and the key factors (i.e., data and methods) that affect their estimation.

\subsection{Data and methods}

\subsubsection{Study area}

The study area consists of the Vu Gia Thu Bon (VGTB) River Basin, located in Central Vietnam and covering parts of the provinces of Quangnam, Danang and Kontum (Figure 2.1). The VGTB is one of the nine largest river basins and the fifth largest in volume in Vietnam (MARD, 2009). The VGTB has been selected as the study area because it has been experiencing substantial and rapid changes in the last few decades. The economy is rapidly shifting from agriculture towards industry and services, and the economic growth rate of both Quangnam and Danang has increased around $10 \%$ each year, more than the average rate of Vietnam (DSO, 2008; QSO, 2008). Droughts in the dry season and severe floods and typhoons during the wet season severely affect the region and are likely to be increased by climate change, especially in the coastal lowlands that are densely populated and characterized by intensive agriculture (MONRE, 2009). The mountain areas are less accessible and developed, but population 
growth, inland migration and the development of several hydropower projects during the last few years have caused substantial land changes and forest loss (DONRE, 2009, p. 200).

\subsubsection{Land cover map for the year 2010}

The land cover of the VGTB for the year 2010 was mapped at $30 \mathrm{~m}$ resolution using Landsat satellite images, ancillary datasets and field observations to support the analysis of the land cover changes and the estimation of the carbon stocks. The map legend was based on the six IPCC classes, namely forest (areas with tree cover larger than 10\%), grassland (areas dominated by grass, shrubs and woody regrowth), cropland, other land, settlement and wetland (water bodies and reservoirs).

The study area encompasses three Landsat tiles within which 12 Landsat scenes acquired during the dry season (January - April) with minimum cloud cover, haze contamination and phenological changes of vegetation (especially crop rotations) were selected. The dates and IDs of the Landsat images are reported in Table 2.1. The images were pre-processed and harmonized using topographic correction (Richter et al., 2009) and radiometric normalization techniques (Canty and Nielsen, 2008). Data gaps due to the Scan Line Corrector (SLC) failure were minimized (Chen et al., 2011) and clouds and cloud shadows were identified and removed (Zhu and Woodcock, 2012) (Table 2.1). After pre-processing, the satellite data were classified into the six IPCC classes using the non-parametric Random Forest algorithm (Breiman, 2001). The algorithm was trained with field observations acquired during a dedicated field trip in March 2012 and further training data acquired through visual analysis of nine high-resolution satellite images (Spot 5, $2.5 \mathrm{~m}$ resolution). The effects of seasonal changes, which were especially marked for intra-annual crop rotations, were well represented in the training dataset to obtain a consistent classification of the class "cropland". Then, the 2010 forest map produced by the Forest Inventory and Planning Institute (FIPI) of Vietnam was used to distinguish five forest types within the areas classified as forest in our land cover map. The fusion of the two maps provided a land cover map with high spatial resolution $(30 \mathrm{~m}$ ) and thematic detail including 10 classes (forest Rich, forest medium, forest poor, forest regrowth, forest plantation, grassland, cropland, settlement, other land, and wetland).

The map accuracy was computed only considering the six IPCC classes, i.e. without distinguishing the five forest types, because this information could not be reliably retrieved only from satellite data. The map was assessed for 300 validation points (stratified by class proportions) through visual interpretation of high-resolution Spot 5 satellite data acquired in 2010 and 2011, apart from limited areas where the images were taken in 2008. 


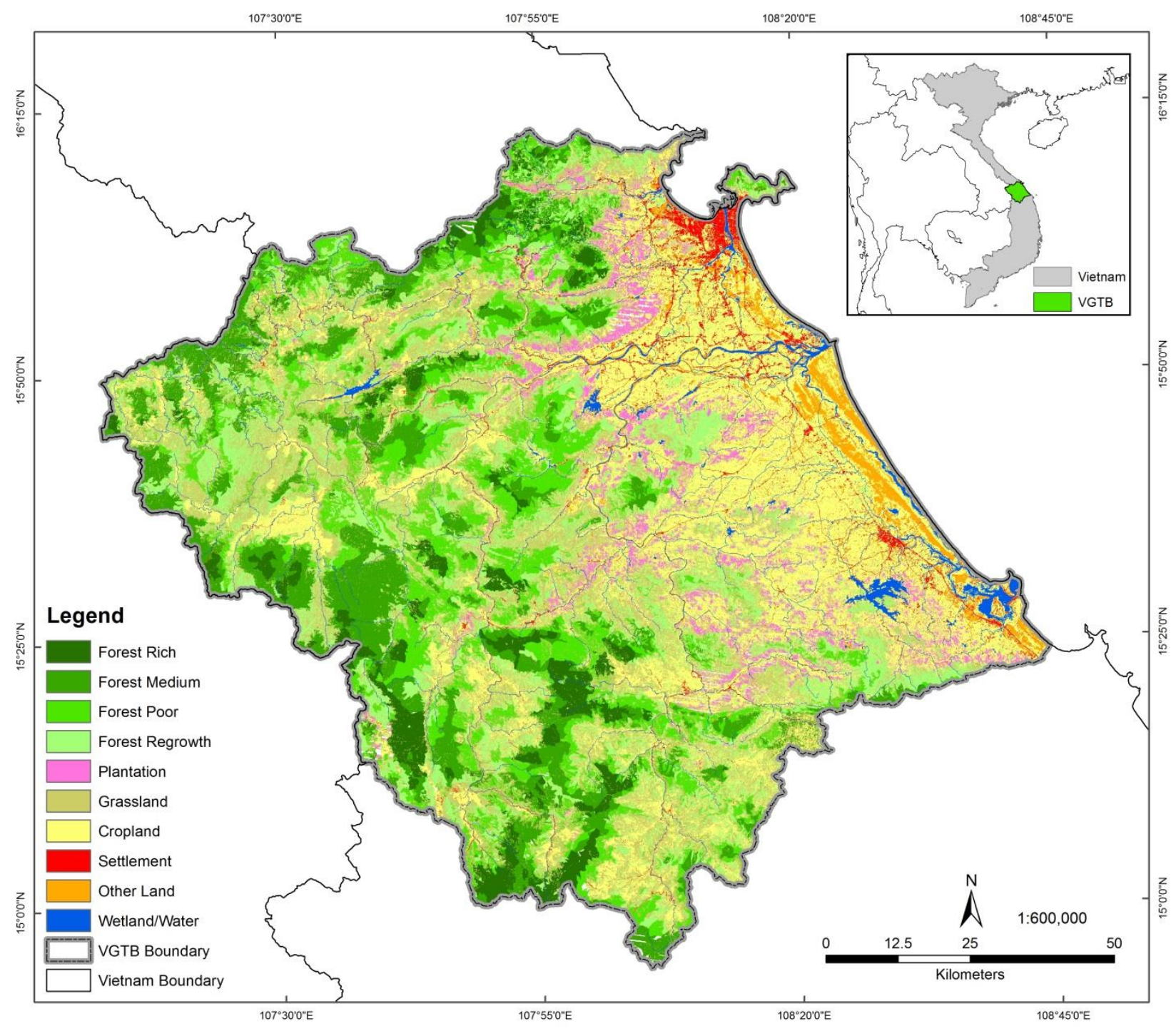

Figure 2.1 Land cover map of Vu Gia Thu Bon (VGTB) for the year 2010. Inset: Location of the VGTB River Basin, Central Vietnam.

\subsubsection{Land cover change between 2001 and 2010}

A land cover change map of the VGTB River Basin was created for the periods $2001-2005$ and 2005 2010 using Landsat data. The base year was set to 2001 instead of 2000 because of the low data quality and large cloud coverage in the Landsat images during the year 2000. The change categories were defined as combinations of the six IPCC land cover classes. The changes within forest areas (i.e. within the five forest types identified in the FIPI map and including the changes from forest to plantation) were not considered because they could not reliably be mapped with automated classification of Landsat data.

The Landsat data were first pre-processed for cloud screening and gap-filling using the same procedures applied for the 2010 land cover map. The data gaps remaining after pre-processing covered $3 \%$ and $15 \%$ of the land area during the two monitoring periods (2001-2005 and 2005-2010 respectively) and were mostly located in the mountain areas on the western border of the study area. Due to the non-random 
nature of the land change processes (e.g., deforestation hot-spots), it was preferred to avoid extrapolation of the detected changes in areas with no data, since the associated uncertainties could not be calculated and were likely to be large. The Landsat images were then transformed separately for each tile using the iteratively reweighted Multivariate Alteration Detection (iMAD) method (Nielsen, 2007) and the change pixels were identified by setting a threshold, which was visually evaluated for each image pair using the iMAD change likelihood information layer. Due to the invariant properties of iMAD, radiometric normalization of the image pairs was not necessary. The type of change for the selected pixels was identified using the Random Forest classification algorithm (Breiman, 2001), trained with reference data obtained through visual interpretation of the 2001, 2005 and 2010 Landsat mosaics and the 2010 Land Cover map. Seasonal changes due to agricultural practices that did not lead to a change in land cover were identified and removed by an additional change detection using the procedure indicated above of four Landsat images acquired in different seasons (day 82 and 290) of the year 2001.

Validation of the land cover change map was performed according to the good practices presented by Olofsson et al. (2014) and Congalton (1991). In total, 340 validation samples were stratified by class area, with 290 points randomly sampled in the 25 change classes identified in the study area and 50 sample points in the six no-change classes. The reference data were extracted from Landsat images for the years 2000 and 2010 and from higher resolution data (Spot5, Rapideye, GoogleEarth) when available. Each reference point and its direct neighbourhood were interpreted by visual analysis to identify the most common change class present within the nine pixels.

\subsubsection{Carbon emissions and removals between 2001 and 2010}

The amounts and spatial distribution of the carbon emissions and removals in the VGTB were obtained by combining the land cover change map for the period 2001 - 2010, which provided the activity data, with the emission factors, mostly derived from ground observations. The emission factors were obtained using the stock-change approach by subtracting the mean carbon stock of the class after the change to that of the class before the change Penman et al. (2003). Positive emission factors indicate release of carbon from land to the atmosphere (emissions) while negative emission factors indicate absorption of carbon from the atmosphere to the land (removals).

The carbon pools included in this study were above- and belowground biomass of living vegetation, which are responsible for the vast majority of carbon emissions and removals in most terrestrial ecosystems. In addition, carbon emissions from soils were estimated for the main land cover change category. Carbon dynamics that did not result in land cover change but occurred within a stable land cover class (as forest degradation or forest growth) were not considered. The carbon emissions and removals were converted to $\mathrm{CO}_{2}$ equivalent units $\left(\mathrm{CO}_{2}\right)$ using the conversion factor of 44/12.

In the case of forest loss, carbon dynamics depend on the type of forest affected by the change activity. This information was not available from the 2001-2010 land cover change map (which identifies only one forest class) and was obtained from the 2010 land cover map using the proximity criterion, attributing each patch of forest converted to another land cover class to the spatially nearest type of forest. Changes from non-forest to forest always assumed that the conversion was to regrowth forest, since other forest classes can develop only in timeframes longer than 10 years (the monitoring period of this study). 
The carbon emissions obtained from this study were compared with the emission databases for tropical deforestation of Zarin et al. (2016) and Harris et al. (2012). Zarin et al. (2016) estimated emissions from aboveground biomass for the period 2001-2013 by combining the Hansen et al. (2013) global forest cover change map with the Baccini et al. (2017) pantropical biomass map. By contrast, Harris et al. (2012) estimated emissions from above- and belowground biomass for the period 2000-2005 by combining the Hansen et al. (2010) global forest loss map with the Saatchi et al. (2011) pantropical biomass map. The emission estimates for the study area (VGTB) were harmonized with regard to time period, carbon pool and assumptions (i.e., no biomass remaining after deforestation) before comparison (see Discussion).

\subsubsection{Carbon stocks and emission factors of biomass}

In this study biomass is defined as the total amount of above- and belowground organic matter in living vegetation expressed in units of dry weight. The carbon stock density of aboveground biomass (AGB) was estimated on the basis of forest inventory plots while, due to the absence of direct measurements, the belowground compartment (BGB) was derived from AGB using the average IPCC root-to-shoot ratios $(R)$ in the tropical moist ecoregion: 0.205 for $A G B<125 \mathrm{Mg} /$ ha and 0.235 for $A G B>125 \mathrm{Mg} /$ ha (Mokany et al. 2006). The biomass values were converted to carbon units using the conversion factor of 0.5 (Penman et al. 2003). Hence, carbon stock in biomass (C) was obtained as

$$
C=(A G B+B G B) \cdot 0.5=(A G B+(A G B \cdot R)) \cdot 0.5
$$

The field data used in this study included two different datasets. The first dataset consists of 2,994 plots of 0.05 ha size collected by the FIPI during the National Forest Inventory in the Quang Nam province between 2007 and 2009 according to a systematic sampling strategy. The second dataset consists of 89 plots of 0.126 ha size acquired in 2011 and 2012 by a dedicated field campaign with a random stratified sampling approach at locations expected to be deforested (i.e., nearby deforestation hot-spots), representative of the carbon emission from forest loss. The data collected in the field consist of the diameter at breast height (DBH) and species identification for all trees with $\mathrm{DBH}>5 \mathrm{~cm}$. The wood density of the tree species was identified using the Global Wood Density Database (Chave et al., 2009; Zanne et al., 2009). For the species not included in the wood density database, the mean value of the species belonging to the same genus and located in the South-East Asia region was used, while the average wood density value of all species recorded in the plots was applied for the species that could not be identified in the field. The AGB was estimated using the generalized allometric equation for moist tropical forest based on DBH and wood density provided by Chave et al. (2005). The field data were then stratified by the 2010 land cover map to estimate the total and average carbon stock per class and related standard error, and to convert the 2010 land cover map in a carbon stock map.

Since no plots were located in the classes cropland, settlement, other land and wetland, the IPCC Tier 1 Default biomass density values (IPCC, 2006) were applied. The carbon density was considered equal to 5 $\mathrm{Mg} \mathrm{C} /$ ha in croplands (Table 5.9 in IPCC 2006). In the case of settlement, other land and wetland, no reference data for their carbon stocks were available but the IPCC Tier 1 Default values assume no carbon remaining in biomass after conversion to these land categories. Given the small areal extent, in this study their carbon stock was also assumed to be zero for the opposite changes (i.e., from these classes to other land cover classes). Having the same emission factors, the classes settlement, other land and wetland were grouped in the class "No vegetation" for emission calculations. 


\subsubsection{Carbon stocks and emission factors of soils under forest change}

Field data or literature values representative of the emissions factors for soil and litter in the VGTB were not available prior to this study (Don et al., 2011). Since it was not feasible to acquire field data for all land change categories due to time and cost constrains, carbon stock changes were estimated only for the main change process observed in the VGTB (i.e., the conversion of forest to cropland) through a dedicated sampling campaign performed in 2012. Field sample plots were also acquired to assess whether relevant emissions were caused from the conversion of forest to plantation (a change process that was not included in the land cover change map) and to quantify the emissions occurring after deforestation but before a follow-up land use is implemented (forest to bare soil).

The field plots were located using a stratified random sampling design using land cover, land cover change and soil type as the stratifying variables. The field observations focused on three sites that presented large deforestation areas (the districts of Tra Giac, Tra Leng and Tu Ba) and on land cover classes occurring on Acrisol, which is the dominat soil group occurring on $74.7 \%$ of the study area (NIAPP, 2005). In total, 27 plots were sampled in deforested areas and in forests representative of the soil organic carbon (SOC) stocks before deforestation, identified as forests located in proximity and with similar environmental conditions to deforested areas. At each sampling plot, five individual soil cores were taken from the first $30 \mathrm{~cm}$ within a $20 \mathrm{~m} \times 20 \mathrm{~m}$ area. After removal of coarse roots and stones with a diameter of $>2 \mathrm{~mm}$, mineral soil samples were dried at $40^{\circ} \mathrm{C}$ and litter samples at $70^{\circ} \mathrm{C}$. Total carbon (TC) concentrations were determined by dry combustion. After removal of organic carbon (OC) by ignition at $450^{\circ} \mathrm{C}$ for $16 \mathrm{~h}$, inorganic $\mathrm{C}$ was quantified with the same elemental analyzer. OC concentrations of the mineral soil were calculated as the difference between TC and inorganic $\mathrm{C}$. Bulk density of the mineral soil was calculated with the mass of the oven dry soil $\left(105^{\circ} \mathrm{C}\right)$ and the core volume. OC stocks were calculated based on bulk density, relative contribution of fine earth material (soil $<2 \mathrm{~mm}$ ) to total soil mass, layer thickness, and OC concentration.

\subsubsection{Uncertainty assessment}

Uncertainty about the carbon emissions was assessed by computing and propagating the uncertainty about the activity data and the uncertainty concerning the emission factors. The uncertainty metric used in this study is one standard deviation $(\sigma)$ of the estimated values, which are the total change area for the activity data and the mean carbon stock change density for the emission factor. These two components were considered uncorrelated because they were obtained with independent data, namely satellite images and forest inventory plots. On this basis, the uncertainty of the emission estimates was computed using analytical error propagation equations for addition and multiplication of two independent random variables.

Uncertainty about the activity data (i.e., the area of each land change category) was computed on the basis of the validation results of the land cover change map. With $\mathrm{p}_{\mathrm{ij}}$ denoting the probability of correctly identifying a change from class $i$ to class $j$, and assuming that classification errors are spatially uncorrelated, the uncertainty of the respective class area $\left(\sigma_{i j}(A D)\right)$ was computed as

$$
\sigma_{i j}(A D)=\sqrt{N_{\text {pixel }(i j)} \cdot \text { Area }_{\text {pixel }}^{2} \cdot p_{i j} \cdot\left(1-p_{i j}\right)}
$$


where $\mathrm{N}_{\text {pixel(ij) }}$ represents the number of pixels of the change class ij and Area pixel the pixel area, equal to 0.09 ha for all classes.

Uncertainty about the emission factors was computed by summing the uncertainties concerning the carbon stock density of the land cover classes before and after the change. Since carbon stocks were obtained as the sum of the above- and belowground components (Equation 2.1), the uncertainties were computed separately for the above- and belowground biomass and then summed as indicated below. The uncertainty about the carbon stock change between the class $i$ and $j$ (emission factor) for aboveground biomass $\left(\sigma_{\mathrm{ij}}(\mathrm{AGB})\right)$ was computed as

$$
\sigma_{i j}(A G B)=\sqrt{\sigma_{i}(A G B)^{2}+\sigma_{j}(A G B)^{2}}
$$

where $\sigma_{i}(A G B)$ and $\sigma_{j}(A G B)$ represent the standard error of the mean aboveground carbon stock of land cover class $i$ and $j$, computed on the basis of the field data as the ratio between the standard deviation of the plot biomass and the square root of the number of plots.

Since the belowground biomass for the class i was computed by multiplication of the mean aboveground biomass $\left(A G B_{i}\right)$ with a root-to-shoot ratio $\left(R_{i}\right)$ (Equation 2.1), the respective uncertainty $\left(\sigma_{i}(B G B)\right)$ included the uncertainty about the input variables as follows:

$$
\sigma_{i j}(E)=\sqrt{\left[A D_{i j}{ }^{2} \cdot \sigma_{i j}(E F)^{2}\right]+\left[E F_{i j}{ }^{2} \cdot \sigma_{i j}(A D)^{2}\right]+\left[\sigma_{i j}(A D)^{2} \cdot \sigma_{i j}(E F)^{2}\right]}
$$

Lastly, the uncertainty about the total emissions for all land changes was obtained by summing the uncertainty concerning the emissions for each change category as in Equation (2.3).

\subsection{Results}

\subsubsection{Land cover map for 2010}

The VGTB river basin comprises 12,385 $\mathrm{km}^{2}$ and in the year 2010 almost half of the land area was covered by Forest (47\%), followed by cropland $(26 \%)$ and grassland $(20 \%)$, while smaller areas were occupied by settlement (3\%), wetland (i.e., water bodies) (3\%) and other Land (2\%) (Figure 2.1, Table 2.1). Among forest areas, regrowth forest was the most common forest type (33\%), followed by poor forest (25\%) and medium forest (25\%), while rich forest represented only $10 \%$ of the forest areas and plantations (mostly short-term rotations of Acacia) were established on $8 \%$ of forest land. The overall accuracy of the land cover map was equal to $82 \%$ (Table 2.1). The user's and producer's accuracy of the six IPCC classes were always higher than $80 \%$ with the exception of cropland and settlement $(71 \%$ and $68 \%$ user's accuracy, respectively), and grassland (68\% producer's accuracy).

\subsubsection{Land cover change in 2001-2010}

The change detection indicated that $4.7 \%$ of land area was affected by change during the period 20012010, equal to 5,770 ha/year (Table 2.1). The change rate was equal to 3.1\% during the sub-period 2005 -2010 and $1.6 \%$ during the sub-period $2001-2005$. The gross deforestation rate proved to be about $2.2 \%$ of land area over the 2001-2010 period, indicating an average annual deforestation rate of $0.22 \%$ that was equally spread over the two sub-periods. The gross deforestation was partly counterbalanced 
by forest regrowth (0.58\% of land area), which mostly occurred during $2005-2010(0.48 \%)$ and only $0.10 \%$ during $2001-2005$.

The most prominent change category during the 2001-2010 period was the transition from forest to cropland, which occurred on $1.43 \%$ of land area, while the reverse process (from cropland to forest) was detected on $0.43 \%$ of land area (Figure 2.2). Another prominent change was the transition of grassland to cropland, which occurred on $0.84 \%$ of land area, and the urbanization process with expansion of new settlements on $0.38 \%$ of land area, while almost no decrease of settlement was mapped. The validation of the land cover change map, computed after aggregating the classes settlement, other land and wetland in the class "No vegetation", indicated that the overall accuracy was $81 \%$ and the producer's and user's accuracies were higher than 70\% (Table 2.3).

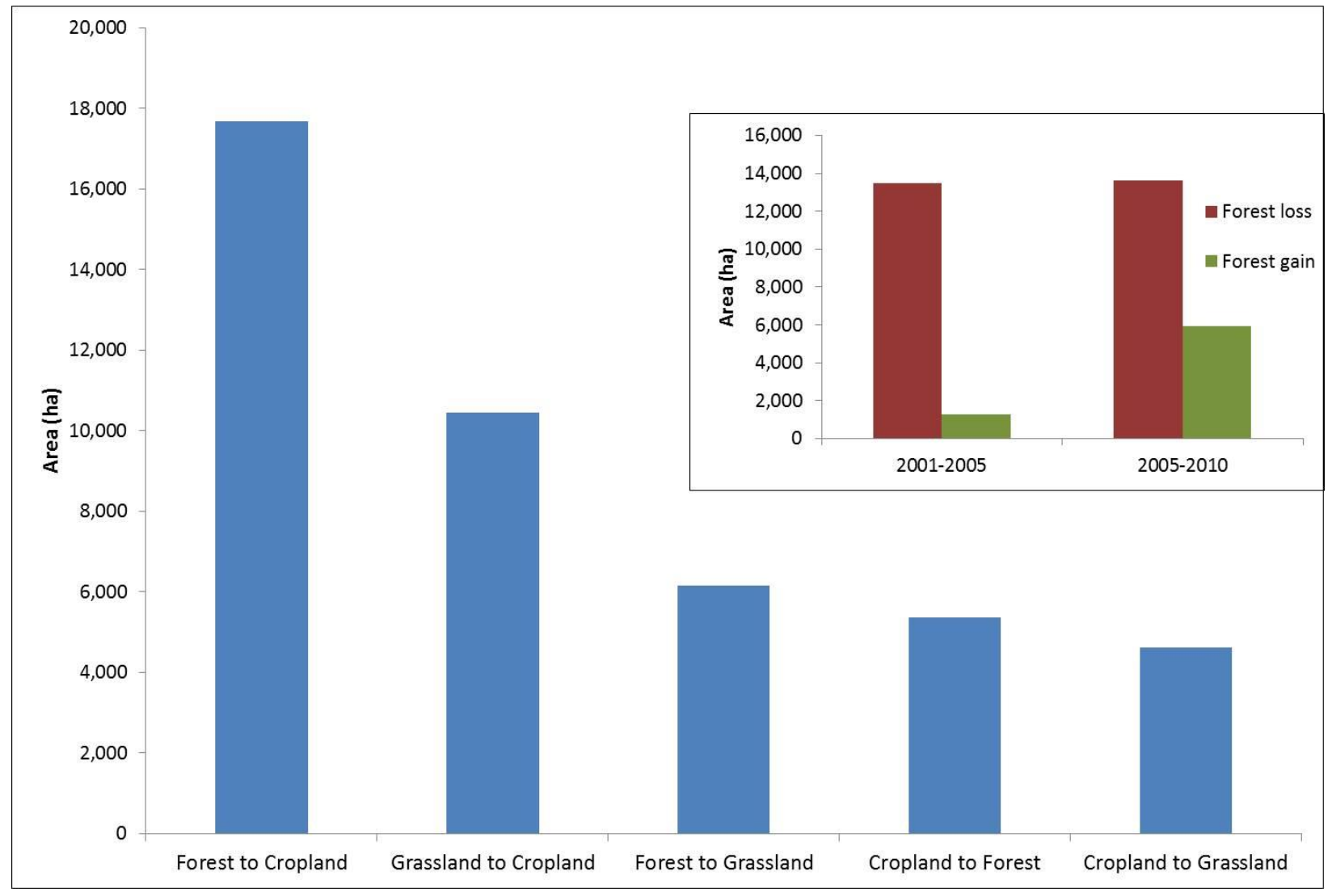

Figure 2.2 Area change for the main land cover change categories in the Vu Gia Thu Bon (VGTB) River Basin for 2001-2010. Inset: Summary of change area for forest loss (from forest to a non-forest class, in red) and forest gain (from a non-forest class to forest, in green) for the two monitoring periods (20012005 and 2005-2010).

\subsubsection{Carbon stocks and emission factors of biomass}

The vegetation of VGTB stores $42.7 \mathrm{Tg}$ carbon in its biomass, with $34.9 \mathrm{Tg}$ in aboveground biomass and $7.9 \mathrm{Tg}$ in belowground biomass. The distribution of carbon stocks varies considerably among the land cover classes (Figure 2.3). Forests store about $92 \%$ of the carbon stock of VGTB on about $47 \%$ of the land area, with most carbon (80\%) contained in rich, medium and poor forest (i.e. excluding regrowth and plantation) on $28 \%$ of land area. Rich forests alone store $28 \%$ of total carbon on $5 \%$ of the land area 
while plantations present a similar extent (4\%) but contain only $2 \%$ of the carbon stock. Medium forest covers the same extent as poor forest ( $12 \%$ of land area for each class) but stores double the amounts of carbon ( $35 \%$ vs. $18 \%$ of total stock, respectively), while regrowth areas contain $10 \%$ of carbon on $15 \%$ of the land area. Almost half of the VGTB ( $46 \%$ of the land area) is covered by low-carbon cropland and grassland, which store only $9 \%$ of total carbon, while the remaining $7 \%$ of land (settlement, other land and wetland) was considered to have no carbon stock in vegetation biomass.

The carbon stock density varies considerably among the vegetation strata and the differentiation of forests into rich (206 Mg C/ha), medium (102 Mg C/ha), poor (44 Mg C/ha), regrowth (22 Mg C/ha) and plantation (16 Mg C/ha) forest represents appropriately the differences in carbon density (Table 2.1). Grassland and cropland showed substantially lower mean values ( 8 and $5 \mathrm{Mg} \mathrm{C} / \mathrm{ha}$, respectively). As a consequence, the emission factors in the conversion of a forest to a non-forest class varied largely depending on the forest type involved in the change process, ranging from 8 to $206 \mathrm{Mg} \mathrm{C} / \mathrm{ha}$ (Table 2.3). The emission factors for the conversion of non-forest to forest presented a smaller range, varying from 14 to $-22 \mathrm{Mg} \mathrm{C} /$ ha (where negative emission factors indicate carbon removals from the atmosphere), due to the fact that only the transition to regrowth forest was possible within the monitoring period of 10 years. Change process among non-forest classes presented the lowest emission factors, ranging from 8 to $-8 \mathrm{Mg} \mathrm{C} /$ ha. Regarding uncertainty, the emission factors for aboveground biomass from forestrelated changes (derived from the field data) presented lower uncertainty (about 2-10\% of the emission factor) than the corresponding values for belowground biomass (derived from Mokany et al., 2006), which were about $5-20 \%$ of the emission factor (Table 2.1). 


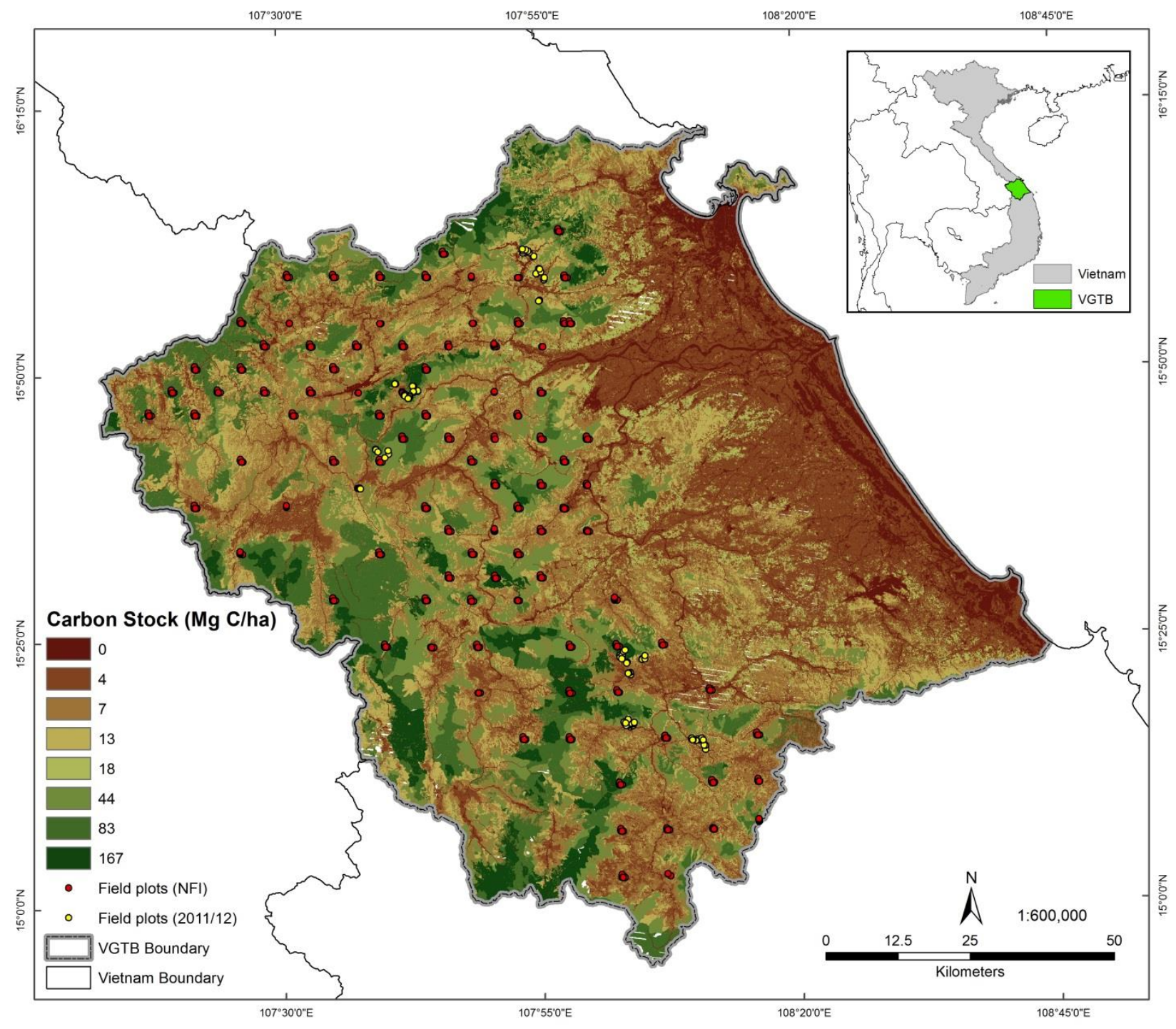

Figure 2.3 Map of the carbon stock density in aboveground biomass for the year 2010 in the Vu Gia Thu Bon (VGTB) River Basin, and location of the forest inventory plots acquired by the National Forest Inventory (NFI) and by an ad-hoc field campaign in 2011 and 2012. Inset: location of the VGTB River Basin, Central Vietnam.

\subsubsection{Carbon stocks and emission factors of soils under forest change}

The mean SOC density in forest areas (including plantations) was $48.7 \pm 3.8 \mathrm{Mg} \mathrm{C} /$ ha (Table 2.3). When considering forest and plantations separately, it resulted that the mean $\mathrm{SOC}$ stock for plantation (49.6 $\pm 5.4 \mathrm{Mg} \mathrm{C} / \mathrm{ha}$ ) was not significantly different from the SOC stocks of forest excluding plantations $(48.1 \pm 4.9 \mathrm{Mg} \mathrm{C} / \mathrm{ha})$, indicating that the emissions for the related change process (conversion of forest to plantation) were negligible. The SOC stocks in recently deforested areas were lower than those in forests, being equal to $43.2 \pm 4.8 \mathrm{Mg} \mathrm{C} /$ ha after deforestation (forest converted to bare soil) and $40.8 \pm 5.5$ $\mathrm{Mg} \mathrm{C/ha}$ in forest converted to croplands during the period 2001-2010. The OC stocks in the litter layer showed similar patterns with the highest (and very similar) values in forest $(1.10 \pm 0.14 \mathrm{Mg} \mathrm{C} / \mathrm{ha}$ ) and plantation (1.09 $\pm 0.06 \mathrm{Mg} \mathrm{C} / \mathrm{ha}$ ) areas, and lower values in croplands $(0.65 \pm 0.09 \mathrm{Mg} \mathrm{C} / \mathrm{ha})$, while no OC 
stocks could be calculated in recently deforested areas due to the absence of a litter layer as a consequence of the burning practices.

Table 2.1 Mean carbon stock density values ( \pm standard error) for aboveground ( $A G B)$, belowground $(B G B)$ and total $(A G B+B G B)$ biomass per land-cover class.

\begin{tabular}{|c|c|c|c|c|c|}
\hline \multirow[b]{2}{*}{ Land cover class } & \multirow[b]{2}{*}{ No. plots } & \multicolumn{3}{|c|}{ Carbon stock (Mg C/ha) } & \multirow[b]{2}{*}{ Source } \\
\hline & & AGB & BGB & $\mathrm{AGB}+\mathrm{BGB}$ & \\
\hline Forest rich & 970 & $166.8 \pm 2.5$ & $39.2 \pm 1.9$ & $206.0 \pm 3.2$ & Field data \\
\hline Forest medium & 629 & $83.0 \pm 1.5$ & $19.5 \pm 3.0$ & $102.5 \pm 1.8$ & Field data \\
\hline Forest poor & 581 & $44.5 \pm 1.3$ & $9.1 \pm 1.6$ & $53.6 \pm 2.1$ & Field data \\
\hline Regrowth & 352 & $18.2 \pm 0.7$ & $3.7 \pm 0.7$ & $22.0 \pm 1.0$ & Field data \\
\hline Plantation & 79 & $12.9 \pm 1.3$ & $2.6 \pm 0.5$ & $15.5 \pm 1.4$ & Field data \\
\hline Grassland & 472 & $6.5 \pm 0.4$ & $1.3 \pm 0.2$ & $7.9 \pm 0.4$ & Field data \\
\hline Cropland & 0 & $4.0 \pm 1.5$ & $1.0 \pm 0.3$ & $5.0 \pm 1.5$ & IPCC Tier 1 \\
\hline
\end{tabular}

The conversion of forest to cropland resulted in a SOC loss for the 10-year monitoring period in the mineral soil of $7.9 \pm 4.0 \mathrm{Mg} \mathrm{C} /$ ha, while the emissions immediately after deforestation were lower $(5.4 \pm 3.6 \mathrm{Mg} \mathrm{C} / \mathrm{ha})$. The emissions from the litter layer were only $0.5 \pm 0.1 \mathrm{Mg} \mathrm{C} / \mathrm{ha}$ in the conversion of forest to cropland and $1.10 \pm 0.08 \mathrm{Mg} \mathrm{C} /$ ha immediately after deforestation (assuming that the litter layer is burned). Hence, in most cases the emission factors relative to the monitoring period for soils were smaller than those for aboveground biomass and presented larger relative uncertainties due to the smaller sample size.

Table 2.2 Area, emission factors (EF) for aboveground ( $A G B$ ), belowground (BGB) and total biomass ( $A G B+B G B)$, and total carbon emissions (emissions) ( \pm standard error) per land-cover change class in the Vu Gia Thu Bon (VGTB) River Basin during the period 2001-2010. The class "no vegetation" includes the classes settlement, other land and wetland, which have the same EF.

\begin{tabular}{|c|c|c|c|c|c|}
\hline \multirow[b]{2}{*}{ Change category } & \multirow[b]{2}{*}{ Area (ha) } & \multicolumn{3}{|c|}{$\mathrm{EF}(\mathrm{Mg} \mathrm{C} / \mathrm{ha})$} & \multirow[b]{2}{*}{ Emissions $\left(\mathrm{Gg} \mathrm{CO}_{2}\right)$} \\
\hline & & AGB & BGB & $A G B+B G B$ & \\
\hline Forest rich to cropland & $28 \pm 1$ & $163 \pm 3$ & $38 \pm 2$ & $201 \pm 4$ & $20 \pm 1$ \\
\hline Forest medium to cropland & $488 \pm 2$ & $79 \pm 2$ & $18 \pm 1$ & $97 \pm 2$ & $1745 \pm 4$ \\
\hline Forest poor to cropland & $482 \pm 2$ & $41 \pm 2$ & $8 \pm 2$ & $49 \pm 3$ & $86 \pm 5$ \\
\hline Regrowth to cropland & $10,630 \pm 10$ & $14 \pm 2$ & $3 \pm 1$ & $17 \pm 2$ & $661 \pm 70$ \\
\hline Plantation to cropland & $6046 \pm 7$ & $9 \pm 2$ & $2 \pm 1$ & $11 \pm 2$ & $233 \pm 45$ \\
\hline Forest rich to grassland & $38 \pm 0$ & $160 \pm 3$ & $38 \pm 2$ & $198 \pm 3$ & $28 \pm 0$ \\
\hline Forest medium to grassland & $256 \pm 1$ & $76 \pm 2$ & $18 \pm 1$ & $95 \pm 2$ & $89 \pm 2$ \\
\hline Forest poor to grassland & $1328 \pm 2$ & $38 \pm 1$ & $8 \pm 2$ & $46 \pm 2$ & $223 \pm 10$ \\
\hline Regrowth to grassland & $3583 \pm 3$ & $12 \pm 1$ & $2 \pm 1$ & $14 \pm 1$ & $185 \pm 14$ \\
\hline Plantation to grassland & $947 \pm 2$ & $6 \pm 1$ & $1 \pm 1$ & $8 \pm 1$ & $27 \pm 5$ \\
\hline Forest rich to no vegetation & $15 \pm 1$ & $167 \pm 3$ & $39 \pm 2$ & $206 \pm 3$ & $12 \pm 0$ \\
\hline Forest medium to no vegetation & $165 \pm 2$ & $83 \pm 2$ & $19 \pm 1$ & $102 \pm 2$ & $62 \pm 1$ \\
\hline Forest poor to no vegetation & $267 \pm 2$ & $44 \pm 1$ & $9 \pm 2$ & $54 \pm 2$ & $52 \pm 2$ \\
\hline Regrowth to no vegetation & $2040 \pm 6$ & $18 \pm 1$ & $4 \pm 1$ & $22 \pm 1$ & $164 \pm 7$ \\
\hline Plantation to no vegetation & $797 \pm 4$ & $13 \pm 1$ & $3 \pm 1$ & $16 \pm 1$ & $45 \pm 4$ \\
\hline Cropland to forest & $5358 \pm 0$ & $-14 \pm 2$ & $-3 \pm 1$ & $-17 \pm 2$ & $-333 \pm 35$ \\
\hline Cropland to grassland & $4619 \pm 8$ & $-3 \pm 2$ & $0 \pm 0$ & $-3 \pm 2$ & $-49 \pm 27$ \\
\hline Cropland to no vegetation & $1346 \pm 0$ & $4 \pm 1$ & $1 \pm 0$ & $5 \pm 2$ & $25 \pm 8$ \\
\hline Grassland to forest & $987 \pm 0$ & $-12 \pm 1$ & $-2 \pm 1$ & $-14 \pm 1$ & $-51 \pm 4$ \\
\hline Grassland to cropland & $10,451 \pm 7$ & $3 \pm 2$ & $0 \pm 0$ & $3 \pm 2$ & $111 \pm 61$ \\
\hline Grassland to no vegetation & $3294 \pm 6$ & $7 \pm 0$ & $1 \pm 0$ & $8 \pm 2$ & $95 \pm 18$ \\
\hline No vegetation to forest & $848 \pm 0$ & $-18 \pm 1$ & $-4 \pm 1$ & $-22 \pm 1$ & $-68 \pm 3$ \\
\hline No vegetation to cropland & $1221 \pm 0$ & $-4 \pm 1$ & $-1 \pm 0$ & $-5 \pm 2$ & $-22 \pm 7$ \\
\hline No vegetation to grassland & $257 \pm 0$ & $-7 \pm 0$ & $-1 \pm 0$ & $-8 \pm 0$ & $-7 \pm 0$ \\
\hline No vegetation to No vegetation & $2247 \pm 0$ & $0 \pm 0$ & $0 \pm 0$ & $0 \pm 0$ & $0 \pm 0$ \\
\hline Total & $57,740 \pm 20$ & & & & $1761 \pm 117$ \\
\hline
\end{tabular}


Table 2.3 Mean OC stock values ( \pm standard error) for mineral soil and litter samples per land cover class. The values for forest and plantation are first presented separately and then combined in the class "forest and plantation," the values for cropland refer to OC stocks in agriculture areas established between 2001 and 2010 on forest soil, and the values for no vegetation refer to OC stocks in bare soil due to recent deforestation.

\begin{tabular}{lccc}
\hline & & \multicolumn{2}{c}{ OC stock (Mg C/ha) } \\
\cline { 3 - 4 } Land cover class & No. plots & Mineral soil & Litter \\
\hline Forest & 9 & $48.1 \pm 3.0$ & $1.1 \pm 0.1$ \\
Plantation & 6 & $49.6 \pm 3.3$ & $1.1 \pm 0.1$ \\
Forest and plantation & 15 & $48.7 \pm 2.1$ & $1.1 \pm 0.1$ \\
Cropland (from 2001) & 6 & $40.8 \pm 3.3$ & $0.6 \pm 0.1$ \\
No vegetation & 6 & $43.2 \pm 2.9$ & $0 \pm 0$ \\
\hline
\end{tabular}

\subsubsection{Carbon emissions and removals in $2001-2010$}

Changes in the land cover that occurred in the VGTB between 2001 and 2010 caused the net emissions of about $1.76 \pm 0.12 \mathrm{Tg} \mathrm{CO}_{2}$ equivalent (Figure 2.4; Table 2.2). The vast majority of carbon emissions were due to forest loss, with the conversion of forest to cropland being the single most important source of $\mathrm{CO}_{2}$ accounting for $67 \%$ of net emissions $(1.17 \pm 0.08 \mathrm{Tg} \mathrm{CO}$ ), followed by the conversion of forest to grassland that caused $31 \%$ of net emissions $\left(0.55 \pm 0.02 \mathrm{Tg} \mathrm{CO}_{2}\right)$. When considering the forest type, most of the emissions from agriculture-driven deforestation occurred on regrowth forest $(0.66 \pm$ $0.07 \mathrm{Tg} \mathrm{CO}_{2}$ ), characterized by a low emission factor (17 $\left.\pm 2 \mathrm{Mg} \mathrm{C} / \mathrm{ha}\right)$. The net emissions were mainly due to the loss of carbon from aboveground biomass (83.2\%), while emissions from belowground biomass contributed to $16.8 \%$ of the net carbon release, reflecting the root-to-shoot ratios used to compute the belowground biomass.

Substantial removals were due to the change of non-forest areas to forest (regrowth), which absorbed $0.45 \pm 0.04 \mathrm{Tg} \mathrm{CO}_{2}$, equal to $22 \%$ of gross emissions from deforestation and $26 \%$ of net land emissions (Table 2.3). Most removals (74\%) were due to the conversion of cropland to forest. Carbon changes due to conversion among non-forest classes produced small carbon emissions or removals, with a net effect of carbon release equal to $9 \%$ of net emissions, mostly due to the conversion of grassland to cropland. The spatial distribution of the emissions and removals shows that the majority of the carbon changes occurred in the most accessible areas, namely the lowlands in the coastal areas and along the river valleys in the midlands and uplands (Figure 2.5).

Emissions from soil were estimated for the conversion of forest to cropland (the main change class in terms of area and emissions), and were equal to $43 \%$ of emissions from biomass $(0.51 \pm 0.26 \mathrm{Tg} \mathrm{CO}$ ). Hence, when considering the three carbon pools (aboveground biomass, belowground biomass and soil carbon), soil carbon accounted for $30 \%$ of total emissions from this change class (Figure 2.4). 


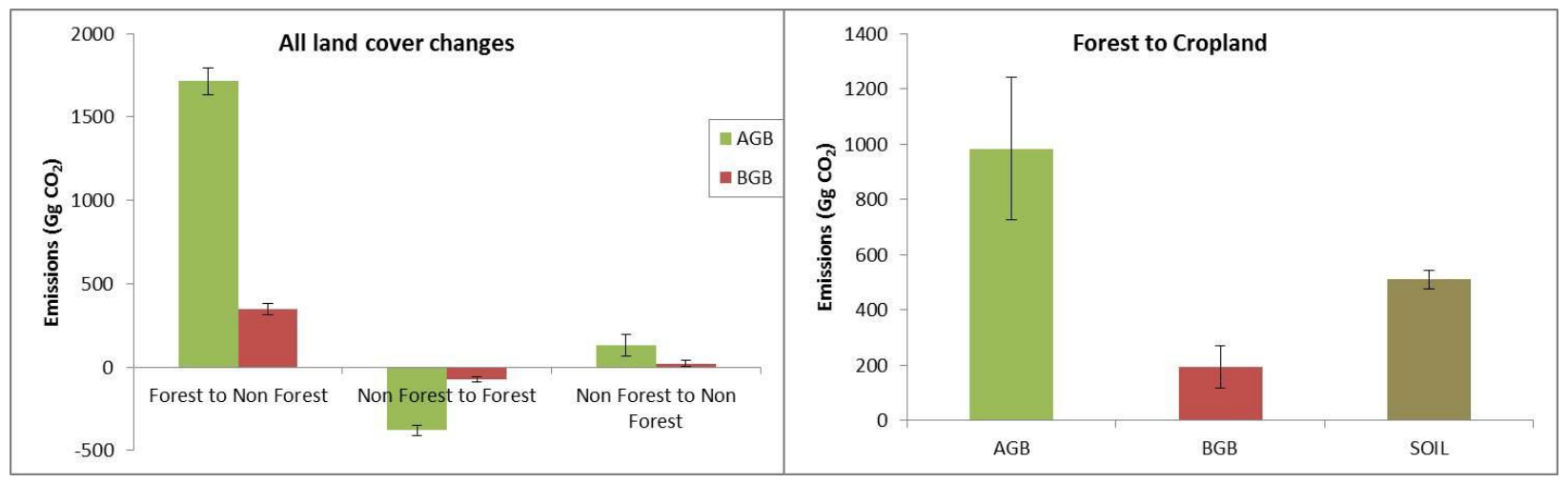

Figure 2.4 Carbon emissions and removals from aboveground (AGB) and belowground (BGB) biomass for aggregated change classes in the Vu Gia Thu Bon (VGTB) River Basin during the period 2001-2010 (left), and carbon emissions from $A G B, B G B$ and soil for the change in class from forest to cropland (right). The non-forest class includes grassland, cropland, settlement, other land and wetland. The uncertainty bars represent \pm 1 standard error.

\subsection{Discussion and conclusions}

Net carbon emissions from land cover change in the VGTB during the last decade were about $1.1 \%$ of the existing stocks and were mostly caused by the conversion of forest to cropland. Most of the emissions were related to the loss of aboveground biomass from forests, showing that the estimation of this carbon pool has the largest impact on the net land emissions. Our study indicates that the stratification by forest type is a critical factor in the estimations because the VGTB is characterized by large variability of forest conditions and deforestation did not occur on "average" forests but mostly affected the regrowing forests (60\%) and the plantations (29\%) characterized by carbon stock densities (16- $22 \mathrm{Mg} \mathrm{C/ha)} \mathrm{substantially} \mathrm{lower} \mathrm{than} \mathrm{those} \mathrm{of} \mathrm{medium} \mathrm{or} \mathrm{rich} \mathrm{forest} \mathrm{(103-206} \mathrm{Mg} \mathrm{C/ha).}$ Regrowth forest and plantations are located in accessible areas, and were largely affected by the expansion of agriculture and the slash-and-burn practices. In contrast, the high-carbon forests remain unaffected only in the remote mountain areas where difficult accessibility and ground steepness prevented their conversion to other land uses.

It is remarkable that, if only one forest class with average carbon stock was considered without further stratification by forest type, the net emissions of VGTB from the above- and belowground biomass would increase about 4 times (Table 2.4). In fact, the mean aboveground forest carbon stock in VGTB calculated as simple average of the field plots would be $81 \mathrm{Mg} \mathrm{C} /$ ha and the corresponding mean emission factor for forest (calculated as ratio between the total aboveground emissions from deforestation and the respective area) would be $77 \mathrm{Mg} \mathrm{C} / \mathrm{ha}$, while it was $21 \mathrm{Mg} \mathrm{C} /$ ha when considering the five forest types. Furthermore, if the average forest carbon stock were calculated on the basis of a literature value for tropical forest instead of than from local field data, the net emissions would have been larger. For example, using the reference emission factor for aboveground biomass in the Brazilian amazon applied by the Amazon Fund (100 Mg C/ha) (BNDES, 2009) would increase the net emission estimates from above- and belowground biomass in the VGTB by almost 5 times, while using the mean IPCC Tier1 default value (140 Mg C/ha in the tropical rain forest ecozone in continental Asia) (IPCC, 2006) would increase the net emissions by about 7 times. 
Larger emissions in the VGTB were also estimated from two existing tropical deforestation emission databases (Table 2.4). According to the recent emission estimates by Zarin et al. (2016), the gross emissions from deforestation from aboveground biomass for 2001-2010 in the VGTB were about 6.4 times higher than our estimates (recomputed considering the same assumptions, i.e. no biomass in the follow-up land cover classes). The difference between the two datasets was mostly due to the forest carbon stock values. According to the biomass map used by Zarin et al. (2016), the mean forest carbon stock in the deforested areas in the VGTB was about $93 \mathrm{Mg} \mathrm{C} / \mathrm{ha}, 4.4$ times higher than the value derived from the field data ( $21 \mathrm{Mg} \mathrm{C} / \mathrm{ha}$ ) in our study (computed as the ratio between total emissions from deforestation and the corresponding area, considering no biomass in the follow-up land cover). Instead, the deforestation area estimates were more similar and accounted for a smaller part of the difference in the emissions. The forest loss area in VGTB during 2001-2010 according to Hansen et al. (2013) (the forest change map used by Zarin et al. [2016]) was 1.5 times higher than our estimates, and showed a similar spatial pattern.

Similarly, higher emissions from deforestation were estimated from the tropical database of Harris et al. (2012) (Table 2.4). This dataset estimated yearly gross emission from deforestation from above- and belowground biomass for the VGTB to be 5.3 times higher when compared to the corresponding value of our study, recomputed considering the same assumption of no biomass in the follow-up land cover classes (1.37 and $0.26 \mathrm{Tg} \mathrm{CO}_{2}$ /year, respectively). It is important to notice that the substantial differences observed at local scale between our estimates and the two tropical emission databases do not provide any indication of their accuracy, which should be computed using a statistical sampling design representative of the complete study area (i.e., the tropical belt). Rather, such differences indicate the relevance of using local field data in contexts characterized by particular forest dynamics, as is the case in the VGTB where most deforestation occurred in low-carbon forest areas. 


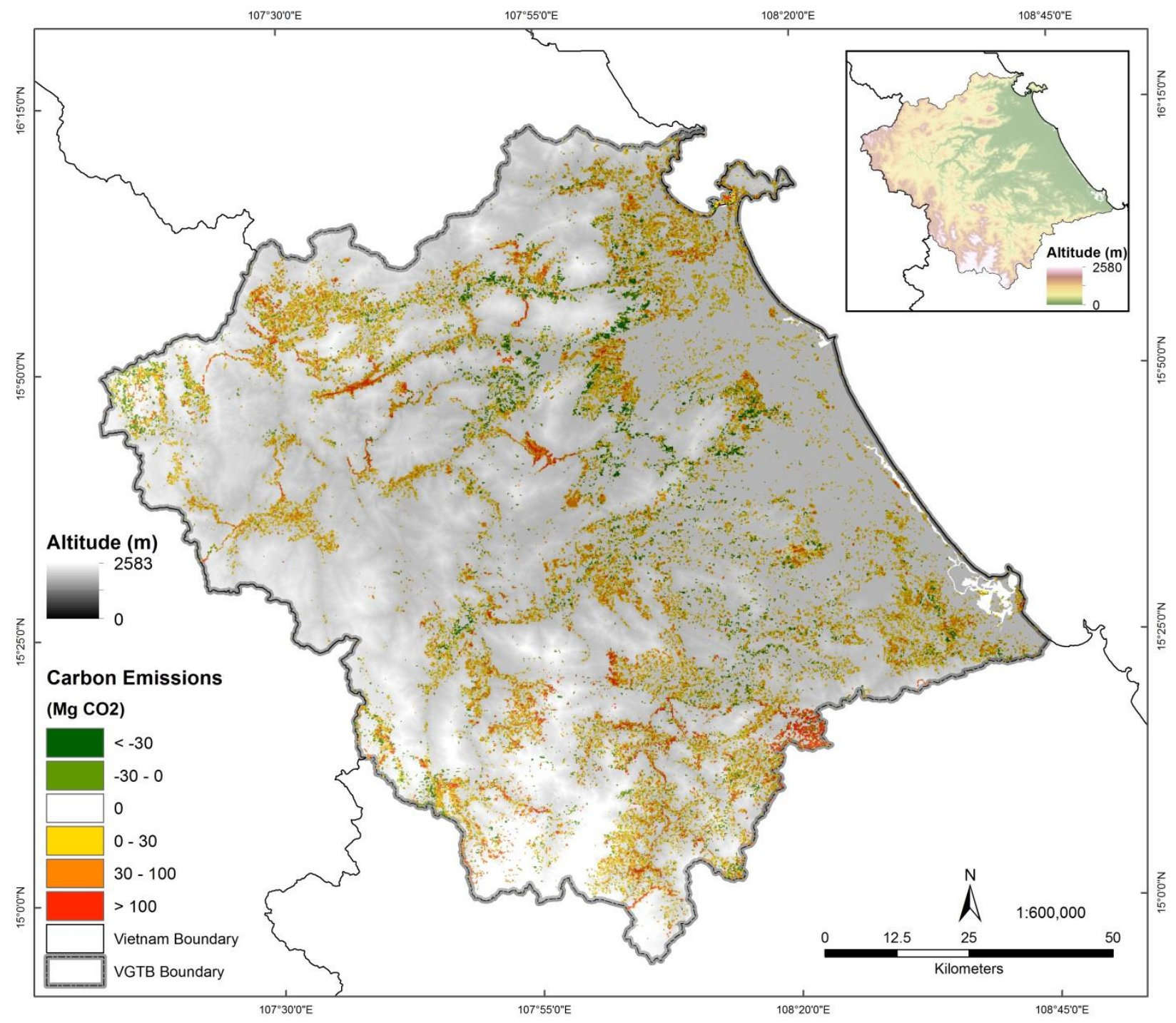

Figure 2.5 Carbon emissions from above- and belowground biomass in the Vu Gia Thu Bon (VGTB) River Basin due to land cover changes between 2001 and 2010, superimposed on the elevation map. Negative emissions represent removals. The emissions are aggregated at $200 \mathrm{~m}$ and the elevation map is shown at $20 \%$ transparency for display purposes. Inset: Elevation map of the VGTB River Basin derived from Shuttle Radar Topography Mission data.

As a consequence of the low emission factors from biomass, the removals from forest regrowth and the emissions from soil were relevant, accounting for $26 \%$ and $30 \%$ of net emissions, respectively (with the former value referring to all land changes and the latter only to the conversion of forest to cropland). While this result strongly supports the importance of regrowing forests and soil in land carbon accounting, their contribution to the total emissions is expected to be lower when deforestation events occur on forests with average or higher $\mathrm{C}$ stocks. On the other hand, since the carbon removals from forest regrowth and emissions from soil are slow processes that continue to occur well beyond the time frame of this study (10-year), their role in carbon accounting becomes more relevant with longer monitoring periods and when considering legacy effects. 
Table 2.4 Comparison of emission estimates obtained from different data sources for $\mathrm{Vu}$ Gia Thu Bon (VGTB) during 2001-2010. The emission estimates from this study are harmonized to the same category before comparison: net emissions from all land changes ("net land") or gross emissions from forest loss with no biomass in the follow-up land-cover classes ("gross forest"). The emission factors (EF) are mean values computed as the ratio between total emissions and the corresponding area change.

\begin{tabular}{lccccc}
\hline Ref. & Emission category & Carbon pool & EF (Mg C/ha) & Emissions $\left(\mathrm{Gg} \mathrm{CO}_{2}\right)$ & Difference (\%) \\
\hline This study & Net land & AGB+BGB & 20.7 & 1761 & - \\
Average VGTB plots & Net land & AGB+BGB & 81.2 & 6937 & $394 \%$ \\
BNDES, 2009[53] & Net land & AGB+BGB & 100.0 & 12,418 & $488 \%$ \\
IPCC [31] & Net land & AGB+BGB & 140.0 & 20.7 & $705 \%$ \\
This study & Gross forest & AGB+BGB & 2563 & - \\
Harris et al. [10] & Gross forest & AGB+BGB & - & 13,678 & $534 \%$ \\
This study & Gross forest & AGB & 21.3 & - \\
[Zarin et al. 12] & Gross forest & AGB & 93.5 & 13,557 & $640 \%$ \\
\hline
\end{tabular}

Similarly, this study found that the SOC stocks of Forest and Plantation were not significantly different, indicating that emissions for this change process were negligible within the 10-year period. However, considering that most plantations were recently established on forest soils, the related soil emissions may increase in longer time frames. This may not be the case for the conversion of young or degraded forest to plantations, as SOC stocks of forest regrowth and Acacia plantations were found not significantly different from each other in North and South Vietnam under the dominant soil group Acrisol. However, if the total ecological value of forests beyond SOC sequestration and timber production is considered, natural forests and regrowths can provide or restore important ecosystem services and biodiversity compared to plantations.

Lastly, C changes within stable land cover classes were not considered in this study due to the absence of reliable data but their impact on the total land carbon balance may not be negligible and should be further investigated, especially in areas where substantial transitions between different forest types occur.

\subsection{Acknowledgements}

This study was supported by the German Federal Ministry of Education and Research (BMBF) under Grant FKZ 01LL0908A-D for the project "Land Use and Climate Change Interactions in the Vu Gia Thu Bon River Basin, Central Vietnam" (LUCCI).; the Norwegian Agency for Development Cooperation (NORAD) through CIFOR's Global Comparative Study on REDD+; the CGIAR Research Program on Forests, Trees and Agroforestry (CRP-FTA) with financial support from the CGIAR Fund. 
Chapter 3

\section{Chapter 3}

Error sources in deforestation detection using BFAST Monitor on Landsat time series across three tropical sites

Michael Schultz, Jan Verbesselt, Valerio Avitabile, Carlos Souza and Martin Herold

Published in IEEE Journal of Selected Topics in Applied Earth Observation and Remote Sensing, 9 (2016), 8, 3667 - 3679, DOI: 10.1109/JSTARS.2015.2477473 


\begin{abstract}
Accurate tropic deforestation monitoring using time series requires methods which can capture gradual to abrupt changes and can account for site-specific properties of the environment and the available data. The generic time series algorithm BFAST Monitor was tested using Landsat time series at three tropical sites. We evaluated the importance of how specific effects of site and radiometric correction affected the accuracy of deforestation monitoring when using BFAST Monitor. Twelve sets of time series of normalized difference vegetation index (NDVI) Landsat data (2000-2013) were analyzed. Time series properties varied according to site (Brazil, Ethiopia, and Vietnam) and which correction scheme was applied: Atmospheric Correction and Haze Reduction 2 and 3 (ATCOR 2 and 3), Landsat Ecosystem Disturbance Adaptive Processing System (LEDAPS), or Dark Object Subtraction (DOS). Mapping accuracy was compared using 1200 reference points per site and consistent designs for sampling, analysis (overall accuracy, user's accuracy, and producer's accuracy), and response (ground truth and very-highresolution data). With the exception of DOS, mapping accuracies across correction methods were found to be similar but varied greatly with site. Mapping errors were modeled using a set of error parameters that yielded information on data and site-specific environmental properties. Important parameters for characterizing mapping errors were found to be variance of the NDVI and soil signal as well as availability of time series data, and forest edge effects. Based upon the results, local fine-tuning of the algorithm is essential for some areas but for others default settings create satisfactory accuracies.
\end{abstract}




\subsection{Background and rationale}

Understanding the causes and impacts of climate change, including the role of deforestation as a major contributor to the global greenhouse effect, is at the heart of environmental science and political debates. Currently, pantropical deforestation contributes $15-20 \%$ to global $\mathrm{CO}_{2}$ emissions (Gullison et al., 2007; van der Werf et al., 2009) and is thus a major point of attention for climate change mitigation efforts (Maniatis and Mollicone, 2010). Deforestation is largely assessed by combining remote sensing data on forest area change with field observation of carbon emission factors (De Sy et al., 2012; Maniatis and Mollicone, 2010). Efforts for reducing emissions from deforestation and forest degradation (REDD) that focus on tackling the problem of forest loss require regular and accurate forest change monitoring (Arino et al., 2012; Harris et al., 2012). At present, however, only very few tropical countries have implemented a national forest monitoring system to quantify emissions from deforestation and forest degradation (Romijn et al., 2012). Recently, global 30-m forest change maps using remote sensing were published (Hansen et al., 2013; Kim et al., 2014). While those efforts shows that progress is being made in processing large amounts of data for global forest assessments, the tools available are not mature enough to be a trustworthy source of information for policy makers at national and local levels. There is currently a tradeoff between the global consistency and local accuracy of remote sensing products (Avitabile et al., 2012), and the complexity of forest change processes results in large variability that is not easily captured by standardized global approaches (Pelletier et al., 2011). Landsat-like time series data and massive processing capabilities offer prospects for advances to be made in forest observation (Hansen and Loveland, 2012). Among the researched targets, forest is most intensively mapped with Landsat (Boyd and Danson, 2005; Wulder and Franklin, 2003) and a wealth of related review papers indicates the advance of automated per-pixel use of all observations and the decline of classical bitemporal change mapping where a high degree of human interaction was necessary (Coppin and Bauer, 1996; Hansen and Loveland, 2012; Singh, 1989). While some methods are designed to tap into an abundance of data (Zhu and Woodcock, 2014), others are designed to cope with very little data (Broich et al., 2011). In some extreme cases, it can take up to 2 years to create a full mosaic-based coverage of a site (Romijn et al., 2012); hence fusing Landsat with other data sources is a valid approach, for instance with radio detection and ranging (RADAR) data (Reiche et al., 2013) or moderate-resolution imaging spectroradiometer (MODIS) data (Bhandari et al., 2012). Those methods are usually very complex and tend to require intense algorithm "fine-tuning" for the variety of specific sites (Woodcock and Ozdogan, 2012). Limited by acquisition strategies or mission durations, such complementary data are not always available and in some cases, Landsat is the only consistent long-term record of a specific site (Gutman and Masek, 2012; Wulder et al., 2012). Algorithms which are data-driven and make use of statistical assumptions can be suitable for ecosystem monitoring, do not rely on thresholds, and offer the advantage of maximum level of objectivity due to the absence of human interaction (Verbesselt et al., 2012). Breaks for additive season and trend (BFAST) Monitor algorithm offers such capabilities and was successfully applied on MODIS and Landsat data (Verbesselt et al., 2012). Forest degradation mapping or drought and flood detection was performed using either the normalized difference vegetation index (NDVI) or the enhanced vegetation index (EVI) as remote sensing metric (DeVries et al., 2015b; Verbesselt et al., 2012; Watts and Laffan, 2014).

Our aim was to test the suitability of BFAST Monitor to monitor deforestation using only Landsat time series across three tropical study sites characterized by limited data availability and different environment properties. Because the algorithm is solely data-driven, a minimum of human interaction is necessary; yet accurate results can be expected when observing anthropogenic and natural changes of 
vegetation phenology (Verbesselt et al., 2012; Watts and Laffan, 2014). However, this approach requires high quality data corrected for radiometric disturbances (e.g., atmospheric effects and illumination) as well as geometric properties (pixel registration and elevation effects). Since tropical forests are characterized by season-specific spectral response, a method failing to account for that can generate mapping inaccuracies of more than $40 \%$ (Langner et al., 2014). BFAST accommodates for seasonal changes using harmonic modeling and therefore allows the use of all available time series observations. The method can be used across sensors and was successfully applied for mapping small-scale changes in the tropics using Landsat data (DeVries et al., 2015b) and in combination with RADAR data (Reiche et al., 2015). Deforestation monitoring is influenced by many factors, among them the different types and drivers of forest change and their impact on the spectral signal influence mapping accuracies, and the amount of available observation data (Souza et al., 2009). Furthermore, time series contaminants introduced by atmospheric and/or topographic features need to be suppressed, as they are recognized sources of noise (Hansen and Loveland, 2012; Song et al., 2001; Wulder and Franklin, 2003) Removing clouds from images is compulsory, as it determines the success of any change detection mapping effort (Hilker et al., 2012). Regardless of the applied monitoring, method accounting for these effects will determine the success of the deforestation mapping. Landsat preprocessing suitability was identified by a performance-based comparison of various preprocessing schemes. Most commonly used correction methods for such applications are summarized in (Vanonckelen et al., 2013). Often used are Landsat Ecosystem Disturbance Adaptive Processing System (LEDAPS) (Vermote et al., 1997), Moderate spectral resolution atmosphere transmittance algorithm (MODTRAN) (Berk et al., 2008), or Dark Object Subtraction (DOS) (Chavez, 1989) and a wealth of their variations (Broich et al., 2009; Hansen et al., 2013; Hansen and Loveland, 2012; Souza et al., 2013). They apply different levels of radiometric correction, depending on the data setup, the properties of the area of interest, and the feature of interest. The methods vary in terms of cost, accessibility, and complexity and therefore determine its usability especially within the REDD context. Although DOS and ATCOR's performance has been assessed for individual images and bitemporal change detection, their performance was not assessed when used in a time series scenario where consecutive observations must be radiometrically consistent over many years. We here describe a study that set out to identify and evaluate error sources of deforestation mapping using Landsat NDVI time series. Our aim was to understand how radiometric correction, site characteristics, and a series of key factors (data availability, atmosphere, topography, variance in data, and edge effects) influence the accuracy of tropical deforestation mapping when using the BFAST Monitor algorithm, and to address the following three questions.

1) How do different radiometric correction approaches of Landsat time series imagery affect the accuracy of tropical deforestation mapping?

2) Which factors are most important in explaining commission and omission errors in deforestation mapping across three tropical sites with different forest and forest change characteristics?

3) What are the potentials and limitations of using Landsat NDVI time series when mapping tropical forest changes?

To answer the research questions, sites in Brazil, Ethiopia, and Vietnam were investigated for recent forest changes occurring from 2010 to 2013, using a consistent reference database. An overview of our approach is presented in Fig. 3.1. 


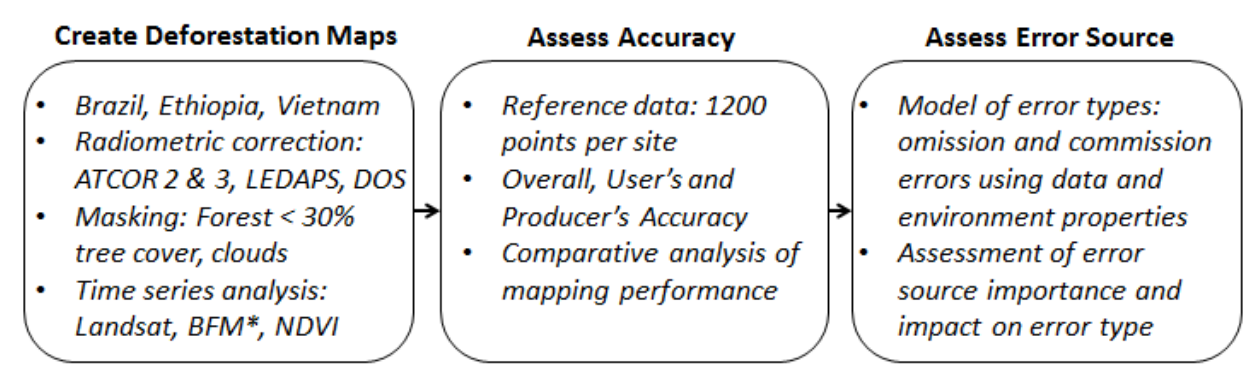

Figure 3.1 Overview of the analysis. First, four maps per site with different radiometric correction methods were generated. Then, their accuracy was reported and mapping performance compared. Third, error types (omission and commission) were modeled using error sources (data availability, topography, atmosphere, data variance, and edge effects).

\subsection{Methods and study regions}

Following the standard of REDD, the definition of forest in our study is an area larger than 0.5 ha with at least $30 \%$ tree crown cover (UNFCCC, 2002). To avoid change overestimation due to misregistration (Townshend et al., 1992), all data used were: United States Geological Survey (USGS) L1T Landsat data from 2000 to 2013 for tiles p124r49, p170r55, and p202r23. We focused solely on deforestation mapping and used the term "forest change" to mean deforestation. Each study region has its specific combination of deforestation drivers and data and environment properties, but we evaluated these in the same way, using the same coherent reference database. Time series data from 2000 to 2009 were used to create a model of stable history against which changes from 2010 to 2013 were identified. For each site, we used imagery available annually from 2009 onward that was of very-high resolution to build a reference database consisting of 1200 points.

Fig. 3.2 presents the locations and center coordinates of each site and Table 3.1 provides an overview of properties and time series statistics. The Vietnam site is situated in the center of the country, and is characterized by monsoon rainfall, influenced by temperate mesothermal climates of the north and tropical conditions of the south. Here, wet evergreen natural forest is impacted by slash and burn agriculture in which a large proportion of newly cleared land is abandoned after one crop cycle (MONRE, $2007,2006)$. The site is characterized by steep slopes impacting surface illumination and sensor exposure, and this site has the lowest data availability. The Ethiopian site is located in the south of the country in the UNESCO Kafa Biosphere Reserve and is characterized by a humid tropical climate. Here, deforestation is mainly driven by expansion of smallholder coffee plantations, which typically results in small incremental changes that gradually push back the fuzzy forest boundary (Schmitt et al., 2010). The Brazilian site, situated in Paragominas, is characterized by tropical equatorial rainforest and climate. Here, the forest is managed and used as production forest: small to large patches of timber extraction co-occur with patches of gradual regrowth. The terrain is almost flat and the data availability is comparatively high. 


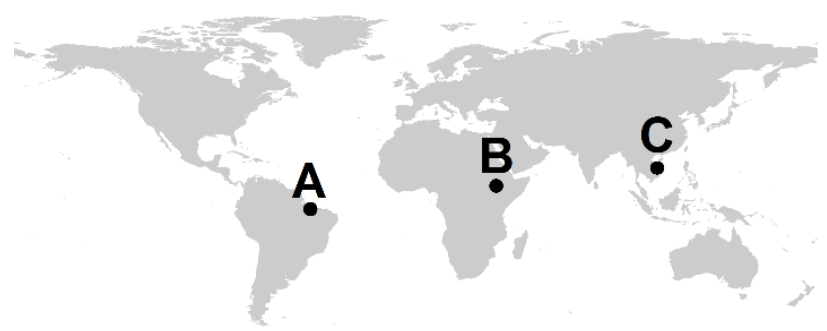

Figure 3.2 Location of study sites; $A=$ Brazil - Paragominas ( $300820.1^{\prime \prime} \mathrm{N}, 47 \stackrel{\circ}{\circ}, 1629.2^{\prime \prime} \mathrm{W}$ ), $\mathrm{B}=$ Ethiopia - Kafa Biosphere (7 을 21.8” N, 35 o 59 19.9” E), C = Vietnam - Tra Bui (15ㅇ 21" 38.7” N, 108 o $\left.216.5^{\prime \prime} \mathrm{E}\right)$, each study site is approximately $500 \mathrm{~km}^{2}$

Table 3.1 Time series and site properties; Major forest types are indicated as Medium High Forest (40$70 \%$ canopy cover, tree height $>15 \mathrm{~m}$ ) (MHF), Closed High Forest ( $>70 \%$ canopy cover, tree height $>$ $15 \mathrm{~m})$ (CHF), Medium young/Secondary Forest (40-70\% canopy cover, tree height $<15 \mathrm{~m}$ ) (MSF)

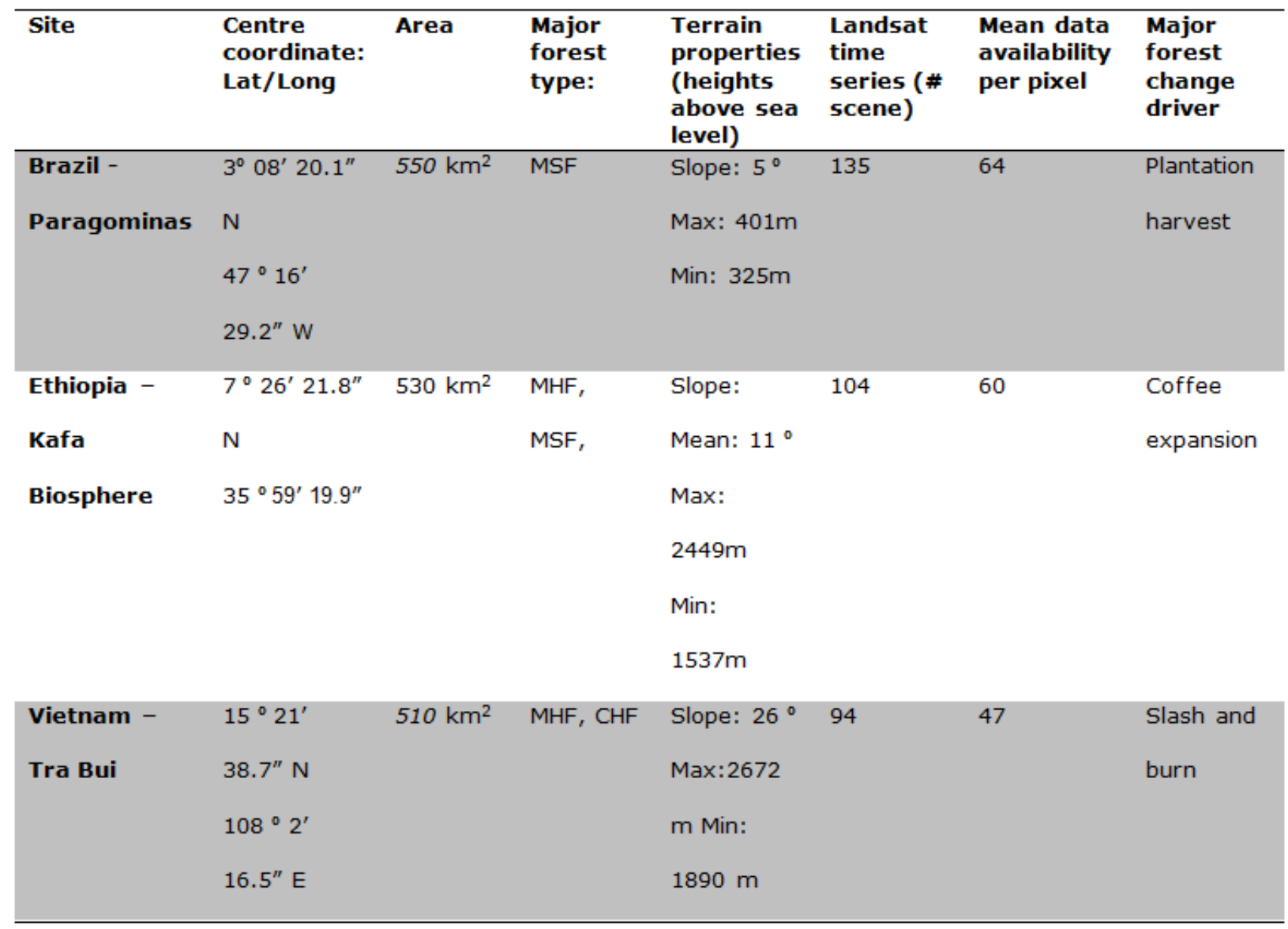

\subsubsection{Image processing}

Except in the case of radiometric correction, all data sets were processed identically. Cloud and cloud shadow were masked using f-mask with standard parameters. It is reported that more than $96 \%$ clouds and cloud shadows are successfully removed by the algorithm, and that remainders are a potential 
source of error (Zhu et al., 2012). However, such outliers, if only occurring occasionally should not create false changes in BFAST Monitor, as a breakpoint requires a structural change of the time series as a whole (Verbesselt et al., 2012). Forest and nonforest areas were determined using an updated version of the 30-m vegetation continuous fields product (VCF) (Sexton et al., 2013), selecting forest as vegetated areas with more than $30 \%$ VCF cover. VCF provides percent information about tree cover of the years 2000-2005 and therefore was updated to the beginning of the year 2010 (start of analysis). Using the VCF product as reference, Landsat data captured from the beginning of 2009 to the first acquisition in 2010 were classified using supervised classification into forest (tree cover $>30 \%$ ) and nonforest (tree cover $<30 \%$ and nonforest classes) (Schultz et al., 2013). Time series with a total data availability of less than 30 valid observations were rejected from the analysis and flagged as no-data. The NDVI (Tucker, 1979) was calculated for each pixel after radiometric correction. The metric was chosen due to its successful application for forest degradation mapping while using BFAST Monitor (DeVries et al., 2015b). Binary maps of deforestation and no deforestation were produced, rejecting deforested areas smaller than 0.5 ha.

\subsubsection{Identifying deforestation}

Deforestation changes the vegetation signal; this change can be quantified by comparing the signal with the signal from the previous vegetation state. We used the BFAST Monitor approach to measure deforestation (Verbesselt et al., 2012, 2010b). It separates the data of a time series into a historic period, i.e., the baseline, and a monitoring period. If the data for the monitoring period deviate markedly from the data for the historic period, a disturbance has occurred. First, a season-trend model consisting of a linear trend model and a harmonic series is created for the historic period

$y_{t}=\alpha_{1}+\alpha_{2} t+\gamma \sin \left(\frac{2 \pi t}{f}+\delta\right)+\epsilon_{t}$

where for each pixel's observations $y_{t}$ at time $t$, a harmonic model is defined by the amplitude $\gamma$, the phase $\delta$, a trend with the intercept $\propto_{1}$, the slope $\propto_{2}$ and the frequency f of occurring observations, where data noise is expressed using the remainder component $\varepsilon_{t}$. Although BFAST Monitor allows multiple orders of the harmonic component, to facilitate comparisons between sites, we simplified it using a first-order harmonic model. The second step in BFAST Monitor is to extend the model by incorporating the monitoring period data; the extended model is then compared with the expected behaviour of the historic period. If the Moving SUMs (MOSUM) of the residuals using the extended model deviate markedly, the time when this occurs is labelled as a deforestation event (Verbesselt et al., 2012, 2010b).

\subsubsection{Radiometric correction methods}

Four commonly used radiometric correction methods converting Landsat raw DN to surface reflectance were compared and their suitability for deforestation mapping tested. Each method radiometrically corrects images taking account of different effects. To guarantee objective comparability, no imagespecific fine-tuning was applied, and default settings have been used.

\section{a) LEDAPS:}

One of the most commonly used radiometric correction methods for Landsat data is the LEDAPS software, available free of charge from the National Aeronautics and Space Administration (NASA) and 
USGS servers (Huang et al., 2009; Masek et al., 2008). The method is based on the Second Simulation of a Satellite Signal in the Solar Spectrum (6S) radiative transfer model (Vermote et al., 1997) and requires external auxiliary data on atmospheric turbidity and ozone concentration from the U.S. National Oceanic and Atmospheric Administration (NOAA). The method is full automatic with no human interaction required. A digital elevation model (DEM) is not needed and bidirectional reflectance distribution function (BRDF) is not accounted for.

b) ATCOR 2 and 3:

The commercial software programs ATCOR 2 and 3 are based on the MODTRAN Algorithm, which has been used for studies on tropical forest change (Balthazar et al., 2012; Souza et al., 2013) or to produce reference quality data (Leinenkugel et al., 2015). These methods do not require external atmospheric data, as atmospheric contamination is described using the scene at hand. In our study, for all scenes in both programs, we selected large area haze removal of thin and moderately thick haze, constant scene emissivity, and land cover dependent, variable atmospheric visibility. Unlike ATCOR 2, ATCOR 3 requires an external DEM, which enables BRDF and topographic correction. The DEM we used was the 30-m advanced spaceborne thermal emission and reflection radiometer (ASTER) Global Digital Elevation Model Version 2 (GDEM V2) DEM (Tachikawa et al., 2011). BRDF correction option (II): Empirical BRDF correction, "different for vegetation and nonvegetation" was selected. BRDF coefficients are calculated based on scene and DEM properties. For reasons of reproducibility, we did not alter the automatically derived standard coefficients. The software requires human interaction of a professional analyst and provides batch processing.

c) DOS:

DOS is a commonly available standard correction method which does not require a radiative transfer model (Chavez, 1988). In this study, we first performed standard sensor calibration (Chander et al., 2009) using standard starting haze values (Chavez, 1989). Second, the lowest pixel values of the respective band with a frequency greater than 1000 were selected and subtracted. No external data or DEM is required and no topographic correction and no BRDF corrections are performed. The method requires only little human interaction and can be semi-automatized.

\subsubsection{Reference data}

Per site, a set of 1200 reference points organized in two strata was used for the comparative validation. First, 200 points were randomly distributed in 100 deforested areas and 100 intact forest areas. These areas had been defined by expert-guided object-oriented classification of annual (2009-2013) very-highresolution imagery either Rapideye $(5 \mathrm{~m}$ ) or Satellite Pour l'Observation de la Terre (SPOT 5) (2.5 m) and were visually interpreted. Vietnam's 100 reference points were confirmed through a stakeholder supported field campaign in 2012 (Schultz et al., 2013). Second, the areas of deforestation identified on each map were randomly sampled at 250 points and then interpreted using the high-resolution data. The analysis used commonly established standards (Congalton, 1991); overall accuracy (oa), producer's accuracy (pa), omission error (100 - pa = omission error) expressing the failure to detect a deforestation event, user's accuracy (ua), and commission error (100 - ua = commission error) expressing the false detection of deforestation, which were calculated and reported (Congalton, 1991; Congalton and Green, 2009). Because binary maps were created, the resulting convolution matrices contained the classes 
"deforestation" and "no deforestation". With $\mathrm{m}$ being the number of classes and $\mathrm{p}_{\mathrm{ii}}$ the convolution of classes, the map overall accuracy is calculated according to this formula:

$o a=\sum_{j=1}^{m} p_{i i}$

Class accuracies from user's and producer's perspectives are calculated for each class according to:

$u a_{i}=p_{i i} / p_{i+}$

$p a_{j}=p_{i i} / p_{+i}$

\subsubsection{Statistical analysis}

Seven error sources organized in five domains were identified to model the commission and omission errors of deforestation. The error sources summarized in Table 3.2 express site-specific data and environment properties and were defined for each reference point; after assessing the map's accuracy, they were used to model the map's errors, and to identify the dependencies that result from errors specific to the site and to radiometric correction. The error sources were divided in the following domains.

a) Data availability:

The data available for the analysis is of major importance when mapping deforestation. The more the data are available, the more accurately dynamics, seasonal changes, and cycles can be represented. If too few observations are available, seasonal patterns may be modeled incorrectly and misinterpreted as change; if temporal detail is inadequate, change may be missed (Souza et al., 2009). The total amount of available data for each pixel ij within a time series is expressed by the variable observations in full time series $\left(\mathrm{N}_{\mathrm{ij}, \mathrm{f}}\right)$. Observations in monitoring period $\left(\mathrm{N}_{\mathrm{ij}, \mathrm{m}}\right)$ is the error source obtained by subtracting the observations of the historical period $\left(N_{i j, h}\right)$ from the full time series $\left(N_{i j, f}\right)$. By making this distinction, it is possible to see which of the two categories accounts for most of the mapping errors

$N_{i j, f}=N_{i j, h}+N_{i j, m}$

Only valid observations (uncontaminated by cloud or cloud shadow or with scan line corrector (SLC) off are taken into account.

b) Atmosphere:

Uncorrected atmospheric haze or missed clouds may lead to errors in change detection (Song et al., 2001). For each pixel $i$, the amount of haze was calculated as a fraction $x_{i}^{*}$ of the total reflectance $x_{i}$ :

$x_{i}^{*}=\frac{x_{i}}{\sum_{j=1}^{b} x_{j}}$

with $\mathrm{b}$ representing the number of all sensor bands (excluding panchromatic and thermals). Imazon's spectral mixture analysis (SMA) tool was used for this calculation (Souza et al., 2009, 2005). The haze value was extracted for the moment in time at which the forest change occurred. The precise timing for points responsible for an error of omission was fed into the reference data by first identifying the year of 
change using the high-resolution data, and then by visually interpreting the Landsat data for the year of change.

c) Topography:

When using Landsat data, topographic effects such as slope can reduce the accuracy of change identification (Broadbent et al., 2008). Using ASTER GDEM V2 (Tachikawa et al., 2011), we expressed topographic slope at each site per pixel in degrees.

d) Variance in data:

The variance of the full time series was calculated for the NDVI value and the soil signal. The soil fraction was calculated for each reference point's pixel in the same way as the haze fraction, but using soil as end member. The variance is calculated for the two parameters for each pixel according to

$\operatorname{Var}\left(X_{i j}\right)=\frac{1}{N_{i j}} \sum_{\alpha=1}^{N_{i j}}\left(x_{i j, \alpha}-\frac{1}{N_{i j}} \sum_{\alpha=1}^{N_{i j}} x_{i j, \alpha}\right)^{2}$

While $X_{i j}$ represents a pixels variance and $\alpha$ specifies the observation. Low variance in the temporal NDVI signal indicates a signal of a more stable forest that is not affected greatly by seasonality and/or anthropogenic impacts (Souza et al., 2005). The variance of the soil signal can be used as a measure of forest disturbance: high variances indicate that the soil is frequently exposed (the usual cause of this is tree cover disturbance), low variance indicates soil exposure is stable (tree cover is constant).

e) Edge effects:

In certain contexts, forest changes tend to occur close to or within a specific distance to the forest edge (Broadbent et al., 2008). For each reference point we calculated the shortest distance to the forest edge and attached it to the reference point. Considering Pythagoras theorem the minimum distance $d_{\min }$ of each reference point to the forest edge needs to be determined

$d_{\min }=\min \sqrt{\left(\left(x_{p}-x_{b}\right)^{2}+\left(y_{p}-y_{b}\right)^{2}\right)}$

With $x_{p}$ and $y_{p}$ representing a reference point and $x_{b}$ and $y_{b}$ any point on the forest boundary. Unlike the other independent variables, distance to forest edge is not an error source but is a potentially useful parameter to describe an error. 
Table 3.2 Potential error sources explaining commission and omission errors. * indicates a parameter that although not an error source explains part of the error

\begin{tabular}{|c|c|c|c|c|}
\hline Domain & Variable & Description & Source & Unit \\
\hline \multirow[t]{2}{*}{$\begin{array}{l}\text { Data } \\
\text { availability }\end{array}$} & $\begin{array}{l}\text { Observations } \\
\text { in full time } \\
\text { series (Of) }\end{array}$ & $\begin{array}{l}\text { Amount of all available } \\
\text { observations per Landsat } \\
\text { time series object }\end{array}$ & $\begin{array}{l}\text { USGS Landsat } \\
\text { time series }\end{array}$ & $\begin{array}{l}\text { Without unit/ } \\
\text { count }\end{array}$ \\
\hline & $\begin{array}{l}\text { Observations } \\
\text { in monitoring } \\
\text { period }\left(\mathrm{O}_{\mathrm{m}}\right)\end{array}$ & $\begin{array}{l}\text { Amount of all available } \\
\text { observations during BFAST } \\
\text { monitor monitoring period } \\
\text { per Landsat time series } \\
\text { object }\end{array}$ & $\begin{array}{l}\text { USGS Landsat } \\
\text { time series }\end{array}$ & $\begin{array}{l}\text { Without unit/ } \\
\text { count }\end{array}$ \\
\hline Atmosphere & $\begin{array}{l}\text { Haze } \\
\text { contamination }\end{array}$ & $\begin{array}{l}\text { Haze contamination at } \\
\text { change date }\end{array}$ & $\begin{array}{l}\text { (Souza et al., } \\
\text { 2005) }\end{array}$ & $\begin{array}{l}\text { Without unit/ } \\
\text { Spectral fraction } \\
(0-100)\end{array}$ \\
\hline Topography & Terrain slope & $\begin{array}{l}\text { Terrain slope at change } \\
\text { event }\end{array}$ & $\begin{array}{l}\text { DEM (Tachikawa } \\
\text { et al., 2011) }\end{array}$ & Degree $\left(0-90^{\circ}\right)$ \\
\hline \multirow[t]{2}{*}{$\begin{array}{l}\text { Variance of } \\
\text { data }\end{array}$} & $\begin{array}{l}\text { Variance of } \\
\text { NDVI }\end{array}$ & $\begin{array}{l}\text { Variance of NDVI across all } \\
\text { observations per Landsat } \\
\text { time series object }\end{array}$ & (Tucker, 1979) & Band Ratio \\
\hline & $\begin{array}{l}\text { Variance of } \\
\text { Soil fraction }\end{array}$ & $\begin{array}{l}\text { Variance of soil fraction } \\
\text { across all observations per } \\
\text { Landsat time series object }\end{array}$ & $\begin{array}{l}\text { (Souza et al., } \\
\text { 2005) }\end{array}$ & $\begin{array}{l}\text { Without unit/ } \\
\text { Spectral fraction } \\
(0-100)\end{array}$ \\
\hline $\begin{array}{l}\text { Edge } \\
\text { effects* }\end{array}$ & $\begin{array}{l}\text { Distance to } \\
\text { forest edge }\end{array}$ & $\begin{array}{l}\text { Distance from change event } \\
\text { to forest edge }\end{array}$ & $\begin{array}{l}\text { Landsat (VCF) } \\
\text { Forest mask } \\
\text { (Sexton et al., } \\
\text { 2013) }\end{array}$ & metre \\
\hline
\end{tabular}

We input these seven error sources as predictor variables (observations in full time series, observations in monitoring period, haze contamination during deforestation event, topographic slope at site of deforestation event, NDVI variance in full time series, variance of exposed soil in full time series, edge effects) into binary logistic regression generalized linear models (GLM) for the two error types (omission vs. positive change, commission vs. positive change) for each pre-processing chain at each site; interactions of variables within the model were not allowed but a minimum correlation among the 
model's error sources remained. First, all predictors were fed into the model to describe the binary outcome and then, using stepwise Akaike Information Criterion (AIC), we removed predictors not significantly contributing to the outcome (Akaike, 1973). As a result, each site's pre-processing model is unique and can contain its own set of predictors. Pseudo $R^{2}$ values were used to determine the coefficient of determination (Nagelkerke, 1991). Next, the relative importance of predictor variables was calculated for each predictor found to contribute significantly to the GLM. Each such predictor was used to run a specific GLM of the outcome and its fit was expressed with the pseudo $R^{2}$. A high $R^{2}$ for an individual model indicates that the model in question is important for the overall model (Saltelli et al., 2008). However, because they are individual models, their $R^{2}$ values do not sum to the $R^{2}$ of the full model (Venables and Ripley, 2002). Each site's major error source was further investigated, by varying the intensity of the error source variable in order to test the impact of the major error source on the probability of it creating a mapping error (Chambers and Hastie, 1992). For instance, the impact of different Edge effect distances on the model outcome was tested: for Vietnam we tested the observations in full time series and for Brazil we tested the variance of the soil signal. Like for the stepwise AIC GLM the logistic fit for the probability $\pi$ of these predictors is constructed using a GLM and ordinary least squares as a fitting method. $\beta_{0}$ and $\beta_{1}$ being the regression variables and $X_{1}$ the predictor

$\ln \left(\frac{\pi}{1-\pi}\right)=\beta_{0}+\beta_{1} X_{1}$

After transforming and simplifying above equation towards $\pi$ and using the derived logistic fit, the probability that a parameter contributes to a commission error can be calculated by

$\pi=\frac{e^{\beta_{0}+\beta_{1} X_{1}}}{1+e^{\beta_{0}+\beta_{1} X_{1}}}$

\subsection{Results}

\subsubsection{Site and Radiometric Preprocessing: Specific Accuracies of Deforestation Mapping}

The mapping accuracies for deforestation detection vary largely among the three sites (Fig. 3.3). If the performance of ATCOR 2 and 3 and LEDAPS only were tested within this study, the mapping accuracies within the sites would vary only marginally by maximum $2 \%$ suggesting that these preprocessing methods perform comparably. DOS, however, performs less well, particularly in Brazil and Ethiopia. Mapping accuracies for Brazil and Vietnam are both around $80 \%$, approving LEDAPS as a robust fullautomatic radiometric preprocessing method for time series analysis. Comparison of ATCOR 2 and 3 suggests that making use of BRDF corrections do not improve results significant. ATCOR 3 performs slightly better than ATCOR 2, which performs similarly to LEDAPS. In the Brazilian and Ethiopian sites, omission error is usually lower than commission error; in the Vietnamese site, however, the opposite occurs. Overall accuracy is usually similar to user's accuracy (commission) but for Vietnam, overall accuracy is similar to producer's accuracy (omission). Likely, the error patterns in Vietnam reflect the nature of the deforestation, which is characterized by large changes that are easier to detect than the more subtle changes occurring in Brazil and particularly in the Ethiopia case, where change tends to be overestimated. Vietnam has the highest accuracies of all sites, then Brazil, and finally Ethiopia.

A detailed assessment of DOS is obsolete due to its poor performance; for instance, in Vietnam, every deforestation event that occurs is mapped with a producer's accuracy of $92 \%$ but at the same time, a lot 
of these mapped changes are false positives indicated by the low user's accuracy of $68 \%$. Most of the forest area here is flagged incorrectly as forest change, and striping effects related to SLC-off dominate the deforestation map (Fig. 3.4). Although ATCOR 3 tends to produce the highest accuracies, it performs only slightly better than ATCOR 2 and LEDAPS. The spatial agreement between the deforestation mapped by the three methods is good, but the patch size of detected changes differs in ATCOR 3processed time series. The low commission error of about $10 \%$ reveals that detected changes are likely to be correct but that it is more difficult to capture all changes that occur (ATCOR 2 and 3 or LEDAPS). At the Ethiopian site, all radiometric preprocessing methods struggle to produce reliable results. The omission error is mostly close to $20 \%$ and overestimation of change produces the largest errors. However, most maps show that changes occur especially on the edges of forests and that large conterminous spots of deforestation occur in the northern part of the site. Overall accuracies indicate that the proposed methods cannot be used to accurately map changes at this site. In Brazil, omission error is about $10 \%$ lower than commission error and is only slightly higher than overall accuracy. Mostly, overestimation of change reduces the accuracy, whereas change that occurs is mapped reliably. LEDAPS performs best at this site, but only slightly better than ATCOR 2 and 3.

Fig. 3.5 depicts time series of one deforestation event for each site. The pixels time series for each preprocessing scheme are shown and its characterization by BFAST Monitor. NDVI values and time series trajectories are very similar for ATCOR 2 and 3 and LEDAPS. These methods accomplish the generation of stable time series within the historic period and yet being sensitive to the deforestation event in the monitoring period. Unlike ATCOR 3 and LEDPAS, ATCOR 2 and DOS do not require any external information and assemble all required thresholds for correction using solely the data set. However, DOS fails to create reliable and stable time series while ATCOR2 performs as well as ATCOR 3 and LEDAPS. 


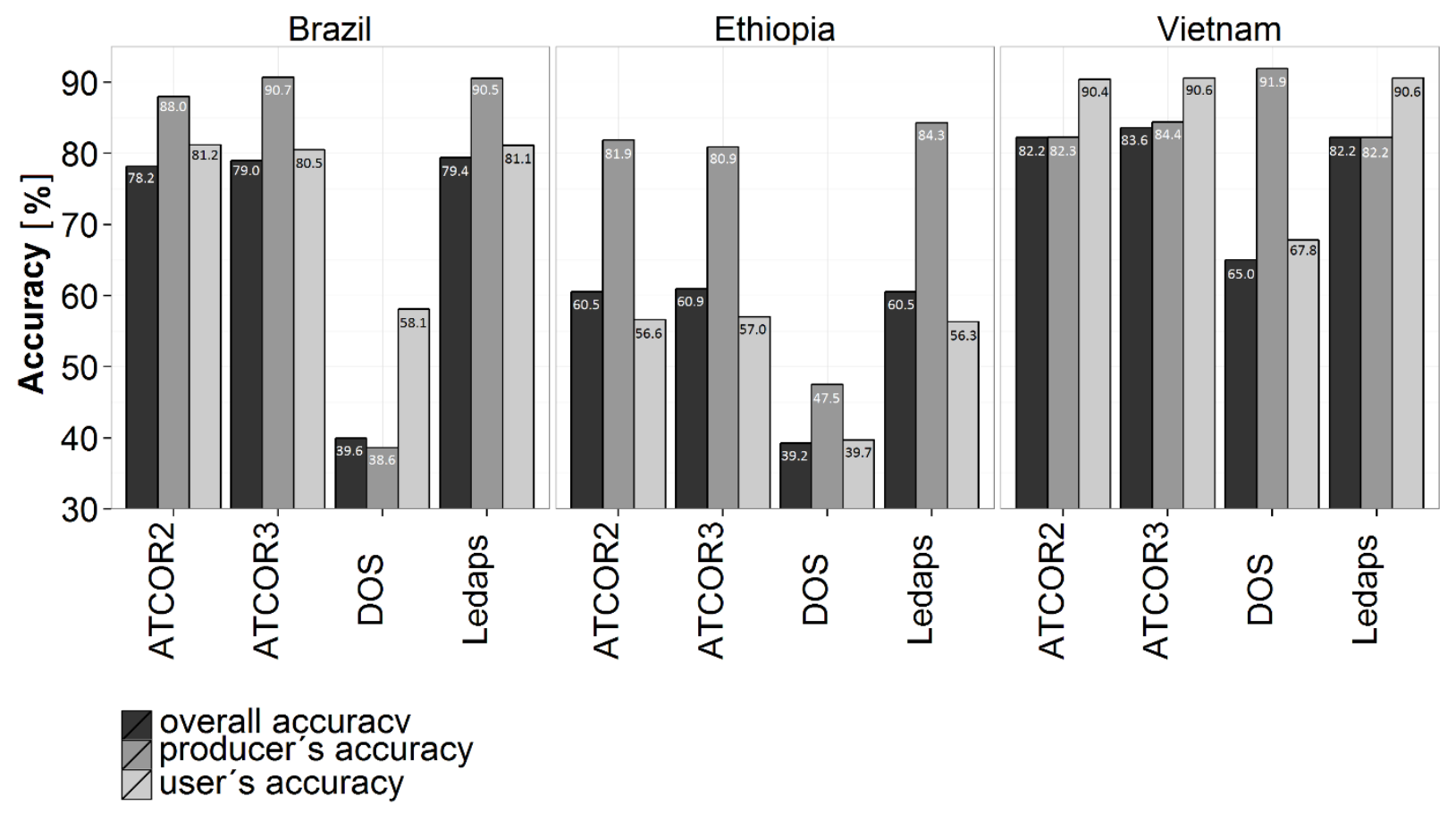

Figure 3.3 Overall accuracy, producer's accuracy (omission error), and user's accuracy (commission error) are shown for the detection of deforestation for the four radiometric correction methods (ATCOR 2 and 3, LEDAPS, DOS) and study sites (Brazil, Ethiopia, and Vietnam). 

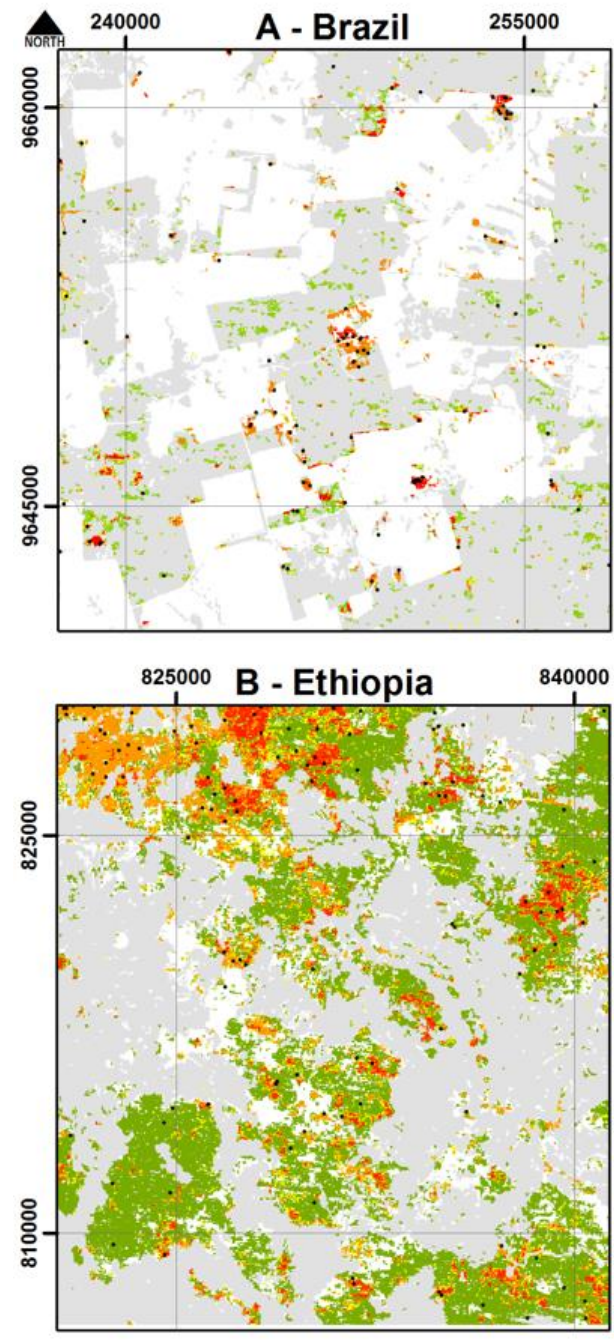

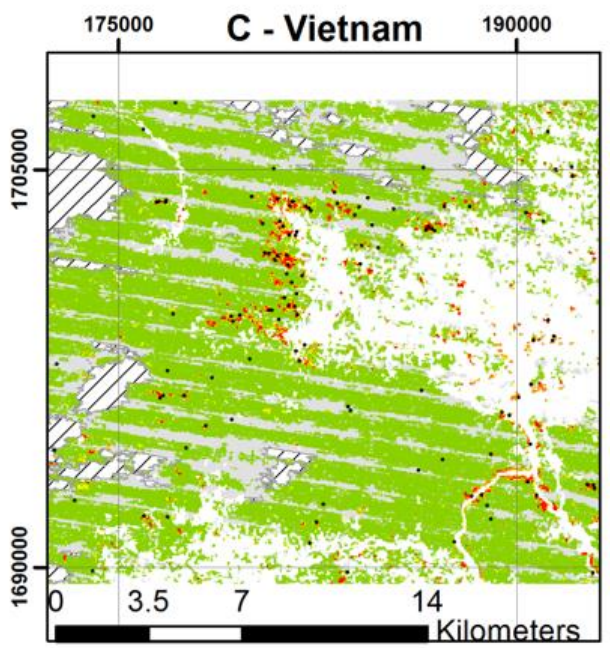

- Reference Point Agreement Of Maps

I/ No data $\square 1 \square 3 \square 2 \square 4$

$\square$ Forest (Tree Cover $>30 \%, \mathrm{mmu}>0.5 \mathrm{ha}$ )

$\square$ No Forest

Figure 3.4 Results of mapped forest changes, displayed as agreement between the maps created by ATCOR 2 and 3, LEDAPS, and DOS. A deforestation detected by all four radiometric correction schemes is scored four. Individual maps can be reviewed in the supplemental material. (a) (Brazil) (UTM Zone 23 S): deforestation occurs in rectangular patches in production forest, (b) (Ethiopia) (UTM Zone $36 \mathrm{~N}$ ): gradual deforestation in large areas, (c) (Vietnam) (UTM Zone $49 \mathrm{~N}$ ): slash and burn deforestation patches of small areas. For visualization purposes, only $10 \%$ of the 1200 sampling points are shown as black dots. 


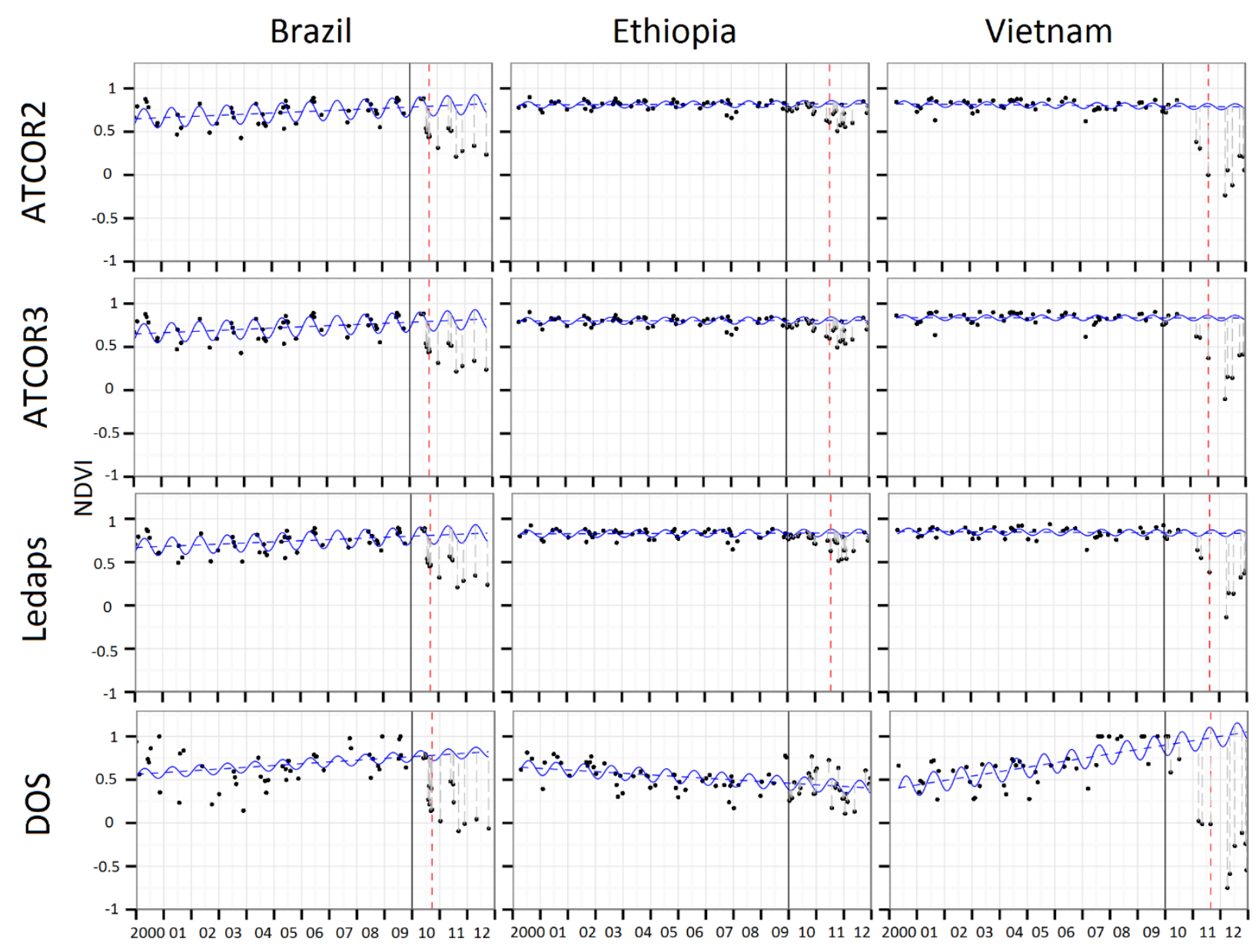

Figure 3.5 Site-specific prototypes of deforestation detection for each preprocessing scheme (ATCOR2, ATCOR3, Ledaps, and DOS). Each graph shows a typical time series of deforestation for each study site. Black dots indicate available measurements and the vertical black line separates historic period (left) from the monitoring period (right). The blue line shows the BFAST Monitor seasonal and trend model and the blue-dotted line shows the BFAST Monitor trend model of the stable history. The red-dotted line indicates the moment in time when BFAST Monitor detected the deforestation. Brazil: high-frequency amplitude indicates forest use, with the signal falling and rising, reflecting the forest plantation use. Ethiopia: stable historic period but low magnitude signal drops during monitoring period due to gradual removal of tree cover. Vietnam: stable historic period with abrupt slash and burn deforestation event, followed by signal recovery after regrowth.

\subsubsection{Site and Radiometric Preprocessing: Specific Importance of Error Sources}

The analysis of the error sources showed that the major drivers of error are data variance, data availability, atmospheric contamination, and edge effects (Fig. 3.6). The $\mathrm{R}^{2}$ values of the commission errors are usually well above 0.5 and for omission errors, they are well below 0.5 . Where preprocessing schemes produce large errors such as DOS, $\mathrm{R}^{2}$ values are generally higher, suggesting the more error there is, the more the error can be explained. Committed deforestation across the sites is largely driven by the variance of the soil signal and as indicated in Fig. 3.6 occurs particularly when low. If the error exceeds the signal's variance, a false positive of deforestation is likely to occur. The same is true particularly for NDVI signal variance in the Brazil case. Besides data variance, forest edge effects also 
largely explain commission of deforestation. Since deforestation in Ethiopia is largely driven by gradual forest removal at the edges, it is more important there than at the other sites. Conversely, Vietnam's reliance on data availability during the historic period explains errors of commission, a poorly understood history may lead to false interpretation of change within the monitoring periods. Already represented with lowest data availability of all sites, the Vietnam case would benefit most from increased data availability to suppress this error source. As the variance of the soil signal and the variance of the NDVI signal are almost equally dominant for LEDAPS and ATCOR 2 and 3, it can be assumed that at this site, these parameters correlate highly. In all sites, topographic effects and atmospheric contamination are only of minor importance.

The main drivers of the omission error are data availability, atmospheric contamination, and data variance. Particularly in Vietnam, omission errors are mainly driven by data availability during the monitoring period and both the variance of the soil signal and the NDVI signal. There and in Ethiopia, it is crucial to have data particularly available on the tail of the time series to avoid omitting deforestation events. However, in Brazil, only haze significantly drives the omission of change. An omitted change is generally difficult to explain and often a result of a lack of sensitivity to the phenomena of interest by the spatial, spectral, or temporal constrains of the observation system.

\subsubsection{Impact of Selected Error Sources on the Probability of the Error Type (Model Outcome)} As data availability, data variance, and edge effects contribute most in creating commission errors and are well explained by their $\mathrm{R}^{2}$, their impact on the model outcome was further explored. Commission errors are a result of poorly modeled time series being unable to distinguish seasonality and data artifacts from real change. For each site, the most dominant error source was selected and its impact on the probability of the error type explored (Fig. 3.7). For Vietnam, time series with the minimum amount of available observations of the full time series (30) have a probability of about 0.8 of creating a commission error. LEDAPS processed time series are least impacted by the amount of available observations in the full time series, whereas DOS processed time series are most impacted by this parameter, and the probability of creating a commission error approaches 0 if more than 60 observations are available in the full time series. In Ethiopia, the distance of mapped changes in relation to the forest boundary is a strong predictor of commission error. Depending on the correction scheme applied, changes occurring closest to the forest boundary create a mapping error with a probability ranging from 0.2 to 0.25 ; if the change is detected more than $1200 \mathrm{~m}$ away from the forest edge, an error of commission will almost certainly result. For Brazil, low variances of time series soil signal are more likely to create commission error than higher variances. The probability of a commission error being created by a variance of more than 40 is close to 0 . High variances may be the result of seasonality effects. BFAST Monitor does adapt to this effect and either detects occurring changes or omits them. 


\begin{tabular}{|c|c|c|c|c|c|c|c|c|c|c|c|c|}
\hline Commission error & \multicolumn{4}{|c|}{ BRAZIL } & \multicolumn{4}{|c|}{ ETHIOPIA } & \multicolumn{4}{|c|}{ VIETNAM } \\
\hline Domain & ATCOR2 & ATCOR3 & LEDAPS & DOS & ATCOR2 & ATCOR3 & LEDAPS & DOS & ATCOR2 & ATCOR3 & LEDAPS & DOS \\
\hline Data availability & - & - & - & - & - & - & - & 0.1 & 0.3 & 0.4 & 0.3 & 0.3 \\
\hline$*_{2}$ & - & - & - & 0.1 & - & - & - & - & 0.1 & - & - & - \\
\hline Atmosphere & - & - & - & 0.1 & - & - & 0.1 & 0.1 & 0.1 & 0.1 & 0.1 & - \\
\hline Topography & - & - & - & 0.1 & - & - & - & - & - & - & - & - \\
\hline Variance in data & 0.5 & 0.6 & 0.5 & - & - & - & 0.1 & 0.1 & - & - & - & - \\
\hline (1) & 0.6 & 0.6 & 0.5 & 0.7 & 0.2 & 0.3 & 0.2 & 0.1 & 0.5 & 0.5 & 0.5 & 0.8 \\
\hline Edge effects & 0.2 & 0.2 & 0.2 & 0.2 & 0.4 & 0.4 & 0.4 & 0.4 & 0.3 & 0.2 & - & 0.3 \\
\hline $\begin{array}{l}\text { Prediction of error: } \\
\mathbf{R}^{2}\end{array}$ & 0.6 & 0.61 & 0.59 & 0.72 & 0.44 & 0.45 & 0.44 & 0.43 & 0.58 & 0.58 & 0.53 & 0.73 \\
\hline $\begin{array}{l}\text { Commission error } \\
(\%)\end{array}$ & 18.84 & 19.45 & 18.87 & 41.89 & 43.45 & 43.01 & 43.66 & 60.34 & 9.63 & 9.41 & 9.39 & 32.24 \\
\hline $\begin{array}{l}\text { Omission error } \\
\text { Domain }\end{array}$ & & & & & & & & & & & & \\
\hline Data availability & - & - & - & 0.1 & 0.1 & 0.1 & 0.1 & - & 0.1 & 0.1 & 0.1 & 0.1 \\
\hline$*_{2}$ & 0.1 & 0.1 & 0.1 & 0.1 & 0.2 & 0.2 & 0.2 & 0.3 & 0.1 & 0.1 & 0.1 & 0.1 \\
\hline Atmosphere & 0.1 & 0.1 & 0.1 & 0.1 & - & - & - & 0.1 & - & - & - & 0.4 \\
\hline Topography & - & - & - & - & - & - & - & - & 0.1 & - & - & - \\
\hline Variance in data & - & - & 0.1 & 0.1 & - & - & - & 0.1 & 0.1 & 0.2 & 0.2 & 0.6 \\
\hline 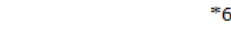 & 0.1 & 0.1 & 0.1 & - & - & - & - & - & 0.1 & 0.3 & 0.3 & 0.1 \\
\hline Edge effects & - & - & & - & - & - & - & - & - & 0.1 & 0.1 & 0.2 \\
\hline $\begin{array}{l}\text { Prediction of error: } \\
\mathbf{R}^{2}\end{array}$ & 0.07 & 0.11 & 0.14 & 0.07 & 0.20 & 0.19 & 0.19 & 0.34 & 0.29 & 0.46 & 0.43 & 0.75 \\
\hline Omission error $(\%)$ & 12.01 & 9.28 & 9.53 & 61.39 & 18.12 & 19.15 & 15.73 & 52.48 & 17.65 & 15.56 & 17.78 & 8.15 \\
\hline
\end{tabular}

Figure 3.6 Error importance matrix. Each column indicates the level of significance of parameters (error sources) used to model commission (upper table) or omission error (lower table). Numbers in the cells indicate the $R^{2}$ of a specific domain of error source. The $R^{2}$ values of individual cells indicate how that particular variable independently explains the error. Bold numbers below the columns indicate the $\mathrm{R}^{2}$ for the best combination of error sources modelling the specific error. The parameters (independent variables) have been selected using stepwise AIC and some parameters may not contribute significantly to explaining the error and therefore are not flagged with an $R^{2}$. Using the individual $R^{2}$ and the significance level the importance of error sources can be estimated. Due to mathematical constraints, the sum of the individual $R^{2}$ differs from the overall $R^{2}$. *1 observations in full time series; *2 observations in monitoring period; *3 haze contamination during deforestation event; *4 topographic slope at site of deforestation event; ${ }^{*} 5 \mathrm{NDVI}$ variance in full time series; ${ }^{*} 6$ variance of exposed soil in full time series; *7 edge effects.
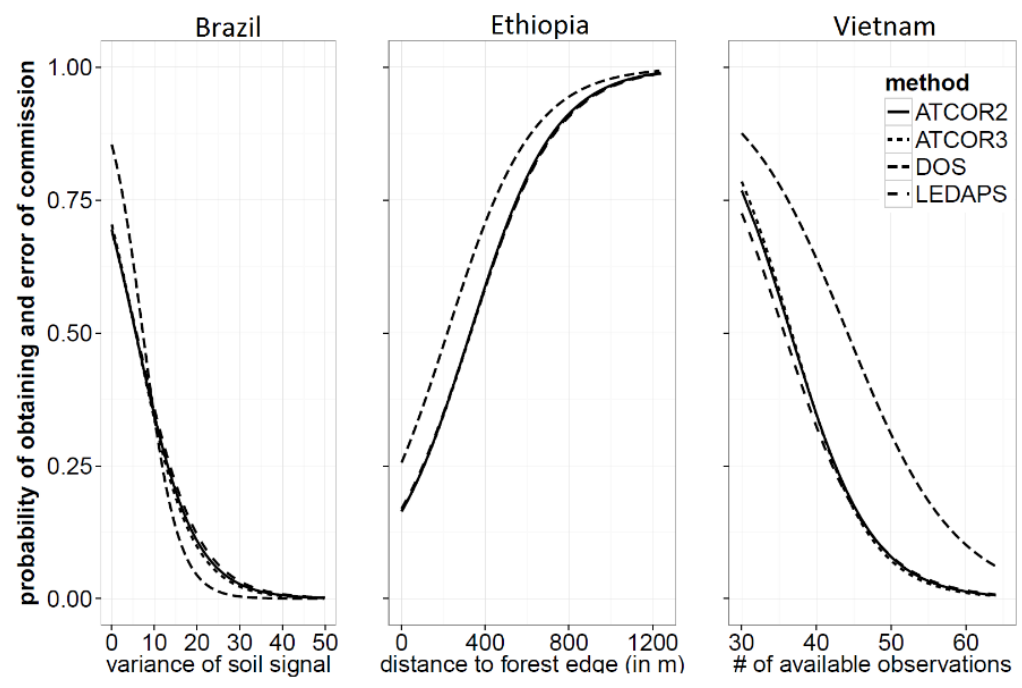

Figure 3.7 Impact of selected error sources on the probability of errors of commission. Each graph represents the predicted probabilities of the specific error source by site (Brazil, Ethiopia, and Vietnam) and by radiometric correction method (ATCOR 2 and 3, LEDAPS, and DOS). ATCOR 2 and 3 and LEDAPS overlap greatly due to their similar accuracy. 


\subsection{Discussion}

Using BFAST Monitor on Landsat NDVI time series, our study assessed the influence of different radiometric correction approaches and other important factors on deforestation mapping. Various radiometric correction methods are available, with or without the correction of BRDF, topographic effects, or atmospheric turbidity (Berk et al., 2008; Broich et al., 2009; Chavez, 1988; Hansen and Loveland, 2012; Richter, 2011; Vermote et al., 1997). We found that with the exception of DOS, there were few differences in the mapping accuracy between the radiometric correction schemes that are based on MODTRAN (ATCOR) and 6S (LEDAPS). The importance of the different error sources varies more due to differences in site properties than by the correction method applied. We will now discuss our findings in relation to the research questions posed in Section 3.1.

1) How do different radiometric correction approaches of Landsat time series imagery affect the accuracy of tropical deforestation mapping?

ATCOR 2 and 3 and LEDAPS use different auxiliary data sources to support the radiometric correction and to correct different effects, yet despite the differences, they achieve similar accuracies. Mapping accuracy could be improved by developing a new correction scheme that uses both auxiliary atmospheric data as with LEDAPS and topographic and BRDF correction as with ATCOR 3. Due to its poor performance, DOS is inappropriate for time series analysis radiometric correction. Because sensor specific calibration and default parameters of the preprocessing schemes have been used, it is likely that higher accuracies could have been achieved on the cost of comparability if image specific fine-tuning was performed. However, since time series of data is used, methods which rely on costly and timeconsuming human interaction for image fine-tuning for preprocessing become prohibitive. Although in this study we focused on relatively small area of interest for proof of concept, large-scale applications such as Hansen's recent global deforestation map (Hansen et al., 2013) are only possible because of nonhuman interactive radiometric preprocessing. The comparison of ATCOR 2 and ATCOR 3 results reveals that the correction of topographic and BRDF effects consistently improves mapping accuracy, but only modestly and also demonstrates the robustness of the NDVI and BFAST Monitor. However, if an imperfect DEM is used to correct topography-related effects, an error rather than a correction is added to the map. Although the DEM we used is known to vary spatially in quality (Tachikawa et al., 2011), we did not assess its impact on the map reliability, as this was beyond the scope of this study.

As reported above, ATCOR 3 yields the best results in terms of accuracy, closely followed by LEDAPS, and then ATCOR 2: its slight superiority is evident in the Vietnamese study area, which has a complex topography. Because of its poor performance, DOS is not recommended for tropical deforestation mapping. ATCOR 2 performs similarly to LEDAPS and is a reliable alternative whenever external auxiliary data are not available. Because BFAST Monitor is designed for large-scale application, LEDAPS products have the advantage to be freely available and automated, while for ATCOR 2 and 3, each scene needs to be processed independently and the gained accuracy is only modest.

2) Which factors are most important in explaining commission and omission errors in deforestation mapping across three tropical sites with different forest and forest change characteristics?

Through literature research and data exploration, five types of error sources were identified: 1) data availability; 2) atmosphere; 3) topography; 4) edge effects; and 5) data variance (Broadbent et al., 2008; Goslee, 2012; Hansen and Loveland, 2012; Newman et al., 2014; Song et al., 2001; Souza et al., 2009; 
Tan et al., 2013). Their importance varies mostly by site (Ethiopia, Brazil, and Vietnam), error type (omission or commission error), and only slightly by radiometric correction schemes. They can explain most of the commission error, but due to the low $R^{2}$ of the model fit, they mostly fail to explain omission of change satisfactory. The omission error is driven by data availability and is significantly affected by the amount of observations available during the monitoring period, haze contamination, and data variance. Our finding that the amount of observations available during the monitoring period is important in all sites suggests that it is critical to incorporate additional data during the monitoring period and to ensure the entire time series is denser. However, the availability of new Landsat-like sensors for instance, the recently launched Landsat 8 , and the Sentinel 1 and 2 indicates that this error source will soon be overcome (Drusch et al., 2012; Roy et al., 2014). Also, RADAR data of similar resolution can be used for that purpose (Reiche et al., 2015). The commission error is largely driven by data variance. At first sight, it is counterintuitive that low data variances are a major factor driving deforestation commission error. When we inspected the time series involved, we found that what determined the commission error was data noise. If few observations are available, even a small number of outliers can be detected as a significant change. Time series equally noisy in the historic period as well as in the monitoring period characterized by a higher variance are better adapted to data noise and therefore less sensitive in creating commission errors. Time series with sparse data either need to be without outliers or should have the similar distribution of outliers in the historic as well as in the monitoring period for the BFAST Monitor approach to adapt to the noise. Furthermore, Fig. 3.7 shows that to obtain reliable results, it is necessary to have a minimum amount of observations in the full time series. Our results confirm previous findings that the fewer the observations available, the higher the risk of creating mapping errors (Hansen and Loveland, 2012).

At the sites in Brazil and Ethiopia, deforestation mainly occurs next to the forest boundaries. Forest changes at the Ethiopian site occur gradually, pushing back the forest boundary, and deforestation deep inside the forest is unlikely. If the distance from the deforestation event to the forest boundary is large, there is a high probability that the detected event is a commission error. Edge effects can help distinguish change from false positives. For best results, it is recommended that local forest disturbance patterns are understood and that algorithms are adjusted to take account of regional conditions.

3) What are the potentials and limitations of using Landsat NDVI time series when mapping tropical forest changes?

Although in previous studies the NDVI has been proven to be a robust measure to describe vegetation stress, it is not necessarily a robust measure to describe tropical deforestation. The low mapping accuracies for Ethiopia demonstrate the limited capabilities of detecting deforestation when using BFAST Monitor on NDVI time series. The site is characterized by gradual low intensity changes (Fig. 3.5). One reason for the low mapping accuracy might be the signal-to-noise ratio of the Ethiopian time series, where the NDVI is only slightly sensitive to gradually degrading forest, a measure of canopy damage such as the normalized difference fraction index (NDFI) can be more sensitive to the subtle or gradual forest changes (Souza et al., 2005). The EVI is particularly sensitive to high biomass and might also improve mapping accuracies (Wardlow et al., 2007). From the satisfactory accuracies achieved for the sites in Vietnam and Brazil, we infer that abrupt, high intensity changes that persist are more likely to be detected correctly. The local adaptation of the algorithm and combining BFAST Monitor outputs (magnitude and time of change) with other site-specific measures in a statistical model will improve 
accuracies of deforestation mapping (DeVries et al., 2015b), but degrades the transferability of the algorithm as additional human interaction is required.

\subsection{Conclusion}

This study explores radiometric correction schemes strategies for monitoring change in the tropics in relation to differences resulting from data availability, signal-to-noise ratio, atmospheric contamination, and deforestation type. Based upon the results, practical guidelines for deforestation monitoring in the tropics when using BFAST Monitor are formulated.

1) Radiometric correction schemes that use radiative transfer models (ATCOR 2 and 3, LEDAPS) produce similar results, with marginal differences in performance. As large-scale applications are desired, highly automated procedures such as LEDAPS are preferred for BFAST Monitor. The varying user's and producer's accuracy between sites show that no single correction technique is consistently superior. If no external auxiliary data are available (as required by LEDAPS), ATCOR 2 is recommended for use. However, since LEDAPS-processed products are available free of charge at the USGS, these are particularly useful in REDD and similar applications. Time series derived using DOS are dominated by noise and are not suitable for time series analysis for deforestation mapping. If small study areas do not include dark objects (e.g., water bodies), data quality will be poor.

2) Mapping errors are largely related to data variance, data availability, and edge effects, but can be explained satisfactorily only for commission errors. First, the probability of creating a commission error depends strongly on data variance, which in turn depends on the amount and quality of available observations. Time series characterized by little data variance are sensitive to data outliers, which are wrongly mapped as change. This effect can be suppressed by prior data handling, such as improved cloud screening, or by mapping a change only if it is found in two or more consecutive observations. In sites where deforestation is proceeding by pushing back the forest boundary, as is the case in Ethiopia, the location of the deforestation event in relation to the forest boundary can predict where an error of commission has most probably occurred. For sites characterized by this phenomenon, an option is to supress changes if they are far from the forest boundary. Second, the error source assessment shows that the time series should be denser, to avoid omission; the priorities are first to increase the number of observations during the monitoring period and then to do likewise for the entire time series. However, due to the poor model fits, the omission error could mostly not be described satisfactorily; we suggest investigating the significance of further potential error sources.

3) The NDVI is designed to quantify the photosynthetically active biomass of plant canopies and is limited by the spectral responses of red and near infrared bands. Although common practice and straightforward to apply, the radiometric spectrum offered by Landsat is not exploited. Deforestation is usually linked to a loss of forest biomass and more precisely to a loss of tree canopy cover. Changes omitted due to rapid regrowth or changes overestimated due to poor signal-to-noise ratios can be supressed using indices that are more sensitive to forest loss. For instance, the NDFI uses Landsat's full radiometric resolution and is sensitive to tree canopy damage. When only a few trees are removed, the high biomass sensitivity of the EVI is particularly useful for mapping gradual deforestation. We suggest using the reference database at hand to explore different indices and combining them in order to identify the most accurate mapping indices. 


\section{Chapter 3}

\subsection{Acknowledgement}

The authors would like to thank the Black Bridge Company (http://www.blackbridge.com/rapideye/) and the Planet Action Organization (http://www.planet-action.org/) for providing high resolution satellite fundamentally necessary for this work. They would also like to thank C. Souza of Imazon for providing with spectral unmixing tools and Vietnamese partners for their field work support. Dr. J. Burrough was the authors' editor of a near-final draft of this paper. 
Chapter 4

\section{Chapter 4}

Performance of vegetation indices from Landsat time series in deforestation monitoring

Michael Schultz, Jan G.P.W. Clevers, Sarah Carter, Jan Verbesselt, Valerio Avitabile, Hien Vu Quang and Martin Herold

Published in International Journal of Applied Earth Observation and Geoinformation, 52 (2016), 318 327, DOI: 10.1016/j.jag.2016.06.020 


\begin{abstract}
The performance of Landsat time series (LTS) of eight vegetation indices (VIs) was assessed for monitoring deforestation across the tropics. Three sites were selected based on differing remote sensing observation frequencies, deforestation drivers and environmental factors. The LTS of each VI was analysed using the Breaks For Additive Season and Trend (BFAST) Monitor method to identify deforestation. A robust reference database was used to evaluate the performance regarding spatial accuracy, sensitivity to observation frequency and combined use of multiple VIs. The canopy cover sensitive Normalized Difference Fraction Index (NDFI) was the most accurate. Among those tested, wetness related VIs (Normalized Difference Moisture Index (NDMI) and the Tasselled Cap wetness (TCW)) were spatially more accurate than greenness related VIs (Normalized Difference Vegetation Index (NDVI) and Tasselled Cap greenness (TCg)). When VIs were fused on feature level, spatial accuracy was improved and overestimation of change reduced. NDVI and NDFI produced the most robust results when observation frequency varies.
\end{abstract}




\subsection{Introduction}

Between 2000 and 2012, global forest loss increased by approximately $2000 \mathrm{~km}^{2}$ per year (Hansen et al., 2013). Deforestation contributed to around $8 \%$ of anthropogenic carbon emissions in the 2000s (Tubiello et al., 2015), and despite forests remaining a sink, emissions from degradation were $0.80 \mathrm{Gt}$ $\mathrm{CO}_{2} \mathrm{yr}^{-1}$ between 1990 and 2015 (Federici et al., 2015). Mechanisms such as Reducing Emissions from Deforestation and Forest Degradation (REDD+) aim to reduce forest loss and increase carbon sequestration in forests (UNFCCC, 2016). Monitoring, Reporting and Verification (MRV) of REDD+ carbon stock changes is mandatory and requires consistent and long term monitoring of forests supported by field observations (Arino et al., 2012; De Sy et al., 2012). The Landsat mission can be a key component of such MRV methodologies, as it provides long term medium resolution $(10-60 \mathrm{~m})$ remote sensing data (Gutman et al., 2008; Skole and Tucker, 1993; Townshend and Justice, 1988). The availability of free Landsat data (Woodcock et al., 2008) created a paradigm change in how Landsat data is used, away from bi-temporal analysis towards time series analysis (Hansen and Loveland, 2012). In addition, an increase in computational capacities (Evangelidis et al., 2014) resulted in forest change maps of unprecedented scale and resolution (Hansen et al., 2013). Time series analysis methods applied to Landsat data were inspired by previous developments of coarse spatial resolution systems such as the Moderate Resolution Imaging Spectroradiometer (MODIS) and the Advanced Very High Resolution Radiometer (AVHRR) (Cihlar et al., 1997, p. 199; de Jong et al., 2012; Forkel et al., 2013; Roerink et al., 2000; Tucker et al., 2005; Verbesselt et al., 2010b). Compared to those missions, Landsat offers the longest running cross-calibrated globally consistent record of the Earth's surface at medium resolution. Since the opening of the archive, many studies demonstrated Landsat's capabilities for mapping forest cover and related changes (Hansen and Loveland, 2012; Loveland and Dwyer, 2012; Pflugmacher et al., 2013; Roy et al., 2014; Trenberth et al., 2013; Woodcock and Ozdogan, 2012; Wulder et al., 2012), with an increasing density of Landsat time series (LTS) (Achard et al., 2014; Broich et al., 2011; Cohen et al., 2010; Huang et al., 2010). Methods developed for temperate forests can often be characterized by a higher frequency of observations than in tropical areas which are characterized by persistent cloud cover (Romijn et al., 2012). When large areas are under investigation, methods have to cope with very different observation frequencies, often requiring complex solutions (Broich et al., 2011). Empirical studies show strong correlations between vegetation indices (VIs), and vegetation parameters such as biomass and canopy closure (Avitabile et al., 2012; Myneni et al., 1995). VIs are useful for assessing the amount and condition of vegetation, while suppressing noise, soil background and atmospheric effects (Jackson and Huete, 1991). VIs have become a standard for the interpretation of vegetation dynamics such as deforestation, and have been applied on LTS (de Jong et al., 2012; Forkel et al., 2013; Verbesselt et al., 2012b). In this paper, we compare the suitability of different VIs for mapping deforestation when using the Breaks For Additive Season and Trend (BFAST) Monitor algorithm. BFAST recently emerged as a reliable tool to detect ecosystem disturbances such as droughts, fires and vegetation changes (Hutchinson et al., 2015; Verbesselt et al., 2012b, 2010b; Watts and Laffan, 2014) in agricultural (Atzberger, 2013) and forested landscapes (Lambert et al., 2015, 2013; Schmidt et al., 2015). Moreover, BFAST Monitor proved its robustness when applied to more infrequent time series such as Landsat, Landsat - SAR fused series or Landsat - MODIS fused series (DeVries et al., 2015a, 2015b; Dutrieux et al., 2015; Hamunyela et al., 2016). The observation frequency of a pixel's time series determines the ability of BFAST Monitor to describe the time series, and therefore affects its ability to detect deforestation. More observations can describe seasonality and deforestation with a higher temporal resolution and thus tend to be more accurate (Schultz et al., 2016a, 2015). So far, the algorithm has only been applied 
to the Enhanced Vegetation Index (EVI), Normalized Difference Moisture Index (NDMI) and Normalized Difference Vegetation Index (NDVI) time series. The performance of BFAST Monitor when using other VIs has not yet been assessed. The goal of this study was to identify which VIs can detect deforestation in the tropics better when applying BFAST Monitor on LTS. Given the constraint of highly varying observation frequencies in the tropics we test the capacity of VIs to produce robust and consistent results while varying observation frequency. Since different VIs might have different success rates depending on the type of deforestation mapped, our study covers three areas in the tropics characterized by different forest change dynamics. In addition, we tested whether data fusion of multiple maps at feature level can provide increased mapping accuracy. Ensemble classification has proved useful in combining various mapping outcomes of various inputs to produce one highly accurate map, and among those classification algorithms, random forest is the most prominent (Ceamanos et al., 2010; Gislason et al., 2006; Pal, 2005). We addressed the following objectives:

- Identify the most spatially accurate VI for deforestation mapping when applying BFAST Monitor to LTS

- Understand the VI's spatial accuracy regarding its sensitivity towards observation frequency per site (Brazil, Ethiopia, Vietnam)

- Explore the potential of feature level data fusion of VIs to complement each other and increase accuracy

To address these objectives, three sites in Brazil, Ethiopia and Vietnam were investigated for recent forest changes (2010 to 2013) using a reference database.

\subsection{Material and Methods}

Figure 4.1 outlines the study. First, LTS were created in three sites (Brazil, Ethiopia, Vietnam) (section 4.2.1), which were selected based on their differing ecosystem characteristics, frequency of observations, and deforestation types. Landsat data processing included screening of each image for clouds and their shadows as well as non-forest masking (section 4.2.2). Eight VIs were computed for the time series of each site, the EVI, Global Environment Monitoring Index (GEMI), Normalized Difference Fraction Index (NDFI), NDMI, NDVI, Soil Adjusted Vegetation Index (SAVI), Tasselled Cap wetness (TCW), Tasselled Cap greenness (TCg) (section 4.2.3). Each of the 24 resulting time series was then analysed for deforestation occurring between 2010 - 2013 using the BFAST Monitor method (section 4.2.4). The spatial accuracy (hereafter referred to as accuracy) of each derived deforestation map was assessed using reference data based on high resolution imagery (section 4.2.5). To understand the VIs sensitivity to the observation frequency a model was constructed depicting this relationship (section 4.2.6).

Feature level data fusion of the VI maps was then tested (section 4.2.7). 


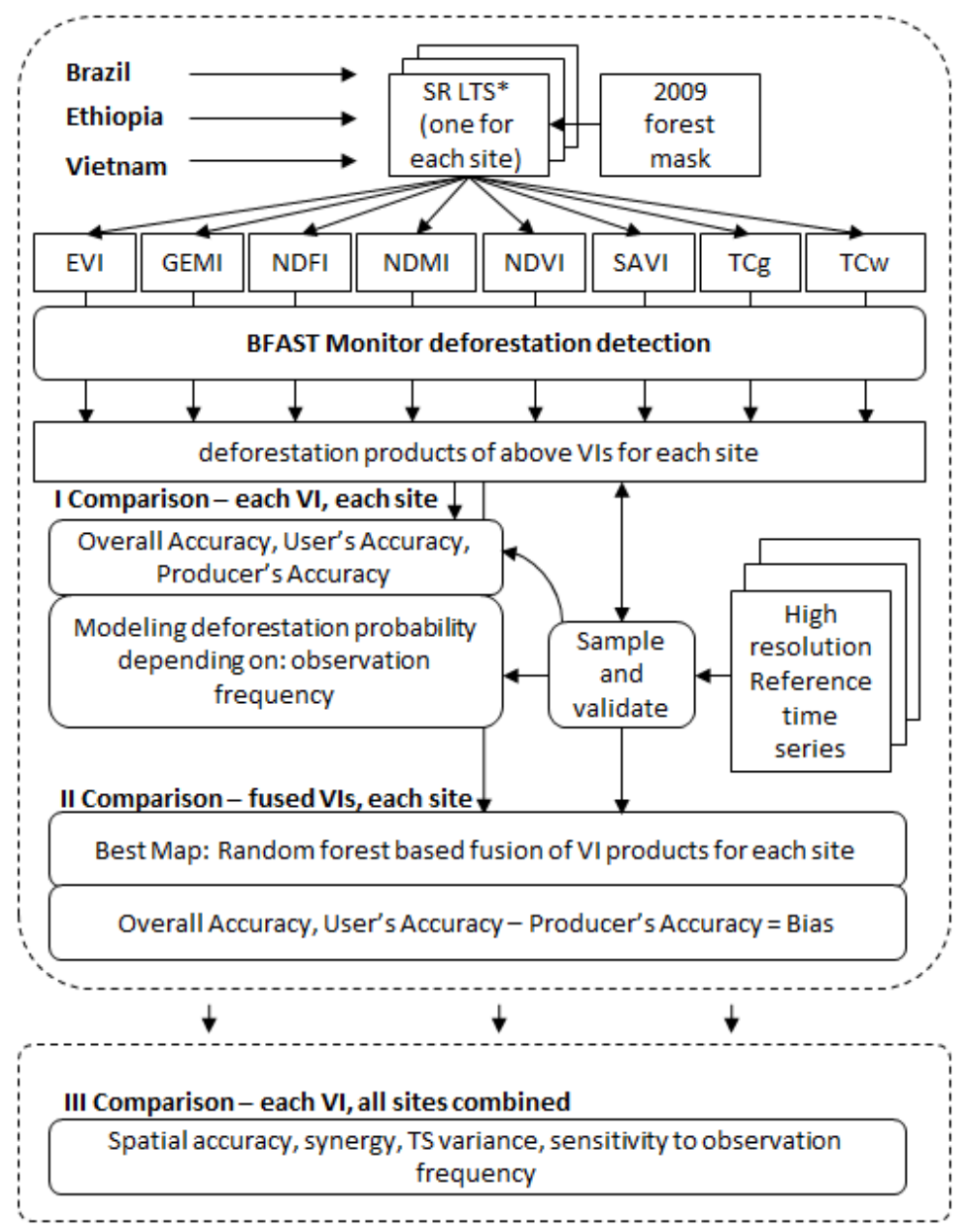

Figure 4.1 Overview of the study setup. *SR LTS = Surface reflectance Landsat time series, TS variance and Synergy are explained in the caption of figure 4.7

\subsubsection{Study sites}

Table 1 provides an overview of site properties and statistics of the time series used. The Brazil site is located within the municipality of Paragominas; its evergreen humid forest is managed and used for timber production. Gradual deforestation occurs as well as large patches of timber extraction. The climate is tropical equatorial with an average precipitation of $29 \mathrm{~mm}$ (June) to $391 \mathrm{~mm}$ (March), and the topography is flat. The Ethiopia site is part of the UNESCO Kafa Biosphere Reserve and deforestation is mainly driven by expansion of smallholder coffee plantations within mixed evergreen and dry-tropics forest production systems. Typically small incremental changes occur which gradually push back the forest boundary. The climate is tropical humid with an average annual precipitation of $1300 \mathrm{~mm}$, and it has a rugged topography (Schmitt et al., 2010). The Vietnam site is situated in the highlands of Quang Nam province; the humid evergreen forest is little managed and natural forest is mainly removed for slash and burn agriculture. The climate is characterized by sudden heavy monsoon rains and has an average precipitation of $35 \mathrm{~mm}$ (February) to $425 \mathrm{~mm}$ (October) due to its situation on the boundary between the mesothermal climate in the north and the tropical conditions in the south (MONRE, 2007, 2006). 
Table 4.1 Description of the study areas. Major forest types are indicated as Medium High Forest (40$70 \%$ canopy cover, tree height $>15 \mathrm{~m}$ ) (MHF), Closed High Forest ( $>70 \%$ canopy cover, tree height $>$ $15 \mathrm{~m}$ ) (CHF), Medium young/secondary Forest (40-70\% canopy cover, tree height $<15 \mathrm{~m})$ (MSF). Statistics on the available Landsat time series are also provided.

\begin{tabular}{|c|c|c|c|c|c|c|}
\hline Site & $\begin{array}{l}\text { Centre } \\
\text { coordinate: } \\
\text { Lat/Long }\end{array}$ & Area & Terrain properties & $\begin{array}{l}\text { Mayor } \\
\text { forest } \\
\text { type: }\end{array}$ & $\begin{array}{l}\text { Major forest } \\
\text { change } \\
\text { driver }\end{array}$ & $\begin{array}{l}\text { Total } \\
\text { Landsat } \\
\text { time series, } \\
\text { observation } \\
\text { frequency } \\
(2000 \text { - } \\
2012)\end{array}$ \\
\hline $\begin{array}{l}\text { Brazil - } \\
\text { Paragominas }\end{array}$ & $\begin{array}{l}3^{\circ} 08^{\prime} 20.1^{\prime \prime} \mathrm{N} \\
47 \circ 16^{\prime} 29.2^{\prime \prime} \mathrm{W}\end{array}$ & $\begin{array}{l}550 \\
\mathrm{~km}^{2}\end{array}$ & $\begin{array}{l}\text { Average slope: } 50 \\
\text { Altitude range: } 325- \\
401 \mathrm{~m}\end{array}$ & MSF & $\begin{array}{l}\text { Plantation } \\
\text { harvest }\end{array}$ & $\begin{array}{l}\text { Max: } 83 \\
\text { Min: } 39 \\
\text { Mean: } 62\end{array}$ \\
\hline $\begin{array}{l}\text { Ethiopia - } \\
\text { Kafa } \\
\text { Biosphere }\end{array}$ & $\begin{array}{l}7 \circ 26^{\prime} 21.8^{\prime \prime} \mathrm{N} \\
35 \circ 59^{\prime} 19.9^{\prime \prime} \mathrm{E}\end{array}$ & $\begin{array}{l}530 \\
\mathrm{~km}^{2}\end{array}$ & $\begin{array}{l}\text { Average slope: } 11^{0} \\
\text { Altitude range: } \\
2449-1537 \mathrm{~m}\end{array}$ & $\begin{array}{l}\text { MHF, } \\
\text { MSF, }\end{array}$ & $\begin{array}{l}\text { Coffee } \\
\text { expansion }\end{array}$ & $\begin{array}{l}\text { Max: } 108 \\
\text { Min: } 30 \\
\text { Mean: } 71\end{array}$ \\
\hline $\begin{array}{l}\text { Viet Nam - } \\
\text { Tra Bui }\end{array}$ & $\begin{array}{l}15 \circ 21^{\prime} 38.7^{\prime \prime} \mathrm{N} \\
108 \circ 2^{\prime} 16.5^{\prime \prime} \mathrm{E}\end{array}$ & $\begin{array}{l}510 \\
\mathrm{~km}^{2}\end{array}$ & $\begin{array}{l}\text { Average slope: } 26^{\circ} \\
\text { Altitude range: } \\
2672-1890 \mathrm{~m}\end{array}$ & $\begin{array}{l}\text { MHF, } \\
\mathrm{CHF}\end{array}$ & $\begin{array}{l}\text { Slash and } \\
\text { burn }\end{array}$ & $\begin{array}{l}\text { Max: } 114 \\
\text { Min: } 31 \\
\text { Mean: } 79\end{array}$ \\
\hline
\end{tabular}

\subsubsection{Data pre-processing}

The Landsat Ecosystem Disturbance Adaptive Processing System (LEDAPS) is a robust system for processing large quantities of remote sensing data for forest change analysis (Masek et al., 2008). It was found to be a suitable pre-processing method when analysing time series of Landsat data with the BFAST Monitor method (Schultz et al., 2016b). To minimize miss-registration errors and to provide radiometric consistency (Song et al., 2001) only LEDAPS surface reflectance (SR) L1T data (sub-pixel accuracy), provided by the United States Geological Survey (USGS) climate data record (Hayes et al., 2008) were used. Cloud and cloud shadows were removed using the FMASK product, which is also distributed by the USGS (Zhu and Woodcock, 2012). An additional buffer of 3 pixels around identified clouds and their shadows was used to further improve FMASK results, removing spurious contamination on the edges of masked clouds. A significant amount of cloud residuals and related artefacts were left in the data, but BFAST Monitor was found to be robust in dealing with such residuals (DeVries et al., 2015b). A forest was defined as an area of at least 0.5 ha with a canopy cover of at least $30 \%$. A drop in canopy cover below that threshold was considered a deforestation event. The forest mask was 
produced using data from 2009 as we investigated changes between 2010 and 2013. Detailed information on the forest mask can be found in (Schultz et al., 2013).

\subsubsection{Vegetation indices}

A set of eight commonly used VIs were selected, including the NDVI, the most frequently used VI in remote sensing science. A search in Scopus revealed that more than 1000 peer reviewed journal articles use the NDVI to study tropical forests (Supplementary materials). The NDVI is designed to monitor photosynthetic active biomass (Tucker, 1979) and makes use of the strong reflection of vegetation within the near-infrared (NIR, TM $(0.76-0.90 \mu \mathrm{m}), \mathrm{ETM}+(0.77-0.90 \mu \mathrm{m}))$ and its distinct difference to the red spectrum (RED, TM/ETM+ (0.63-0.69 $\mu \mathrm{m})$ ). High NDVI values refer to healthy plants, low NDVI values refer to either absence of or low amounts of vegetation. This VI was successfully used in previous studies within a similar context (DeVries et al., 2015b; Verbesselt et al., 2012b, 2010b).

$N D V I=\frac{(N I R-R E D)}{(N I R+R E D)}$

Secondly, the EVI was selected due to its frequent use within tropical landscapes. In comparison to the NDVI, the EVI does not saturate as quickly when mapping high amounts of biomass and is therefore able to distinguish dense vegetation. For Landsat data, atmospheric effects are suppressed using the blue band (BLUE, TM/ETM+ $(0.45-0.52 \mu \mathrm{m})$ ) and adjustable coefficients $\mathrm{C} 1=6$ and $\mathrm{C} 2=7.5$, as well as the sensors gain factor $G=2.5$. An adjustment of canopy background was $L=1$ (Huete et al., 2002, 1994, 1997).

$E V I=G *\left(\frac{(N I R-R E D)}{(N I R+C 1 * R E D-C 2 * B l u e+L)}\right)$

Thirdly, the GEMI was chosen because it is designed to be applicable on a global scale, making it comparable across ecosystems and able to map large areas while still maintaining information about the vegetation cover (Pinty and Verstraete, 1992).

$G E M I=\eta(1-0.25 * \eta)-\frac{R E D-0.125}{1-R E D}$

The factor $\eta$ is calculated according to:

$\eta=\frac{2\left(N I R^{2}-R E D^{2}\right)+1.5 * N I R+0,5 * R E D}{N I R+R E D+0.5}$

Fourthly, the NDMI; often applied to monitor forest disturbances or harvests in boreal and temperate forests (Goodwin et al., 2008; Jin and Sader, 2005; Wilson and Sader, 2002) it has also proven to be an accurate tool when monitoring forests in the tropics (Hayes et al., 2008). Because of the use of the shortwave-infrared (SWIR1, TM/ETM+ $(1.55-1.75 \mu \mathrm{m})$ ) this VI is sensitive to absorption by leaf moisture (Horler and Ahern, 1985) and to canopy cover (Hardisky et al., 1983), thus is potentially suitable for deforestation mapping.

$N D M I=\frac{(N I R-S W I R)}{(N I R+S W I R)}$ 
Fifthly, the SAVI was chosen as it suppresses the influence of soil brightness and therefore has the potential to be particularly sensitive to deforestation in forest landscapes with incomplete forest canopy cover, which is often the case on the edge of a forest or within disturbed forests for example the Ethiopia site. The soil correction is expressed with a variable L, for which we select 0.5 (Huete, 1988; Miura et al., 1998).

$S A V I=(1+L) *\left(\frac{(N I R-R E D)}{(N I R+R E D+L)}\right)$

The above VIs focus on NIR and SWIR ratios and therefore do not utilize the full spectral range available, while the Tasselled Cap transformation utilizes all bands (Kauth et al., 1976). This guided principal component analysis incorporates a multidimensional soil line within the feature space. The TCW, which focusses on the wetness component (Crist and Cicone, 1984), has been used to map forest regrowth using a Landsat time series for boreal forests (Czerwinski et al., 2014). The TCg can describe the amount of green biomass and is often used in combination with TCW (Masek et al., 2008). Here the Tasselled Cap transformation was calculated using the TM or ETM+ bands of Landsat, as given by values for surface reflectance using coefficients for the BLUE band, green band (GREEN, TM/ETM+ $0.52-0.60 \mu \mathrm{m})$ ), RED, NIR, SWIR1 and the second shortwave infrared band (SWIR2, TM $(2.08-2.35 \mu \mathrm{m})$, ETM+ $(2.09-2.35 \mu \mathrm{m})$ ) found in (Crist, 1985):

$T C_{\text {wetness }}=0.0315 * B L U E+0.2021 * G R E E N+0.3102 * R E D+0.1594 * N I R-0.6806 *$

SWIR $1-0.6109 * S W I R 2$

$T C_{\text {greenness }}=-0.1603 *$ Blue $-0.2819 *$ Green $-0.4934 *$ Red $+0.7940 *$ NIR $-0.0002 *$

SWIR $1-0.1446 * S W I R 2$

Finally, the NDFI was chosen as it is sensitive to the state of the canopy cover, and has been successfully applied to monitor deforestation and degradation in Brazil. A spectral mixture analysis (SMA) is the first step in the calculations, with endmembers green vegetation (GV), non-photosynthetically active vegetation (NPV) and soil being then extracted for each observation. The reminder is the shade component given as a percentage (\%) (Souza et al., 2013, 2005):

$N D F I=\frac{G V_{\text {Shade }}-(N P V+\text { Soil })}{G V_{\text {Shade }}+N P V+\text { Soil }}$

With $G V_{\text {Shade }}=100 * \frac{G V}{100-\text { Shade }}$

\subsubsection{Deforestation detection}

Near-real time monitoring maps disturbances as they occur by comparing current observations against those captured previously. We detected deforestation per pixel using the BFAST Monitor method (Verbesselt et al., 2012b) where the time series is separated into a historic period (2000 - 2009), which is used as a baseline, and a monitoring period (2010 - 2013). First, a season-trend model consisting of a 
linear trend model and a first order harmonic series is fitted based on observations within the historic period:

$y_{t}=\alpha_{1}+\alpha_{2} t+\gamma \sin \left(\frac{2 \pi t}{f}+\delta\right)+\epsilon_{t}$

where for each time series (here LTS) $y_{t}$ over time $t$ a harmonic model is defined by the amplitude $\gamma$, the phase $\delta$, the frequency $f$ of the number of occurring observations per year, an overall mean response $\alpha_{1}$ and a slope $\propto_{2}$. Data noise is expressed using the remainder component $\varepsilon_{t}$. Secondly, the model is extrapolated to the monitoring period and is compared to the actual data of the monitoring period. If the absolute value of the moving sums (MOSUM) of the residuals during the monitoring period is significant, a break is detected (Verbesselt et al., 2012b, 2010b). To better compare results of the time series analysis, the $\mathrm{VI}$ ranges have been rescaled from 0 - 1 using the global maximum and minimum of the time series for each site.

\subsubsection{Reference data and accuracy assessment}

Overall accuracy, user's accuracy (inversely related to commission error), producer's accuracy (inversely related to omission error), and bias (bias = user's accuracy - producer's accuracy) have been calculated (Foody, 2002; Hamunyela et al., 2016). Confidence intervals for accuracies were calculated for stratified random sampling (Congalton, 1991; Olofsson et al., 2014) which takes true marginal map proportions into account (Card, 1982). Reference points were randomly selected in each of the 8 maps produced; 100 within areas identified as deforested and 30 within areas not affected by deforestation, leading to 1040 (8 times $30+100)$ reference points per site. Each site's reference points were randomly split into an equal-size training and validation set. The training set was used to train the random forest based data fusion, while the validation set was used for the accuracy assessment and the binary logistic generalized linear models (GLM) described in the next section. To determine the occurrence of deforestation, each reference point was visually interpreted for the extent of a Landsat pixel and its eight directly neighbouring pixels using an annual time series (2009-2013) of high-resolution data (Spot 5 and RapidEye).

\subsubsection{Vl's sensitivity to observation frequency}

Observation frequency is the amount of all valid (cloud free and cloud shadow free) observations during the study duration (2000 - 2013), which varied within and across sites (Table 4.1). A model was created using reference pixels depicting the relationship between the ability of the VI to map deforestation and the observation frequency. For all reference points, the observation frequency was used as a predictor variable within a GLM for the binary outcome of either correct outcomes (correctly identified deforestation) or incorrect outcomes (commission and omission of deforestation). Based on that, the probability of mapping deforestation successfully was calculated for each VI at each site using a logistic fit for the probability $\pi$. This was constructed using ordinary least squares as a fitting method. $\beta_{0}$ and $\beta_{1}$ are the regression variables and $X_{1}$ the amount of valid observations. The GLM (Eq. 4.12) and the related probabilities $\pi$ (Eq. 4.13) are:

$\ln \left(\frac{\pi}{1-\pi}\right)=\beta_{0}+\beta_{1} X_{1}$

$\pi=\frac{e^{\beta_{0}+\beta_{1} X_{1}}}{1+e^{\beta_{0}+\beta_{1} X_{1}}}$ 
The VIs sensitivity to observation frequency was defined as the difference between the maximum and minimum probability of deforestation monitoring success (Eq. 4.14). A high value of difference expresses a high sensitivity to the observations frequency while a low difference expresses the opposite.

VI sensitivity to observation frequency $=\pi_{\max }-\pi_{\min }$

\subsubsection{Data fusion}

In order to test the potential of combined VI deforestation maps to improve mapping accuracy, VIs were fused at feature level using a random forest classification scheme (Gislason et al., 2004; Gutiérrez-Vélez and DeFries, 2013; Immitzer et al., 2012). First, for each site all combinations of any number of the eight VIs (255 per site) making use of up to 8 maps in one fusion product were calculated. These were fed into a supervised random forest classification to identify if a fused map exists that produces higher accuracies than the individual maps. The combination of maps to fuse was classified using a random forest with 500 trees, of 5 nodes. The algorithm was trained using the training set of the reference data described in section 2.5. As an alternative for testing all combinations ( 255 combinations mentioned above) we used the Bayesian information criterion (BIC) as a selector for a site VI combination. BIC was used within a GLM, and compared to testing all combinations is more statistically valid particularly if processing time is scarce. BIC penalizes a large number of free parameters and therefore aims to select few VIs while maintaining high fusion potential (Akaike, 1973; Schwarz, 1978). Naturally, the selection of the VIs by BIC is a subset of all possible combinations. The reference training set was modelled for each site using the information at the designated reference points from all 8 maps. Stepwise BIC was used to identify the best model fit and, therefore, potentially the best map combination. The best BIC combination of VI deforestation maps was then fused for each site using random forest as described earlier.

\subsection{Results}

\subsubsection{Detection of deforestation in 3 sites by 8 VIs}

Figure 4.2 showed representative examples of time series for the same pixel per site for each VI. The figure demonstrated the complexity of deforestation monitoring. For example in Brazil, BFAST Monitor captured a drop of the vegetation signal within the historic period (2005) of a similar magnitude as the 2011 deforestation signal. However, it demonstrated the ability of BFAST Monitor to account for disturbances occurring in the historic period, while still being sensitive to changes occurring within the monitoring period. Overall the intensities and the amplitude of the time series highly varied among sites and VIs. Brazil's EVI and GEMI signal intensities were most spread among the tested VIs. NDFI, NDMI and NDVI has similar intensity patterns with a particularly high saturation of the intensity for NDVI and NDFI values. Both Tasselled Cap VIs showed least fluctuations in intensity and provided a stable signal with a slight signal drop when deforestation occurred.

Ethiopia's seasonal signal had smaller amplitudes than in the other sites, and deforestation appeared as a long gradual negative trend. Even though EVI's linear BFAST component showed a slight positive trend, the signal drop within the monitoring period was detected. The linear component of GEMIs signal showed a positive trend demonstrating the VIs inability to distinguish a clear loss of trees occurring during a deforestation event from seasonality and variations of a stable vegetation signal. Outliers within GEMI time series could not be distinguished from good observations. The contrast between GEMI and NDFI could be observed in Brazil, where the NDFI was characterized by a high capacity to 
differentiate a stable vegetation signal from a deforestation signal, and the GEMI signal was characterized with extreme values. SAVI, NDMI and NDVI showed similar characteristics in the Brazil case but the NDVI's outliers were more frequent and were not easily distinguishable from the remaining signal, suggesting that this VI was less robust than the NDMI. The Tasselled Cap related indices also behaved similarly; however, in Brazil the greenness is characterized by a higher range of intensity values.

Vietnam's time series typically had a stable historic period and abrupt drops in intensity of the signal signalling deforestation events. The EVI's stable signal was not as low as in Ethiopia but lower than in Brazil. Also in Vietnam the GEMI signal was not capable of distinguishing the vegetation signal from the deforestation event. The remaining VIs showed similar signals as in Ethiopia. However, the absolute values of the SAVI and the TCg in particular, varied among the sites suggesting that these VIs were more sensitive to ecosystem type.

Brazil

EVI

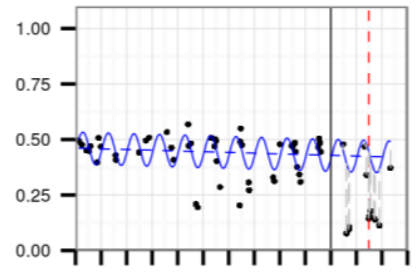

GEMI

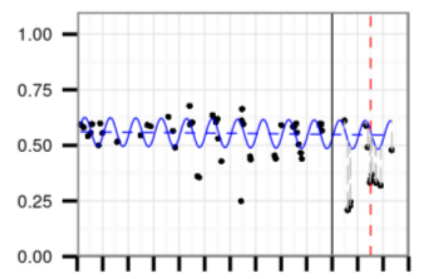

NDFI

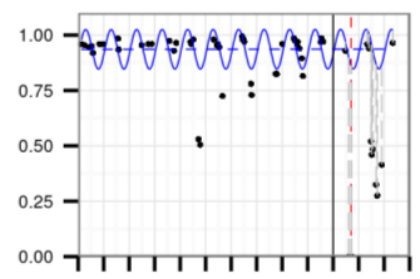

NDMI

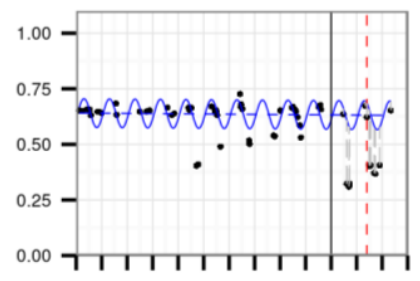

Ethiopia
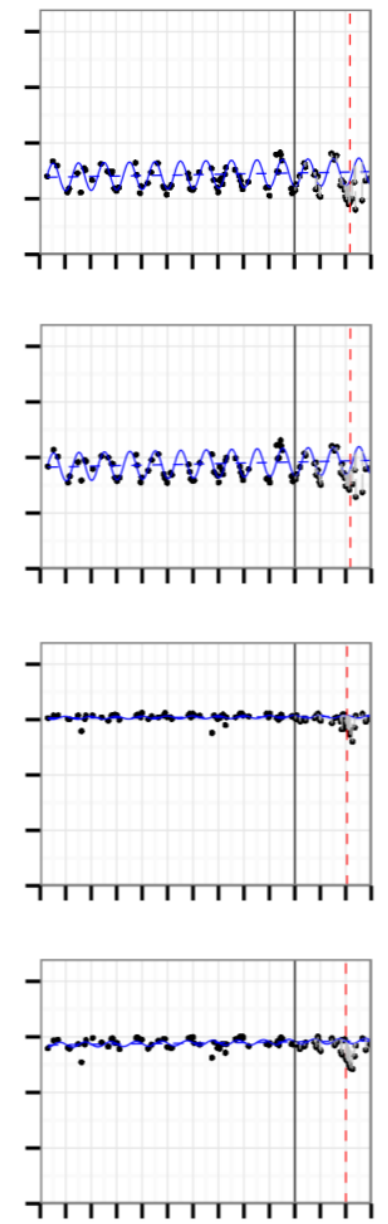

Vietnam
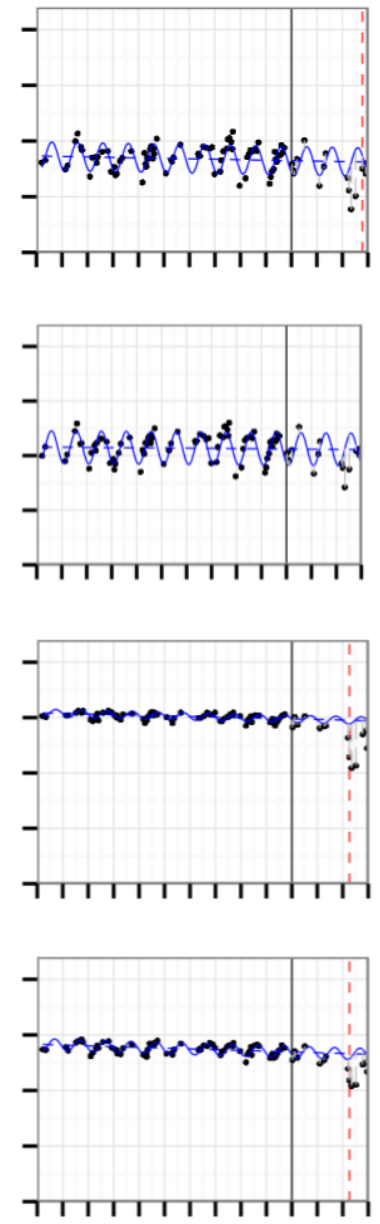
Chapter 4
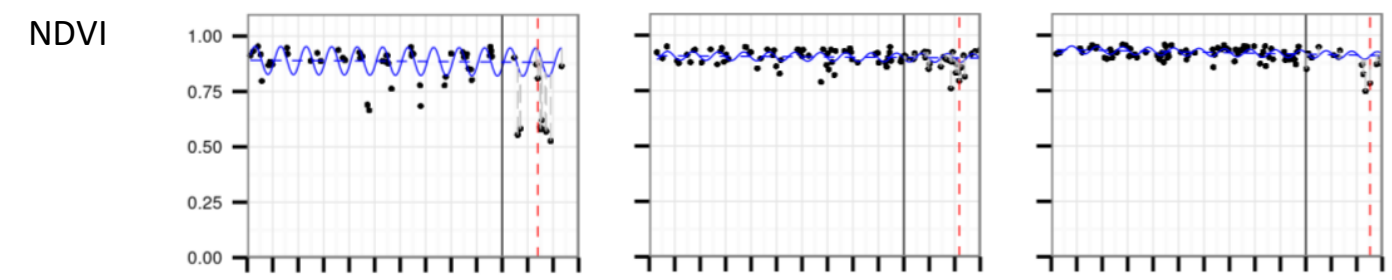

SAVI
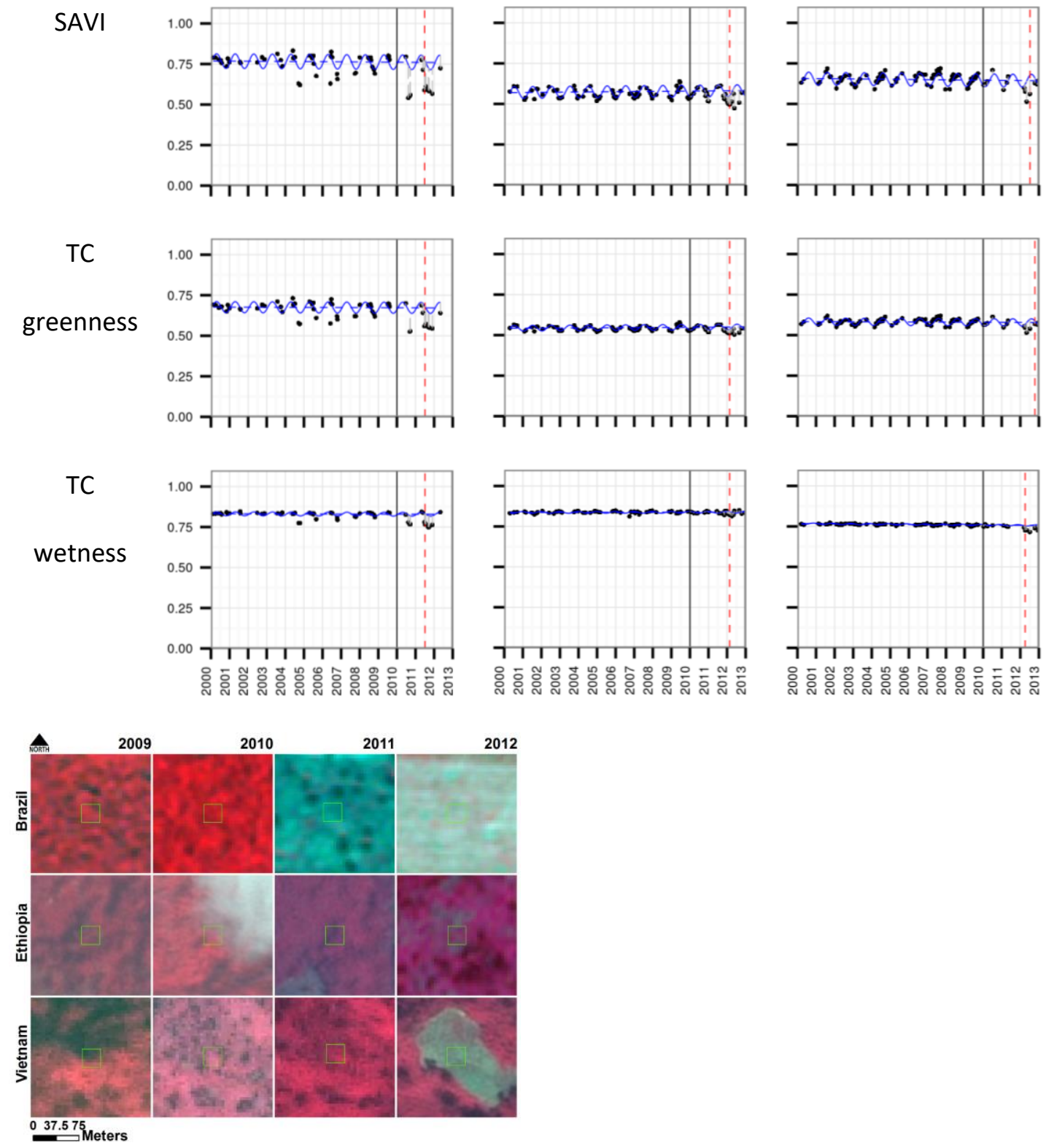

Figure 4.2 Time series plots depicting the signal for each $\mathrm{VI}$, for one representative pixel per site. $\mathrm{VI}$ values are rescaled to $0-1$. Blue lines depict the linear and harmonic component of the BFAST Monitor model, the vertical black line divides the time series in the historic period (left) and the monitoring period (right) while the vertical red line indicates the occurrence of a break within the monitoring period. Deforestation occurrence for this pixel was 2011 in Brazil and Ethiopia, and 2012 in Vietnam. The 
boxes in the bottom are high-resolution false colour composites ( $R=N I R, G=$ Red, $B=$ Green) related to the Landsat pixel (green envelope) displayed for each site shown above.

\subsubsection{Accuracy assessment of deforestation estimates from $8 \mathrm{Vls}$}

The overall accuracies in detecting deforestation for the VIs varied by site and by index (fig. 4.3). Overestimation of change occurred more commonly than underestimation. Satisfactory accuracies $(>80 \%)$ were achieved for the Brazilian and the Vietnamese sites, while accuracies in Ethiopia were lower. Overall accuracies of the individual VIs were similar among the Vietnam and Brazil sites but Vietnam's site is characterized by higher producer's accuracies. Among the indices tested, the NDFI, the $\mathrm{NDMI}$ and the TCw performed comparatively well. Overall, the most successful $\mathrm{VI}$ at detecting deforestation was the NDFI (highest accuracies) and the least successful was the GEMI. Indices like the EVI or SAVI are closely related to the NDVI, but performed consistently worse. The SAVI performed particularly well in Ethiopia.

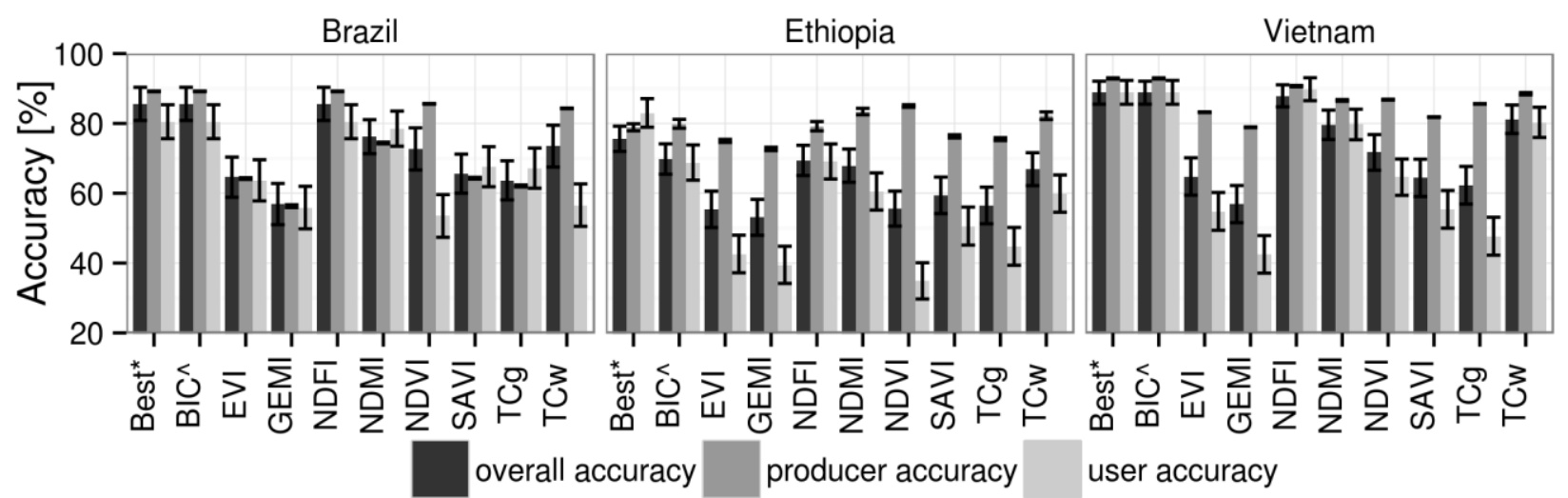

Figure 4.3 Overall accuracy, producer's accuracy (100-omission error) and user's accuracy (100commission error) for the detection of deforestation using the eight indices (EVI, GEMI, NDFI, NDMI, NDVI, SAVI, TCg, TCW) for three study sites (Brazil, Ethiopia, Vietnam). * can be a combination of multiple VIs. Best* for Brazil = NDFI; Ethiopia = EVI, GEMI, NDFI, SAVI and TC wetness; Vietnam = NDFI, NDVI, TCW. BIC^ for Brazil and Vietnam is the same as Best*; Ethiopia = NDMI and TC wetness.

\subsubsection{Impact of observational frequency}

The site-specific VI sensitivity to the detection (binary: correct or not correct) of a deforestation event using GLMs is described in figures 4.4 and 4.5. Among all sites the observation frequency was a determinant for the success of a VI in detecting change. In Vietnam, which is characterized by a highly varying observation frequency (45-110 observations per pixel) for all VIs, probabilities of success were influenced by the observation frequency, with probabilities varying by 0.5 for almost all indices when observation frequencies were varied (fig. 4.5).

In Ethiopia observation frequency was not as important when determining the success rate for most of the VIs except for the NDFI and the NDVI. In Brazil, the NDFI gave the most stable mapping performance regardless of the observation frequency. A time series with 40 observations had a probability of 0.7 to map deforestations correctly and with 80 observations a probability of 0.8 . This is in contrast to the SAVI, which had a probability of 0.25 at 40 observations and a probability of 0.74 at 80 observations, showing major sensitivity to observation frequency. Across all sites, the NDFI, NDMI and TCW handled 
varying observation frequencies best, as determined by their lowest difference in maximum and minimum probability values among all the VIs.
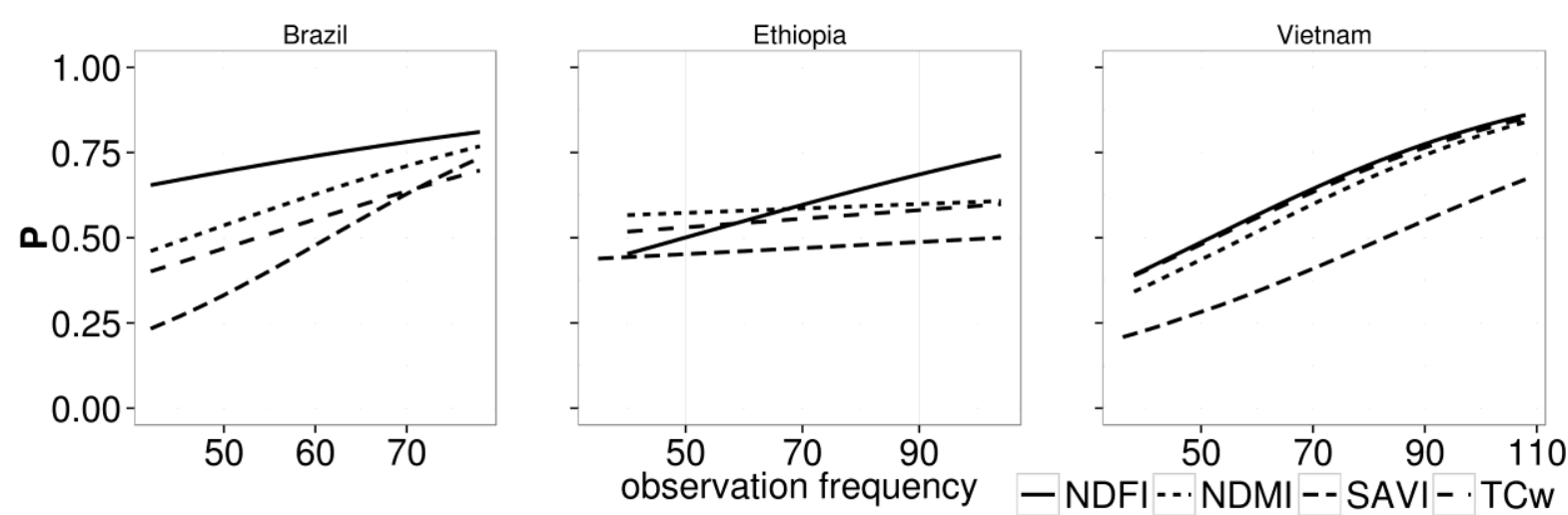

Figure 4.4 Probabilities $(P)$ for detecting a deforestation event in relation to the observation frequency for a selection of VIs.

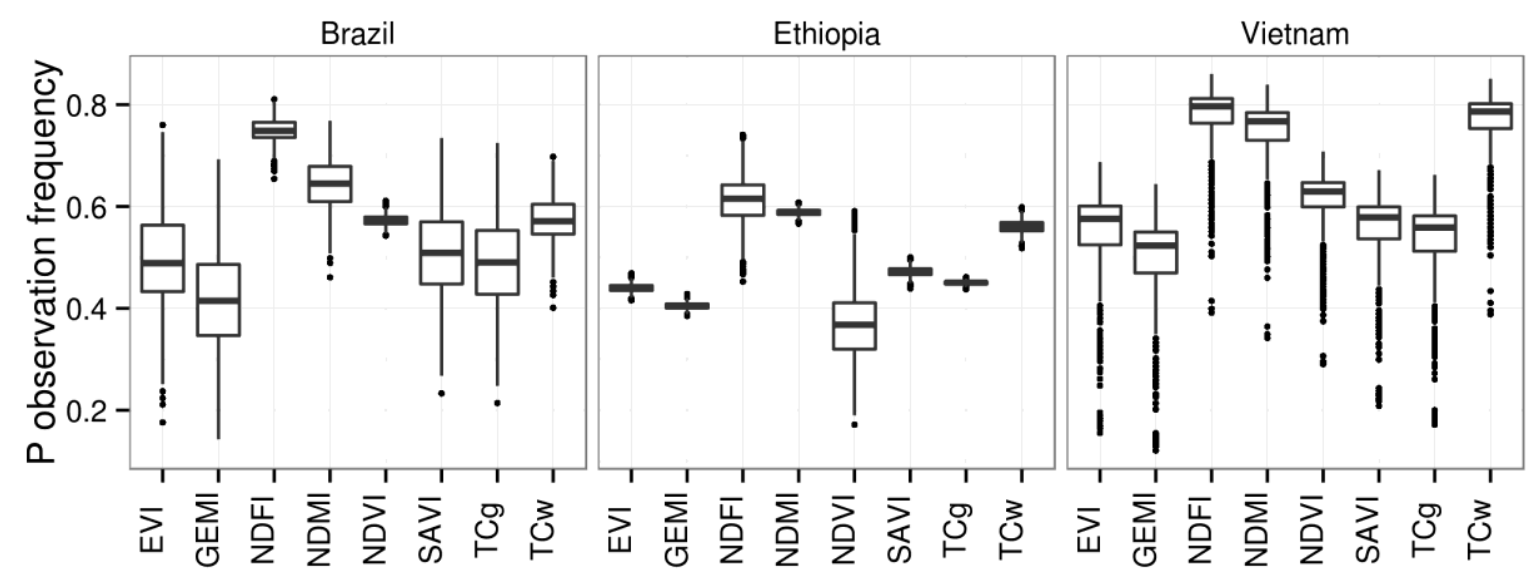

Figure 4.5 Boxplots of probabilities (P) of correct identification of deforestation for all VIs. Note that VIs' performance differs by varying observation frequency

\subsubsection{Fusion of VIs}

Combining different maps can improve mapping accuracies and reduce bias, as was demonstrated in Ethiopia and Vietnam (fig. 4.6). In Brazil however, the fusion of maps did not improve overall accuracy, as the NDFI (85.6\% overall accuracy) remained the top scoring VI. The NDFI is part of the 71 top ranking fusion maps. The best fusion map which did not make use of the NDFI (a mixture of NDMI, NDVI and SAVI) achieved a 78.8\% overall accuracy. Most VIs overestimate change and, when fused, have an increased producer's accuracy. For instance, when NDVI and NDFI are fused the resulting user's accuracy decreased (-4.6\%) and producer's accuracy increased (+3.9\%) in comparison to using NDFI alone in Brazil. In Ethiopia the independent usage of a VI overestimates change and fused maps resulted in an increase of all accuracy measures. The improvement from the single VI with the highest overall accuracy (NDFI, 69.4\%) to the best VI combination (EVI, GEMI, NDFI, NDMI, SAVI, TCW) was more than 6\%. When fusing just two VIs (e.g. GEMI and NDFI) the accuracy was improved by up to $5 \%$. While the NDFI is the 
top scoring $\mathrm{VI}$ in Ethiopia it can be replaced by a combination of other VIs (e.g. fusion of GEMI, NDMI, SAVI, TCW) which improved overall accuracy by $~ 5 \%$. The data fusion combination, which results from the BIC analysis (NDVI, TCW), performed slightly better than NDFI alone. For Vietnam, the BIC combination and the best possible combination were identical (NDFI, NDVI, TC wetness, $88.8 \%$ ).
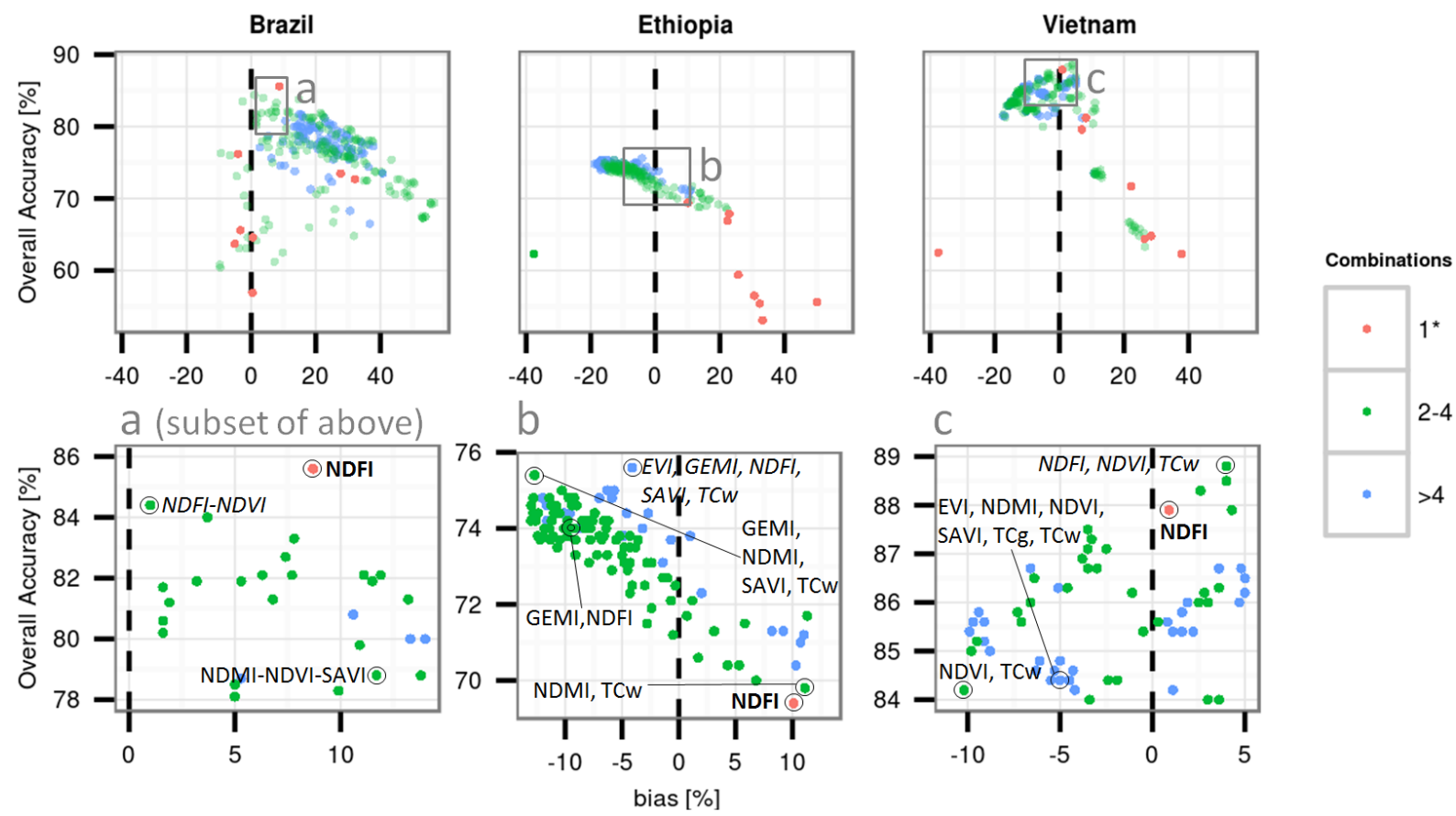

Figure 4.6 Plots depicting bias and overall accuracy for all possible fusion combinations, ${ }^{*}$ red dots (single $\mathrm{VI}$ ) are same accuracies as depicted in figure 4.3. The lower graphs are subsets of the above. Positive bias indicates that errors produced by overestimation are higher than by underestimation of change, and the opposite is true for a negative bias. Emboldened VIs are the individual top performers without data fusion, italicised VIs are the combination creating the highest overall accuracy, other symbols are explained in the text.

\subsection{Discussion}

We assessed the performance of VIs for tropical deforestation mapping using BFAST Monitor on LTS. Within this section research objectives as previously stated, were answered and discussed successively. More general discussion points were provided at the end of the section.

- Identify the most spatially accurate VI for deforestation mapping when applying BFAST Monitor to LTS

The most spatially accurate VI tested in this study was the NDFI (fig. 4.7). Previous studies confirm the NDFIs suitability for deforestation mapping, since the NDFIs estimate of canopy cover closure is highly correlated to deforestation and forest degradation (Herold et al., 2011; Hirschmugl et al., 2014; Morton et al., 2011; Souza et al., 2013). Based on the full radiometric resolution available, the rationing of GV, NPV, soil and shade provided a TS signal robust to noises and sensitive to deforestation. Next best accuracies were produced by the wetness related VIS NDMI and TCW. These VIs are highly correlated to forest disturbances (Jin and Sader, 2005) since both make use of SWIR1 ( 1.5 $\mu \mathrm{m})$ and NIR ( $0.7 \mu \mathrm{m})$. The wavelengths were found to be sensitive to canopy water content and suited for forest change 
mapping as demonstrated elsewhere (DeVries et al., 2015b). Greenness related VIs (GEMI, EVI, NDVI, SAVI, TCg) were least successful, in they were not able to properly isolate the change signal from noise and could not provide a TS signal suitable for deforestation detection. Their sensitivity to leaf pigments was less useful than the wetness related VIs' sensitivity to canopy water content. The EVI and the SAVI performed similarly to the NDVI, while overall the SAVI outperformed the EVI in Ethiopia where forest was less dense and exposed more soil than in the other sites. Hence, the SAVI was more accurate than the NDVI or the EVI, with other studies confirming these findings (Huete et al., 1997).

- Understand the VIs spatial accuracy regarding its sensitivity towards observation frequency per site (Brazil, Ethiopia, Vietnam)

VIs' sensitivity to observation frequency varied across sites. No single VI was able to provide consistent high accuracies regardless of the observation frequency. Some VIs are particularly sensitive to observation frequency when deforestation occurred gradually, for example in Ethiopia the NDFI, and the NDVI and when deforestation is abrupt, for example in Vietnam and Brazil all VI except NDFI, NDVI are sensitive to observation frequency. Overall the NDVI and the NDFI were least sensitive to observation frequency (fig. 4.7). With few observations available the NDFI was able to provide the best deforestation estimates, however when deforestation was gradual (Ethiopia) NDFI mapping accuracies increase with observation frequency. Other VIs at that site were less sensitive to observation frequency, as found in (Schultz et al., 2016b) and their insensitivity to the type of deforestation within different ecosystems is a bigger constraint to their mapping success than a lack of observations. Among the VIs tested, in Ethiopia, the NDFI is the only with the potential of provided high mapping accuracy with higher observation frequencies. Across sites, in general high ranges of observation frequencies probabilities suggest that most VIs would benefit from more observations.

- Explore the potential of feature level data fusion of VIs to complement each other and increase accuracy

Most VIs tended to overestimate change, but when fused they created more realistic area statistics. The best synergy was achieved with NDFI and TCW (fig. 4.7), which both tap into the full radiometric information provided by the sensor but potentially complement each other well by focusing on GV (NDFI) and on wetness (TCW), each covering a different and therefore complementary source of information related to deforestation. Combinations of other VIs, which individually performed worse than the NDFI, could outperform the NDFI. Thus, feature level data fusion could produce better results for deforestation monitoring than the application of individual VIs. For the Brazilian site most indices had a low bias, which might be related to the simple nature of the deforestation type there. Since the forest is used for production, large-scale clearing occurred periodically and was therefore identified by the VIs. The deforestation detection in Brazil was however challenged by the occurrence of clearings to establish new plantations during the historic period. Commission errors were occurring because of uncorrected atmospheric effects as reported in (Schultz et al., 2013). Detection of complex deforestation in Ethiopia benefited greatly from feature level data fusion and in Vietnam bias was reduced. In this paper, data fusion involved testing each possible combination, which could be prohibitive for large scale applications due to the large processing power required. However, using the $\mathrm{BIC}$ an approach was presented to find a successful feature level VI fusion using a GLM. Often the BIC suggested a meaningful combination of VI (comparable to the outputs from the other analysis) while keeping the number of VIs involved lower. Selecting a fusion combination based on BIC is therefore a 
useful alternative if all potential combinations cannot be calculated but a good selection of VIs is desired.

Besides the research objectives, two further insights were noted in this study. First, both Tasselled cap measures showed very low time series variances (fig. 4.7), suggesting a strong resilience's towards noise. However, earlier studies showed that a specific level of signal variance was required for a successful application of BFAST Monitor (DeVries et al., 2015b; Schultz et al., 2016b). Although the two aforementioned tasselled-cap VIs produced very low LTS variances (fig. 4.7), their performance differed largely. This confirmed that although time series variance is important, it's more important for a successful BFAST Monitor application that a VI signal sensitive to deforestation at the site of interest is provided. Secondly, although the NDVI is the most frequently used VI (supplemental material) for deforestation mapping in the tropics, its performance compared to other VI does not justify this degree of use. This frequent use may be because mapping accuracy is not the main objective when selecting a VI for tropical deforestation mapping or analysts are unaware of NDVI's shortcomings.

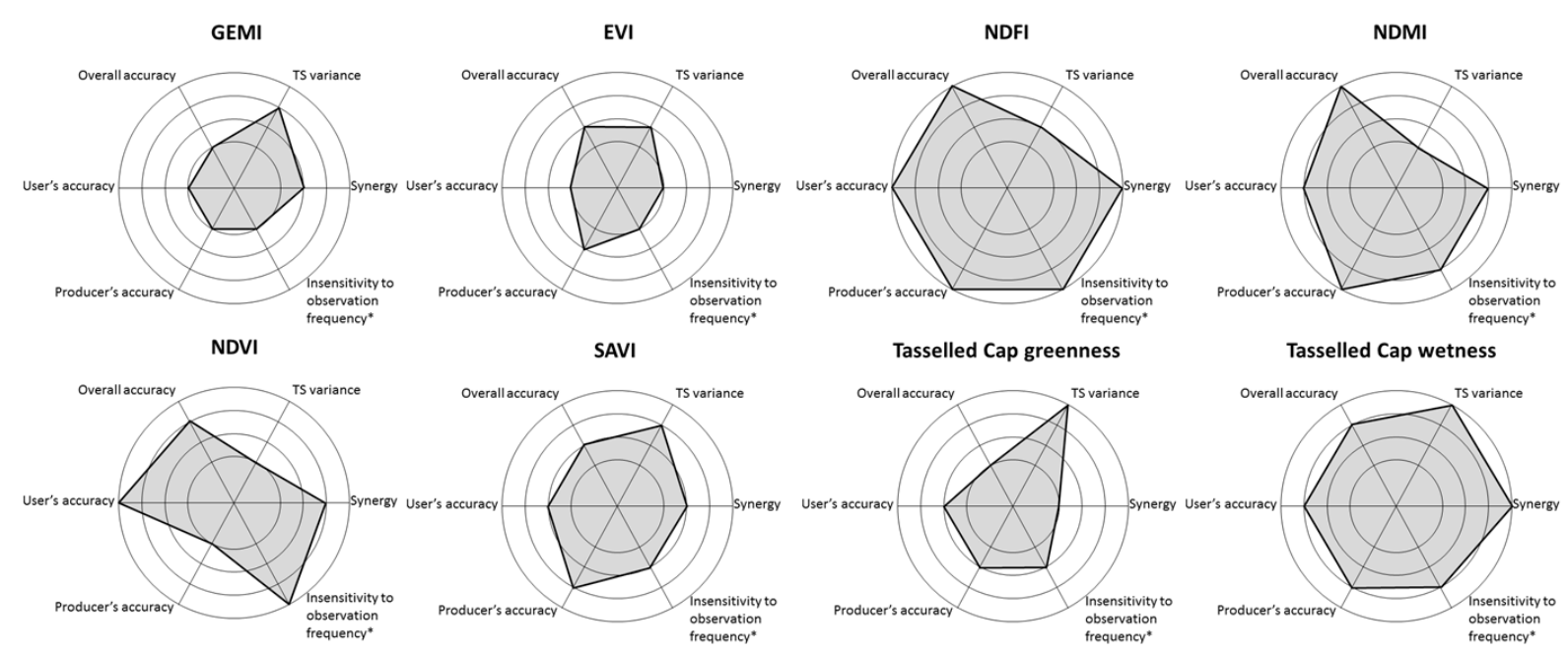

Figure 4.7 Summary of relative VI performance. Spider web nodes at the outer circles indicate high performance, nodes close to the web centre indicate poor performance. Within the categories, VIs were sorted according to their performance and divided into four quantiles, hence each category's quantile is represented twice within the figure. Overall accuracy (across sites, mean overall accuracy), user's accuracy (across sites, mean user's accuracy), producer's accuracy (across sites, mean producer's accuracy), *insensitivity to observation frequency opposite of sensitivity to observation frequency (across sites, inverted VI's mean sensitivity to observation frequency), synergy (across sites, sum of VI's occurrence in top ten highest overall accuracy fused maps), TS variance (across sites, inverted mean variance of VIs historic period)

\subsection{Conclusion}

This paper compared VIs' performance of LTS for deforestation monitoring using BFAST Monitor. VIs were tested in different sites across the tropics and accuracy statistics based on reference data were produced, for each VIs, its fusion suitability and its sensitivity to observation frequency. A canopy cover sensitive VI (NDFI) performed better than wetness related VIs (NDMI, TCW) and greenness related VIs (EVI, GEMI, NDVI, SAVI, TCg) performed the worst. For tropical deforestation monitoring, we expect an increased use of indices making use of the full radiometric resolution of Landsat data, such as the NDFI. 
Additionally, wetness (TCW) and/or SWIR1/NIR based indices (NDMI) will be selected over NIR/RED based indices (NDVI, EVI, SAVI). The sensitivity of a VI to observation frequency varied depending on the site. Mapping results of NDFI and NDVI were most insensitive overall to observation frequency while the other VIs benefited most from increased observation frequency. The Ethiopia site was an exception because deforestation was difficult to detect within a landscape with complex forest change processes and the NDFI was the only VI which achieved acceptable performance. Fusing deforestation maps based on different VIs increased overall mapping accuracy and consequently reduced overestimation of change. Landscapes characterized by subtle deforestation processes (Ethiopia, gradual expansion of coffee plantation in forests) benefited more from feature level data fusion than landscapes with abrupt deforestation processes (Vietnam, slash and burn; Brazil, plantation forest). In the presence of endmembers the NDFI was the VI with highest performance and also when fused with other VIs. If the SMA which is necessary for the NDIF could not be performed, other VIs (TCg, NDVI, NDMI) produced similar mapping accuracies to the NDFI when fused.

\subsection{Acknowledgments}

This work was funded by the German federal ministry of science and education (BMBF) LUCCI project and the research was carried out within the facilities of Wageningen University. Thanks go to black bridge company and the planet action organization for providing high resolution satellite data. We thank the USGS for making the Landsat data available and we thank the entire remote sensing community for their hard work of creating a better tomorrow using state of the art technologies. 
Chapter 5

\section{Chapter 5}

Forest cover and vegetation degradation detection in the Kavango Zambezi Transfrontier Conservation Area using BFAST Monitor

Michael Schultz, Aurélie Shapiro, Jan G.P.W. Clevers, Craig Beech and Martin Herold

Under review in Remote Sensing special Issue "Remote Sensing of Tropical Environmental Change" 


\begin{abstract}
Forest cover and vegetation degradation was monitored across the Kavango-Zambezi Transfrontier Conservation Area (KAZA) in southern Africa and the performance of three different methods in detecting degradation was assessed using reference data. Breaks for Additive Season and Trend (BFAST) Monitor was used to identify potential forest cover and vegetation degradation using Landsat Normalized Difference Moisture Index (NDMI) time series data. Parametric probability-based magnitude thresholds, non-parametric random forest in conjunction with Soil Adjusted Vegetation Index (SAVI) time series, and the combination of both methods were evaluated for their suitability to detect degradation for six land cover classes ranging from closed canopy forest to open grassland. The performance of degradation detection was largely dependent on tree cover and vegetation density. Satisfactory accuracies were obtained for closed woodland (user's accuracy $87 \%$, producer's accuracy $71 \%$ ) and closed forest (user's accuracy 92\%, producer's accuracy 90\%) and lower accuracies for open canopies. The performance of the three methods was more similar for closed canopies and differed for land cover classes with open canopies. Highest user's accuracy was achieved when methods were combined and best performance for producer's accuracy when random forest was used.
\end{abstract}




\subsection{Introduction}

The Kavango-Zambezi Transfrontier Conservation Area (KAZA) is the largest transboundary conservation area in Africa and home to a large diversity of animal species, including a major part of the Upper Zambezi basin and the Okavango basin and delta. It includes the Caprivi Strip of Namibia, southeastern Angola, southwestern Zambia, the northern wildlands of Botswana and western Zimbabwe. The changes in climate regimes and increased human activities are driving human-wildlife conflicts (HWC). From 2007 - 2014 large animal herds have changed their movement patterns for several reasons, increasing chances of HWC within KAZA (Naidoo et al., 2014). Related economic losses have been incurred further fueling the spiral of HWC (Naidoo et al., 2016). When animal movement patterns and human-induced land change are known, planned and managed wildlife corridors can be a suitable solution to manage HWC (Metcalfe and Kepe, 2008). Such efforts are equally important for nations in slowing down forest decline and conserving or increasing carbon sink capacities of forests, promoted by Reducing Emissions from Deforestation and forest Degradation (REDD+) projects (Scholz and Schmidt, 2008). Monitoring, Reporting and Verification (MRV) of activity data (Herold and Skutsch, 2011) has been proven to create additional revenues when properly implemented (TÜV SÜD, 2018), providing operational financial alternatives to land use change moving away from more exploitative approaches (Nellemann, 2012). Bitemporal remote sensing based measurements of locations with human induced land change in the KAZA area were completed previously for subsets of the area (Petit et al., 2001). In particular, the Caprivi strip is a common study area, showing an ongoing human expansion of cropland and settlements and a transformation of closed woodland into secondary woods and shrub lands (Kamwi et al., 2017). A long-term study from 1975 - 2014 used decadal remote sensing data observing an acceleration of such trends (Wingate et al., 2016). Ecosystems in that area were impacted by an abundance of factors, such as the El Niño-Southern Oscillation (Mason, 2001), large-scale burning (Roy et al., 2008), and flooding events (Pekel et al., 2016). In comparison to other areas, uncertainties of remote sensing based measurements in savannah land cover types were particularly high (Avitabile et al., 2016a). Isolation of ecosystem variability and anthropogenic degradation was achieved using high temporal resolution coarse spatial resolution time series for small areas (Pricope et al., 2015). Other large-scale applications on continental or national scales have been achieved using sample-based approaches (Brink and Eva, 2009; Lambin and Ehrlich, 1997), (Mosugelo et al., 2002). For KAZA, no large-scale study exists where spatially explicit recent land degradation is measured satisfying current mapping and reporting practices (Olofsson et al., 2014). Long-term consistent observations have been used to measure global changes in tree cover, but these studies focused on dense forest and tended to exclude or omit detection in savannah landscapes and bushlands which are predominant in KAZA (Woodcock et al., 2008), (Hansen et al., 2013). Breaks For Additive Season and Trend (BFAST) (Verbesselt et al., 2010b) type models have been used to measure forest decline across the tropics (DeVries et al., 2015b; Pratihast et al., 2014; Schultz et al., 2016a, 2015), but in contrast to (Hansen et al., 2013) application remained local, similar to radio detection and ranging (RADAR) and optical time series fusion approaches (Reiche et al., 2018, 2015). The more popular BFAST Monitor (BFM) (Verbesselt et al., 2012a) applications have been found to be used robustly with different data streams (Dutrieux et al., 2015), to describe patterns of anthropogenic forest change (Jakovac et al., 2017), for reconstructing land use history (Dutrieux et al., 2016), track regrowth dynamics after degradations (DeVries et al., 2015a), in combination with community-based monitoring (Pratihast et al., 2014), for long-term studies (Murillo-Sandoval et al., 2017) and also to map vegetation decline in arid and semi-arid environments (Maynard et al., 2016; Watts and Laffan, 2014). Preferred sensors were most often on Landsat satellites, where BFM results 
were often post-processed using the so-called magnitude of change. Potential changes were determined using either a threshold (DeVries et al., 2015b) or a random forest (Breiman, 2001) machine learning algorithm to classify magnitude values (DeVries et al., 2016; Pratihast et al., 2014; Schultz et al., 2016a). Using BFM, multiple forest types were studied regarding their biomass and changes, mostly excluding sparsely vegetated areas (Urbazaev et al., 2016). To date no large-scale application of BFM exists where vegetation degradation is measured for a range of ecosystems from open to closed canopy, or from moist to dry vegetation.

KAZA is characterized by a gradient of vegetation cover ranging from closed woodlands in the northern parts to open grasslands in the south. Only few BFM studies exist which apply accurate estimation of changes (Olofsson et al., 2014) including reporting accuracy confidences (Card, 1982), besides existing consolidated standard measures (R. Congalton, 1991) as they require exhaustive reference data. We studied the performance of degradation detection using BFM for different canopy cover types, using modifications of existing methods (DeVries et al., 2015b; Schultz et al., 2016a), accounting for good practices and introducing a new method by combining the two aforementioned. Studies within similar setups (DeVries et al., 2015b; Liu et al., 2018; Pratihast et al., 2016; Schultz et al., 2016a) used the normalized difference moisture index (NDMI) $($ Gao, 1996) or the soil adjusted vegetation index (SAVI) (Huete, 1988). Aforementioned accuracies were generally moderate ranging approximately around 70$80 \%$, mostly lacked comprehensive reporting and did not split observed land into specific land cover classes. Particularly, commission of change was identified as a large error source for BFM applications (Schultz et al., 2015). We combined advantages of existing non-parametric random forest based methods (Schultz et al., 2016a), field data time series fusions (DeVries et al., 2016; Pratihast et al., 2016) and conservative parametric magnitude threshold-based approaches (DeVries et al., 2015b) to identify the suitability of BFM to detect land cover degradation related to forest and vegetation. Main objective of this study was to assess the performance difference in degradation detection for six different classes in KAZA using BFM. In this respect, post-processing of threshold-based and random forest based BFM were compared in terms of the accuracy of detecting degradation. Finally, the effectiveness of combining both threshold-based and random forest based BFM post-processing methods was studied.

Three research questions were addressed:

- How does degradation detection performance differ for six different land cover classes in KAZA using BFM?

- How does threshold based and random forest based BFM post-processing for degradation detection compare?

- How are method variations impacting degradation detection accuracy and how to combine threshold based and random forest based BFM post-processing methods effectively?

\subsection{Methods}

Figure 5.1 provides an outline of the current study. A description of the study area and relevant land cover classes subjected to degradation detection are provided in section 5.2.1. Landsat derived NDMI and SAVI data from the United States Geological Survey (USGS) were used for the degradation detection. Data pre-processing, time series construction and time series analysis are presented in section 5.2.2. This includes statistical tests of the SAVI and NDMI time series for the occurrence of significant signal drops from 2006 - 2016 compared to 1984 - 2005 observations using BFM. In contrast, vegetation changes only caused by seasonality were considered as stable vegetation (no change) 
(Verbesselt et al., 2012a). Section 5.2.3 describes reference data used for accuracy assessment and for method calibration. Part of the reference data were used for a threshold-based approach (DeVries et al., 2015b), a random forest feature level fusion based approach (Schultz et al., 2016a), and their combination to understand BFM suitability for the detection of land cover specific degradations (section 5.2.4).

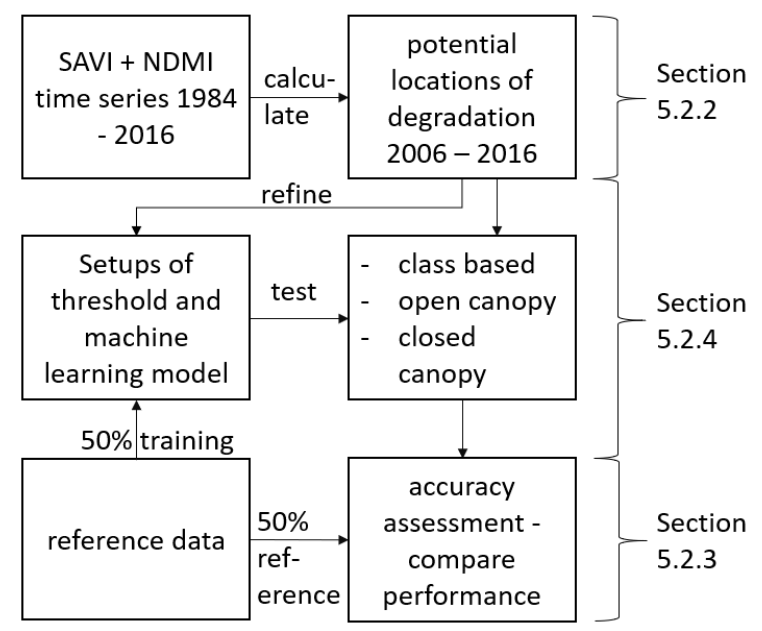

Figure 5.1 Overview of the methods applied in this study

\subsubsection{Study Area}

KAZA comprises mixed savannah and dry forest landscapes with large grassland ranges, the world's largest inland delta and dense bushlands and forested areas with a highly varying vegetation canopy (Figure 5.2). Tree cover increases from south to north. In addition to the effects of human activities, land cover is impacted by varying dry and wet seasons and responses in spectral reflectance factors vary throughout the year. The near-infrared (NIR) and shortwave infrared (SWIR) bands are especially sensitive to these variations as foliage disappears in the dry season and reoccurs again in the wet season. Land cover in 2005 was identified from existing products (Pekel et al., 2016; Thompson, 2014) and the identification of natural vegetated areas at $30 \mathrm{~m}$ resolution for the year 2005 (Thompson, 2014) was used as benchmark map. We updated locations of wetlands using global surface water data (Pekel et al., 2016) and applied a minimum mapping unit of 0.5 ha for all land cover types subjected to the degradation analysis. Table 1 provides an overview of the identified classes and Figure 5.2 shows locations of the six vegetated land cover classes $(a-f)$ that were considered for the degradation detection. In 2005, closed canopy woodland (CW) was predominantly covered by trees and underlying herbaceous species covering roughly $5 \%$ of KAZA. Closed canopy forest (CF) was characterized by multiple vegetation strata and a closed tree cover, occupying about $4 \%$ of the study site. Closed canopy bushland (CB) covered about $2 \%$ of KAZA and it is the smallest considered land cover class consisting of medium sized canopy short bushlands and shrub vegetation. One fifth of KAZA was covered by open canopy woodland (OW) and about half of the study site was occupied by open canopy bushland (OB). A tenth of KAZA was open grassland (OG) with almost no bush, shrub or tree presence. Other land covers included anthropogenic categories, wetland and/or water areas, bare land and rocks which were not addressed in our investigations. 


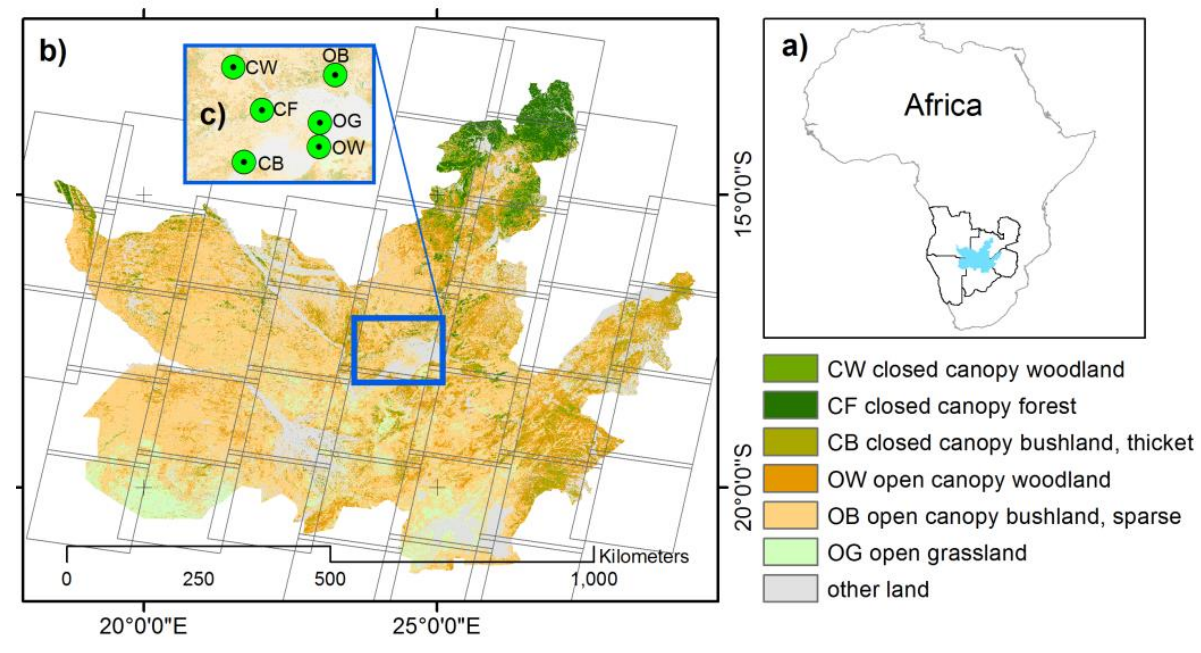

Figure 5.2 a) black lines are borders of countries covered by Kavango Zambezi Transfrontier Conservation Area (KAZA) (blue blob) clockwise from top left: Angola, Zambia, Zimbabwe, Botswana and Namibia; b) land cover in 2005 for the KAZA study site, grey frames show Landsat tiles used; c) shown in blue subset of KAZA green ribbon, dots are the examples of land cover sites visited during field trip where degradation occurred as displayed in figure 5.3

Table 5.1 classes and their definition, class $1-6$ were subjected to anthropogenic degradation detection (Pekel et al., 2016; Thompson, 2014)

\section{\# Class name}

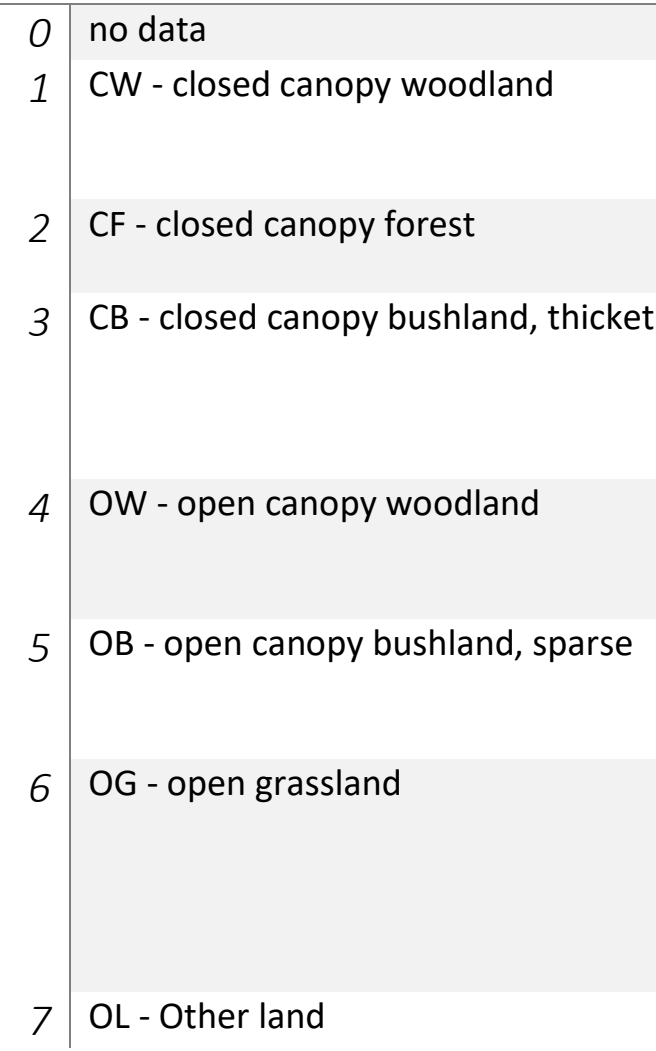

\section{Description}

\section{Absence of data}

predominantly tree and

herbaceous strata, where tree cover may be greater than $70 \%$ multiple vegetation strata likely, where tree cover is likely to be greater than $70 \%$ closed-medium canopy short bushland and/or thicket areas multiple vegetation strata likely, where shrub and bush cover is likely to be greater than $70 \%$

Open canopy woodland and/or bushland, where the tree and bush cover is likely to be between 40 $70 \%$

Sparse canopy woodland and / or bushland, where the tree and bush cover is likely to be less than $\mathbf{4 0}$ $\%$

Grass dominated areas with little or no tree, shrub or bush cover

(tree and bush cover is likely to be less than 5-10 $\%$ and/or where the herbaceous cover is likely to be less than $40 \%$.)

Other land than the above 


\subsubsection{Pre-processing and time series analysis}

The Landsat precision terrain corrected (L1TP) surface reflectance (SR) (Masek et al., 2012) product was used in this study. In particular, SAVI and NDMI climate data record (CDR) (USGS, 2016) collection 1, level 1 data with less than $30 \%$ cloud cover from 01.01.1984 to 01.01.2016 was used. It was processed and provided by the Earth Resources Observation and Science (EROS) Center Science Processing Architecture (ESPA). In the following the term pixel was used to describe the spatial location of a single Landsat resolution cell $(30 \times 30 \mathrm{~m})$. A time series of a pixel consists of Landsat observations (measurements) for that specific pixel. Observations either radiometrically saturated (Roy et al., 2002), with a high confidence flag for cloud or its shadow (Zhu and Woodcock, 2012) were dropped from the analysis. About half a billion (477.04 million) valid observations were available where the majority of pixels was represented by at least 288 observations. If the number of valid observations for a pixel was larger than 30, two (irregular) time series of NDMI and SAVI observations were created for this pixel. Each time series was tested for significant changes of vegetation index (VI) values using BFM (Verbesselt et al., 2012). BFM checks whether signal intensities at the tail of a time series are different from the previous measurement period. The tail of our time series ranged from 2006 onwards (monitoring period). Previously captured data (historic period) were used to produce a historic model consisting of a harmonic component, a trend and a reminder component. Equation 5.1 describes the used BFM:

$y_{t}=\alpha_{1}+\alpha_{2} t+\gamma \sin \left(\frac{2 \pi t}{f}+\delta\right)+\epsilon_{t}$

For each time series $y_{t}$ over time $t$, a model is created for observation frequency $f$ captured during the historic period. $\propto_{1}$ is the overall mean response and $\propto_{2}$ its slope, both formulating a linear trend function of the overall signal intensity through time. Seasonality with a harmonic order of one is expressed by the amplitude $\gamma$ and its phase $\delta$. The residual between modelled and measured values is expressed by $\varepsilon_{t}$. The model of the time series is forecasted and compared to the measured values captured during the monitoring period. In case the absolute value of the moving sum of the residuals of monitored and measured values is significant, a break is detected and its timing assigned to the pixel. The difference of modelled and measured value for this moment in time is also provided and referred to as magnitude. Magnitude was derived as done previously (Schultz et al., 2016a). If modelled and measured values are in correspondence no breakpoint is provided for the pixel; however, the largest difference between measured and modelled value (magnitude) is still provided. Once the time series of a pixel produced a breakpoint, no further breakpoints can be detected afterwards.

\subsubsection{Sample-based reference data set}

Sampling design (Foody, 2009), response design (Cohen et al., 2010) and analysis (Olofsson et al., 2014a) were considered for the creation of the reference data set (Strahler et al., 2006), resulting in a reference data base consisting of 31,778 reference points.

\subsubsection{Sampling design}

Each Landsat tile was sampled individually by using a stratification based on the occurrence of negative magnitude values for a BFM breakpoint and on land cover. Hence, if all six land cover classes were present within a tile and all showed breakpoints, six class proportions were considered for estimation of the sampling size. Each sampling size of BFM breakpoints for each land cover fraction was calculated using equation 5.2 (Foody, 2009): 
$n=\frac{z_{\frac{\alpha}{2}}^{2} P(1-P)}{h^{2}}$

Where $\mathrm{n}$ is the sample size, $\mathrm{h}$ the half-width of the desired confidence interval (here, $\mathrm{h}=0.01$ ), $\mathrm{P}$ the respective class proportion and $z_{\frac{\alpha}{2}}$ the critical level of the desired significance level (here, $\alpha=0.05$ ). Design-based sampling and random stratification did not necessarily provide sufficient material to hit change sites. When interpreted, BFM suggested change was frequently found to be stable (no change). Stratification of reference points by magnitude was applied earlier (DeVries et al., 2015b), where large portions of sampling points were spread particularly in areas represented by very low magnitude or very high magnitude values in order to increase chances of successfully hitting actual change by a random sampling design. Here, random sampling of breakpoints within a specific land cover class was stratified by spreading $50 \%$ of sample points within those pixels represented by the lowest $20 \%$ magnitude values and the other $50 \%$ in the residual pixels. Each stratum was considered sufficiently sampled if at least 40 real changes could be identified. Because of spreading more reference points through the data, reference samples found to be stable increased as well.

\subsubsection{Response design}

Each time series of a pixel identified by the sampling design was interpreted using TimeSync (Cohen et al., 2010) and inspected if a time series was impacted by a degradation or remained unchanged for any moment in time from 2006 - 2016. During a field trip in October 2016 a total of 131 reference points located in the center of the study site were visited. Open data kit forms on smart phones were used to capture ground truth data. Date, GPS position and photos in the cardinal directions were used to report timing, location and condition of the visited plots (Pratihast et al., 2014). Alongside with local experts from the World Wide Fund for Nature (WWF) and the Peace Parks Foundation (PPF) the timing and observed driver of change was captured and recorded to create unambiguous plot descriptions. Questionnaires were developed to address changes within Landsat pixels of $30 \mathrm{~m}$, and the interpreter in the field was asked to address environment properties within a $15 \mathrm{~m}$ radius. Agricultural expansion, anthropogenic caused fires and infrastructure development were found to be the most dominant land conversion processes in the area. Examples of collected ground truth of recent degradation activities for each land cover class captured during the field campaign in 2016 are shown in figure 5.3. The figure shows red arrows marking visible degradation. During the field trip it was concluded that different intensity levels of anthropogenic degradation were prominent in the visited areas, which is also characterized by differences in BFM magnitude. Most intense degradation was found in close proximity $(0-160 \mathrm{~m})$ of human dwellings where the predominant land use was characterized by cultivation. Here, vegetation degradation was characterized by highly degraded landscapes through firewood collection, selective logging and burning. 
Chapter 5

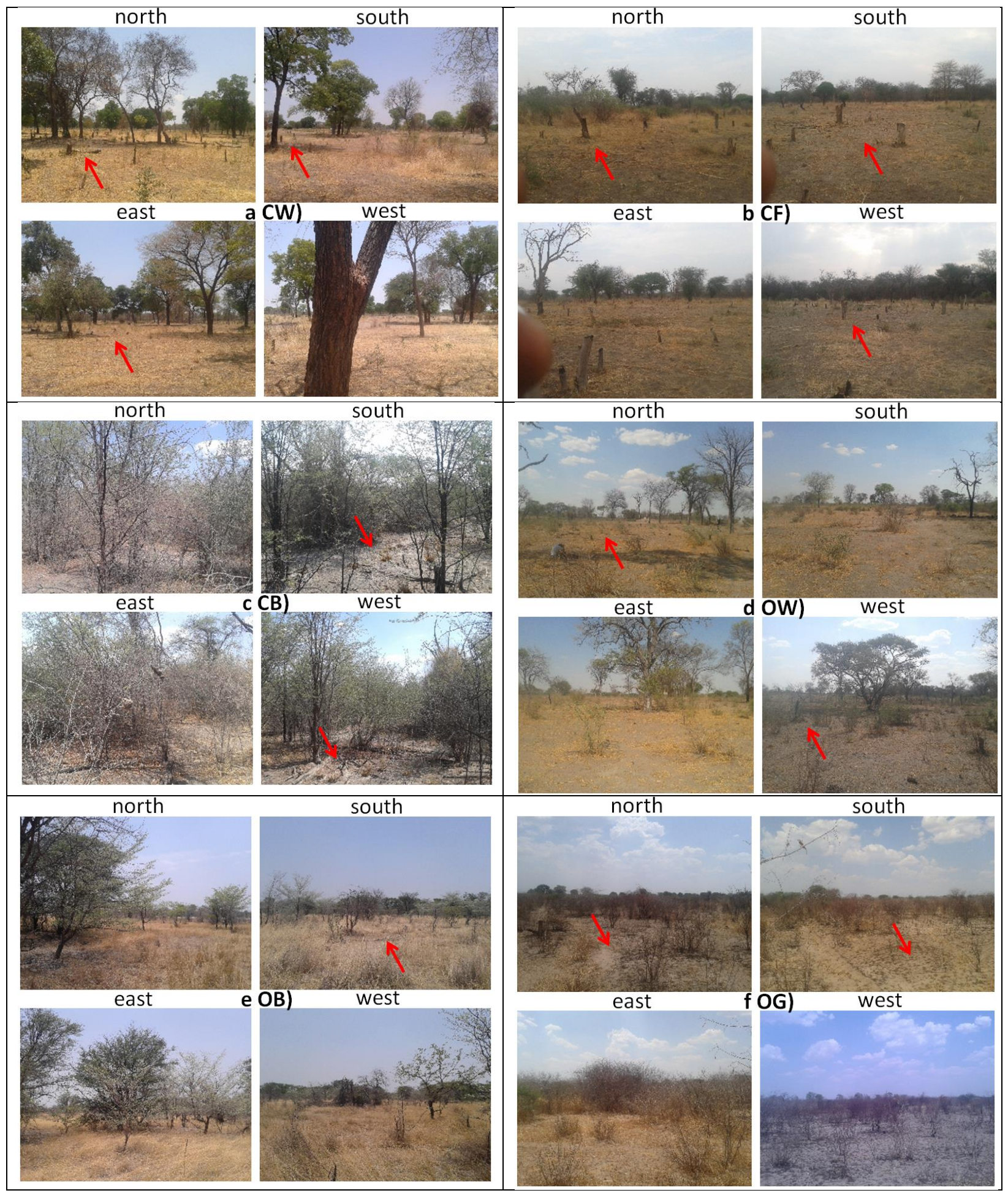


Figure 5.3 Examples of collected ground truth of recent degradation activities for each land cover class captured during a field campaign in October 2016; red arrows mark visible degradation for a) closed canopy woodland (CW) where tree trunks outnumber existing trees; b) closed canopy forest (CF) where tree trunks indicate previous forest density; c) closed canopy bushland (CB) where footpaths and broken trees indicate firewood collection; d) thicket open canopy woodland (OW) where tree trunks and footpaths are visible; e) open canopy bushland (OB) where footpaths are visible; f) sparse open grassland (OG) where traces of animal and human footprints are visible

\subsubsection{Analysis}

Comparing reference data with the produced map yields the accuracy of the map (R. Congalton, 1991). Overall accuracy, producer's accuracy, omission error (1 - producer's accuracy) expressing the underestimation of a class, user's accuracy, and commission error (1 - user's accuracy) expressing overestimation of a class, were calculated and reported (R. Congalton, 1991; Congalton and Green, 2009). According to best practices provided by (Olofsson et al., 2014), accuracy estimates were corrected for true marginal map proportions (Card, 1982) correcting for map class proportions as matched by the reference data based on the reference samples. Hence, confidence intervals for overall, producer's and user's accuracy were calculated as well.

\subsubsection{Forest cover and vegetation degradation detection}

Random forest (Breiman, 2001; Schultz et al., 2016a) and probabilistic threshold-based (DeVries et al., 2015b) models were used to post-process BFM results. Negative magnitudes are likely linked to loss of vegetation (DeVries et al., 2015b), while positive magnitudes can suggest an onset of vegetation growth or recovery from previous degradations (DeVries et al., 2015a). Because this study focused on the measurement of degradation (removal of vegetation), any pixel characterized by a positive magnitude was discarded from further analysis. Detected BFM breakpoints with a negative magnitude are prone to errors of commission rather than omission (Schultz et al., 2015). BFMs tendency to overestimate change was reported and addressed earlier (DeVries et al., 2015b; Schultz et al., 2016a). Each land cover type per Landsat tile was calibrated separately for degradation detection. Sections 5.2.4.1 - 5.2.4.3 describe three generic approaches. The three approaches were employed to understand method suitability, to identify common trends shared among them and ultimately resolve the BFM service to depict land cover specific degradation. Section 5.2.4.1 describes an approach to determine degradation per land cover type by the NDMI change magnitude based on probabilities, a modification of earlier work (DeVries et al., 2015b). Section 5.2.4.2 uses a combination of SAVI and NDMI as feature space for a random forest classification to determine degradation (Schultz et al., 2016a). Section 5.2.4.3 combines advantages of both methods.

\subsubsection{Degradation estimation by magnitude threshold}

The BFM magnitude provides the deviations of observed and modelled values within the monitoring period. A model was created using reference pixels depicting the ability of the NDMI magnitude to serve as method to distinguish degraded from stable land cover. For all reference points for a specific tile and land cover, the NDMI magnitude was used as a predictor variable within a binary logistic generalized linear model (GLM) for either degradation or stable land cover. Based on that, the probability of mapping degradation by magnitude was calculated for each land cover for each tile using a logistic fit for the probability $\pi$. We used a similar approach before to determine the relationship between observation frequency and deforestation detection ability (Schultz et al., 2016a). The model was constructed using 
ordinary least squares fitting, where $\beta_{0}$ and $\beta_{1}$ were the regression variables and $X_{1}$ the magnitude value. The GLM formula was:

$\ln \left(\frac{\pi}{1-\pi}\right)=\beta_{0}+\beta_{1} X_{1}$

The formula for the calculation of the probabilities was:

$\pi=\frac{e^{\beta_{0}+\beta_{1} X_{1}}}{1+e^{\beta_{0}+\beta_{1} X_{1}}}$

The Akaike Information Criterion (AIC) was used to determine the goodness of fit (Akaike, 1973). Finally, a magnitude threshold was selected for each land cover, where user's and producer's accuracy of change balanced out or in other words where the area bias of change was minimal. Any pixels associated with magnitudes larger than the identified magnitude threshold were treated as stable land, while smaller (more negative) magnitudes were identified as change.

\subsubsection{Degradation estimation by random forest classification}

Previous work identified the fusion of SAVI and NDMI magnitude features by random forest as suitable method to distinguish deforestation from stable land cover for a study site similar to KAZA (Schultz et al., 2016a). We used the same combination of VIs but altered the configuration of random forest. Random forest is a supervised non-parametric classification method making use of a defined set of decision trees, a so-called forest. Each tree consists of branches (nodes) where weights of input layers are randomly varied to create a model suitable for the classification of the given feature space towards the trained classes. When executed, a reference data set is used to estimate the performance of the decision tree and potentially reiterate to find better node weights of input parameters (bootstrapping). Our random forest varied from one to 100 trees of two nodes splitting the available reference data into a $50 \%$ training fraction and a $50 \%$ validation fraction. First, the number of trees necessary to allow random forest to perform enough iterations for model creation was tested for each land cover. Secondly, the identified forest size was reiterated 100 times in a Monte Carlo approach to describe the variation in resulting accuracies by its intrinsic randomness.

\subsubsection{Degradation estimation by combination of magnitude threshold and random forest classification}

Both methods described in the previous sections (5.2.4.1 and 5.2.4.2) were combined to use their joint strength. Low magnitude values (note that low magnitude values are high negative values) tend to be likely linked to deforestation or degradation (DeVries et al., 2015b). Any threshold set that removes high magnitude values can result in an omission of potential changes, which were high in terms of magnitude and thus subtle events. Setting the threshold too low might result in omission of many valid changes and can result in a low producer's accuracy of change. The opposite is true for the user's accuracy of change and comparatively high magnitude thresholds. The advantage of random forest is the non-parametric robustness, but it lacks parametric accommodation of real world change intensities. We chose a magnitude threshold in such a way that a producer's accuracy of change would not drop below $80 \%$ and applied a further classification by random forest for the remaining magnitudes. Hence a two-stage change filter was applied, where we first removed obvious or highly unlikely changes by a soft magnitude threshold and then classified the remaining portion of change to reduce the potential error of commission. 


\subsection{Results}

Selected examples of the time series trajectories and BFM models for the field validation are shown in figure 5.4. The time series in our study were characterized by an abundance of observations from 2013 onwards with a scarce observation frequency from 1985 - 1990. Amplitude ranges for the NDMI of different land covers varied. In contrast to the other time series, CF showed the most stable time series with the least outliers and signal drops for a degradation event were clearly distinct from previous observations (history period). CW was less stable, yet degradation was distinctively identifiable in this example (figure 5.4a). Both aforementioned land cover time series showed highest NDMI values and largest amplitudes. NDMI values for CB and OG were subtler. Values and amplitudes were low and degradation events were not as distinct from undisturbed observations as for CW and CF. CB and OW trajectories were similar, characterized by medium values, amplitudes and fluctuations. 


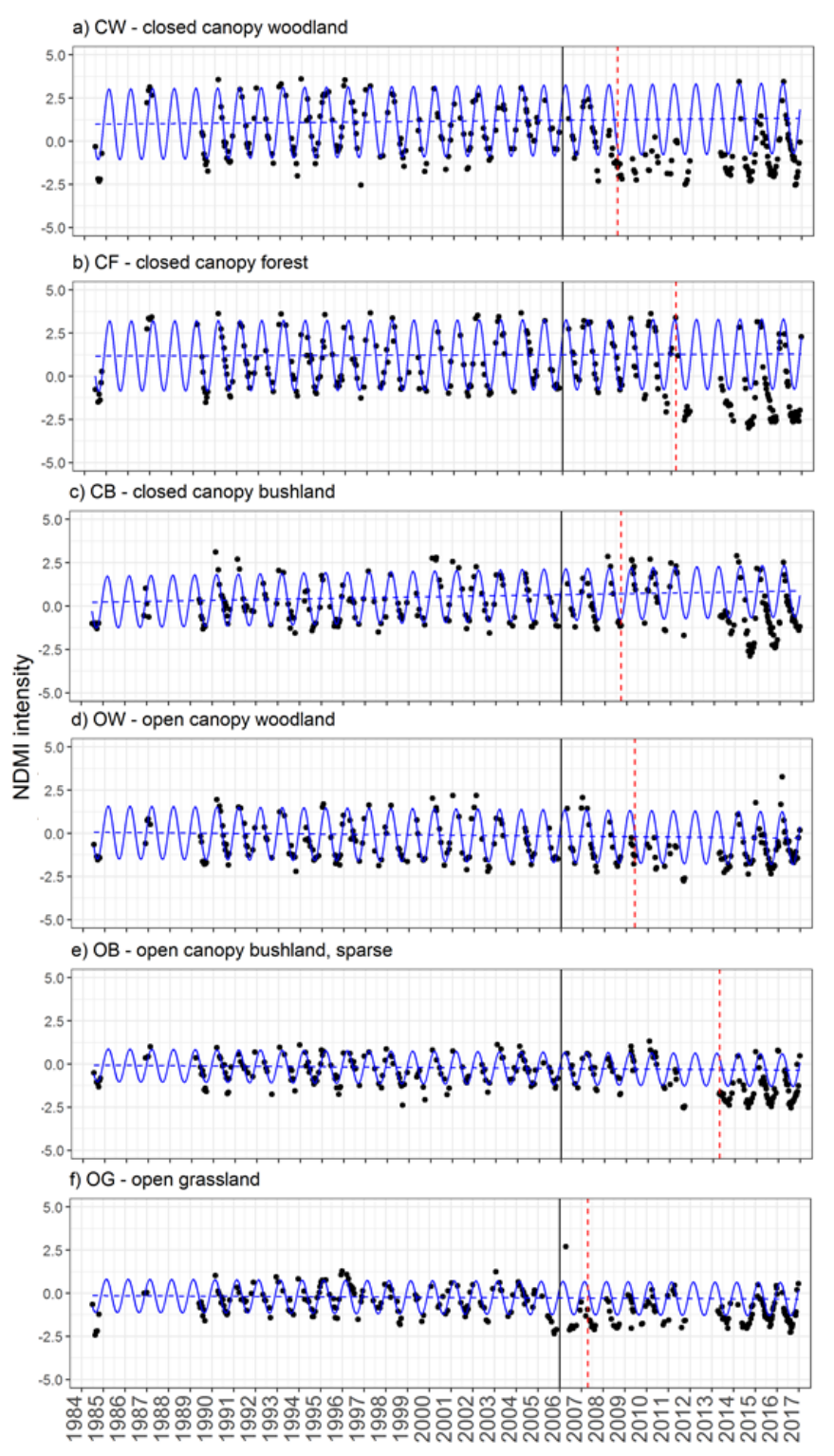

Figure 5.4 black points of NDMI values displayed as time series trajectories and its BFM model allocated within the considered land cover classes; vertical line left side shows historic period, right side monitoring period; vertical dotted line indicates a breakpoint as detected by BFM; blue lines depict the linear and harmonic component of the model

Figure 5.5 shows the spatial pattern of measured degradation for selected examples. Across methods, threshold-based degradation patterns appeared as conterminous patches while those for random forest alone were more scattered indicating less areas impacted by degradation. Random forest and thresholdbased approach combined showed smallest amount of area impacted by degradation. The effect on the resulting detected changes was especially profound for open land cover, while changes of detected degradation across methods varied less for closed cover canopies. 

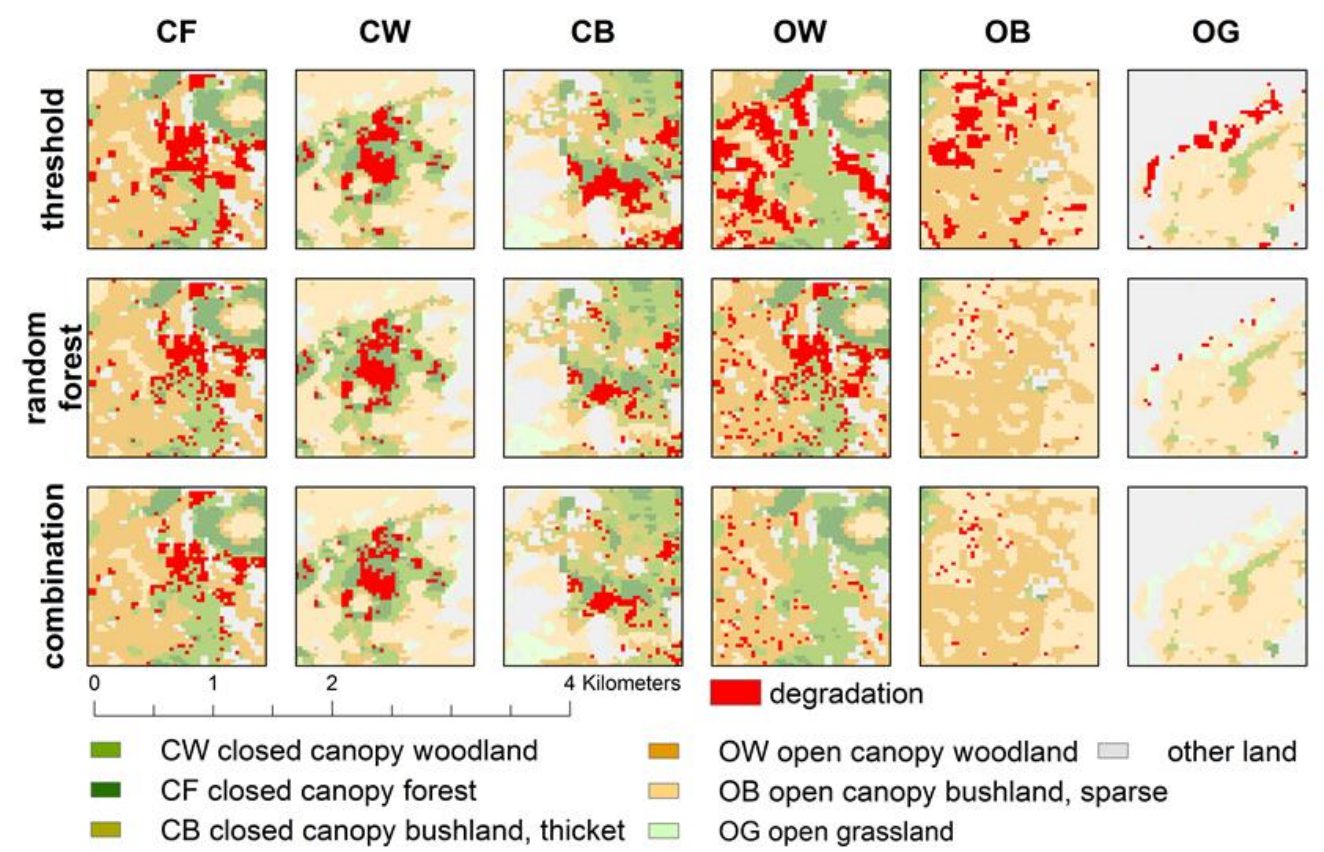

OW open canopy woodland $\square$ other land OB open canopy bushland, sparse OG open grassland

Figure 5.5 Examples of mapped land cover specific degradation shown in red for the different methods used

\subsubsection{Magnitude threshold-based degradation determination}

The relationship between the size of the magnitude and the probability to detect degradation (equation 5.4) for the different land cover types is shown in figure 5.6. For the sake of simplicity within this paragraph the term land cover refers to land cover specific degradation. The probability of detecting degradation increased with decreasing magnitude for all classes. Differences among the relationships exist regarding the probability maxima, the shape and the position of the trajectory. These three function categories are each represented by two land cover classes. First, CW and CF were " $\mathrm{s}$ " shaped functions, reaching a plateau at probabilities of $0.8-1.0$. For these classes larger magnitude values were linearly related to the probability. Furthermore, only magnitudes of these two land cover classes can identify a degradation event with high probability by using only magnitude values (magnitude $<-1.5$, then $P \approx 1.0)$. CW and CF also showed fast increase of the probability at rather low magnitudes $(0.0-$ 1.0). Secondly, OW and OG showed almost linear relationships between probability and magnitude. The slope of the relationship increased for class OW for magnitudes lower than -0.75 , while it remained constant for OG. The maximum negative magnitude reached by OG was -1.84 and for OW it was -1.79 , still suggesting that these magnitudes not necessarily were related to actual degradation events $(P<$ 0.75). Thirdly, functions for $O B$ and $C B$ were located in the middle of figure 5.6. The shape of the functions was a less defined " $s$ " shape than for the categories CW and CF, whereas also a plateau in probability was not reached. The slope of the two functions was located from magnitude -0.4 up to -1.1, similar to $C F$. The minimum magnitude of $C B$ was -1.81 at a probability of 0.92 and for $O B$ the minimum magnitude was -1.24 at a probability of 0.79 . 


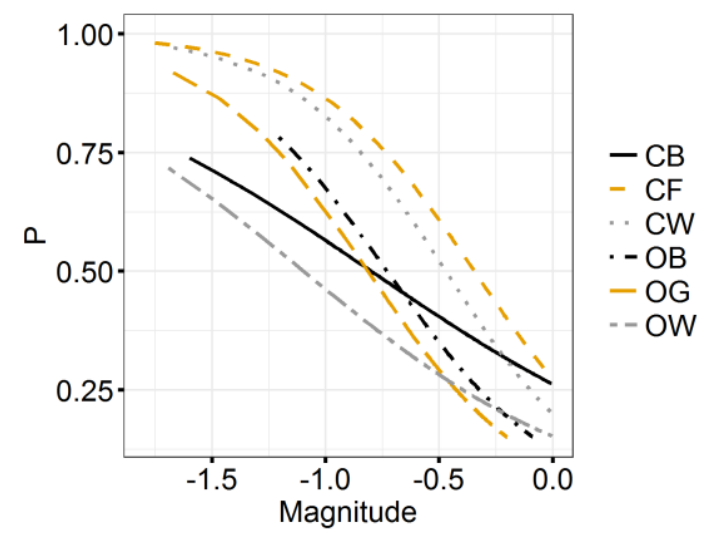

Figure 5.6 Probabilities (P) for detecting a deforestation event in relation to the magnitude for the specific land cover classes

Figure 5.7 displays overall accuracy, user's and producer's accuracy and confidence intervals for a range of magnitude thresholds for a degradation event per land cover class. The trends in accuracy in figure 5.7 were similar for all classes. When the magnitude threshold was lowered, the producer's accuracy decreased, and the user's accuracy increased. The upper line of graphs is characterized by closed canopies (land cover CW, CF and CB) and the overall accuracy peaks at the intersection of user's and producer's accuracy, while for the bottom graphs, characterized by open canopies (OW, OB and OG), overall accuracy gradually increased and it saturated when the magnitude threshold was lowered. Three further phenomena were observed when the magnitude threshold was lowered. First, the confidence interval for user's accuracy and producer's accuracy generally increased and shortly before reaching $100 \%$ diminished (0\% respectively for producer's accuracy), except for OG. For this effect open canopies were more severely impacted than closed canopies. Lowest accuracy confidences were generally found in the mid-range of magnitude values (-0.5 to - 0.9). Secondly, changes in open canopies accuracy and confidence changes occurred mostly at larger magnitudes than for closed canopies where variations of accuracy and confidences were evident throughout the full range of negative magnitudes. As a result, slopes of user's and producer's accuracy functions were relatively flatter for closed canopies and steeper for open canopies. Closed canopies usually occupied a larger range of magnitudes while for open canopies major variations occurred for a short magnitude range. 


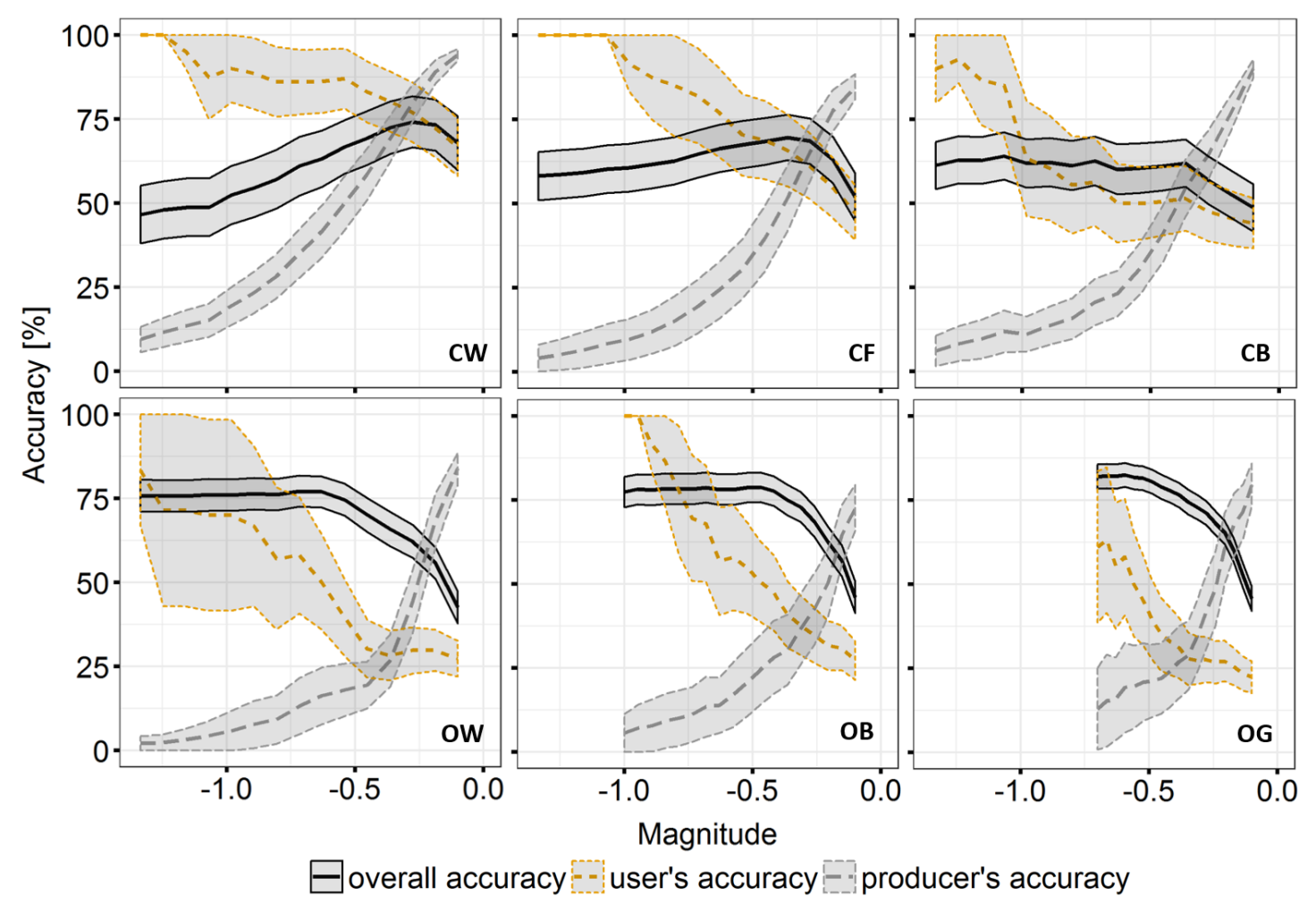

Figure 5.7 Land cover degradation specific accuracies in relation to the magnitude threshold, grey ribbons show confidence interval

\subsubsection{Random forest based degradation determination}

Figure 5.8a shows the relation between random forest tree size and its accuracy to classify degradation events using magnitudes based on the reference data and a 50/50 training validation bootstrapping. Random forest sizes from 1 - 15 trees showed low producer's accuracy for change and low overall accuracy. From 25 to 75 trees accuracies stabilized and no major changes in accuracy were observed. As a result, a random forest tree size of 80 was selected for all random forest classifications using the NDMI-SAVI magnitude feature spaces. Figure $5.8 \mathrm{~b}$ shows the stability of the performance of the random forest classification. A Monte Carlo experiment was performed 100 times where training and validation samples were randomly changed. A random forest model with 80 trees showed that the user's accuracy can vary up to $3 \%$, the producer's accuracy up to $9 \%$, and the overall accuracy up to $8 \%$. The confidence interval remained fairly stable with only minor variations. The relationship between tree size and accuracies was similar for other land covers, but absolute accuracies varied. Results are summarized in figure 5.9. 


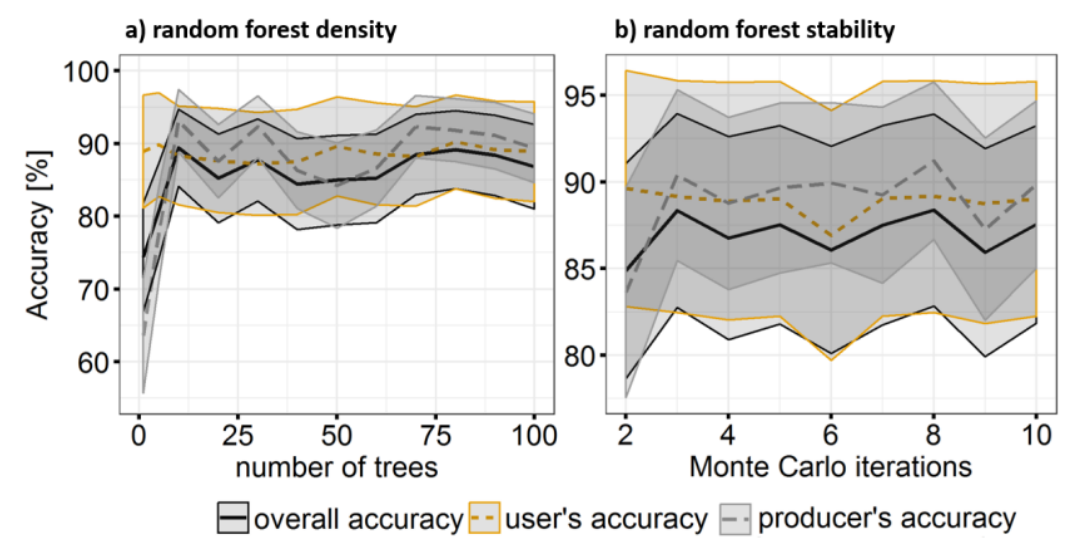

Figure 5.8 a) Relationship between accuracy and the number of trees used for random forest classification for class CF (closed canopy forest); b) variation of accuracy due to random forest randomness when using 80 trees across 100 iterations

\subsubsection{Combination of magnitude threshold and random forest classification}

Accuracy trends were similar for the detection of land cover specific degradation using all three methods (figure 5.9). The highest combination (area bias) of producer's and user's accuracy was found for CF (92.1\% and $90.1 \%$, respectively). Degradation of open land cover was detected with lower accuracy than degradation of closed canopies, with open land cover classes especially characterized by large area estimation uncertainties (high difference between user's and producer's accuracy). Estimates of user's accuracy were usually higher than those of the producer's accuracy. For CF the user's and producer's accuracy were more similar in relation to the accuracies of other classes, meaning that degradation detection within this class had the lowest area bias and thus allowed for most accurate area estimations. Confidence intervals for the producer's and user's accuracy were different, with a confidence for user's accuracy at about $7 \%$ and a confidence for producer's accuracy at about $15 \%$. Nonparametric random forest classification always outperformed probability based threshold classification. User's accuracy improved when random forest and the threshold classification methods were combined, while the producer's accuracy decreased. Although random forest outperformed the threshold approach, random forest uncertainties were higher than those generated by the threshold method, especially for the producer's accuracies of OW, OB and OG. 


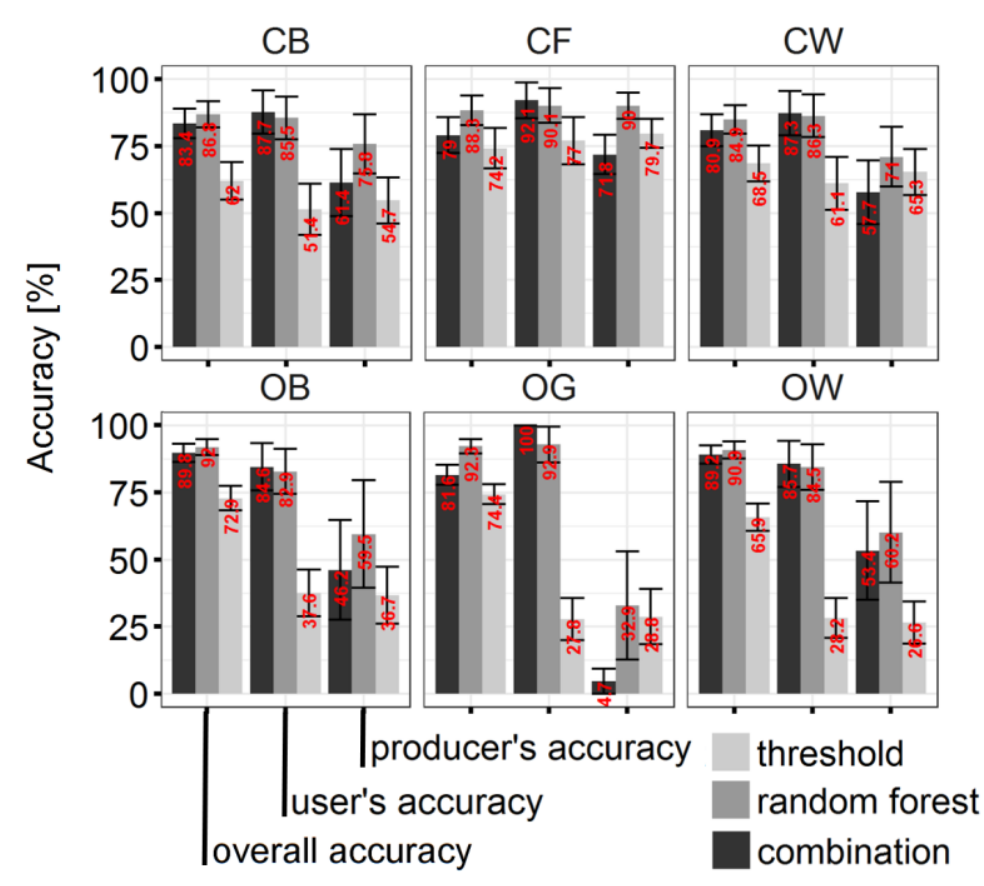

Figure 5.9 Grouped bar plot of land cover specific accuracies for detecting degradation compared by method, whiskers show confidence interval

\subsection{Discussion}

In this study the performance of detecting degradation of natural land cover using BFAST Monitor and Landsat NDMI and SAVI time series was assessed for different land cover classes. Within this section research objectives as previously stated are addressed and discussed successively. More general discussion points are provided at the end of the section.

- How does degradation detection performance differ for six different land cover classes in KAZA using BFM?

The performance of detecting degradation for each land cover class was most successful in the order $\mathrm{CW}, \mathrm{CF}, \mathrm{CB}, \mathrm{OW}, \mathrm{OB}$ and $\mathrm{OG}$. Sensitivity to different land cover types of BFM in conjunction with Enhanced Vegetation Index (EVI) was observed in a semi-arid landscape (Watts and Laffan, 2014) and confirmed by this analysis, although we use NDMI; EVI and NDMI share the near-infrared wavelength. For all three methods tested, the degradation for closed canopy land cover was more accurately detected than degradation within open canopy land cover types. Other studies confirm that closed canopy degradation was less prone to error in contrast to open canopy (Kamwi et al., 2017). The suitability of BFM for detecting forest degradation using threshold or random forest methods has been assessed in earlier studies (DeVries et al., 2015b; Schultz et al., 2016a). The NDMI is specifically sensitive to vegetation and its water content, which is more abundant when more vegetation is present. Since SAVI is an index removing the effect of increasing soil exposure, it was used in combination with NDMI. The combination (using random forest) was up to 3.7 times (open woodland user's accuracy $100 \%$ for the combination method and $28 \%$ for the threshold-based method) more successful than using NDMI alone (threshold-based). In closed canopies and forested areas the differences in accuracies between threshold-based, random forest and combination methods were less distinct. Confidence intervals were generally larger for user's accuracy than for producer's accuracy. This effect is related to the sampling 
design which promotes producer's accuracy as only areas which were identified as potential change by BFM were sampled. A reliable independent reference data set does not yet exist for this region. Because change areas were significantly smaller than stable areas (no change detected), any mapping errors within the change class increased the uncertainty of the true marginal map proportion resulting in a low confidence for change errors of omission while the confidence interval for errors of omission for stable land cover remained narrow. Overall accuracies shown in figure 5.9 also account for stable land and are characterized by small confidence intervals as they accommodate both confidence of stable and change classes.

- How does threshold based and random forest based BFM post-processing for degradation detection compare?

Parametric probability based threshold selection using GLM and AIC as proposed by (DeVries et al., 2015b) provided comprehensible and reproducible results. In contrast, results for the non-parametric random forest classification varied due to the randomness of the method. The performance depends on tree iteration and bootstrapping, where use of reference data is a prerequisite (Schultz et al., 2016a). Random forest bootstrapping tends to blur proper distinction of training and reference data as observations are randomly swapped and shuffled to achieve the best mapping result. The use of random forest in conjunction with field data was deemed appropriate and a successful tool in similar environments (DeVries et al., 2016; Pratihast et al., 2016), although its error margins have not been highlighted. Although the magnitude threshold-based approach can be more intuitive, it fails to depict the ecosystem complexity and its related degradation processes. Typically, the random forest machine learning approach will fail to produce the same result as demonstrated in figure $5.8 \mathrm{~b}$.

- How are method variations impacting degradation detection accuracy and how to combine threshold based and random forest based BFM post-processing methods effectively?

Across observed land cover types, the impact of a decrease in magnitude as threshold on the confidence interval varied, because degradation reference points gradually were allocated to stable land with a decrease in magnitude (more negative). This reduced confidence in the producer's accuracy for degradation. As the confidence interval of the producer's accuracy for degradation was increased, the user's accuracy simultaneously increased along with the confidence interval. Figure 5.10 reveals that the confidence intervals and accuracy for stable land cover were behaving in an opposite direction as for degraded areas, but changes and expansion of the confidence interval were lower as their area is larger and thus an increase in error introduced by true marginal map proportions is less severe. Changing the magnitude threshold affected the accuracy, but more importantly the accuracy confidence, especially for open canopies where confusion (error rate) was higher. Random forest on the other hand was solely impacted by the number of trees and its internal randomness. As a result, the accuracy varied but confidence remained stable if iterations were kept stable (figure 5.8). When threshold-based degradation detection alone was used, optimal results were achieved at the intersection of user's and producer's accuracy for change (DeVries et al., 2015b). When combined with random forest particularly the commission of change was suppressed, and the magnitude threshold should be set as conservatively and subtle as possible to avoid any omission of degradation. Pixels characterized by very small magnitudes and by high probabilities of degradation $(P>0.8)$ can be considered as an accurate degradation detection, while remaining pixels can be subject to more selective random forest 
classification. The combination of both methods secured pixels that were almost certain having changed using a threshold-based method, whereas more complex changes were addressed by random forest.

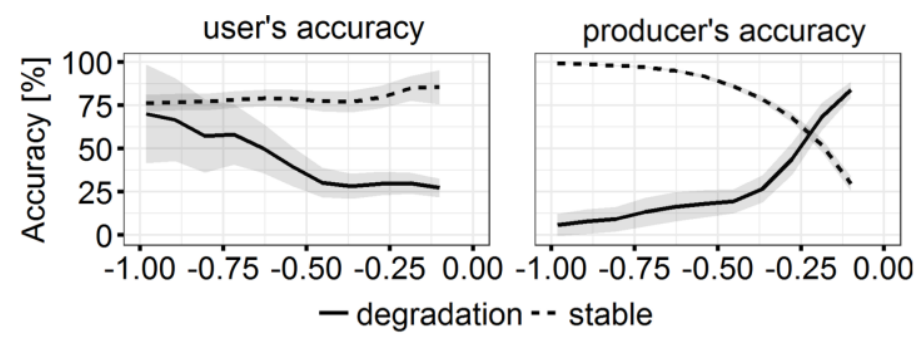

Figure 5.10 Relationship of accuracy and confidence interval with change magnitude for stable and degraded land cover type OW (open canopy woodland)

\subsection{Conclusions}

Landsat NDMI time series analysis using BFM detected degradations of heavily vegetated areas within large savannah landscapes, especially when tree cover was high (CW and CF). Distinct signal drops of BFM change magnitude were used in non-parametric and parametric approaches to detect degradations. As vegetation cover decreased, the performance of degradation detection dropped. When combining NDMI and SAVI at feature level detection performance was increased, especially for sparse vegetation cover. Hence different land cover degradations require specific VIs for accurate monitoring programmes. In comparison, non-parametric random forest was found to be more accurate in detecting change than a threshold-based approach. Especially confidence intervals were affected by the threshold-based approached when the magnitude threshold varied. Large area monitoring programmes covering different ecosystems and land cover types therefore require specific VIs time series and an individual BFM model calibration. Variations in BFM harmonic order, different models to address model history or BFM sequential approaches (for instance, year-wise monitoring) also require specific VIs and land cover specific adjustments. Alternatively, spectral endmember-based approaches have shown promising results for forested landscapes (Schultz et al., 2016a; Souza Jr. et al., 2005) and therefore specific land cover endmembers can be of use for different sets of land cover types. Increasing observation frequency also can increase the probability of detecting degradation events (Reiche et al., 2015; Schultz et al., 2016a). Hence, incorporating other data sources such as Sentinel-1 and - 2 is desirable as observation frequency can be increased at no-cost (Reiche et al., 2018).

\subsection{Acknowledgments}

The authors thank the World Bank for funding and WWF, PPF and WUR for enabling this study. We are thankful for the brave field trip team and the kind revisions which greatly improved this work. 
Chapter 6

Chapter 6

Synthesis 


\subsection{Main results}

Measurement of tropical deforestation is relevant for addressing global climate change. Consistent measurements of locations of ongoing deforestation across large areas can be achieved using remote sensing time series, which support tropical forest management as suggested by the Reducing Emissions from Deforestation and forest Degradation (REDD+) program. In conjunction with Landsat Time Series (LTS) we identified Breaks for Additive Season and Trend (BFAST) Monitor as a robust tool for deforestation activities. Objective of this thesis was the study of BFAST Monitor for tropical deforestation monitoring as a tool for supporting carbon emissions accounting.

Figure 6.1 outlines how the different chapters relate to each other revolving around BFAST Monitor. Firstly, in chapter 2 BFAST Monitor was identified as potentially useful tool given the need of deforestation monitoring. Subsequently in Chapters 3 to 5 error sources, pre-processing, post processing, $\mathrm{VI}$ usage, forest and land cover target implications regarding the application of BFAST Monitor were researched.

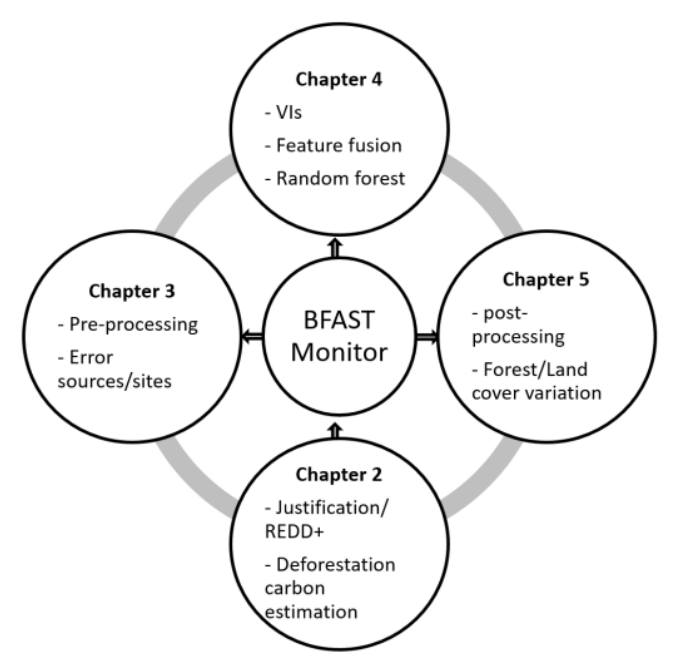

Figure 6.1 Overview of the thesis chapters and their relation towards each other; the center circle is the core issue the different chapters revolved around, which is represented by the larger outer circles; arrows represent the direction of research motivation and the grey ribbon represents the interlinkage of the different chapters 
Table 6.1 provides an overview of the deforestation detection accuracies achieved in the various setups explored in this thesis. This overview serves as a reference for the application of BFAST Monitor and can help to decide in which circumstances satisfactory accuracies can be achieved and it highlights setups where performance shortcuts are to be expected.

Table 6.1 Extract of Chapter 3-5 results where forest and land cover specific user's accuracy (ua), producer's accuracy (pa) in \%, important vegetation indices $(\mathrm{VI})$ are shown; *KAZA related targets were not investigated for error sources but compared for post-processing technique, ${ }^{* *}$ Chapter 5 Combination $=$ Generalized linear model $(G L M)$ threshold based random forest combination, $R F=$ Random forest, GLM $=$ GLM threshold only

region Class name

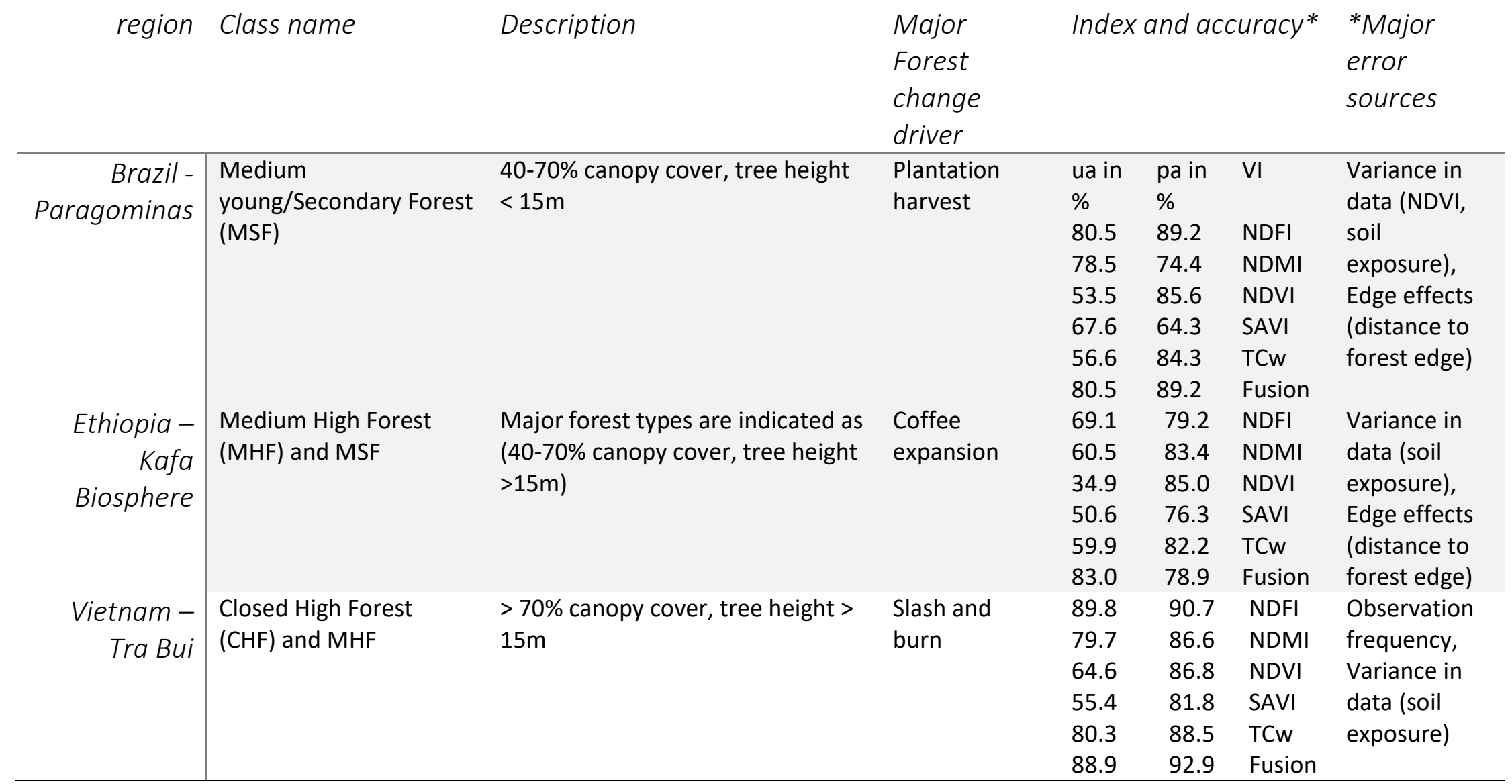




\begin{tabular}{|c|c|c|c|c|c|c|c|}
\hline & & & & & & & $\begin{array}{l}\text { BFAST } \\
* \text { Monitor } \\
* * \text { post } \\
\text { processing }\end{array}$ \\
\hline \multirow{18}{*}{$\begin{array}{r}\text { Southern } \\
\text { Africa, } \\
\text { Namibia, } \\
\text { Botswana, } \\
\text { Zambia, } \\
\text { Zimbabwe, } \\
\text { Angola } \\
(K A Z A)\end{array}$} & \multirow{3}{*}{$\begin{array}{l}\text { CW - closed canopy } \\
\text { woodland }\end{array}$} & \multirow{3}{*}{$\begin{array}{l}\text { predominantly tree and } \\
\text { herbaceous strata, where tree } \\
\text { cover may be greater than } 70 \%\end{array}$} & \multirow{18}{*}{$\begin{array}{l}\text { Agricultural } \\
\text { expansion, } \\
\text { anthropogenic } \\
\text { caused fires } \\
\text { and } \\
\text { infrastructure } \\
\text { development }\end{array}$} & 87.3 & 57.7 & Fusion & Combination \\
\hline & & & & 86.3 & 71 & Fusion & \\
\hline & & & & 61.1 & 65.3 & NDMI & threshold \\
\hline & \multirow{3}{*}{$\begin{array}{l}\text { CF - closed canopy } \\
\text { forest }\end{array}$} & \multirow{3}{*}{$\begin{array}{l}\text { multiple vegetation strata likely, } \\
\text { where tree cover is likely to be } \\
\text { greater than } 70 \%\end{array}$} & & 92.1 & 71.8 & Fusion & Combination \\
\hline & & & & 90.1 & 90 & Fusion & \\
\hline & & & & 77 & 79.7 & NDMI & threshold \\
\hline & \multirow{3}{*}{$\begin{array}{l}\text { CB - closed canopy } \\
\text { bushland, thicket }\end{array}$} & \multirow{3}{*}{$\begin{array}{l}\text { closed - medium canopy short } \\
\text { bushland and/or thicket areas } \\
\text { multiple vegetation strata likely, } \\
\text { where shrub and bush cover is } \\
\text { likely to be greater than } 70 \%\end{array}$} & & 87.7 & 61.4 & Fusion & Combination \\
\hline & & & & 85.5 & 75.8 & Fusion & \\
\hline & & & & 51.4 & 54.7 & NDMI & threshold \\
\hline & \multirow{3}{*}{$\begin{array}{l}\text { OW - open canopy } \\
\text { woodland }\end{array}$} & \multirow{3}{*}{$\begin{array}{l}\text { Open canopy woodland and/or } \\
\text { bushland, where the tree and bush } \\
\text { cover is likely to be between } 40 \text { - } \\
70 \%\end{array}$} & & 85.7 & 53.4 & Fusion & Combination \\
\hline & & & & 84.5 & 60.2 & Fusion & \\
\hline & & & & 28.2 & 26.6 & NDMI & threshold \\
\hline & & \multirow{3}{*}{$\begin{array}{l}\text { Sparse canopy woodland and / or } \\
\text { bushland, where the tree and bush } \\
\text { cover is likely to be less than } 40 \%\end{array}$} & & 84.6 & 46.2 & Fusion & Combination \\
\hline & \multirow{2}{*}{ bushland, sparse } & & & 82.9 & 59.5 & Fusion & \\
\hline & & & & 37.6 & 36.7 & NDMI & threshold \\
\hline & \multirow[t]{3}{*}{ OG - open grassland } & \multirow{3}{*}{$\begin{array}{l}\text { Grass dominated areas with little } \\
\text { or no tree, shrub or bush cover } \\
\text { (tree and bush cover is likely to be } \\
\text { less than } 5-10 \% \text { and/or where } \\
\text { the herbaceous cover is likely to be } \\
\text { less than } 40 \% \text {.) }\end{array}$} & & 100 & 4.7 & Fusion & Combination \\
\hline & & & & 92.9 & 32.9 & Fusion & \\
\hline & & & & 27.8 & 28.8 & NDMI & threshold \\
\hline
\end{tabular}




\subsubsection{What is the proportion of carbon emissions from deforestation in relation to other terrestrial carbon pools for a REDD+ relevant site in central Vietnam?}

In chapter 2 we aimed to understand the relevance of carbon emissions caused by deforestation in relation to other terrestrial carbon sources. For a REDD+ relevant study site in Vietnam components of carbon dynamics for different land cover types were measured and compared. Relevant biomass data were measured in situ during two field campaigns in 2011 and 2012. (Morton, 2016) suggested that residual carbon stocks in deforested land require quantification when moving towards complete carbon accounting. Although most carbon changes due to deforestation in the 2000s were estimated for the tropical regions (Achard et al., 2014; Baccini et al., 2012; Pan et al., 2011; Zarin et al., 2016), often only gross emissions from above-ground biomass were considered, lacking quantification of forest regrowth processes. Because post deforestation land uses and soil organic carbon (SOC) play a key role in carbon cycles (Bongers et al., 2015; Chazdon et al., 2016; Don et al., 2011; Espírito-Santo et al., 2014; Grace et al., 2014), we measured them to understand the impact of deforestation on the carbon balance of tropical forests.

Our study quantified the carbon emissions and removals in vegetation biomass due to land cover changes that occurred between 2001 and 2010 including deforestation in the Vu Gia Thu Bon River Basin of Central Vietnam. A bi-temporal Landsat time series was used to assess activity data for the historical reference period (IPCC, 2006). The vast majority of carbon emissions were due to deforestation, with the conversion of forest to cropland accounting for $67 \%$ of net emissions. Roughly $60 \%$ of these were released by above-ground biomass (AGB), 10\% from below-ground biomass (BGB) and 30\% by SOC. Deforestation emission rates were dependent on forest type. For instance, plantations yielded 16- 22 $\mathrm{Mg} \mathrm{C} / \mathrm{ha}$ for the observed period, while medium and dense forest yielded $103-206 \mathrm{Mg} \mathrm{C} / \mathrm{ha}$. If a distinct classification of forest types is disregarded and standard IPCC values are used (IPCC, 2006), total net emissions increased up to 7 times. Other carbon transitions included forest regrowth storing roughly $22 \%$ of carbon. The remaining transitions occurred inside non-forest land cover classes.

Because carbon emissions caused by deforestation were the largest source of carbon emissions and prone to the highest uncertainties, forests are of prime importance for consistent monitoring efforts. We concluded that specifically ongoing remote sensing time series can serve as book keeping method for ongoing deforestation monitoring. Results of chapter 2 provided motivation to research consistent Landsat time series analysis for ongoing accurate area reporting of deforestation activities.

\subsubsection{What is the performance of BFAST Monitor for deforestation detection and what are the major sources of error?}

In chapter 3, three sites (Brazil, Ethiopia and Vietnam) across the tropics were studied that were characterized by different environments and data properties. Varying data preprocessing was tested regarding the performance for detecting deforestation when using BFAST Monitor and Normalized Difference Vegetation Index (NDVI) LTS. Additionally, we described error sources specific for each site and the used pre-processing scheme to understand the suitability of BFAST Monitor for deforestation detection. Removal of data contaminants and use of radiative transfer models for data correction determine image data quality when converting raw sensor data to surface reflectance. Factors such as topography, observation frequency and type of deforestation are known to impact detection 
performance thus the development of various remote sensing fusion algorithms to dense time series (Hilker et al., 2009; Reiche et al., 2016). The Landsat Ecosystem Disturbance Adaptive Processing System (LEDAPS) (Vermote et al., 1997) and Atmospheric Correction and Haze Reduction models (ATCOR 2 and 3) are widely used for Landsat applications (Richter, 2011) and hence were considered to identify a suitable LTS pre-processing scheme for BFAST Monitor application.

Landsat data corrected using dark object subtraction (DOS) are dominated by noise and are not suitable for deforestation mapping. For other correction methods tested, mapping accuracies were found to be similar, but they varied greatly with site. The varying user's and producer's accuracy between sites show that no single correction technique is consistently superior. As large-scale applications are desired, highly automated procedures such as LEDAPS are preferred for BFAST Monitor. Local fine-tuning of the algorithm is essential for some areas. Mapping errors were modelled using a set of error parameters that yielded information on data and site-specific environmental properties. Relevant parameters for characterizing mapping errors in order of importance were: data availability, atmosphere (haze contamination), topography, forest edge effects and data variance, although their importance varies more by site than per applied pre-processing scheme. Specifically, the probability of making a commission error depends strongly on data variance, which in turn depends on the amount and quality of available observations. Time series characterized by little data variance are sensitive to data outliers, which are wrongly mapped as change. Time series with sparse data either need to be without outliers or should have a similar distribution of outliers in the historic as well as in the monitoring period for the BFAST Monitor approach to adapt to the noise. A site specific minimum amount of observations was necessary to map deforestation accurately. Deforestation characterized by abrupt tree removal in forests of Brazil and Vietnam were detected reliably (overall accuracy $79 \%$ and $82 \%$, respectively). In Ethiopia, where deforestation was gradual and less abrupt than in the other sites, detection accuracy was $60 \%$. There the location of the deforestation event in relation to the forest boundary can predict where an error of commission has most probably occurred. Across sites and methods BFAST Monitor overestimated deforestation, hence the commission error was better modelled and understood than the omission error. The omission error was high, partly because the largest error occurred by overestimation of deforestation rather than underestimation. Among the tested error sources, the observation frequency influenced the error of omission most, hence more dense time series particularly reduce the omission of degradation.

Although NDVI is designed to quantify the photosynthetically active biomass of plant canopies it is limited to those spectral responses captured by red and near infrared bands. Hence, we concluded that other vegetation indices (VIs) might yield better performance, particularly when tapping into the full radiometric spectrum offered by Landsat. For instance, the Normalized Difference Fraction Index (NDFI) uses Landsat's full radiometric resolution and is sensitive to tree canopy damage. When only a few trees are removed, the high biomass sensitivity of the Enhanced Vegetation Index (EVI) is particularly useful for mapping gradual deforestation. We concluded that a range of suitable VIs require testing to identify a VI optimal for deforestation detection in conjunction with BFAST Monitor, thus defining our research aims for the following chapters. 


\subsubsection{Which vegetation indices suit BFAST Monitor best for deforestation detection?} Chapter 2 concluded that differences in vegetation and forest carbon yield existed and if accounted in disrespect to the existence of forest types and vegetation densities error margins increased up to four times. Chapter 3 showed that BFAST Monitor can be a suitable device for consistent deforestation monitoring. Chapter 4 then provided a study about the suitability of different VIs for degradation detection in conjunction with BFAST Monitor. The study used the same sites as the previous chapters and was therefore linked to the same reference data, forest types and deforestation drivers.

We tested a larger range of VIs for detecting deforestation. EVI, Global Environment Monitoring Index (GEMI), NDFI, NDMI, NDVI, Soil Adjusted Vegetation Index (SAVI), Tasselled Cap wetness (TCW) and Tasselled Cap greenness ( $\mathrm{TCg}$ ) were tested. Because time series variance and observation frequency were found to be the main parameters explaining detection errors in chapter 3 , we compared the performance of these VIs in detecting deforestation against these parameters. Inspired by ensemble classification (Breiman, 2001) we tested whether data fusion of multiple maps at feature level can provide increased mapping accuracy. Data fusion proved useful in combining various mapping outcomes of various inputs to produce one highly accurate map (Ceamanos et al., 2010).

Among tested VIs the NDFI performed better than wetness related VIs (NDMI, TCW). The greenness related VIs (EVI, GEMI, NDVI, SAVI, TCg) performed the worst. Sensitivity of a VI to observation frequency varied depending on the site. Mapping results of NDFI and NDVI were most insensitive to observation frequency, while the other VIs benefited most from an increased observation frequency. The Ethiopia site was an exception; there the NDFI was the only VI that achieved acceptable performance. Fusing deforestation maps based on different VIs increased overall mapping accuracy and consequently reduced overestimation of change. Landscapes characterized by subtle deforestation processes (the Ethiopia site with gradual expansion of coffee plantation in forests) benefited more from feature level data fusion than landscapes with abrupt deforestation processes (Vietnam, slash and burn; Brazil, plantation forest). When VIs were fused using any combination including the NDFI, they outperformed other combinations. Because the NDFI relies on Spectral Mixture Analysis (SMA) it requires more complex processing and calculation procedures than the other VIs that simply rely on band ratios. Besides the NDFI, also the fusion of SAVI and NDMI was a usefully combination to detect deforestation.

\subsubsection{To which extent is BFAST Monitor suited to detect degradation across large areas of forests, bushlands and grasslands?}

In chapters 3 and 4 we found that BFAST Monitor performance varied among different forest types, the associated environments, data conditions and deforestation drivers. Deforestation measured within Brazil and Vietnam was characterized by abrupt events (plantation harvest, slash and burn), which resulted in distinct drops of change magnitudes that were well accommodated by vegetation sensitive VIs. The Ethiopian landscape was characterized by subtle gradual deforestation related to the ongoing degradation activity (DeVries et al., 2015b). In comparison to the other sites, deforestation was less accurately picked up by BFAST Monitor. Hence, in chapter 5 we aimed to understand the limitations of BFAST Monitor by testing the performance across a large savannah landscape with varying degrees of 
tree cover (closed canopy woodland (CW), closed canopy forest (CF), closed canopy bushland (CB), open canopy woodland (OW), open canopy bushland (OB), open grassland (OG)).

We used modifications of a parametric NDMI magnitude threshold based method (DeVries et al., 2015b) and a non-parametric NDMI and SAVI feature fusion (Schultz et al., 2016a) based approach to test BFAST Monitor degradation detection performance for the Kavango-Zambezi Transfrontier Conservation Area (KAZA) in southern Africa. Both methods yielded satisfactory accuracies when tree cover was high (CW, $\mathrm{CF}$ ), but could not detect degradation accurately for land cover with few or no trees (OB, OG and OW). Feature fusion based, and magnitude-based methods were combined to take advantage of both methods. While the northern part of KAZA was mainly covered by forested land and southern areas by open bushlands, an accuracy gradient was observed from high accuracy in northern KAZA to lower accuracy in the southern parts when detecting degradation. We concluded that specific land cover types require their own VI accommodating their characteristics. Additionally, BFAST Monitor land cover specific model fine tuning as well as incorporating different data sources (such as Sentinel-1 and -2) might increase accuracies. BFAST Monitor can be applied consistently across large areas but revealed limitations when detecting degradation for sparsely vegetated land cover.

\subsection{Thesis reflection and results in perspective}

More than half a decade ago Hansen and Loveland (2012) postulated ongoing disappearance of forests by bi-temporal change detection ( 2 scenes) in favor of multiple observations ( $>\sim 30$ scenes) time series analysis techniques. The evolution of this trend is reflected in this thesis. In Chapter 2 we concluded that complete carbon accounting requires ongoing monitoring of forests to quantify net and gross carbon balances accurately, ideally when they occur. Others agree on these conclusions (Arino et al., 2012; De Sy et al., 2012). Time series analysis is a requirement that we addressed in chapters 3 and 4 for deforestation detection and in chapter 5 for land cover degradation monitoring. This section addresses our results in perspective to ongoing trends where we compared our work in a broader context in subsection 6.2.1. Sub-section 6.2.2 provides a reflection to related efforts and the last sub-section 6.2.3 of this section provides a comparison of the results from chapter 5 to the only existing comparable product by Hansen et al. (2013).

\subsubsection{Broader Implications}

In chapter 3 we found that largest differences in deforestation detection performance were caused by different forest change drivers and the properties of the related forest. Detection of gradual deforestation in Ethiopia's disturbed forests was less accurate than that of undisturbed abrupt deforestation as measured in Vietnam. Additionally, in chapter 5 we found that detection performance was dependent on tree cover canopy intensity. Thus, breakpoints-based time series deforestation detection provides the capacity to detect obvious changes when tree cover is dense but struggles to detect small more subtle changes, especially when tree cover is sparse or absent. Degradation of forest and vegetation mapped in chapter 5 was located within an area linked to very high uncertainties of biomass estimates (Avitabile et al., 2016). Additionally, in chapter 2 we identified that low biomass yields are connected to large uncertainties. Depending on the used emission factors suggested by literature forest carbon emissions were up to $700 \%$ higher than those we have estimated through field campaigns in 2011 and 2012. Thus, Landsat breakpoint detection-based deforestation and degradation 
monitoring for REDD+, is an efficient alternative to bi-temporal approaches for large areas of the tropics (e.g. Vietnam and Brazil), but does not provide accurate estimates everywhere.

\subsubsection{Implications to similar and related studies}

All BFAST Monitor studies shown in figure 6.4 make use of a single VI, therefore single VI usage is widespread practice in this context. NDMI used by DeVries et al. (2015b) on the Bonga site in Ethiopia (overlapping with our chapter 3 and 4 Ethiopia site) produced an overall accuracy for detecting forest disturbance of $78 \%$, while we achieved an accuracy of $68 \%$ for deforestation detection with the same VI. By combining multiple VI features of the site (EVI, GEMI, NDFI, SAVI, Tcw) we were able to improve our mapping performance to $76 \%$. DeVries used a parametric generalized linear model (GLM) thresholdbased method to fine tune his results while we used a machine learning based approach. As a result, DeVries's individually well calibrated threshold method is performance wise comparable to our selflearning machine-based classification. However, in contrast to this threshold approach ours was applicable with no further human calibration other than existing reference data to different sites as the selection and weighting of VIs usage was chosen by the machine learning algorithm. This raises the question at which scale it becomes more efficient that a machine decides on method calibration rather than a human. Figure 6.2 provides a subset of the fusion results displayed in chapter 4 where mapping accuracy increased, and error of commission decreased as different VIs were fused at feature level. For application across large areas (33x larger then DeVries's site) in chapter 5 (KAZA, approx 3,000km south of Bonga) we used a generic simplification of DeVries's threshold approach and found that the machinebased results were better. Hence, small scale application benefit from human thought calibration as specific details can be understood and accommodated while large scale applications with their variety of specific differences can be addressed with similar performance by machine learning algorithms. Application of random forest machine learning was also found useful in similar studies when incorporating ground truth observations captured by community based monitoring (CBM) (Pratihast et al., 2016, 2014).

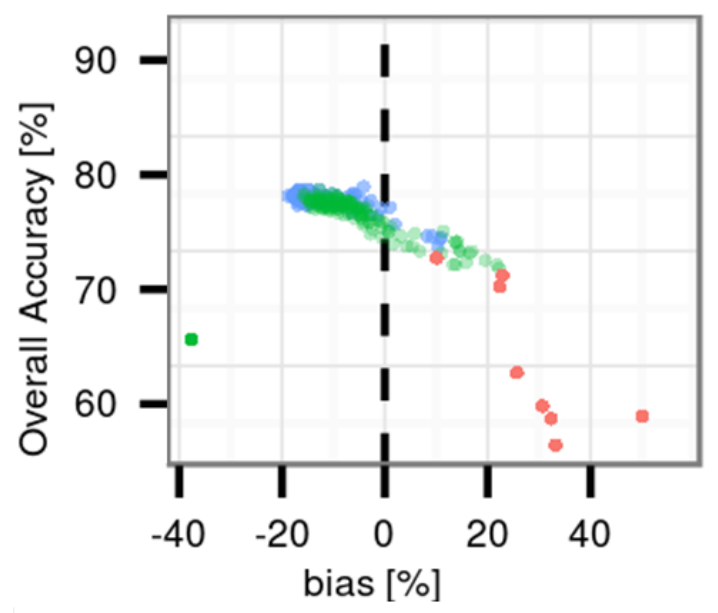

Figure 6.2 Plots depicting bias and overall accuracy for all possible fusion combinations for the Bonga Ethiopia site, red dots (single VI), green dots 2-4 VIs combined, blue dots $>4$ VIs combined. Positive bias indicates that errors produced by overestimation are higher than by underestimation of change, and the opposite is true for a negative bias. 
Besides the common usage of a single VI for BFAST Monitor related studies even more remarkable is the overwhelming usage of NDVI for similar studies despite its deficiencies in contrast to other VIs such as NDMI, Tasseled cap wetness or NDFI. A survey of scientific studies listed in Scopus where key words related to "remote sensing" or "earth observation" and "forest or rainforest" and NDVI or EVI or SAVI or NDMI/Normalized Difference Wetness Index (NDWI = NDMI) revealed that roughly $80 \%$ of all studies made use of the NDVI, although only $6 \%$ of studies made use of NDMI (Figure 6.3). Results of chapter 4 reflect that other VIs deserve more attention as they can yield higher accuracies. Even more remarkable is that to date less than ten scientific studies make use of the most accurate VI for tropical forest earth observation application, the NDFI (Reiche et al., 2013; Schultz et al., 2016a; Souza et al., 2013, 2005).

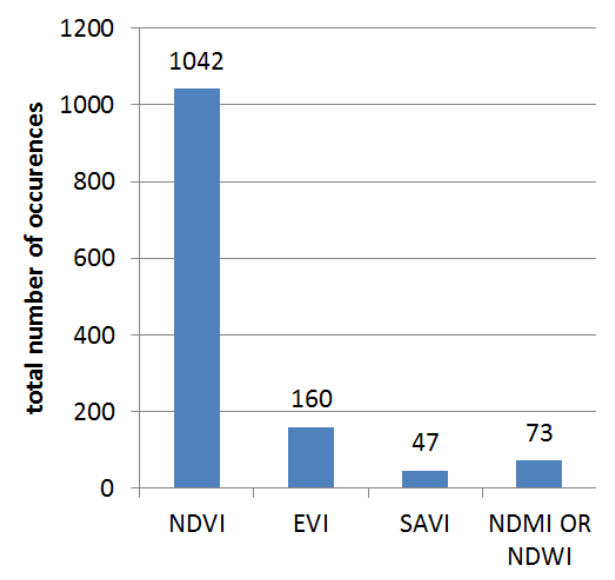

Figure 6.3 Occurrences of VIs in scientific literature of peer-reviewed remote sensing forestry journal articles in Scopus where the VI occurs for search hits for the combination of 'remote sensing', 'forestry' and the specific VI (e.g. 'NDVI')

Usage of NDFI or VI fusion can improve accuracy and thus credibility of BFAST Monitor studies related to reconstructing of tropical forest land use history (Dutrieux et al., 2016), suppression of noise and normalization of seasonality (Hamunyela et al., 2016) or tracking disturbance regrowth (DeVries et al., 2015a).

Figure 6.4 shows how our studies were spatially aligned with the existing body of literature dealing with similar activities. Error sources and VI suitability surrounding areas close to our sites in Chapter 3 and 4 can benefit from an increased understanding of researched BFAST Monitor error sources and VI suitability. Chapter 2-4 relate to Grogan's et al. (2016) usage of NDMI for deforestation detection in south east Asia and hence put them in perspective to NDFI performance and potential linked to carbon emission caused by deforestation (Chapter 2). Reflections concerning the Ethiopian site related to DeVries et al. (2015b) and Pratihast et al. (2014) were expressed earlier in this section. BFAST NDVI based vegetation dynamics assessment of Mt. Kilimanjaro (Detsch et al., 2016) relates to our study of chapter 5 where vegetation degradation was assessed under similar conditions similarly concluding of performance difference caused by differing vegetation cover. The Brazil site of the thesis is surrounded by an abundance of studies. Due to the importance of changes occurring in the Amazon forest to global life itself, most BFAST related research was performed by Wageningen University (Dutrieux et al., 2016; 
Hamunyela et al., 2016; Jakovac et al., 2017) benefiting from aforementioned BFAST Monitor suitability identified in this thesis.

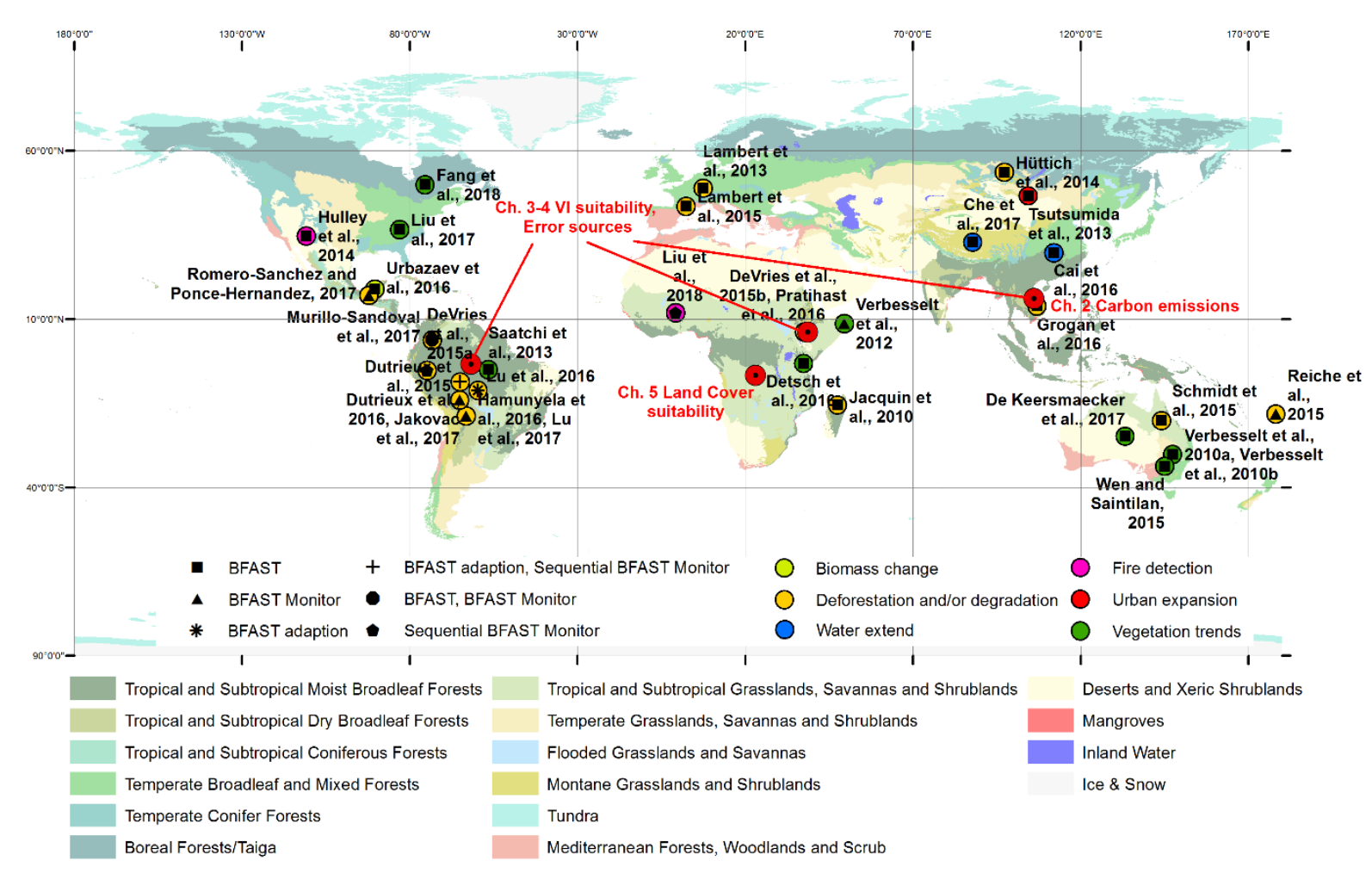

Figure 6.4 Studies addressed in this thesis are shown in red and current locations of scientific BFAST applications in black; symbols show BFAST type and colored circles show BFAST mapping applications (edit from chapter 1 )

\subsubsection{Comparison with current Hansen map}

In this section, the forest loss map of (Hansen et al., 2013) was compared with the land cover degradation map created in chapter 5 . We acknowledge that the definition of forest loss of Hansen's map is different from that of our product, thus limiting comparison. However, both products claim to detect forest decline for the KAZA area using Landsat. Hence, the products share the same sensor specifications, data and cover the same temporal range. Non-forest land was masked using the land cover map of chapter 5 and the remaining classes closed wood land and closed forest were combined and are in this section referred to as forest (covering $8 \%$ of KAZA). Hansen's map suggests that a total of 53,300 ha (1.2 \%) of forest was lost from 2006 - 2016 for the study site. Our map in contrast suggested a forest degradation of 149,754 ha (3.1\%), about 96,454 ha more than Hansen. Both maps change areas combined sum up to 188,707 ha and agree on 14,347 (7\%) of the combined detected change areas. Simple accuracy measures (Congalton, 1991) were calculated using the reference data base of chapter 5 , where overall accuracy of the chapter 5 degradation map was $81 \%$ and overall accuracy of Hansen's 
map was $58 \%$. Producer's accuracy was dissimilar between the products, accounting $22 \%$ for Hansen's map and $71 \%$ for our map, while user's accuracy was similar ( $88 \%$ and $90 \%$, respectively). Thus, both maps tend to omit change, to a larger extent in Hansen's map, while both maps slightly overestimate change. It is important to recap that the used reference data was not limited to forest loss but covers also forest degradation and thus potentially suggest that areas have changed which were not yet completely deforested. One mayor reason for Hansen's large omission error is that the product is targeting deforestation while being compared against a degradation targeted reference database.

Figure 6.5 shows the spatial patterns of the detected forest changes in both, our map (chapter 5) and Hansen's. The overlap between both maps is shown in blue. Hot spots of changes were similar and overlapped in both products. Disagreement occurred near overlapping changes. Chapter 5 degradation spots were generally scattered in all kinds of forms while Hansen's changes were in most cases rectangular patches. Subset a) shows degradation occurrence as it can be the result of infrastructure development, b) shifting cultivation patterns and c) and d) multiple change types. 


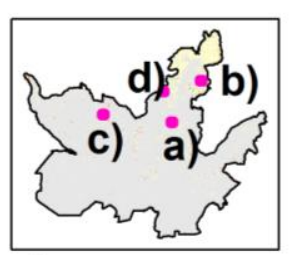

a)

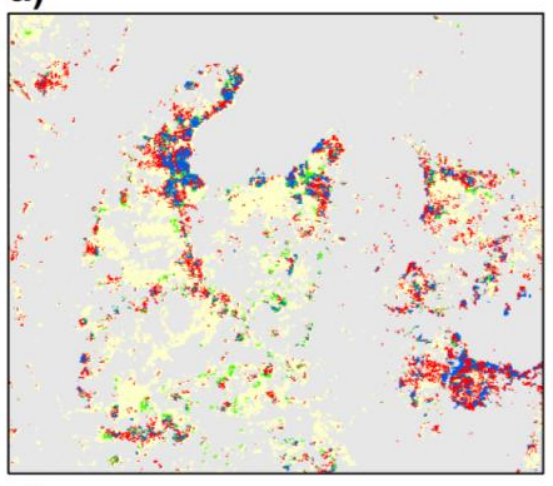

c)

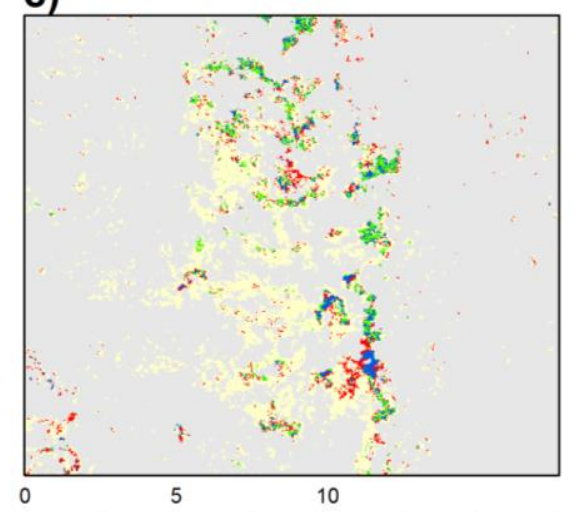

forest loss/degradation stable

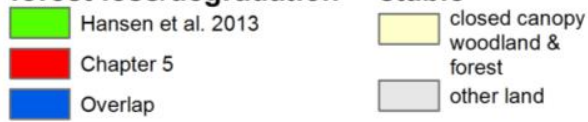

b)

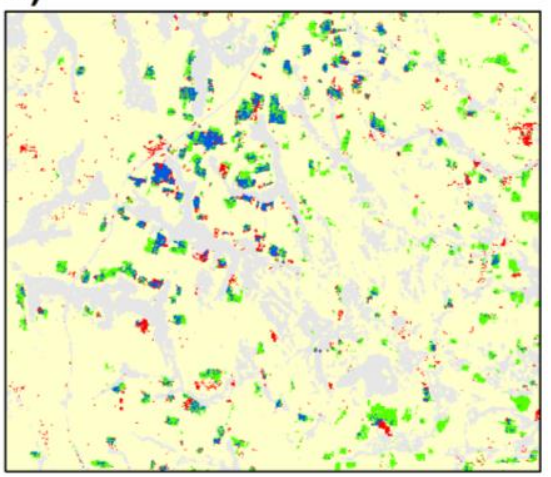

d)

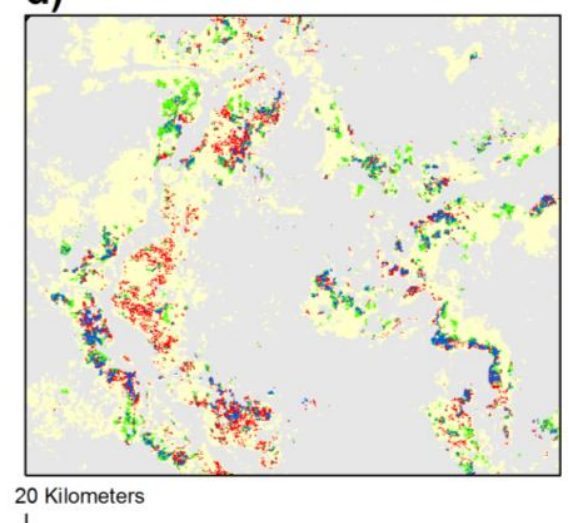

Figure 6.5 Comparison of the chapter 5 degradation map and the 2016 version of Hansen forest loss map (Hansen et al., 2013). Degradation occurrence from 2006 - 2016 is shown in RGB; top left rectangle shows KAZA and provides an overview of the location of four selected subsets $(a-d)$

\subsection{Outlook}

Previously, capacities of countries to monitor deforestation were identified as 'low' (Romijn et al., 2012). The method proposed in chapter 5 was recently successfully applied in southern Laos within a certified REDD+ system, generating carbon credits today. Operational transferability of our method alongside capacity building for locals to perform time series based remote sensing deforestation monitoring themselves was demonstrated (TÜV SÜD, 2018). Because Laos was identified to possess low capacities to implement a REDD+ project but successfully did so using our methods, implementation of a remote sensing-based deforestation monitor system seems not to be a matter of capacity but of political will.

Although few countries monitor deforestation (De Sy et al., 2015), the ease of access and grasp for such activities was never better due to the intuitive concept of time series analysis. Three key pillars will 
shape the implementation of deforestation monitoring for everyone's convenient use. First, an advance in remote sensing technologies with a new generation of satellite systems (section 6.3.1). Secondly, omnipresent fast and cheap access to processing infrastructures such as the Amazon Web Service (AWS) or Google Earth Engine (GEE) as demonstrated by (Hansen et al., 2013). A stable infrastructure from the client side within Annex I countries is not necessary, as servers are located within stable grids (e.g. Europe or Northern America) and are suited for uninterrupted running in an automatized monitoring practice by machines. Rapid growth of processing power is ingrained by Moore's law, whereas novelty for its application is brought by the increasingly high-speed internet even in most remote places. Thirdly, within Annex I countries an increase of ground truth data collection by locals (Pratihast et al., 2016) embedded in citizen science (CS) projects is occurring. Aiming at calibrating previously mentioned machine dependent processing infrastructures using mostly mobile devices and related applications, a process known as citizen observatory or in REDD+ terms community-based monitoring (CBM) is getting more and more important (section 6.3.2).

\subsubsection{Remote sensing potentials}

Increased observation frequency is arguably the most important factor providing leverage for improving deforestation monitoring performance and beyond. Any observation created today is priceless as it can never be re-created (Woodcock and Ozdogan, 2012). BFAST Monitor relies on a high frequency of available observations during the historic period to avoid errors of commission and on high frequency of observations within the monitoring period to avoid errors of omission. Research combining multiple Remote Sensing data sources is increasingly prolific (Murillo-Sandoval et al., 2017) and broadly recognized as important avenue in remote sensing science (Reiche et al., 2016). Moderate Resolution Imaging Spectroradiometer (MODIS) (Hilker et al., 2009) and Advanced Land Observing Satellite (ALOS) fusion with Landsat were interlinked to populate past time series in order to increase observation density (Reiche et al., 2013). Specifically the fusion of RADAR and optical data is suited to accommodate detection of deforestation in densely clouded areas (Reiche et al., 2018). Inter-calibration of strategic missions brings data together that naturally complement each other. For instance, Landsat-8, Sentinel2A and Sentinel-2B provide a global median average revisit interval of 2.9 days (Li and Roy, 2017).

\subsubsection{Combination with volunteer geographic information (VGI) and community-based monitoring (CBM)}

By using part of the reference data as training for a supervised classification we have shown in chapter 4 and 5 how this training set can be of use as additional step for post-processing detected changes. In chapter 5 non-parametric machine learning post-processed results created higher accuracies than parametric threshold based approaches. Although both approaches used part of the reference data provided by a human to calibrate a model, the machine learning based method yielded a higher accuracy. Citizen Science (CS), VGI technologies (Stehman et al., 2018) and emerging technologies used in CBM (Pratihast et al., 2016) have the potential to open new avenues for land monitoring including deforestation and degradation detection. Differences between VGI and CBM vanish and it can be argued that CBM is part of VGI and thus CS. Fritz et al. (2017) compiled a global VGI reference dataset of land cover and land use consisting of more than 150,000 records, including forest. Proposed usage of geowiki.net and laco-wiki.org is adaptable to collect changes such as occurring deforestation. When fed into 
a classification procedure this might improve detection performance of a remote sensing deforestation monitoring system.

By "outsourcing" the collection of reference data into aforementioned online platforms used by Fritz et al. (2017), volunteer's contributions can be channeled into scientific use. Non-scientific citizen contributions of volunteers will advance deforestation detection science. For example, Open Foris of the Food and Agriculture Organization (FAO) provides software tools for reference data collection (http://www.fao.org/forestry/fma/openforis/en/). OpenStreetMap (OSM) provides an ecosystem of VGI applications. Fusing OSM and remote sensing by machine learning was recently implemented and this outperforming existing approaches (Schultz et al., 2017), yet no consolidated VGI RS coupled deforestation monitoring system exists. The drawback of VGI is its questionable accuracy, which has been discussed throughout its existence (Antoniou and Skopeliti, 2015; Goodchild and Li, 2012). Conflation of VGI data and expert data creation by scientist for cross checks and quality assessment is urgently needed (See et al., 2016). Hence, we envision science guided near-real time paced interlinked human crowd - machine systems for land monitoring. 


\section{References}

Achard, F., Beuchle, R., Mayaux, P., Stibig, H.-J., Bodart, C., Brink, A., Carboni, S., Desclée, B., Donnay, F., Eva, H.D., Lupi, A., Raši, R., Seliger, R., Simonetti, D., 2014. Determination of tropical deforestation rates and related carbon losses from 1990 to 2010. Glob. Change Biol. 20, 25402554.

Akaike, H., 1973. Information Theory and an Extension of the Maximum Likelihood Principle. Proc 2nd Int Symp Inf Theory 267-281.

Alley, R.B., Berntsen, T., Bindoff, N.L., Chen, Z., Chidthaisong, A., Friedlingstein, P., Gregory, J.M., Hegerl, G.C., Heimann, M., Hewitson, B., Hoskins, B.J., Joos, F., Jouzel, J., Kattsov, V., Lohmann, U., Manning, M., Matsuno, T., Molina, M., Nicholls, N., Overpeck, J., Qin, D., Raga, G., Ramaswamy, V., Ren, J., Rusticucci, M., Solomon, S., Somerville, R., 2007. IPCC report summary for policymakers, Group.

Antoniou, V., Skopeliti, A., 2015. Measures and indicators of VGI quality: An overview. ISPRS Ann. Photogramm. Remote Sens. Spat. Inf. Sci. 2, 345.

Arino, O., Asner, G., Boschetti, L., Braatz, B., Chiuvieco, E., Csiszar, I., Cutler, M., Engelhart, S., 2012. A sourcebook of methods and procedures for monitoring and reporting anthropogenic greenhous gas emissions and removals associated with deforestation, gains and losses of carbon stock in forests remaining forest, and forestation. GOFC-GOLD, Wageningen.

Atzberger, C., 2013. Advances in Remote Sensing of Agriculture: Context Description, Existing Operational Monitoring Systems and Major Information Needs. Remote Sens. 5, 949-981.

Avitabile, V., Baccini, A., Friedl, M. a., Schmullius, C., 2012. Capabilities and limitations of Landsat and land cover data for aboveground woody biomass estimation of Uganda. Remote Sens. Environ. $117,366-380$.

Avitabile, V., Herold, M., Heuvelink, G., Lewis, S.L., Phillips, O.L., Asner, G.P., Armston, J., Ashton, P.S., Banin, L., Bayol, N., others, 2016a. An integrated pan-tropical biomass map using multiple reference datasets. Glob. Change Biol. 22, 1406-1420.

Avitabile, V., Schultz, M., Herold, N., De Bruin, S., Pratihast, A.K., Manh, C.P., Quang, H.V., Herold, M., 2016b. Carbon emissions from land cover change in Central Vietnam. Carbon Manag. 7, 333346.

Baccini, A., Goetz, S.J., Walker, W.S., Laporte, N.T., Sun, M., Sulla-Menashe, D., Hackler, J., Beck, P.S., Dubayah, R., Friedl, M., Samanta, S., Houghton, R., 2012. Estimated carbon dioxide emissions from tropical deforestation improved by carbon-density maps. Nat. Clim. Change 2, 182-185.

Baccini, A., Walker, W., Carvalho, L., Farina, M., Sulla-Menashe, D., Houghton, R., 2017. Tropical forests are a net carbon source based on aboveground measurements of gain and loss. Science 358, 230-234.

Balthazar, V., Vanacker, V., Lambin, E.F., 2012. Evaluation and parameterization of ATCOR3 topographic correction method for forest cover mapping in mountain areas. Int. J. Appl. Earth Obs. Geoinformation 18, 436-450.

Berk, A., Anderson, G.P., Acharya, P.K., Shettle, E.P., 2008. MODTRAN 5.2.0.0 User's Manual. Burlington. Bhandari, S., Phinn, S., Gill, T., 2012. Preparing Landsat Image Time Series (LITS) for monitoring changes in vegetation phenology in Queensland, Australia. Remote Sens. 4, 1856-1886.

BNDES, 2009. Amazon fund annual report. Brazilian Development Bank, Brazil.

Bongers, F., Chazdon, R., Poorter, L., Peña-Claros, M., 2015. The potential of secondary forests. Science 348, 642-643.

Boyd, D.S., Danson, F.M., 2005. Satellite remote sensing of forest resources: three decades of research development. Prog. Phys. Geogr. 29, 1-26. 
Breiman, L., 2001. Random forests. Mach. Learn. 5-32.

Brink, A.B., Eva, H.D., 2009. Monitoring 25 years of land cover change dynamics in Africa: A sample based remote sensing approach. Appl. Geogr. 29, 501-512.

Broadbent, E., Asner, G., Keller, M., Knapp, D., Oliveira, P., Silva, J., 2008. Forest fragmentation and edge effects from deforestation and selective logging in the Brazilian Amazon. Biol. Conserv. 141, 1745-1757.

Broich, M., Hansen, M.C., Potapov, P., Adusei, B., Lindquist, E., Stehman, S.V., 2011. Time-series analysis of multi-resolution optical imagery for quantifying forest cover loss in Sumatra and Kalimantan, Indonesia. Int. J. Appl. Earth Obs. Geoinformation 13, 277-291.

Broich, M., Stehman, S.V., Hansen, M.C., Potapov, P., Shimabukuro, Y.E., 2009. A comparison of sampling designs for estimating deforestation from Landsat imagery: A case study of the Brazilian Legal Amazon. Remote Sens. Environ. 113, 2448-2454.

Cai, X., Feng, L., Hou, X., Chen, X., 2016. Remote sensing of the water storage dynamics of large lakes and reservoirs in the Yangtze River Basin from 2000 to 2014. Sci. Rep. 6, 36405.

Canadell, J.G., Schulze, E.D., 2014. Global potential of biospheric carbon management for climate mitigation. Nat. Commun. 5, 5282-5282.

Canty, M.J., Nielsen, A.A., 2008. Automatic radiometric normalization of multitemporal satellite imagery with the iteratively re-weighted MAD transformation. Remote Sens. Environ. 112, 1025-1036.

Card, D.H., 1982. Using known map category marginal frequencies to improve estimates of thematic map accuracy. Am. Soc. Photogramm. 48, 431-439.

Ceamanos, X., Waske, B., Benediktsson, J.A., Chanussot, J., Fauvel, M., Sveinsson, J.R., 2010. A classifier ensemble based on fusion of support vector machines for classifying hyperspectral data. Int. J. Image Data Fusion 1, 293-307.

Chambers, J.M., Hastie, T.J., 1992. Statistical Models in S. Wadsworth \& Brooks/Cole., Boca Raton.

Chander, G., Markham, B.L., Helder, D.L., 2009. Summary of current radiometric calibration coefficients for Landsat MSS, TM, ETM+, and EO-1 ALI sensors. Remote Sens. Environ. 113, 893-903.

Chave, J., Andalo, C., Brown, S., Cairns, M.A., Chambers, J., Eamus, D., Fölster, H., Fromard, F., Higuchi, N., Kira, T., others, 2005. Tree allometry and improved estimation of carbon stocks and balance in tropical forests. Oecologia 145, 87-99.

Chave, J., Coomes, D., Jansen, S., Lewis, S.L., Swenson, N.G., Zanne, A.E., 2009. Towards a worldwide wood economics spectrum. Ecol. Lett. 12, 351-366.

Chavez, P., 1989. Radiometric calibration of Landsat Thematic Mapper multispectral images. Photogramm. Eng. Remote Sens. 55, 1285-1294.

Chavez, P.S., 1988. An improved dark-object subtraction technique for atmospheric scattering correction of multispectral data. Remote Sens. Environ. 24, 459-479.

Chazdon, R.L., Broadbent, E.N., Rozendaal, D.M., Bongers, F., Zambrano, A.M.A., Aide, T.M., Balvanera, P., Becknell, J.M., Boukili, V., Brancalion, P.H., others, 2016. Carbon sequestration potential of second-growth forest regeneration in the Latin American tropics. Sci. Adv. 2, e1501639.

Che, X., Yang, Y., Feng, M., Xiao, T., Huang, S., Xiang, Y., Chen, Z., 2017. Mapping extent dynamics of small lakes using downscaling MODIS surface reflectance. Remote Sens. 9, 82.

Chen, J., Zhu, X., Vogelmann, J.E., Gao, F., Jin, S., 2011. A simple and effective method for filling gaps in Landsat ETM+ SLC-off images. Remote Sens. Environ. 115, 1053-1064.

Chuvieco, E., 2009. Fundamentals of satellite remote sensing. CRC press.

Ciais, P., Dolman, A., Bombelli, A., Duren, R., Peregon, A., Rayner, P., Miller, C., Gobron, N., Kinderman, G., Marland, G., others, 2014. Current systematic carbon-cycle observations and the need for implementing a policy-relevant carbon observing system. Biogeosciences 11, 3547-3602.

Cihlar, J., Ly, H., Li, Z., Chen, J., Pokrant, H., Huang, F., 1997. Multitemporal, multichannel AVHRR data sets for land biosphere studies - Artifacts and corrections. Remote Sens. Environ. 60, 35-57. 
Cohen, W.B., Yang, Z., Kennedy, R., 2010. Detecting trends in forest disturbance and recovery using yearly Landsat time series: 2 . TimeSync - Tools for calibration and validation. Remote Sens. Environ. 114, 2911-2924.

Congalton, R., 1991. A review of assessing the accuracy of classifications of remotely sensed data. Remote Sens. Environ. 37, 35-46.

Congalton, R. g., Green, K., 2009. Assessing the Accuraccy of remotely sensed data principles and practices. CRC press, New York.

Coppin, P.R., Bauer, M.E., 1996. Digital change detection in forest ecosystems with remote sensing imagery. Remote Sens. Rev. 13, 207-234.

Crist, E.P., 1985. SHORT COMMUNICATION A TM Tasseled Cap Equivalent Transformation for Reflectance Factor Data. Remote Sens. Environ. 306, 301-306.

Crist, E.P., Cicone, R.C., 1984. A Physically-Based Transformation of Thematic Mapper Data-The TM Tasseled Cap. IEEE Trans. Geosci. Remote Sens. GE-22, 256-263.

Czerwinski, C.J., King, D.J., Mitchell, S.W., 2014. Mapping forest growth and decline in a temperate mixed forest using temporal trend analysis of Landsat imagery, 1987-2010. Remote Sens. Environ. 141, 188-200.

DANDIA, 2008. Climate and disaster check of Danish sector programmes in Vietnam. Hanoi.

de Jong, R., Verbesselt, J., Schaepman, M.E., de Bruin, S., 2012. Trend changes in global greening and browning: contribution of short-term trends to longer-term change. Glob. Change Biol. 18, 642655.

De Keersmaecker, W., Lhermitte, S., Hill, M.J., Tits, L., Coppin, P., Somers, B., 2017. Assessment of regional vegetation response to climate anomalies: A case study for Australia using GIMMS NDVI time series between 1982 and 2006. Remote Sens. 9, 34.

De Sy, V., Herold, M., Achard, F., Asner, G.P., Held, A., Kellndorfer, J., Verbesselt, J., 2012. Synergies of multiple remote sensing data sources for REDD+ monitoring. Curr. Opin. Environ. Sustain. 4, 696-706.

De Sy, V., Herold, M., Achard, F., Beuchle, R., Clevers, J., Lindquist, E., Verchot, L., 2015. Land use patterns and related carbon losses following deforestation in South America. Environ. Res. Lett. 10, 124004.

Detsch, F., Otte, I., Appelhans, T., Hemp, A., Nauss, T., 2016. Seasonal and long-term vegetation dynamics from 1-km GIMMS-based NDVI time series at Mt. Kilimanjaro, Tanzania. Remote Sens. Environ. 178, 70-83.

DeVries, B., Decuyper, M., Verbesselt, J., Zeileis, A., Herold, M., Joseph, S., 2015a. Tracking disturbanceregrowth dynamics in tropical forests using structural change detection and Landsat time series. Remote Sens. Environ. 169, 320-334.

DeVries, B., Pratihast, A.K., Verbesselt, J., Kooistra, L., Herold, M., 2016. Characterizing forest change using community-based monitoring data and Landsat time series. PloS One 11, e0147121.

DeVries, B., Verbesselt, J., Kooistra, L., Herold, M., 2015b. Robust monitoring of small-scale forest disturbances in a tropical montane forest using Landsat time series. Remote Sens. Environ. 161, 107-121.

Don, A., Schumacher, J., Freibauer, A., 2011. Impact of tropical land-use change on soil organic carbon stocks-a meta-analysis. Glob. Change Biol. 17, 1658-1670.

DONRE, 2009. Water resources in the Vu Gia Thu Bon River Basin. Department of Natural Resources and Environment of Quangnam, Vietnam.

Drusch, M., Del Bello, U., Carlier, S., Colin, O., Fernandez, V., Gascon, F., Hoersch, B., Isola, C., Laberinti, P., Martimort, P., Meygret, ., Spoto, F., Sy, O., Marchese, F., Bargellini, P., 2012. Sentinel-2: ESA's Optical High-Resolution Mission for GMES Operational Services. Remote Sens. Environ. 120, 2536. 
DSO, 2008. Danang statistical year book 2006. Danang Statistical Office Vietnam, Danang.

Dutrieux, L.P., Jakovac, C.C., Latifah, S.H., Kooistra, L., 2016. Reconstructing land use history from Landsat time-series: Case study of a swidden agriculture system in Brazil. Int. J. Appl. Earth Obs. Geoinformation 47, 112-124.

Dutrieux, L.P., Verbesselt, J., Kooistra, L., Herold, M., 2015. Monitoring forest cover loss using multiple data streams, a case study of a tropical dry forest in Bolivia. ISPRS J. Photogramm. Remote Sens., Multitemporal remote sensing data analysis 107, 112-125.

Espírito-Santo, F.D.B., Gloor, M., Keller, M., Malhi, Y., Saatchi, S., Nelson, B., Junior, R.C.O., Pereira, C., Lloyd, J., Frolking, S., Palace, M., Shimabukuro, Y.E., Duarte, V., Mendoza, A.M., López-González, G., Baker, T.R., Feldpausch, T.R., Brienen, R.J.W., Asner, G.P., Boyd, D.S., Phillips, O.L., 2014. Size and frequency of natural forest disturbances and the Amazon forest carbon balance. Nat. Commun. 5, 3434-3434.

Evangelidis, K., Ntouros, K., Makridis, S., Papatheodorou, C., 2014. Geospatial services in the Cloud. Comput. Geosci. 63, 116-122.

Fang, X., Zhu, Q., Ren, L., Chen, H., Wang, K., Peng, C., 2018. Large-scale detection of vegetation dynamics and their potential drivers using MODIS images and BFAST: A case study in Quebec, Canada. Remote Sens. Environ. 206, 391-402.

FAO, 2011. Assessing foret degradation - Towards the development of globally applicable guidelines. Forest Resources Assessment Working Paper 117.

FAO, 2010. Global Forest Resources Assessment 2010. Rome.

Federici, S., Tubiello, F.N., Salvatore, M., Jacobs, H., Schmidhuber, J., 2015. New estimates of CO2 forest emissions and removals: 1990-2015. For. Ecol. Manag., Changes in Global Forest Resources from 1990 to 2015352 , 89-98.

Foody, G., 2002. Status of land cover classification accuracy assessment. Remote Sens. Environ. 80, 185201.

Foody, G.M., 2009. Sample size determination for image classification accuracy assessment and comparison. Int. J. Remote Sens. 30, 5273-5291.

Forkel, M., Carvalhais, N., Verbesselt, J., Mahecha, M.D., Neigh, C.S.R., Reichstein, M., 2013. Trend Change Detection in NDVI Time Series: Effects of Inter-Annual Variability and Methodology. Remote Sens. 5, 2113-2144.

Fritz, S., See, L., Perger, C., Mccallum, I., Schill, C., Schepaschenko, D., Duerauer, M., Karner, M., Dresel, C., Laso-Bayas, J.-C., others, 2017. A global dataset of crowdsourced land cover and land use reference data. Sci. Data 4, 170075.

Gao, B.-C., 1996. NDWI-A normalized difference water index for remote sensing of vegetation liquid water from space. Remote Sens. Environ. 58, 257-266.

Ghazoul, J., Sheil, D., 2010. Tropical rain forest ecology, diversity, and conservation.

Gillespie, T.W., Foody, G.M., Rocchini, D., Giorgi, A.P., Saatchi, S., 2008. Measuring and modelling biodiversity from space. Prog. Phys. Geogr. 32, 203-221.

Gislason, P.O., Benediktsson, J.A., Sveinsson, J.R., 2006. Random forests for land cover classification. Pattern Recognit. Lett. 27, 294-300.

Gislason, P.O., Benediktsson, J.A., Sveinsson, J.R., 2004. Random Forest classification of multisource remote sensing and geographic data, in: Geoscience and Remote Sensing Symposium, 2004. IGARSS '04. Proceedings. 2004 IEEE International. Presented at the Geoscience and Remote Sensing Symposium, 2004. IGARSS '04. Proceedings. 2004 IEEE International, pp. 1049-1052 vol.2.

Goetz, S.J., Hansen, M., Houghton, R.A., Walker, W., Laporte, N., Busch, J., 2015. Measurement and monitoring needs, capabilities and potential for addressing reduced emissions from deforestation and forest degradation under REDD+. Environ. Res. Lett. 10, 123001. 
Goodchild, M.F., Li, L., 2012. Assuring the quality of volunteered geographic information. Spat. Stat. 1, 110-120.

Goodwin, N.R., Coops, N.C., Wulder, M.A., Gillanders, S., Schroeder, T.A., Nelson, T., 2008. Estimation of insect infestation dynamics using a temporal sequence of Landsat data. Remote Sens. Environ. $112,3680-3689$.

Goslee, S.C., 2012. Topographic Corrections of Satellite Data for Regional Monitoring. Photogramm. Eng. Remote Sens. 78, 973-981.

Grace, J., Mitchard, E., Gloor, E., 2014. Perturbations in the carbon budget of the tropics. Glob. Change Biol. 20, 3238-3255.

Griffiths, P., Kuemmerle, T., Baumann, M., Radeloff, V.C., Abrudan, I.V., Lieskovsky, J., Munteanu, C., Ostapowicz, K., Hostert, P., 2014. Forest disturbances, forest recovery, and changes in forest types across the Carpathian ecoregion from 1985 to 2010 based on Landsat image composites. Remote Sens. Environ. 151, 72-88.

Griscom, B., Shoch, D., Stanley, B., Cortez, R., Virgilio, N., 2009. Sensitivity of amounts and distribution of tropical forest carbon credits depending on baseline rules. Environ. Sci. Policy 12, 897-911.

Grogan, K., Pflugmacher, D., Hostert, P., Verbesselt, J., Fensholt, R., 2016. Mapping Clearances in Tropical Dry Forests Using Breakpoints, Trend, and Seasonal Components from MODIS Time Series: Does Forest Type Matter? Remote Sens. 8, 657.

Gullison, R.E., Frumhoff, P.C., Canadell, J.G., Field, C.B., Daniel, C., Hayhoe, K., Avissar, R., Curran, L.M., Friedlingstein, P., Chris, D., 2007. Tropical Forests and Climate Policy. Science 316, 1-2.

Gutiérrez-Vélez, V.H., DeFries, R., 2013. Annual multi-resolution detection of land cover conversion to oil palm in the Peruvian Amazon. Remote Sens. Environ. 129, 154-167.

Gutman, G., Byrnes, R., Masek, J.G., Covington, S., Justice, C.O., Franks, S., Headley, R., 2008. Towards monitoring land-cover and land-use changes at a global scale: The Global Land Survey 2005. Photogramm. Eng. Remote Sens. 74, 6-10.

Gutman, G., Masek, J.G., 2012. Long-term time series of the Earth's land-surface observations from space. Int. J. Remote Sens. 33, 4700-4719.

Hamunyela, E., Verbesselt, J., Herold, M., 2016a. Using spatial context to improve early detection of deforestation from Landsat time series. Remote Sens. Environ. 172, 126-138.

Hansen, M.C., Loveland, T.R., 2012. A review of large area monitoring of land cover change using Landsat data. Remote Sens. Environ. 122, 66-74.

Hansen, M.C., Potapov, P.V., Moore, R., Hancher, M., Turubanova, S.A., Tyukavina, A., Thau, D., Stehman, S.V., Goetz, S.J., Loveland, T.R., Kommareddy, A., Egorov, A., Chini, L., Justice, C.O., Townshend, J.R.G., 2013. High-Resolution Global Maps of 21st-Century Forest Cover Change. Science 342, 850-853.

Hansen, M.C., Potapov, P. V, Moore, R., Hancher, M., Turubanova, S.A., Tyukavina, A., 2013. HighResolution Global Maps of 21st-Century Forest Cover Change. Science 134, 850-853.

Hardisky, M.A., Klemas, V., Smart, R.M., 1983. The Influence of Soil Salinity , Growth Form , and Leaf Moisture on-the Spectral Radiance of partina alterniflora Canopies. Photogramm. Eng. Remote Sens. 49, 77-83.

Harris, N.L., Brown, S., Hagen, S.C., Saatchi, S.S., Petrova, S., Salas, W., Hansen, M.C., Potapov, P.V., Lotsch, a., 2012. Baseline Map of Carbon Emissions from Deforestation in Tropical Regions. Science 336, 1573-1576.

Hayes, D.J., Cohen, W.B., Sader, S.A., Irwin, D.E., 2008. Estimating proportional change in forest cover as a continuous variable from multi-year MODIS data. Remote Sens. Environ. 112, 735-749.

Herold, M., Román-Cuesta, R.M., Mollicone, D., Hirata, Y., Laake, P.V., Asner, G.P., Souza, C., Skutsch, M., Avitabile, V., MacDicken, K., 2011. Options for monitoring and estimating historical carbon emissions from forest degradation in the context of REDD+. Carbon Balance Manag. 6, 13. 
Herold, M., Skutsch, M., 2011. Monitoring, reporting and verification for national REDD + programmes: two proposals. Environ. Res. Lett. 6, 14002.

Hilker, T., Lyapustin, A.I., Tucker, C.J., Sellers, P.J., Hall, F.G., Wang, Y., 2012. Remote sensing of tropical ecosystems: Atmospheric correction and cloud masking matter. Remote Sens. Environ. 127, 370-384.

Hilker, T., Wulder, M. a., Coops, N.C., Seitz, N., White, J.C., Gao, F., Masek, J.G., Stenhouse, G., 2009. Generation of dense time series synthetic Landsat data through data blending with MODIS using a spatial and temporal adaptive reflectance fusion model. Remote Sens. Environ. 113, 19881999.

Hirschmugl, M., Steinegger, M., Gallaun, H., Schardt, M., 2014. Mapping Forest Degradation due to Selective Logging by Means of Time Series Analysis: Case Studies in Central Africa. Remote Sens. 6, 756-775.

Hoa, N.T., Hasegawa, T., Matsuoka, Y., 2014. Climate change mitigation strategies in agriculture, forestry and other land use sectors in Vietnam. Mitig. Adapt. Strateg. Glob. Change 19, 15-32.

Hooke, R.L., Martín-Duque, J.F., Pedraza, J., 2012. Land transformation by humans: a review. GSA Today 22, 4-10.

Horler, D., Ahern, F., 1985. Forestry information content of Thematic Mapper data. Int. J. Remote Sens. 7, 405-428.

Hosonuma, N., Herold, M., De Sy, V., De Fries, R.S., Brockhaus, M., Verchot, L., Angelsen, A., Romijn, E., 2012. An assessment of deforestation and forest degradation drivers in developing countries. Environ. Res. Lett. 7, 44009.

Houghton, J., Meira Filho, L., Lim, B., Treanton, K., Mamaty, I., others, 1997. Revised 1996 IPCC guidelines for national greenhouse gas inventories. v. 1: Greenhouse gas inventory reporting instructions.-v. 2: Greenhouse gas inventory workbook.-v. 3: Greenhouse gas inventory reference manual.

Houghton, R., Byers, B., Nassikas, A.A., 2015. A role for tropical forests in stabilizing atmospheric CO 2. Nat. Clim. Change 5, 1022.

Huang, C., Goward, S., Masek, J., Gao, F., Vermote, E., Thomas, N., Schleeweis, K., Kennedy, R., Zhu, Z., Eidenshink, J., Townshend, J., 2009. Development of time series stacks of Landsat images for reconstructing forest disturbance history. Int. J. Digit. Earth 2, 195-218.

Huang, C., Goward, S.N., Masek, J.G., Thomas, N., Zhu, Z., Vogelmann, J.E., 2010. An automated approach for reconstructing recent forest disturbance history using dense Landsat time series stacks. Remote Sens. Environ. 114, 183-198.

Huete, A., Didan, K., Miura, T., Rodriguez, E.P., Gao, X., Ferreira, L.G., 2002. Overview of the radiometric and biophysical performance of the MODIS vegetation indices. Remote Sens. Environ. 83, 195213.

Huete, A., Justice, C., Liu, H., 1994. Development of vegetation and soil indices for MODIS-EOS. Remote Sens. Environ. 49, 224-234.

Huete, A.R., 1988. A soil-adjusted vegetation index (SAVI). Remote Sens. Environ. 25, 295-309.

Huete, A.R., Liu, H.Q., Batchily, K., van Leeuwen, W., 1997. A comparison of vegetation indices over a global set of TM images for EOS-MODIS. Remote Sens. Environ. 59, 440-451.

Hulley, G., Veraverbeke, S., Hook, S., 2014. Thermal-based techniques for land cover change detection using a new dynamic MODIS multispectral emissivity product (MOD21). Remote Sens. Environ. $140,755-765$.

Hutchinson, J.M.S., Jacquin, a., Hutchinson, S.L., Verbesselt, J., 2015. Monitoring vegetation change and dynamics on U.S. Army training lands using satellite image time series analysis. J. Environ. Manage. 150, 355-366. 
Hüttich, C., Stelmaszczuk-Górska, M., Eberle, J., Kotzerke, P., Schmullius, C., 2014. Operational forest monitoring in Siberia using multi-source Earth observation data. Sib. Lesn. Ž. 1, 38-52.

Immitzer, M., Atzberger, C., Koukal, T., 2012. Tree species classification with Random forest using very high spatial resolution 8-band worldView-2 satellite data. Remote Sens. 4, 2661-2693.

IPCC, 2006. Guidelines for National Greenhouse Inventories. Geneva.

Jackson, R.D., Huete, A.R., 1991. Interpreting vegetation indices. Prev. Vet. Med. 11, 185-200.

Jacquin, A., Sheeren, D., Lacombe, J.-P., 2010. Vegetation cover degradation assessment in Madagascar savanna based on trend analysis of MODIS NDVI time series. Int. J. Appl. Earth Obs. Geoinformation 12, S3-S10.

Jakovac, C.C., Dutrieux, L.P., Siti, L., Peña-Claros, M., Bongers, F., 2017. Spatial and temporal dynamics of shifting cultivation in the middle-Amazonas river: Expansion and intensification. PLoS One 12, e0181092.

Jin, S., Sader, S. a., 2005. Comparison of time series tasseled cap wetness and the normalized difference moisture index in detecting forest disturbances. Remote Sens. Environ. 94, 364-372.

Kamwi, J.M., Kaetsch, C., Graz, F.P., Chirwa, P., Manda, S., 2017. Trends in land use and land cover change in the protected and communal areas of the Zambezi Region, Namibia. Environ. Monit. Assess. 189, 242.

Kauth, R.J., Thomas, G.S., Kauth, R.J., Thomas, G.S., 1976. The Tasselled Cap- a Graphic Description of the Spectral-Temporal Development of Agricultural Crops as Seen by Landsat*.

Kim, D.-H., Sexton, J.O., Noojipady, P., Huang, C., Anand, A., Channan, S., Feng, M., Townshend, J.R., 2014. Global, Landsat-based forest-cover change from 1990 to 2000. Remote Sens. Environ.

Klein Goldewijk, K., Beusen, A., Van Drecht, G., De Vos, M., 2011. The HYDE 3.1 spatially explicit database of human-induced global land-use change over the past 12,000 years. Glob. Ecol. Biogeogr. 20, 73-86.

Lambert, J., Denux, J.-P., Verbesselt, J., Balent, G., Cheret, V., 2015. Detecting Clear-Cuts and Decreases in Forest Vitality Using MODIS NDVI Time Series. Remote Sens. 7, 3588-3612.

Lambert, J., Drenou, C., Denux, J.-P., Balent, G., Cheret, V., 2013. Monitoring forest decline through remote sensing time series analysis. GIScience Remote Sens. 50, 437-457.

Lambin, E.F., Ehrlich, D., 1997. Land-cover changes in sub-Saharan Africa (1982-1991): Application of a change index based on remotely sensed surface temperature and vegetation indices at a continental scale. Remote Sens. Environ. 61, 181-200.

Langner, A., Hirata, Y., Saito, H., Sokh, H., Leng, C., Pak, C., Raši, R., 2014. Spectral normalization of SPOT 4 data to adjust for changing leaf phenology within seasonal forests in Cambodia. Remote Sens. Environ. 143, 122-130.

Leinenkugel, P., Wolters, M.L., Oppelt, N., Kuenzer, C., 2015. Tree cover and forest cover dynamics in the Mekong Basin from 2001 to 2011. Remote Sens. Environ. 158, 376-392.

Li, J., Roy, D.P., 2017. A Global Analysis of Sentinel-2A, Sentinel-2B and Landsat-8 Data Revisit Intervals and Implications for Terrestrial Monitoring. Remote Sens. 9, 902.

Liu, J., Heiskanen, J., Maeda, E.E., Pellikka, P.K., 2018. Burned area detection based on Landsat time series in savannas of southern Burkina Faso. Int. J. Appl. Earth Obs. Geoinformation 64, 210220.

Liu, L., Zhang, X., Yu, Y., Donnelly, A., 2017. Detecting spatiotemporal changes of peak foliage coloration in deciduous and mixedforests across the Central and Eastern United States. Environ. Res. Lett. $12,24013$.

Loveland, T.R., Dwyer, J.L., 2012. Landsat: Building a strong future. Remote Sens. Environ. 122, 22-29.

Lu, M., Hamunyela, E., Verbesselt, J., Pebesma, E., 2017. Dimension Reduction of Multi-Spectral Satellite Image Time Series to Improve Deforestation Monitoring. Remote Sens. 9, 1025. 
Lu, M., Pebesma, E., Sanchez, A., Verbesselt, J., 2016. Spatio-temporal change detection from multidimensional arrays: Detecting deforestation from MODIS time series. ISPRS J. Photogramm. Remote Sens. 117, 227-236.

Maniatis, D., Mollicone, D., 2010. Options for sampling and stratification for national forest inventories to implement REDD+ under the UNFCCC. Carbon Balance Manag. 5, 9-9.

MARD, 2012. Decision No 2089/QĐ-BNN-TCLN on forest area 2011 of Vietnam. Vietnam.

MARD, 2009. 10 largest river basins in Vietnam. Hanoi.

Markham, B.L., Helder, D.L., 2012. Forty-year calibrated record of earth-reflected radiance from Landsat: A review. Remote Sens. Environ. 122, 30-40.

Masek, J., Vermote, E., Saleous, N., Wolfe, R., Hall, F., Huemmrich, F., Gao, F., Kutler, J., Lim, T., 2012. LEDAPS Landsat calibration, reflectance, atmospheric correction preprocessing code. Model Prod. Available -Line Httpdaac Ornl Gov Oak Ridge Natl. Lab. Distrib. Act. Arch. Cent. Oak Ridge Tenn. USA

Masek, J.G., Huang, C., Wolfe, R., Cohen, W., Hall, F., Kutler, J., Nelson, P., 2008. North American forest disturbance mapped from a decadal Landsat record. Remote Sens. Environ. 112, 2914-2926.

Mason, S.J., 2001. El Niño, climate change, and Southern African climate. Environmetrics 12, 327-345.

Maynard, J.J., Karl, J.W., Browning, D.M., 2016. Effect of spatial image support in detecting long-term vegetation change from satellite time-series. Landsc. Ecol. 31, 2045-2062.

McKinney, M.L., Lockwood, J.L., 1999. Biotic homogenization: a few winners replacing many losers in the next mass extinction. Trends Ecol. Evol. 14, 450-453.

Metcalfe, S., Kepe, T., 2008. "Your Elephant on Our Land" The Struggle to Manage Wildlife Mobility on Zambian Communal Land in the Kavango-Zambezi Transfrontier Conservation Area. J. Environ. Dev. 17, 99-117.

Metz, B., Davidson, O., Bosch, P., Dave, R., Meyer, L., 2007. Climate change 2007: mitigation: contribution of working group III to the fourth assessment report of the intergovernmental panel on climate change: summary for policymakers and technical summary. Cambridge University Press.

Meyfroidt, P., Lambin, E.F., 2008a. The causes of the reforestation in Vietnam. Land Use Policy 25, 182197.

Meyfroidt, P., Lambin, E.F., 2008b. Forest transition in Vietnam and its environmental impacts. Glob. Change Biol. 14, 1319-1336.

Minang, P.A., Van Noordwijk, M., Duguma, L.A., Alemagi, D., Do, T.H., Bernard, F., Agung, P., Robiglio, V., Catacutan, D., Suyanto, S., others, 2014. REDD+ Readiness progress across countries: time for reconsideration. Clim. Policy 14, 685-708.

Miura, T., Huete, A.R., van Leeuwen, W.J.D., Didan, K., 1998. Vegetation detection through smoke-filled AVIRIS images: An assessment using MODIS band passes. J. Geophys. Res. Atmospheres 103, 32001-32011.

Mokany, K., Raison, R., Prokushkin, A.S., 2006. Critical analysis of root: shoot ratios in terrestrial biomes. Glob. Change Biol. 12, 84-96.

MONRE, 2010. Vietnam's second national communication to the united nations framework convention on climate change. Ministry of Natural Resources and Environment, Hanoi.

MONRE, 2009. Climate change, sea level rise scenarios for Vietnam. Ministry of Natural Ressources and Environment, Hanoi.

MONRE, 2007. Climate characteristics of Central Vietnam. Ministry of Natural Ressources and Environment, Hanoi.

MONRE, 2006. Land Use Map of Quang Nam province. Ministry of Natural Ressources and Environment, Hanoi.

Morton, D.C., 2016. Forest carbon fluxes: A satellite perspective. Nat. Clim. Change 6, 346. 
Morton, D.C., DeFries, R.S., Nagol, J., Souza Jr., C.M., Kasischke, E.S., Hurtt, G.C., Dubayah, R., 2011. Mapping canopy damage from understory fires in Amazon forests using annual time series of Landsat and MODIS data. Remote Sens. Environ. 115, 1706-1720.

Mosugelo, D.K., Moe, S.R., Ringrose, S., Nellemann, C., 2002. Vegetation changes during a 36-year period in northern Chobe National Park, Botswana. Afr. J. Ecol. 40, 232-240.

Murillo-Sandoval, P.J., Van Den Hoek, J., Hilker, T., 2017. Leveraging Multi-Sensor Time Series Datasets to Map Short-and Long-Term Tropical Forest Disturbances in the Colombian Andes. Remote Sens. 9, 179.

Myneni, R.B., Hall, F.G., Sellers, P.J., Marshak, a. L., 1995. The Interpretation o Spectral Vegetation Indexes. IEEE Trans. Geosci. Remote Sens.

Nagelkerke, N.J.D., 1991. A note on a general definition of the coefficient of determination. Biometrika 78, 691-692.

Naidoo, R., Du Preez, P., Stuart-Hill, G., Beytell, P., Taylor, R., 2014. Long-range migrations and dispersals of African buffalo (Syncerus caffer) in the Kavango-Zambezi Transfrontier Conservation area. Afr. J. Ecol. 52, 581-584.

Naidoo, R., Fisher, B., Manica, A., Balmford, A., 2016. Estimating economic losses to tourism in Africa from the illegal killing of elephants. Nat. Commun. 7.

National Strategy on Green Growth, 2012. Decision No 1393/ QĐ-Tg dated on 25.Sept.2012 on approval of National Strategy on Green Growth. Vietnam.

Nellemann, C., 2012. Green carbon, black trade: illegal logging, tax fraud and laundering in the world's tropical forests. United Nations Environment Programme, GRID-Arendal.

Newman, M.E., McLaren, K.P., Wilson, B.S., 2014. Assessing deforestation and fragmentation in a tropical moist forest over 68 years; the impact of roads and legal protection in the Cockpit Country, Jamaica. For. Ecol. Manag. 315, 138-152.

NIAPP, 2005. Soil map for the province Da Nang and Quang Nam. National Institute of Agriculture Planning and Projection, Hanoi.

Nielsen, A.A., 2007. The regularized iteratively reweighted MAD method for change detection in multiand hyperspectral data. IEEE Trans. Image Process. 16, 463-478.

Olander, L.P., Gibbs, H.K., Steininger, M., Swenson, J.J., Murray, B.C., 2008. Reference scenarios for deforestation and forest degradation in support of REDD: a review of data and methods. Environ. Res. Lett. 3, 25011.

Olofsson, P., Foody, G.M., Herold, M., Stehman, S.V., Woodcock, C.E., Wulder, M.A., 2014. Good practices for estimating area and assessing accuracy of land change. Remote Sens. Environ. 148, 42-57.

Pal, M., 2005. Random forest classifier for remote sensing classification. Int. J. Remote Sens. 26, 217222.

Pan, Y., Birdsey, R., Fang, J., Houghton, R., Kauppi, P., Kurz, W.A., Phillips, O.L., Lewis, S.L., Canadell, J.G., Ciais, P., Jackson, R.B., Pacala, S., David, A., Piao, S., Rautiainen, A., Sitch, S., Large, D.H.A., Sink, P.C., 2011. Carbon Sink in the World's Forests. Wildl. Res. 8-8.

Pedroni, L., 2012. Approved VCS Methodology VM0015.

Pekel, J.-F., Cottam, A., Gorelick, N., Belward, A.S., 2016. High-resolution mapping of global surface water and its long-term changes. Nature 540, 418-422.

Pelletier, J., Ramankutty, N., Potvin, C., 2011. Diagnosing the uncertainty and detectability of emission reductions for REDD + under current capabilities: an example for Panama. Environ. Res. Lett. 6, 24005.

Penman, J., Gytarsky, M., Hiraishi, T., Krug, T., Kruger, D., Pipatti, R., Buendia, L., Miwa, K., Ngara, T., 2003. Good Practice Guidance for Land Use , Land-Use Change and Forestry (No. 4887880030). Hayama. 
Petit, C., Scudder, T., Lambin, E., 2001. Quantifying processes of land-cover change by remote sensing: resettlement and rapid land-cover changes in south-eastern Zambia. Int. J. Remote Sens. 22, 3435-3456.

Pflugmacher, D., Cohen, W.B., Kennedy, R.E., Yang, Z., 2013. Using Landsat-derived disturbance and recovery history and lidar to map forest biomass dynamics. Remote Sens. Environ.

Pinty, B., Verstraete, M.M., 1992. GEMI: a non-linear index to monitor global vegetation from satellites. Vegetatio 101, 15-20.

Poorter, L., Bongers, F., Aide, T.M., Zambrano, A.M.A., Balvanera, P., Becknell, J.M., Boukili, V., Brancalion, P.H., Broadbent, E.N., Chazdon, R.L., others, 2016. Biomass resilience of Neotropical secondary forests. Nature 530, 211.

Pratihast, A.K., DeVries, B., Avitabile, V., De Bruin, S., Herold, M., Bergsma, A., 2016. Design and implementation of an interactive web-based near real-time forest monitoring system. PloS One 11, e0150935.

Pratihast, A.K., DeVries, B., Avitabile, V., de Bruin, S., Kooistra, L., Tekle, M., Herold, M., 2014. Combining satellite data and community-based observations for forest monitoring. Forests 5, 2464-2489.

Pricope, N.G., Gaughan, A.E., All, J.D., Binford, M.W., Rutina, L.P., 2015. Spatio-Temporal Analysis of Vegetation Dynamics in Relation to Shifting Inundation and Fire Regimes: Disentangling Environmental Variability from Land Management Decisions in a Southern African Transboundary Watershed. Land 4, 627-655.

QSO, 2008. Quangnam statistical year Book 1997-2007. Quangnam Statistical Office, Vietnam.

REDD Vietnam, 2012. Vietnam's opinions on REDDC emissions reduction in the Carbon fund 4th Meeting.

Reiche, J., Hamunyela, E., Verbesselt, J., Hoekman, D., Herold, M., 2018. Improving near-real time deforestation monitoring in tropical dry forests by combining dense Sentinel-1 time series with Landsat and ALOS-2 PALSAR-2. Remote Sens. Environ. 204, 147-161.

Reiche, J., Lucas, R., Mitchell, A.L., Verbesselt, J., Hoekman, D.H., Haarpaintner, J., Kellndorfer, J.M., Rosenqvist, A., Lehmann, E.A., Woodcock, C.E., others, 2016. Combining satellite data for better tropical forest monitoring. Nat. Clim. Change 6, 120-122.

Reiche, J., Souza, C.M., Hoekman, D.H., Member, S., Verbesselt, J., Persaud, H., Herold, M., 2013. Feature Level Fusion of Multi-Temporal ALOS PALSAR and Landsat Data for Mapping and Monitoring of Tropical Deforestation and Forest Degradation. IEEE J. Sel. Top. Appl. Earth Obs. Remote Sens. 1-15.

Reiche, J., Verbesselt, J., Hoekman, D.H., Herold, M., 2015. Fusing Landsat and SAR time series to detect deforestation in the tropics. Remote Sens. Environ. 156, 276-293.

Richter, R., 2011. Atmospheric / Topographic Correction for Satellite Imagery (ATCOR - 2/3 User Guide). ATCOR-23 User Guide Version 63.

Richter, R., Kellenberger, T., Kaufmann, H., 2009. Comparison of Topographic Correction Methods. Remote Sens. 1, 184-196.

Roerink, G.J., Menenti, M., Verhoef, W., 2000. Reconstructing cloudfree NDVI composites using Fourier analysis of time series. Int. J. Remote Sens. 21, 1911-1917.

Romero-Sanchez, M.E., Ponce-Hernandez, R., 2017. Assessing and Monitoring Forest Degradation in a Deciduous Tropical Forest in Mexico via Remote Sensing Indicators. Forests 8, 302.

Romijn, E., Herold, M., Kooistra, L., Murdiyarso, D., Verchot, L., 2012. Assessing capacities of non-Annex I countries for national forest monitoring in the context of REDD+. Environ. Sci. Policy 19-20, 3348.

Romijn, E., Lantican, C.B., Herold, M., Lindquist, E., Ochieng, R., Wijaya, A., Murdiyarso, D., Verchot, L., 2015. Assessing change in national forest monitoring capacities of 99 tropical countries. For. Ecol. Manag. 352, 109-123. 
Roy, D.P., Borak, J.S., Devadiga, S., Wolfe, R.E., Zheng, M., Descloitres, J., 2002. The MODIS land product quality assessment approach. Remote Sens. Environ. 83, 62-76.

Roy, D.P., Boschetti, L., Justice, C.O., Ju, J., 2008. The collection 5 MODIS burned area product-Global evaluation by comparison with the MODIS active fire product. Remote Sens. Environ. 112, 36903707.

Roy, D.P., Wulder, M. a., Loveland, T.R., C.E., W., Allen, R.G., Anderson, M.C., Helder, D., Irons, J.R., Johnson, D.M., Kennedy, R., Scambos, T. a., Schaaf, C.B., Schott, J.R., Sheng, Y., Vermote, E.F., Belward, a. S., Bindschadler, R., Cohen, W.B., Gao, F., Hipple, J.D., Hostert, P., Huntington, J., Justice, C.O., Kilic, a., Kovalskyy, V., Lee, Z.P., Lymburner, L., Masek, J.G., McCorkel, J., Shuai, Y., Trezza, R., Vogelmann, J., Wynne, R.H., Zhu, Z., 2014. Landsat-8: Science and product vision for terrestrial global change research. Remote Sens. Environ. 145, 154-172.

Saatchi, S., Asefi-Najafabady, S., Malhi, Y., Aragão, L.E., Anderson, L.O., Myneni, R.B., Nemani, R., 2013. Persistent effects of a severe drought on Amazonian forest canopy. Proc. Natl. Acad. Sci. 110, 565-570.

Saatchi, S.S., Harris, N.L., Brown, S., Lefsky, M., Mitchard, E.T. a., Salas, W., Zutta, B.R., Buermann, W., Lewis, S.L., Hagen, S., Petrova, S., White, L., Silman, M., Morel, a., 2011. Benchmark map of forest carbon stocks in tropical regions across three continents. Proc. Natl. Acad. Sci. 2005.

Saltelli, A., Ratto, M., Andres, T., Campolongo, F., Cariboni, J., Gatelli, D., Saisana, M., Tarantola, S., 2008. Global Sensitivity Analysis. The Primer. John Wiley \& Sons, Ltd, Chichester.

Sayre, R., Dangermond, J., Frye, C., Vaughan, R., Aniello, P., Breyer, S., Cribbs, D., Hopkins, D., Nauman, R., Derrenbacher, W., others, 2014. A new map of global ecological land units-an ecophysiographic stratification approach. Wash. DC Assoc. Am. Geogr.

Schmidt, M., Lucas, R., Bunting, P., Verbesselt, J., Armston, J., 2015. Multi-resolution time series imagery for forest disturbance and regrowth monitoring in Queensland, Australia. Remote Sens. Environ. $158,156-168$.

Schmitt, C.B., Senbeta, F., Denich, M., Preisinger, H., Boehmer, H.J., 2010. Wild coffee management and plant diversity in the montane rainforest of southwestern Ethiopia. Afr. J. Ecol. 48, 78-86.

Scholz, I., Schmidt, L., 2008. Reducing emissions from deforestation and forest degradation in developing countries: meeting the main challenges ahead. Deutsches Institut für Entwicklungspolitik Bonn.

Schultz, M., Clevers, J., Carter, S., Verbesselt, J., Avitabile, V., Vu Quang, Hien, 2016a. Performance of vegetation indices from Landsat time series in deforestation monitoring. Int. J. Appl. Earth Obs. Geoinformation 52, 318-327.

Schultz, M., Verbesselt, J., Avitabile, V., Souza, C., Herold, M., 2016b. Error sources in deforestation detection using BFAST monitor on Landsat time series across three tropical sites. IEEE J. Sel. Top. Appl. Earth Obs. Remote Sens. 9, 3667-3679.

Schultz, M., Verbesselt, J., Herold, M., Avitabile, V., 2013. Assessing error sources for Landsat time series analysis for tropical test sites in Viet Nam and Ethiopia. Earth Resour. Environ. Remote SensingGIS Appl. IV 23-25 Sept. 2013 Dresd. Ger. 8893, 11-11.

Schultz, M., Voss, J., Auer, M., Carter, S., Zipf, A., 2017. Open land cover from OpenStreetMap and remote sensing. Int. J. Appl. Earth Obs. Geoinformation 63, 206-213.

Schwarz, G., 1978. Estimating the Dimension of a Model. Ann. Stat. 6, 461-464.

See, L., Mooney, P., Foody, G., Bastin, L., Comber, A., Estima, J., Fritz, S., Kerle, N., Jiang, B., Laakso, M., others, 2016. Crowdsourcing, citizen science or volunteered geographic information? The current state of crowdsourced geographic information. ISPRS Int. J. Geo-Inf. 5, 55.

Sexton, J.O., Song, X.-P., Feng, M., Noojipady, P., Anand, A., Huang, C., Kim, D.-H., Collins, K.M., Channan, S., Dimiceli, C., Townshend, J.R., 2013. Global, 30-m resolution continuous fields of tree cover: 
Landsat-based rescaling of MODIS Vegetation Continuous Fields with lidar-based estimates of error. Int. J. Digit. Earth 130321031236007-130321031236007.

Shimabukuro, Y.E., Batista, G.T., Mello, E.M.K., Moreira, J.C., Duarte, V., 1998. Using shade fraction image segmentation to evaluate deforestation in Landsat Thematic Mapper images of the Amazon Region. Int. J. Remote Sens. 19, 535-541.

Singh, A., 1989. Review article digital change detection techniques using remotely-sensed data. Int. J. Remote Sens. 10, 989-1003.

Skole, D., Tucker, C., 1993. Tropical Deforestation and Habitat Fragmentation in the Amazon: Satellite Data from 1978 to 1988. Science 260, 1905-1910.

Song, C., Woodcock, C.E., Seto, K.C., Lenney, M.P., Macomber, S.A., 2001. Classification and Change Detection Using Landsat TM Data : When and How to Correct Atmospheric Effects ? Remote Sens. Environ. 75, 230-244.

Souza, C., Cochrane, M., Sales, M., Monteiro, A., Mollicone, D., 2009. Case studies on measuring and assessing forest degradation integrating forest transects and remote sensing data to quantify carbon loss due to degradation in the Brazilian Amazon. Rome.

Souza, C., Siqueira, J., Sales, M., Fonseca, A., Ribeiro, J., Numata, I., Cochrane, M., Barber, C., Roberts, D., Barlow, J., 2013. Ten-Year Landsat Classification of Deforestation and Forest Degradation in the Brazilian Amazon. Remote Sens. 5, 5493-5513.

Souza, C.M., Roberts, D. a., Cochrane, M. a., 2005. Combining spectral and spatial information to map canopy damage from selective logging and forest fires. Remote Sens. Environ. 98, 329-343.

Souza Jr., C.M., Roberts, D.A., Cochrane, M.A., 2005. Combining spectral and spatial information to map canopy damage from selective logging and forest fires. Remote Sens. Environ. 98, 329-343.

Stehman, S.V., Fonte, C.C., Foody, G.M., See, L., 2018. Using volunteered geographic information (VGI) in design-based statistical inference for area estimation and accuracy assessment of land cover. Remote Sens. Environ. 212, 47-59.

Stibig, H.-J., Achard, F., Carboni, S., Rasi, R., Miettinen, J., 2014. Change in tropical forest cover of Southeast Asia from 1990 to 2010. Biogeosciences 11, 247.

Strahler, A.H., Boschetti, L., Foody, G.M., Friedl, M.A., Hansen, M.C., Herold, M., Morisette, J.T., Stehman, S.V., Woodcock, C.E., 2006. GLOBAL LAND COVER VALIDATION: RECOMMENDATIONS FOR EVALUATION AND ACCURACY ASSESSMENT OF GLOBAL LAND COVER MAPS. JRC European Commission.

Tachikawa, T., Kaku, M., Iwasaki, A., Gesch, D., Oimoen, M., Zhang, Z., Danielson, J., Krieger, T., Curtis, B., Haase, J., Abrams, M., Crippen, R., Carabajal, C., 2011. ASTER Global Digital Elevation Model Version 2 - Summary of Validation Results.

Tan, B., Masek, J.G., Wolfe, R., Gao, F., Huang, C., Vermote, E.F., Sexton, J.O., Ederer, G., 2013. Improved forest change detection with terrain illumination corrected Landsat images. Remote Sens. Environ. 136, 469-483.

Thompson, M., 2014. Land-Cover Classification for Peace Parks, KAZA Extension for Namibia, Botswana, Zimbabwe and Zambia - Data Users Report and Meta Data. GeoTerralmage, Pretoria.

Thonfeld, F., Hecheltjen, A., Braun, M., Menz, G., 2010. From algorithms to processing chains: a review of land cover and land use change detection methodologies, in: ESA Living Planet Symposium.

Townshend, J.R.G., Justice, C.O., 1988. Selecting the spatial resolution of satellite sensors required for global monitoring of land transformations. Int. J. Remote Sens. 9, 187-236.

Townshend, J.R.G., Justice, C.O., McManus, J., 1992. The impact of misregistration on change detection. IEEE Trans. Geosci. Remote Sens. 30, 1054-160.

Trenberth, K.E., Anthes, R.A., Belward, A., Brown, O.B., Habermann, T., Karl, T.R., Running, S., Ryan, B., Tanner, M., Wielicki, B., 2013. Challenges of a Sustained Climate Observing System, in: Asrar, G.R., Hurrell, J.W. (Eds.), Climate Science for Serving Society. Springer Netherlands, pp. 13-50. 
Tsutsumida, N., Saizen, I., Matsuoka, M., Ishii, R., 2013. Land cover change detection in Ulaanbaatar using the breaks for additive seasonal and trend method. Land 2, 534-549.

Tubiello, F.N., Salvatore, M., Ferrara, A.F., House, J., Federici, S., Rossi, S., Biancalani, R., Condor Golec, R.D., Jacobs, H., Flammini, A., Prosperi, P., Cardenas-Galindo, P., Schmidhuber, J., Sanz Sanchez, M.J., Srivastava, N., Smith, P., 2015. The Contribution of Agriculture, Forestry and other Land Use activities to Global Warming, 1990-2012. Glob. Change Biol. 21, 2655-2660.

Tucker, C., Pinzon, J., Brown, M., Slayback, D., Pak, E., Mahoney, R., Vermote, E., El Saleous, N., 2005. An extended AVHRR 8-km NDVI dataset compatible with MODIS and SPOT vegetation NDVI data. Int. J. Remote Sens. 26, 4485-4498.

Tucker, C.J., 1979. Red and photographic infrared linear combinations for monitoring vegetation. Remote Sens. Environ. 8, 127-150.

TÜV SÜD, 2018. Reducing emissions from deforestation and carbon enhancement from in Xe Pian National Protected Area, Lao PDR. Environmental Technology, Carbon Management Service Solitaire, I.T.I. Road, Aundh, Pune- 411007, INDIA.

UN, 2012. Climate change Fact Sheet: the effects of climate change in Viet Nam and the UN's Responses. UN New York.

UNFCCC, 2016. UNFCCC REDD+ [WWW Document]. UNFCCC. URL http://unfccc.int/land_use_and_climate_change/redd/items/7377.php (accessed 1.26.16).

UNFCCC, 2008. Challenges and opportunities for mitigation in the agricultural sector. U. N. Framew. Conv. Clim. Change.

UNFCCC, 2002. The Marrakesh Accords \& The Marrakesh Declaration.

Urbazaev, M., Thiel, C., Migliavacca, M., Reichstein, M., Rodriguez-Veiga, P., Schmullius, C., 2016. Improved Multi-Sensor Satellite-Based Aboveground Biomass Estimation by Selecting Temporally Stable Forest Inventory Plots Using NDVI Time Series. Forests 7, 169.

USGS, 2016. Landsat Processing Details.

van der Werf, G., Morton, D., DeFries, R., Oliver, J., Kasubhatla, P., Jackson, R., Collatz, G., Randerson, J., 2009. CO 2 emissions from forest loss. Nature 2, 737-738.

van der Werf, G.R., Morton, D.C., DeFries, R.S., Olivier, J.G.J., Kasibhatla, P.S., Jackson, R.B., Collatz, G.J., Randerson, J.T., 2009. CO2 emissions from forest loss. Nat. Geosci. 2, 737-738.

Vanonckelen, S., Lhermitte, S., Van Rompaey, A., 2013. The effect of atmospheric and topographic correction methods on land cover classification accuracy. Int. J. Appl. Earth Obs. Geoinformation 24, 9-21.

Vargas, R., Paz, F., de Jong, B., 2013. Quantification of forest degradation and belowground carbon dynamics: Ongoing challenges for monitoring, reporting and verification activities for REDD+. Taylor \& Francis.

Venables, W.N., Ripley, B.D., 2002. Modern Applied Statistics with S. Springer, New York.

Verbesselt, J., Hyndman, R., Newnham, G., Culvenor, D., 2010a. Detecting trend and seasonal changes in satellite image time series. Remote Sens. Environ. 114, 106-115.

Verbesselt, J., Hyndman, R., Zeileis, A., Culvenor, D., 2010b. Phenological change detection while accounting for abrupt and gradual trends in satellite image time series. Remote Sens. Environ. 114, 2970-2980.

Verbesselt, J., Zeileis, A., Herold, M., 2012. Near real-time disturbance detection using satellite image time series. Remote Sens. Environ. 123, 98-108.

Vermote, E.F., Tanré, D., Deuzé, J.L., Herman, M., Morcrette, J.-J., 1997. Second Simulation of the Satellite Signal in the Solar Spectrum, 6s : An Overview. IEEE Trans. Geosci. Remote Sens. 35.

Vietnam National Strategy on Climate Change, 2011. Decision No 2193/QD-Tg dated on 05 Oct.2011 about approval of National Strategy on Climate Change. Vietnam. 
Wardlow, B.D., Egbert, S.L., Kastens, J.H., 2007. Analysis of time-series MODIS 250??m vegetation index data for crop classification in the U.S. Central Great Plains. Remote Sens. Environ. 108, 290-310.

Waters, C.N., Zalasiewicz, J., Summerhayes, C., Barnosky, A.D., Poirier, C., uszka, A.G., Cearreta, A., Edgeworth, M., Ellis, E.C., Ellis, M., Jeandel, C., Leinfelder, R., McNeill, J.R., Richter, D. deB, Steffen, W., Syvitski, J., Vidas, D., Wagreich, M., Williams, M., Zhisheng, A., Grinevald, J., Odada, E., Oreskes, N., Wolfe, A.P., 2016. The Anthropocene is functionally and stratigraphically distinct from the Holocene. Science 351.

Watts, L.M., Laffan, S.W., 2014. Effectiveness of the BFAST algorithm for detecting vegetation response patterns in a semi-arid region. Remote Sens. Environ. 154, 234-245.

Wen, L., Saintilan, N., 2015. Climate phase drives canopy condition in a large semi-arid floodplain forest. J. Environ. Manage. 159, 279-287.

Wilson, E.H., Sader, S.A., 2002. Detection of forest harvest type using multiple dates of Landsat TM imagery. Remote Sens. Environ. 80, 385-396.

Wingate, V.R., Phinn, S.R., Kuhn, N., Bloemertz, L., Dhanjal-Adams, K.L., 2016. Mapping decadal land cover changes in the woodlands of north eastern Namibia from 1975 to 2014 using the Landsat satellite archived data. Remote Sens. 8, 681.

Woodcock, C.E., Allen, R., Anderson, M., Belward, A., Bindschadler, R., Cohen, W., Gao, F., Goward, S., Helder, D., Helmer, E., Nemani, R., Oreopoulos, L., Schott, J., Thenkabail, P., Vermote, E.F., Vogelmann, J.E., Wulder, M.A., Wynne, R., 2008. Free Access to Landsat Imagery. Science 320.

Woodcock, C.E., Ozdogan, M., 2012. Trends in Land Cover Mapping and Monitoring, in: Gutman, D.G., Janetos, A.C., Justice, C.O., Moran, D.E.F., Mustard, J.F., Rindfuss, R.R., Skole, D., II, B.L.T., Cochrane, M.A. (Eds.), Land Change Science. Springer Netherlands, pp. 367-377.

World Bank, 2008. Forest carbon partnership facility (FCPF) readiness plan idea note (R-PIN) for Vietnam. Washington DC.

Wulder, M.A., Franklin, S.E., 2012. Remote sensing of forest environments: concepts and case studies. Springer Science \& Business Media.

Wulder, M.A., Masek, J.G., Cohen, W.B., Loveland, T.R., Woodcock, C.E., 2012. Opening the archive: How free data has enabled the science and monitoring promise of Landsat. Remote Sens. Environ., Landsat Legacy Special Issue 122, 2-10.

Wulder, M., Franklin, S., 2003. Remote Sensing of Forest Environments. Kluwer Academic Publishers, Boston.

Zanne, A., Lopez-Gonzalez, G., Coomes, D., Ilic, J., Jansen, S., Lewis, S., Miller, R., Swenson, N., Wiemann, M., Chave, J., 2009. Data from: towards a worldwide wood economics spectrum. Dryad Digital Reposit.

Zarin, D.J., Harris, N.L., Baccini, A., Aksenov, D., Hansen, M.C., Azevedo-Ramos, C., Azevedo, T., Margono, B.A., Alencar, A.C., Gabris, C., others, 2016. Can carbon emissions from tropical deforestation drop by $50 \%$ in 5 years? Glob. Change Biol. 22, 1336-1347.

Zhu, Z., 2017. Change detection using landsat time series: A review of frequencies, preprocessing, algorithms, and applications. ISPRS J. Photogramm. Remote Sens. 130, 370-384.

Zhu, Z., Woodcock, C.E., 2014. Continuous change detection and classification of land cover using all available Landsat data. Remote Sens. Environ. 144, 152-171.

Zhu, Z., Woodcock, C.E., 2012. Object-based cloud and cloud shadow detection in Landsat imagery. Remote Sens. Environ. 118, 83-94. 


\section{Summary}

Addressing climate change is an important task for mankind. Because deforestation is the second largest source of greenhouse gas emissions, one approach deemed appropriate to address climate change is reducing emissions from deforestation and forest degradation (REDD+). For this approach spatial explicit information of forest changes is required. Among other tools, remote sensing is particularly useful as it is applicable for large areas and can provide a consistent source of information. Among existing remote sensing missions, the Landsat program provides globally available, medium resolution, temporal consistent observations of the earth surface. When these observations are organized in time series, algorithms can be used to estimate whether a forest has disappeared or remained stable. In combination with knowledge of affected forest emission factors carbon emissions of forest can be measured historically. Currently an increasing number of approaches is facilitating time series analysis using hundreds of observations for each location allowing automatized large-scale time series analysis. The Breaks For Additive Season and Trend (BFAST) Monitor method is increasingly applied and useful for breakpoint detection of time series. Breakpoints can appear in time series when observations deviate from the behavior that was expected.

Literature suggested that BFAST Monitor was increasingly used for various applications including deforestation monitoring. We found that in the light of carbon accounting, continuous and reproducible deforestation detection is necessary. Hence, aim of our work was to understand to which extent BFAST Monitor can serve as a tool for this purpose. Central question to our research ambition was how different input features and post-processing strategies of BFAST Monitor will affect deforestation detection performance. By keeping the analysis method stable but varying sites, indices, forest and vegetation types, forest cover, pre-processing and post-processing we understood the limitations and suitability of BFAST Monitor for different conditions related to deforestation monitoring.

In chapter 2 we specified carbon emission pools caused by tropical deforestation and created a historical carbon balance based on field measurements and Landsat data. In accordance with existing literature we identified that deforestation is the largest source of carbon emissions from land cover change. Involved above-ground biomass (AGB), below-ground biomass (BGB) and soil organic carbon (SOC) were measured for different forest types to quantify carbon dioxide $\left(\mathrm{CO}_{2}\right)$ greenhouse gas (GHG) emission pools caused by deforestation. We concluded that a continuous deforestation monitor provides valuable information for accounting carbon emissions from tropical deforestation. Time series analysis such as BFAST Monitor can offer such capacities and justification for its application was identified.

As a result, in chapter 3 we researched the BFAST Monitor method as a tool for detecting breakpoints related to deforestation. The performance for detecting deforestation areas (activity data) using Normalized Difference Vegetation Index (NDVI) Landsat Time Series (LTS) for three sites (Brazil, Ethiopia and Vietnam) across the tropics characterized by different forests, environments and data properties was tested. Error sources for omission and commission of deforestation detection were studied. We concluded that BFAST Monitor can be a suitable deforestation detection method. We found that the 
major sources of error were caused by data variance and observation frequency and accuracy varied largely by site.

Because the NDVI only uses the red and Near-Infrared (NIR) reflectance, the suitability of other Vegetation Indices (VIs) for deforestation detection was tested in chapter 4 for the three aforementioned study sites. Site and forest specific VI suitability was identified and sensitivity of VIs to important error sources reported. We concluded that the spectral mixture analysis (SMA) based Normalized Difference Fraction Index (NDFI) was most successful in comparison to other popular indices like Normalized Difference Moisture Index (NDMI), Tasselled Cap wetness (TCW), Tasselled Cap greenness (TCg), Enhanced Vegetation Index (EVI), Soil Adjusted Vegetation Index (SAVI) or Global Environment Monitoring Index (GEMI). In addition, VIs were fused at feature level to expose their complementary use.

While previous chapters exclusively focused on detecting deforestation in closed forest and densely vegetated forest, within chapter 5 we explored to which extent BFAST Monitor can be a reliable degradation detection method across other vegetation land cover types which can include trees (closed canopy woodland, closed canopy forest, closed canopy bushland, open canopy woodland, open canopy bushland, open grassland). For this purpose, we shifted terminology from deforestation to degradation detection to accommodate the possibility that vegetation was not entirely removed and to allow comparison of different land covers. For instance, a grassland cannot be deforested as it does not contain trees but can be exposed to degradation. We concluded that the BFAST Monitor performance varied for different land cover types. High accuracies were achieved for closed canopy and forested land cover, while open canopies yielded low accuracies.

We concluded that BFAST Monitor is particularly useful for the detection of distinct deforestation when observation frequency is high. Errors of commission can be avoided when more observations are available in the historic period and errors of omission when observations within the monitoring period are abundant. Hence, BFAST Monitor particularly benefits from increased observations as they become available through sensors like Sentinel 2 and many other upcoming radio detection and ranging (RADAR) devices. Because machine learning was found useful to post-process BFAST Monitor results using reference data citizen science (CS) collected reference data, though community-based monitoring (CBM) will also shape the future of breakpoint detection. 


\section{Acknowledgements}

Christiane Schmullius is a visionary of remote sensing. Thank you for teaching me the fundamentals of remote sensing.

Martin, thank you for providing me the opportunity to write a PhD thesis at your group. Over a decade of joint evolution and collaboration connects us. I remember working as a student assistant during my Bsc. in Jena along with you. Certainly, we did not behave overly healthy, working late at night on global land cover mapping and validation with Jacqui, Mart and Keule, tossing in cakes or burgers when required. As a result, it was fun to work with you. Anyone working in your proximity may recall an anecdote about the high energy and wild opportunism revolving around your character. We created a common heritage future endeavors can build upon.

Providing guidance and invoking growth for students, is supreme mastery of a teacher. Writing these very lines at this very moment is happening because Jan (J.G.P.W.) Clevers provided his patience and guidance to me. I'm indebted and grateful for the important and valuable support you gave to me. Whenever I'm wondering how I could manage to finish this thesis, you are on my mind.

Valerio, it took me to understand your visions and ways. During field work we hiked fractions of the HoChi-Minh alpine mountain trail where your Italian calmness caused me to develop a fear of heights (!). In contrast to the patience and wisdom you allocated to me it was worth it :). We worked side by side on academic and industrial projects in different countries and found time after work to cherish each other. Believe it or not you keep providing inspiration for me: daily.

Jan Verbesselt you were a profound supervisor introducing me to remote sensing time series analysis, the R software and Linux: the essential tools required to do the research of this thesis. My research directly rests upon yours. Your professionality and precision for details are unmatched. Because of you, $R$ and Linux became an integral part of my everyday life.

Other people had to suffer from my newly found Linux 'enthusiasm'. Thank you, Simon and Mathieu, for rebooting kiwi countless times when I was remotely working on it. Thank you, CGI, for your patience having me around and teaching me new skills always with a big smile, particular thanks to Philip, Harm and John.

The people at our department made the PhD a fun, unique and nourishing experience. I feel humble, thankful and proud to have you next to me, thank you: Richard, Giulia, Mathieu, Simon, Peter, Sarah, Co, Meheret, Hannes, Jose, Erika, Arun, Brice, Patric, Roberto, Laure, Kalkidan, Astrid, Yang, Tsoefiet, Rosa, Juha, Adlo, Alvaro, Qijun, Maria, Marston, Konstantin, Nandika, Niki, Jalal, Joao, Daniela, Eskender, Loïc, Ben, Eliakim, Kim, Benjamin, Aldo, Sytze, Arnold, Willy, Lammert, Ron, Marcello, Arend, Frans and John.

Once my best friend Daniel taught me open face Chinese poker, it greatly improved our coffee breaks: Richard, Mathieu, Simon and Peter thanks for the important distraction: "before, during, or after the break". Walks around the lake behind Gaia kept me sane, Amandine thank you for all the super funny and beautiful moments we share. Zuzi and Giles and Drove people thank you for the parties and Hippi activities. Jens thanks for the fun and recreation in Africa and Europe.

My dear Vietnam field work band Arun, Giulia and Mr. Hien. We sustained suffering and fun alongside. It fills my heart with joy to see you raising your beautiful children and accomplishing your dreams. 
Maria, Guus and Lukasz, my kind office mates with whom I shared a large fraction of my life. Guus thank you for the math advices you gave me and Lukasz for all the inspiration you gave me through your optimism and good nature. Maria, thank you for the warmth and the beijos I received every morning and evening entering and leaving the office. I admire your faith and strength, you inspire me. I wish for many more happy moments for us to come.

In my opinion Antoinette and Truus run the Wageningen CGI, it makes sense to have Martin and Arnold around doing science and this and that, but nothing challenges our dear secretaries' skills in keeping things organized and well-coordinated. Thank you for many funny and joyful conversations and your kind work.

Thank you, PE\&RC council I had a fun time strategically shaping the future of PhD live with you. Claudius and Lennart you are awesome and you know it. You are sentinels, protecting us poor little idealistic and young hearted PhD students from the capitalist commercial system ; ).

Epic travels happened during my PhD time: Thank you Johanna for the countless summer trips to the hidden lake in Rhenen, wonderful horseback riding trips across Europe, road trips in America and Africa. We had it all and gazed at some of the most breathtaking treasures of nature. Merci Saeid, Sahar, AliReeza Ibrahim and Shanaz for showing me beautiful Persia and sharing many happy moments with me. Alex thank you for frequently working with me in in Laos. Thank you Aurelié for our joint field work in Afrika and the great opportunities our work provided to me.

It's a pity horses don't enjoy reading English language but who knows where technology brings us: Sir Harald thank you for enduring me when Marion taught me how to ride you. Mirkel you gave me the thrills, yours and Reto's gallop and long jumps are bliss. Maestro you lazy and brave being, it's been an honor to meet you. If I dream of either riding through lonesome wilderness or leading a pack: you and I seize it. Thank you Annett, Meike, Joanna, Simone, Patrick and my other dear riding friends for the fun rides through Veluwe and at Manege Quadenoord, the lovely borels, kindness and warmth shared every week (twice during the years I possessed a car (special thanks to Titia)).

Thank you, my beloved mom and dad, big sister and enshrined grandma. Always, anytime and regardless of matter, issue, thought, time or space your support and love are my innermost sources of strength. 


\section{List of Publications}

Schultz, M., Voss, J., Auer, M., Carter, S., Zipf, A., 2017. Open land cover from OpenStreetMap and remote sensing. Int. J. Appl. Earth Obs. Geoinformation 63, 206-213.

Avitabile, V., Schultz, M., Salvini, G., Pratihast, A.K., Bos, A., Herold, N., Cuong, P.M., Hien, V.Q., Herold, M., 2017. Forest Change and REDD+ Strategies, in: Land Use and Climate Change Interactions in Central Vietnam. Springer, pp. 33-68.

Avitabile, V., Schultz, M., Herold, N., De Bruin, S., Pratihast, A.K., Manh, C.P., Quang, H.V., Herold, M., 2016. Carbon emissions from land cover change in Central Vietnam. Carbon Manag. 7, 333-346.

Schultz, M., Clevers, J., Carter, S., Verbesselt, J., Avitabile, V., Vu Quang, Hien, 2016a. Performance of vegetation indices from Landsat time series in deforestation monitoring. Int. J. Appl. Earth Obs. Geoinformation 52, 318-327.

Schultz, M., Verbesselt, J., Avitabile, V., Souza, C., Herold, M., 2016b. Error sources in deforestation detection using BFAST monitor on Landsat time series across three tropical sites. IEEE J. Sel. Top. Appl. Earth Obs. Remote Sens. 9, 3667-3679.

Schultz, M., Verbesselt, J., Herold, M., Avitabile, V., 2013. Assessing error sources for Landsat time series analysis for tropical test sites in Viet Nam and Ethiopia. Earth Resour. Environ. Remote SensingGIS Appl. IV 23-25 Sept. 2013 Dresd. Ger. 8893, 11-11. 


\section{Short Biography}

I'm probably one of the first humans who grew up simultaneously in a virtual and the real world. Us socalled data natives, learned to extend ourselves digitally. When I was four years old I used to play a computer game with 2-bit colors running on disk operating system on a computer my dad has built himself (!), in our garden shag, on the outskirts of my birth town. The electronics of the keyboard for that device were in a wooden frame and the transparent plastic keys contained precisely crafted pieces of small paper glued in, each marked with a hand-written character. In the year 1989, my dad could follow a single bit's journey through a computer device, something utterly impossible on today's machines. For me and my family these things and having one of the first home-based phones in easternGermany came naturally. Everyone in my close family possess a postgraduate degree for either signal processing, machine or energy engineering. My dad served as a communication officer and after the Perestroika he buildup telecommunication in central-Asian. My mom leads a development section for packaging and my sister makes sure the German power grid is future proof. Together we spend our free time and vacations outside hiking, camping, swimming and skiing in the most beautiful nature sites of Thüringen and across Europe.

I went to a regular elementary school followed by high school, finishing mayors in math and physics. During high school I became a passionate gamer along with my mates we organized local area network parties in Arnstadt and surrounding areas. In Jena I finished my Bsc. in Geography and Msc. In Geoinformatics. During that time, I met key persons of my life among my friends and students, colleagues and lecturers. Jena taught me how I can transform my passion for computers to greater purpose, shifting from consumption to creation. Upon understanding the possibilities of geoinformatics and particularly remote sensing the opportunities and gifts given to my generation began to martialize for me. Jena related to a phase of my live where I could test myself, working and traveling in countries ranging from the United Arab Emirates to Australia performing an abundance of different jobs. Hence the saying: "You got to go there to come back": I realized Geoinformatics and remote sensing is an important vocation of mine.

Through a PhD thesis in Wageningen I received the chance to help address human induced climate change, an important challenge for me and the other members of my species. Because of the impact of other cultures, work ethics and ideas of life, my horizon for the possibilities what my own life may become vastly expanded and transformed. Both, an exhausting and exciting process. Wageningen gave me the opportunity to develop skills relevant to act upon climate change. For more than half a decade I supported the first successful climate mitigation project in Laos (in proximity to my PhD site in Vietnam) by providing on-site lectures and consulting of national and international partners putting my new knowledge to action. Over the years I consulted mayor non-governmental organizations, companies and national bodies to support their causes for a sustainable future in various countries in Asia and Afrika.

Today I find myself at the heart of Europe, Heidelberg. Here I was entrusted supporting a Horizon 2020 project dedicated to the fusion of geospatial science, citizens and machines. I believe that the ongoing and logical evolution of ever seamlessly machine human interaction provides the capacity to address the complex decisions my generation must take, to nourish both: our societies and a living planet. 


\section{PE\&RC Training and Education Statement}

With the training and education activities listed below the PhD candidate has complied with the requirements set by the C.T. de Wit Graduate School for Production Ecology and Resource Conservation (PE\&RC) which comprises of a minimum total of 32 ECTS (= 22 weeks of activities)

\section{Review of literature (6 ECTS)}

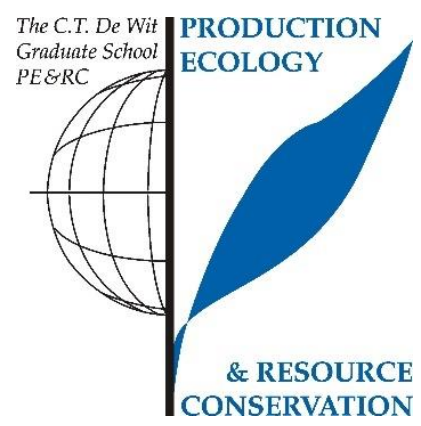

- $\quad$ Literature Review of state-of-the-art methods (2012):

$\circ$ Remote Sensing pre-processing techniques

- Remote Sensing time series analysis

- Error Source Assessment

- Machine Learning

- Reducing Emissions from Deforestation and Land Degradation (REDD) related literature

\section{Writing of project proposal (4.5 ECTS)}

- Multi-resolution time series analysis using spatial/temporal segments to support REDD (2012)

\section{Postgraduate courses (4.5 ECTS)}

- Geostatistics; PE\&RC (2011)

- $\quad$ European Space Agency (ESA) advanced land training course; Jagiellonian University (2011)

- Multivariate analysis; PE\&RC (2012)

\section{Invited review of (unpublished) journal manuscripts (5 ECTS)}

- Zentralblatt für Geologie und Paläontologie, Teil 1: Assessment of land-cover dynamics in a sub-catchment of Oti basin (West Africa): A case study of Kara River basin (2014)

- Remote Sensing of Environment: Investigating the Spatial and Temporal Dynamics of Land Cover using Thematic Time-series, in South East Queensland, Australia (2014)

- International Journal of Remote Sensing: An overview of $21 \mathrm{global}$ and 43 regional land cover mapping products (2015)

- International Journal of Applied Earth Observation and Geoinformation: Estimating winter wheat biomass by assimilating leaf area index derived from fusion of Landsat- 8 and MODIS data (2015)

- Remote Sensing: Multi-temporal Landsat Images and Ancillary Data for Land use/cover Change (LULCC) Monitoring in the Southwest of Burkina Faso, West Africa (2015)

\section{Competence strengthening / skills courses (5.7 ECTS)}

REDD+Science+Governance opportunities and Challenges; REDD@WUR (2012)

- Scientific writing; WGS (2012)

- Information literacy PhD including Endnote introduction; WUR Library (2013)

- Efficient writing strategies; WGS (2013)

- Entrepreneurship in and outside science; WGS (2014) 
PE\&RC Annual meetings, seminars and the PE\&RC weekend (2.4 ECTS)

- $\quad$ PE\&RC First years weekend (2011)

- PE\&RC Last years weekend (2015)

- PE\&RC Day $(2011,2013,2015)$

\section{Discussion groups / local seminars / other scientific meetings (9.6 ECTS)}

- Climate change \& soil-water-atmosphere interactions; PE\&RC discussion group (2011-2012)

- $\quad$ Project workshops and progress discussions of Land use and Climate Change Interactions (LUCCI) in Vietnam (DaNang (1x), Hanoi Quang (1x), Tam Ky (2x) Nam Province) and Germany (Cologne (3x), Jena) (2011-2014)

- $\quad$ REDD Discussion group meetings; PE\&RC discussion group (2014-2015)

- Global Land Forum; Paris (2015)

\section{International symposia, workshops and conferences (8.6 ECTS)}

- SPIE; Dresden; oral presentation (2013)

- ESA Living Planet Symposium; Edinburgh; poster presentation (2013)

- $\quad$ ESA Land Product Validation and Evolution Workshop; Frascati; poster presentation (2014)

- $\quad$ EARSEL; Berlin; oral and poster presentation (2014)

- PhD Conference Earth System Science; MPI Jena; oral presentation (2014)

\section{Lecturing / Supervision of practicals / tutorials (2.4 ECTS)}

- Lecture "IMGtools (Spectral Mixture Analysis) WUR-course September 2011" (2011)

- Lecture "Use ArcGIS10.1 Right! Save time and gain accuracy on your PhD" (2012)

\section{Supervision of MSc students ( 6 ECTS)}

- Jeroen van de Voort: object oriented change detection using high resolution data of a tropical area of interest

- Jose Gonzalez de Tanago Menaca: exploring the potential of spatial segments for RS time series analysis 
PE\&RC Training and Education Statement

The research described in this thesis was financially supported by the German Bundesministerium für Bildung und Forschung (BMBF)

Financial support from Wageningen University, Laboratory of Geo-information Science and Remote Sensing for printing this thesis is gratefully acknowledged.

Cover design by Michael Schultz

Printed by: Digiforce || ProefschriftMaken 